\title{
Polymorphisms in interstitial lung diseases : friend or foe?
}

Citation for published version (APA):

Wijnen, P. A. H. M. (2011). Polymorphisms in interstitial lung diseases : friend or foe? [Doctoral Thesis, Maastricht University]. Datawyse / Universitaire Pers Maastricht. https://doi.org/10.26481/dis.20110318pw

Document status and date:

Published: 01/01/2011

DOI:

10.26481/dis.20110318pw

Document Version:

Publisher's PDF, also known as Version of record

\section{Please check the document version of this publication:}

- A submitted manuscript is the version of the article upon submission and before peer-review. There can be important differences between the submitted version and the official published version of record.

People interested in the research are advised to contact the author for the final version of the publication, or visit the DOI to the publisher's website.

- The final author version and the galley proof are versions of the publication after peer review.

- The final published version features the final layout of the paper including the volume, issue and page numbers.

Link to publication

\footnotetext{
General rights rights.

- You may freely distribute the URL identifying the publication in the public portal. please follow below link for the End User Agreement:

www.umlib.nl/taverne-license

Take down policy

If you believe that this document breaches copyright please contact us at:

repository@maastrichtuniversity.nl

providing details and we will investigate your claim.
}

Copyright and moral rights for the publications made accessible in the public portal are retained by the authors and/or other copyright owners and it is a condition of accessing publications that users recognise and abide by the legal requirements associated with these

- Users may download and print one copy of any publication from the public portal for the purpose of private study or research.

- You may not further distribute the material or use it for any profit-making activity or commercial gain

If the publication is distributed under the terms of Article $25 \mathrm{fa}$ of the Dutch Copyright Act, indicated by the "Taverne" license above, 


\title{
Polymorphisms in interstitial lung diseases
}

\author{
Friend or foe?
}


The study presented in this thesis was performed within NUTRIM School for Nutrition, Toxicology and Metabolism which participates in the Graduate School VLAG (Food Technology, Agrobiotechnology, Nutrition and Health Sciences), accredited by the Royal Netherlands Academy of Arts and Sciences.

\section{niutim}

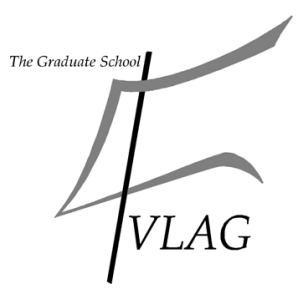

(c) 2011 P. Wijnen, Maastricht

Cover photo by Petal Wijnen: DNA stairs, Botanical Garden, Perth, Australia Layout: Tiny Wouters

Production: Datawyse | Universitaire Pers Maastricht

ISBN: 978-90-78076-07-0

The printing of this thesis was financially supported by the ild care foundation (www.ildcare.nl), Merck, Sharpe \& Dohme B.V., Merck MilliPore Lab Solutions, Novartis Pharma B.V., E.C. Noyons Stichting, Nycomed bv, Roche Diagnostics Nederland BV, and Zambon Nederland B.V. 


\title{
Polymorphisms in interstitial lung diseases
}

\author{
Friend or foe?
}

\author{
PROEFSCHRIFT
}

ter verkrijging van de graad van doctor aan de Universiteit Maastricht, op gezag van de Rector Magnificus, Prof. mr. G.P.M.F. Mols, volgens het besluit van het College van Decanen, in het openbaar te verdedigen

op vrijdag 18 maart 2011 om 14.00 uur

door

Petal Wijnen 
Promotores:

Prof. dr. M. Drent

Prof. dr. M.P. van Dieijen-Visser

Copromotor:

Dr. O. Bekers

Beoordelingscommissie:

Prof. dr. C.T.R.M. Schrander-Stumpel (voorzitter)

Prof. dr. A. Bast

Prof. dr. C.A. Bruggeman

Prof. dr. P. Camus, UMC Le Bocage, Dijon, France

Dr. ir. H.J.T. Ruven, St. Antonius Ziekenhuis, Nieuwegein 
Voor jou 



\section{Contents}

Abbreviations 9

Chapter 1 General introduction 13

Chapter 2 Relationship between drug-induced interstitial lung diseases 27 and CYP polymorphisms

Chapter 3 Pharmacogenetic testing after a simple DNA isolation method 43

Chapter 4 Role of cytochrome P450 polymorphisms in the development 55 of pulmonary drug toxicity. A case-control study in the Netherlands

Chapter 5 Depressive effect of an antidepressant: therapeutic failure of 71 venlafaxine in a case lacking CYP2D6 activity

Chapter 6 Variant VKORC1 and CYP2C9 alleles in patients with diffuse alveolar haemorrhage caused by oral anticoagulants

Chapter 7 The role of TNF-a G-308A polymorphisms in the course of pulmonary sarcoidosis

Chapter 8 Butyrophilin-like 2 in pulmonary sarcoidosis: a factor for susceptibility and progression?

Chapter 9 Summary, general discussion and directions for future research

Samenvatting

Appendix Drugs and other substances metabolized by and influencing CYP enzymes

List of publications

Dankwoord

Curriculum Vitae 



\section{Abbreviations}

ACCESS A Case Control Etiologic Study of Sarcoidosis

ADR adverse drug reaction

$\mathrm{Ag}$ antigen

AIP acute interstitial pneumonia

ANCA anti-neutrophil cytoplasmic antibody

ANF antinuclear factor

APC antigen presenting cell

BAL bronchoalveolar lavage

BALF bronchoalvealar lavage fluid

BHL bilateral hilar lymphadenopathy

BMI body mass index

BS buccal swab

BTNL2 butyrophiline-like 2

CARD15 caspase recruitment domain 15

CI confidence interval

CNS central nervous system

COP cryptogenic organizing pneumonia

COX2 cyclooxegenase-2

CR1 complement receptor 1

CT computed tomography

CTD-ILD connective tissue disease-associated interstitial lung disease

CV

CXR chest X-ray

CYP cytochrome P450

CYP1A2 cytochrome P450 1A2

CYP2C9 cytochrome P450 2C9

CYP2C19 cytochrome P450 2C19

CYP2D6 cytochrome P450 2D6

CYP3A4 cytochrome P450 3A4

CYP3A5 cytochrome P450 3A5

DAH diffuse alveolar hemorrhage

DBS dried blood spot

DI-ILD drug-induced interstitial lung disease

DIP desquamative interstitial pneumonia

DLCO diffusing capacity for carbon monoxide

DNA deoxyribonucleic acid

EDTA ethylenediaminetetraacetic acid

EM extensive metabolizer

FDA Food and Drug Administration

$\mathrm{FEV}_{1} \quad$ forced expiratory volume in one second 
FRET fluorescence resonance energy transfer

FVC forced vital capacity

$\mathrm{Hb}$ hemoglobin

HLA human leukocyte antigen

HP hypersensitivity pneumonitis

HRCT high resolution computed tomography

$\mathrm{Ht}$ hematocrit

HT heterozygote

IFN- $\mathrm{Y}$ interferon-gamma

IL interleukin

ILD interstitial lung disease

IM intermediate metabolizer

INR international normalized ratio

IPF idiopathic pulmonary fibrosis

LAM lymphangioleiomyotosis

LD lactate dehydrogenase

LIP lymphocytic interstitial pneumonia

LTA lymphotoxin alpha

MHC major histocompatibility complex

MT mutation

MTHFR methylenetetrahydrofolate reductase

MTX methotrexate

MUMC Maastricht University Medical Centre

NE norepinephrine

NSIP non-specific interstitial pneumonia

ODV O-desmethylvenlafaxine

OR odds ratio

PAP pulmonary alveolar proteinosis

PCR polymerase chain reaction

PM poor metabolizer

RA rheumatoid arthritis

RB-ILD respiratory broncheolitis

RFI respiratory functional impairment

RFLP restriction fragment length polymorphism

SD standard deviation

SNP single nucleotide polymorphism

SNRI serotonin-norepinephrine reuptake inhibitor

SSO sequence specific oligonucleotides

SSP sequence specific primers

TDM therapeutic drug monitoring

TGF- $\beta$ transforming growth factor beta

Th1 T-helper cell 1 
TLR2 Toll-like receptor 2

TNF-a tumor necrosis factor alpha

TPMT thiopurine methyltransferase

UM ultra-extensive metabolizer

US United States

UV ultra violet

VEGF vascular endothelial growth factor

VKORC1 vitamin $\mathrm{K}$ epoxide reductase complex 1

vs versus

WASOG World Association of Sarcoidosis and Other Granulomatous diseases

WT wild type 



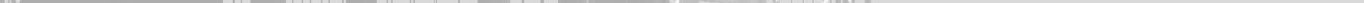





\section{Introduction}

\section{Interstitial lung diseases}

Interstitial lung diseases (ILD) are a rapidly growing and increasingly complex component of clinical practice. They represent a group of heterogeneous disorders that diffusely involve the lung parenchyma. The term 'interstitial' was originally applied to these disorders because they are associated with thickening of the alveolar septum. The 'interstitium' is that part of the alveolar structures bounded by the alveolar epithelial and endothelial basement membranes. The normal alveolar interstitium is composed of connective tissue components (e.g. collagen, elastic fibers, mesenchymal cells), and inflammatory and immune effector cells (monocytes/macrophages and lymphocytes). Generally, ILD involve alveolar epithelial and endothelial cells as well. In addition, although these diseases primarily attack the alveolar structures (inflammation and fibrosis), many also involve airways, arteries and veins. ${ }^{1,2}$ ILD can lead to diffuse remodelling and architectural damage to normal lung tissue and progressive loss of lung function.

Although idiopathic pulmonary fibrosis (IPF) and sarcoidosis are the two most common forms of ILD encountered in clinical practice, well over 100 different types of ILD have been identified on the basis of clinical presentation, radiographic findings, and histopathologic examination. ${ }^{3-5}$ The patient's age, cigarette-smoking status, and gender will provide useful clues. IPF for example is almost always an adult disorder, typically occurring in patients over 60 years of age. Patients with idiopathic non-specific interstitial pneumonia (NSIP) of the fibrotic variety are usually younger than 60 years of age. Although pulmonary sarcoidosis can manifest in the elderly patient, it is more common in young adults and middle-aged people. Respiratory bronchiolitis associated with ILD (RB-ILD) is seen almost exclusively in cigarette smokers, but it can occur in both men and women of all ages. In contrast, the very rare disorder Lymphangioleiomyomatosis (LAM) occurs exclusively in women of childbearing age.

A detailed occupational history and changes in domestic environment are also essential, as it may lead to identification of a specific inhalation cause or trigger for ILD. At-risk occupations for ILD include miners (pneumoconiosis); sandblasters and granite workers (silicosis); dental workers (dental workers' pneumoconiosis); welders, shipyard workers, pipe fitters, electricians, and mechanics (asbestosis); farm workers, poultry workers, bird fanciers, and bird breeders (hypersensitivity pneumonitis); and workers in aerospace, nuclear, computer, and electronics industries (berylliosis). History of existing, persistent and/or altered environmental 'fibrogenic' factors at home, the workplace, in automobiles or frequently visited facilities/homes or hobbies such as exposure 
to birds, moulds, woodworking, use of sauna and hot tubs are often ignored but equally important and may provide a useful clue for specific diagnosis and management of hypersensitivity pneumonitis. ${ }^{6}$

An overview of the different diseases, also known collectively as ILD, is shown in Table 1.1.

Table 1.1 Interstitial Lung Diseases (ILD).

\begin{tabular}{|c|c|}
\hline ILD of known causes & $\begin{array}{l}\text { Drug-Induced (DI-ILD)* } \\
\text { Asbestos } \\
\text { Beryllium } \\
\text { Radiation Fibrosis } \\
\text { Silicosis } \\
\text { Infection }\end{array}$ \\
\hline Idiopathic interstitial pneumonia (IIP) & $\begin{array}{l}\text { Idiopathic Pulmonary Fibrosis (IPF) } \\
\text { non-IPF IIP: } \\
\text { - Familial Pulmonary Fibrosis } \\
\text { - Desquamative Interstitial Pneumonia (DIP) } \\
\text { - Acute Interstitial Pneumonia (AIP) } \\
\text { - Non-specific Interstitial Pneumonia (NSIP) } \\
\text { - Cryptogenic Organizing Pneumonia (COP) } \\
\text { - Lymphocytic Interstitial Pneumonia (LIP) } \\
\text { - Respiratory Bronchiolitis (RB-ILD) }\end{array}$ \\
\hline Granulomatous ILD & $\begin{array}{l}\text { Sarcoidosis } \\
\text { Histiocytosis-X } \\
\text { Hypersensitivity Pneumonitis (HP) }\end{array}$ \\
\hline Other & $\begin{array}{l}\text { Diffuse Alveolar Hemorrhage (DAH) } \\
\text { Connective Tissue Disease-associated ILD } \\
\text { (CTD-ILD) } \\
\text { Eosinophilic Pneumonia } \\
\text { Lymphangioleiomyomatosis (LAM) } \\
\text { Pulmonary Alveolar Proteinosis (PAP) } \\
\text { Wegener's granulomatosis and other vasculitidies }\end{array}$ \\
\hline
\end{tabular}

* the ILD with bold typeface will be addressed in the coming chapters.

\section{Drug-induced interstitial lung disease}

Drug-induced interstitial lung disease (DI-ILD) is the most common form of drug-induced respiratory disease. The drugs involved not only include prescribed and over-the-counter-drugs, but also illicit drugs, herbs, alcohol, and dietary ingredients. ${ }^{7-10}$ An ever increasing number of drugs can produce or reproduce variegated patterns of naturally-occurring infiltrative lung disease. ${ }^{7,9,11}$ Although, only in a limited number of cases drugs unequivocally have been identified as cause, it is important to acknowledge the potential role of medication in the development of drug-induced ILD. 7,12 This is due to the severity of the potentially irreversible damage to the lungs and the improvement that is often easily achieved by stopping administration of drugs. 
Rational treatment of drug-toxicities in cases where the mechanism of toxicity is known is common clinical practice. However, often the connection with druguse and the development of related inflammatory damage or idiosyncratic toxicities is hard to recognize and objectify, especially in those cases using multiple drugs. ${ }^{13}$ Furthermore, the list of drugs involved has grown rapidly over the last decades. An example of a drug-induced ILD, in this case caused by nitrofurantoin, is shown in Figure 1.1. For a list of the most important categories of substances which can cause respiratory problems with some examples see Table 1.2, and also www.pneumotox.com for an extensive overview of drugs known to be able to damage the respiratory system.
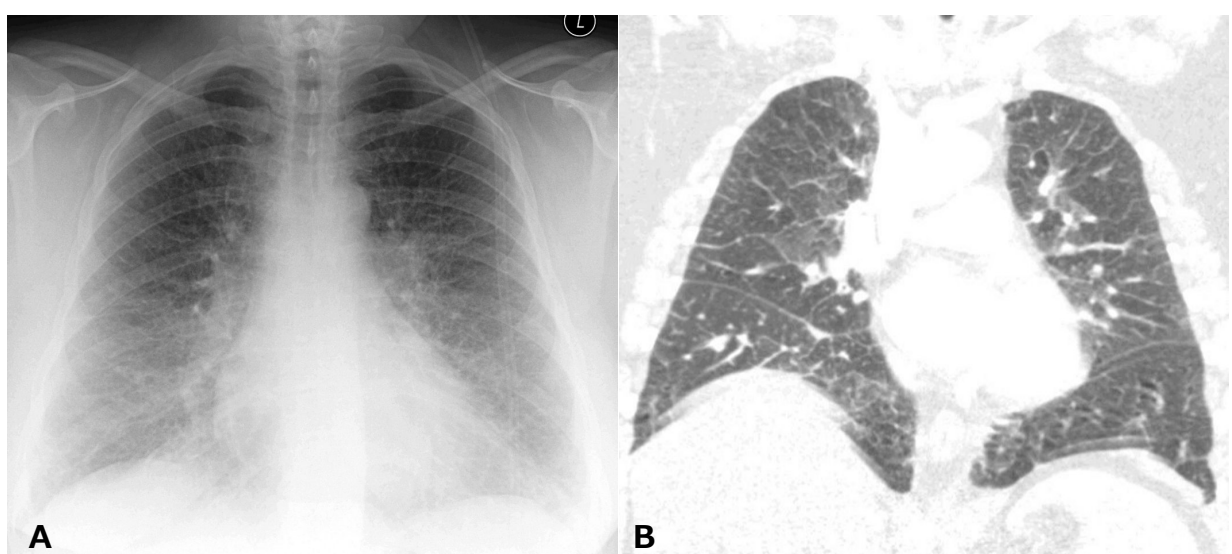

Figure 1.1 Chest X-ray (A) showing a diffuse interstitial pattern and a high resolution CT-scan (B) demonstrating thickened septa and patchy ground-glass opacities of a patient with druginduced interstitial lung disease associated with nitrofurantoin.

Table 1.2 Summary of the categories of substances known to cause respiratory problems with some examples of the possible causative agents.

\begin{tabular}{|c|c|c|c|c|}
\hline Drugs* (illicit) & Biomolecules & Blood/Stem-cells & $\begin{array}{r}\text { Herbs/Dietary } \\
\text { supplements }\end{array}$ & Miscellaneous \\
\hline Amiodarone & Interferons & Retinoic acid & Ephedra & Talc \\
\hline Cocaine & Immunoglobulins & Blood products & Comfrey & Silicone \\
\hline Methotrexate & $\begin{array}{l}\text { Anti-thymocyte } \\
\text { globuline }\end{array}$ & $\begin{array}{l}\text { Stem-cell } \\
\text { transplantation }\end{array}$ & Germander & Mineral oil \\
\hline $\begin{array}{l}\text { Nitrofurantoin } \\
\text { Methadone }\end{array}$ & & Blood transfusion & Aristolochic acid & \\
\hline Oral anticoagulants & & & & \\
\hline
\end{tabular}

*see appendix for a complete list of drugs and other substances involved, sorted by CYP enzymes. 


\section{Diffuse alveolar hemorrhage}

Diffuse alveolar hemorrhage (DAH) can be a fulminant and often fatal bleeding complication, but can also occur as an almost sub-clinical condition with a pneumonia-like manifestation. DAH results in accumulation of iron in the lungs and, in turn, iron causes oxidative stress and inflammation. It has been suggested that oxidative damage plays a role in the pathophysiology of various diseases. ${ }^{14}$ It is important to prevent or recognize DAH at an early stage to avoid irreversible damage. Particularly, in critically ill patients with unexplained infiltrates, DAH should be considered. DAH events can occur as a result of over-anticoagulation due to coumarin sensitivity, resulting in a relative vitamin $\mathrm{K}$ deficiency. It can also occur as a result of the ingestion or inhalation of socalled super-warfarines, (illicit) drugs or toxic fumes. ${ }^{15-18}$ An example of a lung with DAH is shown in Figure 1.2 and the histological aspect is illustrated in Figure 1.3A. At present, the diagnosis of DAH is often made by observing an increased percentage of siderophages (iron-positive macrophages, $>20 \%$ ) in bronchoalveolar lavage fluid (BALF), indicated with Perl's staining, as shown in Figure $1.3 \mathrm{~B} .{ }^{19}$
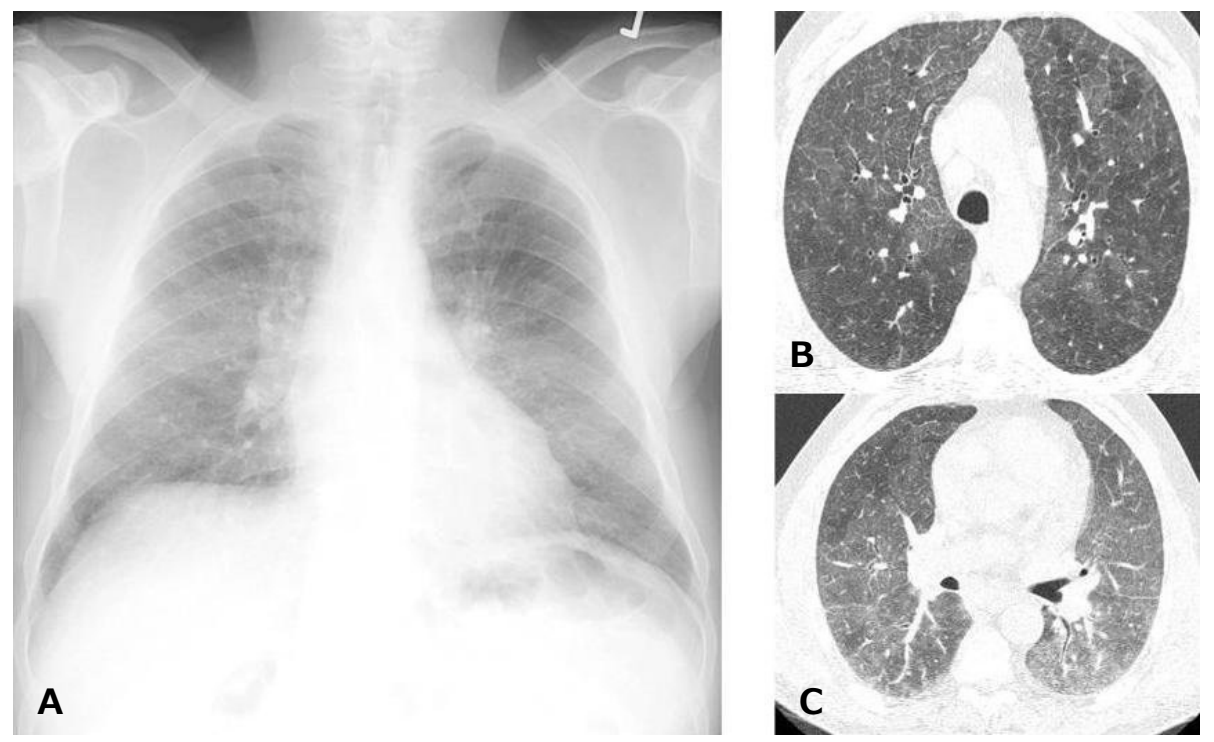

Figure 1.2 Chest X-ray (A) and high resolution CT-scan (B/C) of a patient suffering from diffuse alveolar hemorrhage (DAH) showing widespread ground-glass attenuation. 

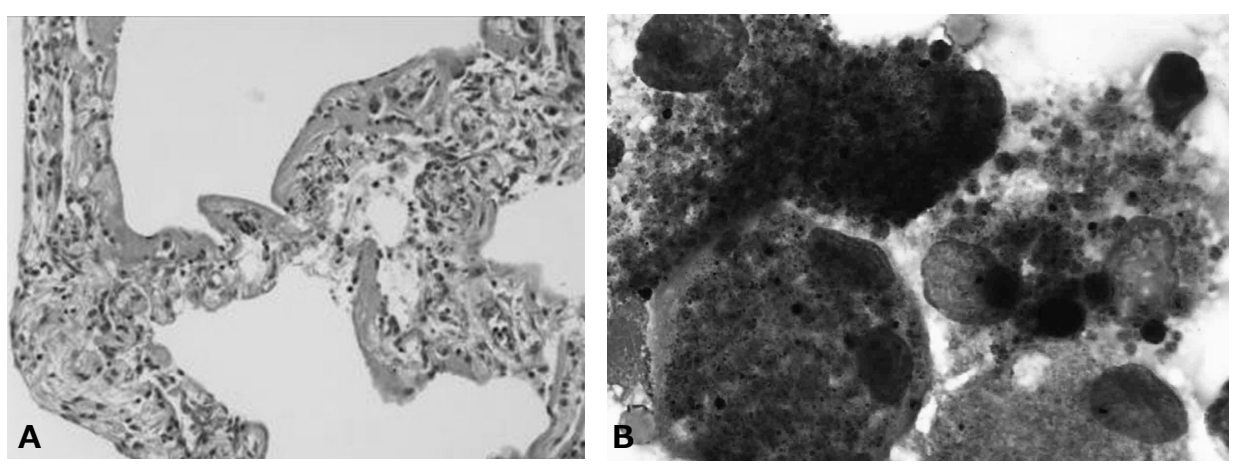

Figure 1.3 Histological appearance (A) of diffuse alveolar hemorrhage (DAH). Acute phase of DAH: alveolar walls with interstitial oedema, congested capillaries, and hyaline membranes with regenerating alveolar epithelium underneath. Perls' stained bronchoalveolar lavage (BAL) fluid cells (B; dark grey=positive).

\section{Sarcoidosis}

Sarcoidosis is a systemic granulomatous disorder of unknown cause, characterized by the presence of noncaseating granuloma, see Figure 1.4 for a schematic presentation of granuloma formation. ${ }^{20,21}$

Sarcoidosis occurs throughout the world, affecting all genders, races and ages. However, several studies demonstrated a peak incidence of the disease occurring in individuals ranging between 25-55 years of age, with a greater presence of men in the under 40-years of age category. ${ }^{22,23}$ Epidemiologic studies regarding the incidence, prevalence, and mortality rates of sarcoidosis are difficult because of the highly variable disease presentation ${ }^{24}$ and the lack of a known etiology. Regional variabilities due to race and gender, as well as phenotypic variability, further confound epidemiological measurements. Involvement of the lungs or intrathoracic lymph nodes is clinically evident in $90 \%$ of the symptomatic patients during their disease and up to $30 \%$ show spontaneous remission. ${ }^{25}$ In $10-30 \%$ of the patients the disease becomes chronic, what can result in significant lung function impairment. ${ }^{26,27}$ The diagnosis of sarcoidosis is often one of exclusion of other diseases and involves biopsies and chest X-rays (CXR) or high resolution computed tomography (HRCT) scans. Five stages of the radiographical abnormality were recognized: stage 0 (normal CXR), stage I (bilateral hilar lymphadenopathy [BHL]), stage II (BHL and parenchymal abnormalities), stage III (parenchymal abnormalities without $\mathrm{BHL}$ ), and stage IV (end stage lung fibrosis), see also Figure $1.5 .^{28} \mathrm{An}$ acute form of sarcoidosis is the so-called Löfgren's syndrome with distinct skin (Erythema nodosum) and lung (CXR stage I) presentation. 

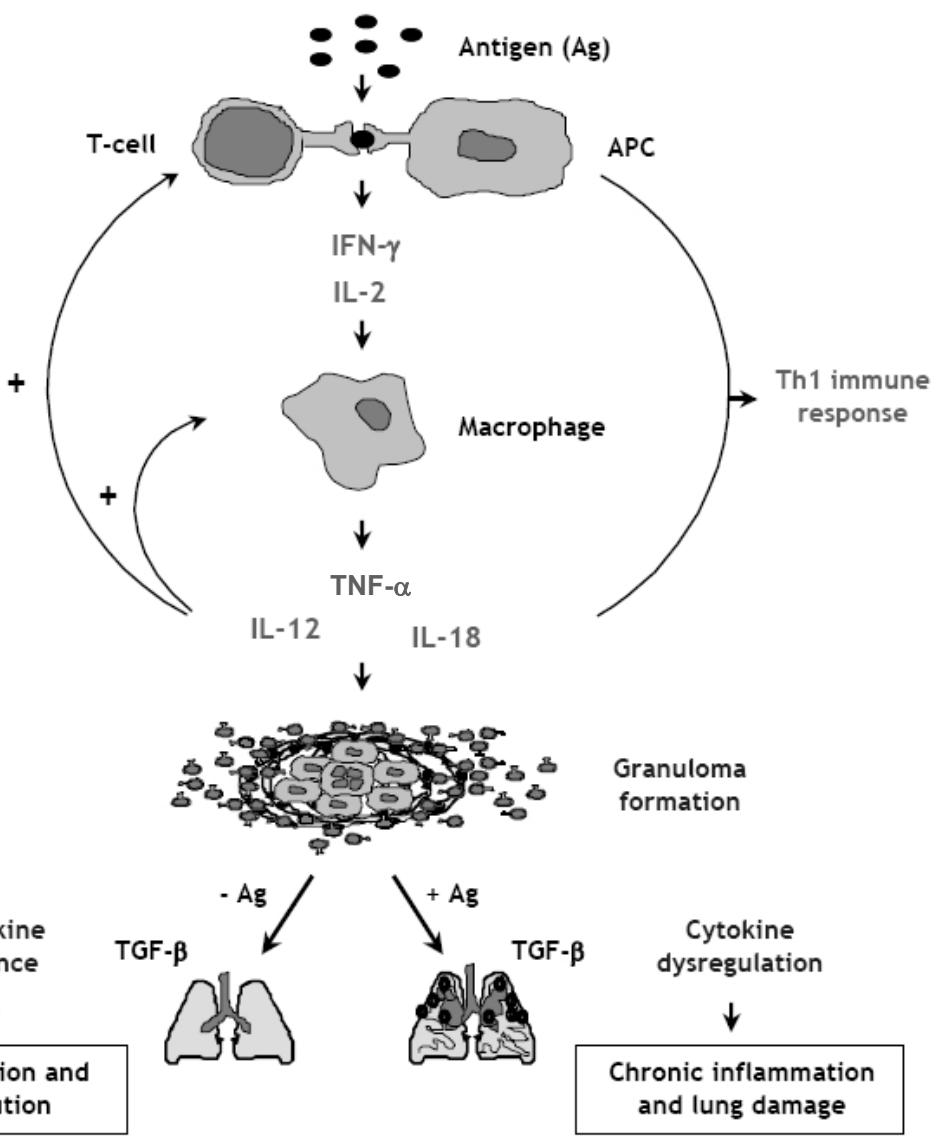

Figure 1.4 A schematic presentation of granuloma formation in sarcoidosis.

$\mathrm{Ag}=$ antigen; $\mathrm{APC}=$ antigen presenting cell; IFN- $\gamma=$ interferon-gamma; IL=interleukin; Th1=T-helper 1 ; TNF- $a=$ tumor necrosis factor alpha; TGF- $\beta=$ transforming growth factor beta (adapted from Moller $^{29}$ ).

Hypothetical model of the pathogenesis of sarcoidosis. An antigen induces antigenspecific, Th1-mediated granulomatous inflammation with production of Th1 cytokines (IFN- $\gamma$, IL-2). Granuloma formation is set in motion by activated macrophages and T-cells along with other effector cells (e.g. fibroblasts) under the regulatory influence of local cytokine production. Removal of the antigen allows TGF- $\beta$ to downregulate the immune response.

Although the specific trigger of sarcoidosis is still unknown, there appear to be some pre-requisites to develop the condition. The first being predisposition, the second is exposure and the third circumstances. The (genetic) predisposition appears to be not dependent upon a single gene and/or polymorphism, for in 
several studies a range of different polymorphisms have been investigated and found to have an influence on the contracting or progression of the disease. ${ }^{30-36}$ In Table 1.3 an overview is presented of some of the most common polymorphisms and triggers that have been associated with sarcoidosis, but up until now no single agent or trigger stands out as cause.

Table 1.3 An overview of some of the polymorphisms and triggers that have been associated with sarcoidosis.

\begin{tabular}{llll}
\hline HLA & TNF & various & triggers/jobs/exposure \\
\hline DRB1*03 & TNF- $a$ G-308A & BTNL2 G16043A & health care workers \\
DRB1*1501 & TNF- $a$ G-238A & BTNL2 G16071A & firefighters/fumes \\
DQB1*0602 & TNF- $a$ C-857T & CARD15 C2104T & teachers/chalk \\
& & CARD15 A1761G & insecticides/pesticides \\
& & CR1 C5507G & molds/(agricultural) dust/clay \\
& VEGF C813T & manmade fibers \\
& & bacteria \\
& & metals (e.g. aluminum, zirconium) \\
& & talc \\
\hline
\end{tabular}
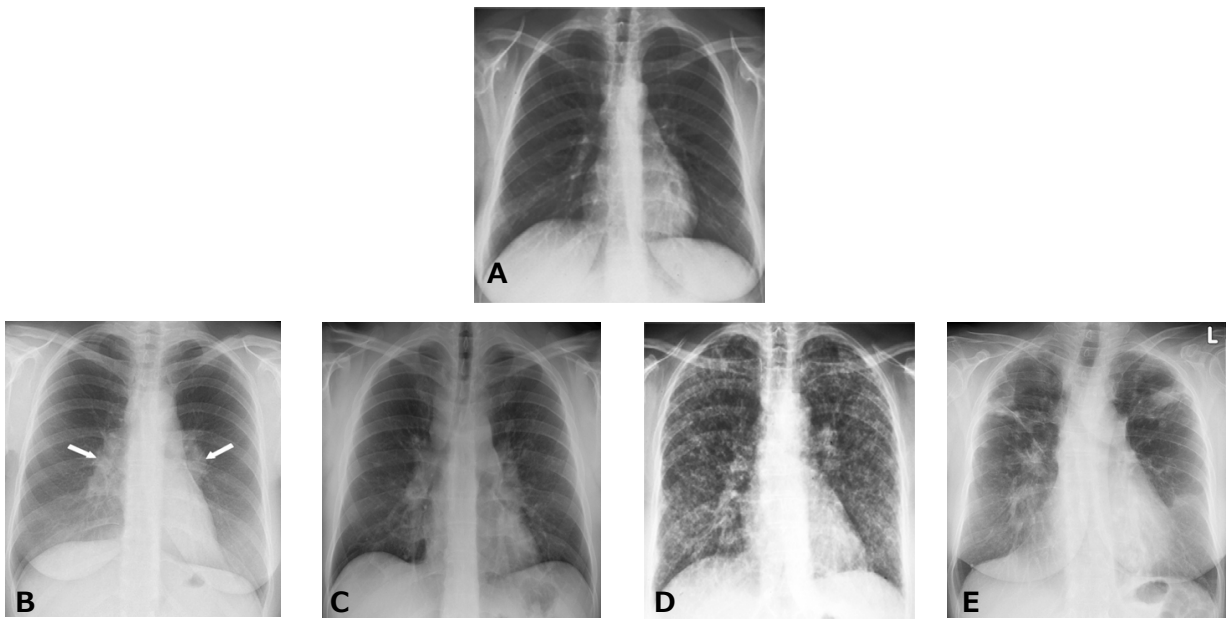

Figure 1.5 Chest X-ray (CXR) stages 0-IV: radiographic appearances of sarcoidosis.

(A) Stage 0 (5-15\%): normal chest radiograph; (B) Stage I (45-65\%): bilateral hilar lymphadenopathy (arrows), without evidence of interstitial lung disease; (C) Stage II (30-40\%): both lymphadenopathy and parenchymal abnormalities (nodular and reticulonodular opacities); (D) Stage III (10-15\%): parenchymal infiltration without hilar lymph node enlargement (reticulonodular infiltrates); (E) Stage IV (15-25\%): obvious interstitial abnormalities with fibrotic lesions. 


\section{Polymorphisms}

The human DNA comes with faults (mutations) that can influence the function of a protein or enzyme. Mutations are random mistakes and they are called polymorphisms whenever the DNA mutation occurs in more than one percent of the population. A polymorphism can affect the function of a protein in a positive or negative manner, depending on where it is positioned or what its effect on the length or amino acid build-up of the final protein is. For example, a polymorphism that causes a so-called stop codon in the coding region of the protein will produce a truncated protein that almost always has a severely altered function or no functionality left at all. Whereas a polymorphism in the promoter region of the protein, for instance, can cause a heightened rate of production of the protein involved.

Polymorphisms and, more specific single nucleotide polymorphisms (SNP), can be investigated using different PCR methods or detection techniques (e.g. restriction fragment length polymorphism (RFLP) using restriction enzymes, or real-time PCR assays using fluorescence resonance energy transfer (FRET) or hydrolysis probes). In the studies presented in this thesis SNPs were detected using melting point analysis with fluorescent hybridization probes using the FRET principle. This detection method uses the properties of a donor fluorophore that transfers its energy to an acceptor that has to be in close proximity (no more than three base pairs apart) in order to accept the energy and emit at a different wavelength when returning to its ground state. The FRET principle is visually explained in Figure 1.6 and an example of the melting curve results obtained when running a FRET assay on a LightCycler ${ }^{\circledR}$ are shown in Figure 1.7. In the upper part of Figure 1.7 the lessening of the fluorescence signal as the temperature of the samples was raised is clearly visible. This rise in temperature (the so-called melting) will cause the probes to be melted off their complementary piece of DNA. Moreover, because the distance of the two fluorophores in that situation will become more than the required maximum of three base pairs, FRET is no longer possible and a reduction of signal is apparent (Figure 1.6). As the probes that spans the SNP is complementary, either to the wild type DNA or to the SNP one wishes to examine, more heat is needed to melt it off when the fit is perfect. So when both alleles (heterozygote) are present, one part of the probes will melt off at a lower temperature than the other. When applying the first derivative to these melting curves, the bottom part of Figure 1.7 is produced and the different melting temperatures will be more clearly visible as separate peaks. In the shown example the used probe spanning the SNP was complementary to the wild type, therefore producing a peak for the mutation at a lower temperature. 


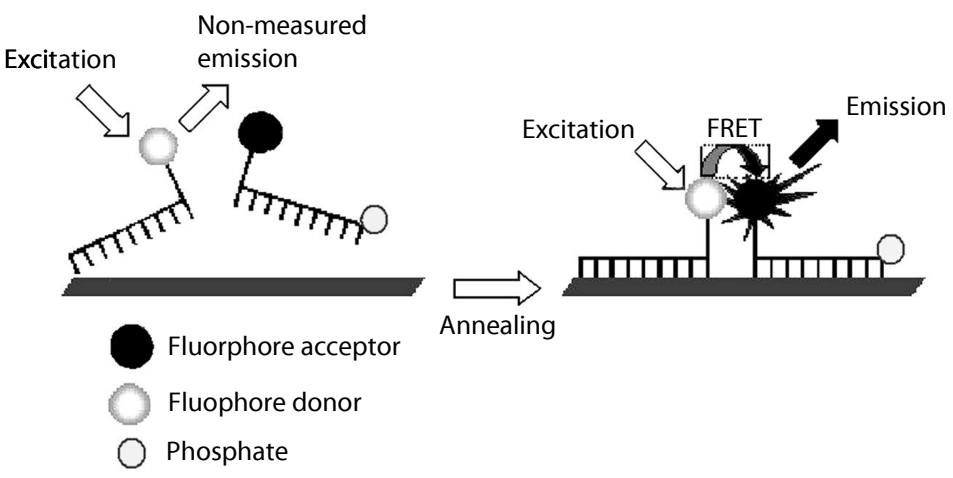

Figure 1.6 Principle of fluorescence resonance energy transfer (FRET) assays.

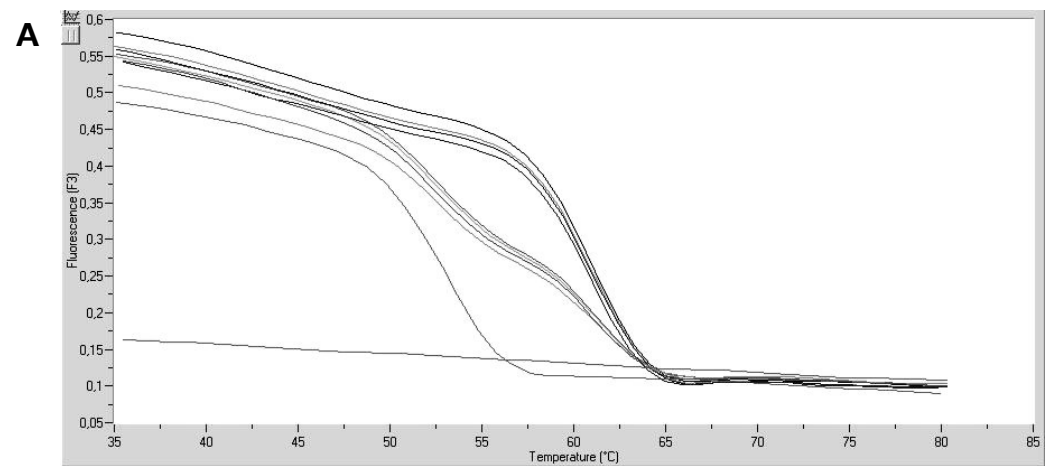

B

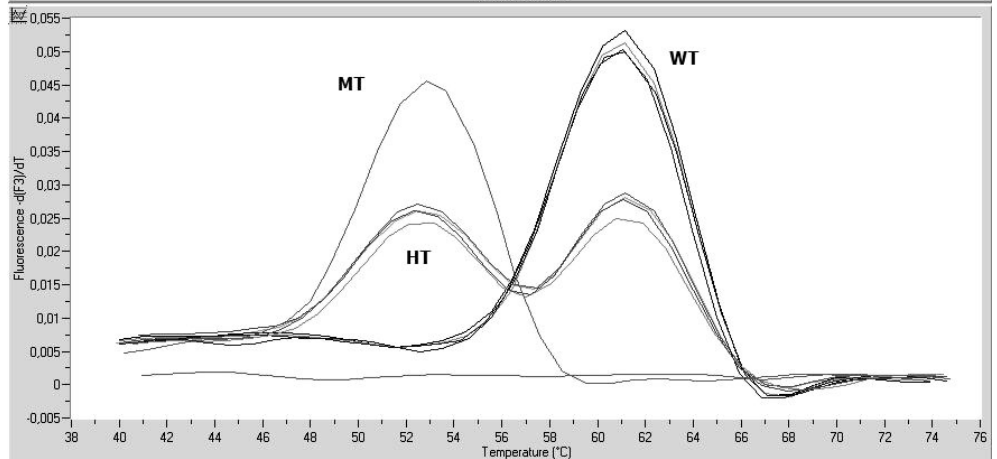

Figure 1.7 Results of a cytochrome $2 \mathrm{C} 19$ assay, with melting curves (A) and the first derivative (B). MT = mutation $($ CYP2C19*2/*2), HT=heterozygote $($ CYP2C19*1/*2), WT=wildtype (CYP2C19*1/*1). 


\section{Scope and aims of the study}

The aims of the studies presented in this thesis were to investigate several polymorphisms and assess their possible role in the cause and course of interstitial lung disease (ILD). ILD, especially drug-induced ILD (DI-ILD), can occur as a cause of drug(s) or drug-drug interactions. The CYP enzyme family plays an important role in the metabolization of all sorts of ingested or inhaled xenobiotic substances. In Chapter 2 the possible role of cytochrome P450 (CYP) enzymes in DI-ILD is reviewed. Chapter 3 describes a simple and uncomplicated method to isolate DNA from easy obtainable and patient friendly dried blood spot and/or buccal swab samples prior to real-time polymerase chain reactions (PCR). The aim of Chapter 4 was to establish whether allelic variation in specific CYP polymorphic genes, namely CYP2D6, CYP2C9, and CYP2C19, contributes to variability in drug response and unexpected toxicity. Therefore, a case-control study was conducted. The cases consisted of patients with DI-ILD. Two control groups were used: one group of healthy volunteers and one group of patients with idiopathic pulmonary fibrosis (IPF). In Chapter 5 the role of CYP polymorphisms is further illustrated in the case-report describing the therapeutic failure of venlafaxine in a case lacking CYP2D6 activity. In Chapter $\mathbf{6}$ it was hypothesized that in patients treated with coumarins a serious complication i.e. diffuse alveolar hemorrhage (DAH) may be associated with vitamin $\mathrm{K}$ epoxide reductase complex 1 (VKORC1) and CYP (CYP2C9 and CYP2C19) variant alleles. Clinical information of patients using coumarins with at least one episode of DAH was gathered retrospectively during a seven year period. The aim of Chapter $\mathbf{7}$ was to evaluate the relationship between the presence of tumor necrosis factor (TNF) polymorphisms, human leukocyte antigen (HLA)-DRB1*03 linkage and the prognosis of sarcoidosis. In a retrospective case-control study TNF-a G-308A, TNF- $a$ G-238A and LTA were genotyped in 625 sarcoidosis patients. These patients were classified into patients with persistent disease and patients with non-persistent disease using chest X-ray appearances and lung function parameters after at least two years of follow-up. The aim of Chapter $\mathbf{8}$ was to assess the association of butyrophilin-like 2 (BTNL2) G16071A with the course of pulmonary sarcoidosis and verify association with disease predisposition. In addition, the linkage between BTNL2 G16071A and certain HLA-DRB1/DQB1 types was investigated. In a retrospective case-control study BTNL2 G16071A, HLA-DQB1 and DRB1 were typed in 632 sarcoidosis patients. These patients were classified into 304 patients with persistent and 328 patients with nonpersistent sarcoidosis using chest $X$-ray stages after at least two years followup. Finally, in Chapter 9, a summary and the implications of the findings presented in this thesis are argued and directions for future research are briefly discussed. 


\section{References}

1. Crystal RG, Gadek JE, Ferrans VJ, Fulmer JD, Line BR, Hunninghake GW. Interstitial lung disease: current concepts of pathogenesis, staging and therapy. Am J Med. 1981;70:542-68.

2. Travis WD, Hunninghake G, King TE, Jr., Lynch DA, Colby TV, Galvin JR, Brown KK, Chung MP, Cordier JF, du Bois RM, Flaherty KR, Franks TJ, Hansell DM, Hartman TE, Kazerooni EA, Kim DS, Kitaichi M, Koyama T, Martinez FJ, Nagai S, Midthun DE, Muller NL, Nicholson AG, Raghu G, Selman M, Wells A. Idiopathic nonspecific interstitial pneumonia: report of an American Thoracic Society project. Am J Respir Crit Care Med. 2008;177:1338-47.

3. Meyer KC. Bronchoalveolar lavage as a diagnostic tool. Semin Respir Crit Care Med. 2007;28:546-60.

4. Drent M, Mansour K, Linssen C. Bronchoalveolar lavage in sarcoidosis. Semin Respir Crit Care Med. 2007;28:486-95.

5. Demedts $M$, Behr J, Buhl R, Costabel U, Dekhuijzen R, Jansen HM, MacNee W, Thomeer M, Wallaert B, Laurent F, Nicholson AG, Verbeken EK, Verschakelen J, Flower CD, Capron F, Petruzzelli S, De Vuyst P, van den Bosch JM, RodriguezBecerra E, Corvasce G, Lankhorst I, Sardina M, Montanari M. High-dose acetylcysteine in idiopathic pulmonary fibrosis. N Engl J Med. 2005;353:2229-42.

6. Baughman RP, du Bois RM, Lynch JP, Wells AU. Diffuse Lung Disease A Practical Approach: Hodder Arnold London;2004.

7. Camus $P$, Fanton $A$, Bonniaud $P$, Camus $C$, Foucher $P$. Interstitial lung disease induced by drugs and radiation. Respiration. 2004;71:301-26.

8. Wijnen PA, Drent M, Nelemans PJ, Kuijpers PM, Koek GH, Neef C, Haenen GR, Bekers O. Role of cytochrome $\mathrm{P} 450$ polymorphisms in the development of pulmonary drug toxicity: a case-control study in the Netherlands. Drug Saf. 2008;31:1125-34.

9. Foucher P, Biour M, Blayac JP, Godard P, Sgro C, Kuhn M, Vergnon JM, Vervloet D, Pfitzenmeyer $P$, Ollagnier $M$, Mayaud $C$, Camus $P$. Drugs that may injure the respiratory system. Eur Respir J. 1997;10:265-79.

10. Bressler R. Grapefruit juice and drug interactions. Exploring mechanisms of this interaction and potential toxicity for certain drugs. Geriatrics. 2006;61:12-8.

11. Camus $P$, Kudoh $S$, Ebina $M$. Interstitial lung disease associated with drug therapy. Br J Cancer. 2004;91 Suppl 2:S18-23.

12. Drent M, Singh S, Gorgels AP, Hansell DM, Bekers O, Nicholson AG, van Suylen RJ, du Bois RM. Drug-induced pneumonitis and heart failure simultaneously associated with venlafaxine. Am J Respir Crit Care Med. 2003;167:958-61.

13. Nemery B, Bast A, Behr J, Borm PJ, Bourke SJ, Camus PH, De Vuyst P, Jansen HM, Kinnula VL, Lison $D$, Pelkonen $O$, Saltini $C$. Interstitial lung disease induced by exogenous agents: factors governing susceptibility. Eur Respir J Suppl. 2001;32: 30s-42s.

14. Rahman I, Skwarska E, Henry M, Davis M, O'Connor CM, FitzGerald MX, Greening A, MacNee W. Systemic and pulmonary oxidative stress in idiopathic pulmonary fibrosis. Free Radic Biol Med. 1999;27:60-8.

15. Balkisson R, Murray $D$, Hoffstein V. Alveolar damage due to inhalation of amitrolecontaining herbicide. Chest. 1992;101:1174-6.

16. Jinn $\mathrm{Y}$, Akizuki $\mathrm{N}$, Ohkouchi $\mathrm{M}$, Inase $N$, Ichioka $M$, Marumo $F$. Acute lung injury after inhalation of water-proofing spray while smoking a cigarette. Respiration. 1998;65:486-8.

17. Kayser K, Plodziszewska M, Waitr E, Slodkowska J, Altiner M, Gabius HJ. Diffuse pulmonary hemosiderosis after exposure to pesticides. A case report. Respiration. 1998;65:214-8. 
18. Spahr JE, Maul JS, Rodgers GM. Superwarfarin poisoning: a report of two cases and review of the literature. Am J Hematol. 2007;82:656-60.

19. De Lassence A, Fleury-Feith J, Escudier E, Beaune J, Bernaudin JF, Cordonnier C. Alveolar hemorrhage. Diagnostic criteria and results in 194 immunocompromised hosts. Am J Respir Crit Care Med. 1995;151:157-63.

20. Baughman RP, Lower EE, du Bois RM. Sarcoidosis. Lancet. 2003;361:1111-8.

21. Kataria YP, Holter JF. Sarcoidosis: A Model of Granulomatous Inflammation of Unknown Etiology Associated with a Hyperactive Immune System. Methods. 1996; 9:268-94.

22. Design of a case control etiologic study of sarcoidosis (ACCESS). ACCESS Research Group. J Clin Epidemiol. 1999;52:1173-86.

23. Rossman MD, Kreider ME. Lesson learned from ACCESS (A Case Controlled Etiologic Study of Sarcoidosis). Proc Am Thorac Soc. 2007;4:453-6.

24. Judson MA, Baughman RP, Thompson BW, Teirstein AS, Terrin ML, Rossman MD, Yeager $\mathrm{H}$, Jr., McLennan $\mathrm{G}$, Bresnitz EA, DePalo L, Hunninghake G, Iannuzzi MC, Johns CJ, Moller DR, Newman LS, Rabin DL, Rose C, Rybicki BA, Weinberger SE, Knatterud GL, Cherniak R. Two year prognosis of sarcoidosis: the ACCESS experience. Sarcoidosis Vasc Diffuse Lung Dis. 2003;20:204-11.

25. Rybicki BA, Maliarik MJ, Major M, Popovich J, Jr., Iannuzzi MC. Epidemiology, demographics, and genetics of sarcoidosis. Semin Respir Infect. 1998;13:166-73.

26. Baughman RP, Winget DB, Bowen EH, Lower EE. Predicting respiratory failure in sarcoidosis patients. Sarcoidosis Vasc Diffuse Lung Dis. 1997;14:154-8.

27. Arcasoy SM, Christie JD, Pochettino A, Rosengard BR, Blumenthal NP, Bavaria JE, Kotloff RM. Characteristics and outcomes of patients with sarcoidosis listed for lung transplantation. Chest. 2001;120:873-80.

28. DeRemee RA. The roentgenographic staging of sarcoidosis. Historic and contemporary perspectives. Chest. 1983;83:128-33.

29. Moller DR. Cells and cytokines involved in the pathogenesis of sarcoidosis. Sarcoidosis Vasc Diffuse Lung Dis. 1999;16:24-31.

30. Castro-Giner F, Kogevinas $M$, Machler $M$, de Cid $R$, Van Steen $K$, Imboden $M$, Schindler C, Berger W, Gonzalez JR, Franklin KA, Janson C, Jarvis D, Omenaas E, Burney P, Rochat T, Estivill X, Anto JM, Wjst M, Probst-Hensch NM. TNFA -308G >A in two international population-based cohorts and risk of asthma. Eur Respir $\mathrm{J}$. 2008;32:350-61.

31. Grunewald J, Eklund A, Olerup O. Human leukocyte antigen class I alleles and the disease course in sarcoidosis patients. Am J Respir Crit Care Med. 2004;169: 696-702.

32. Grutters JC, Sato $H$, Pantelidis P, Lagan AL, McGrath DS, Lammers JW, van den Bosch JM, Wells $A U$, du Bois RM, Welsh KI. Increased frequency of the uncommon tumor necrosis factor $-857 \mathrm{~T}$ allele in British and Dutch patients with sarcoidosis. Am J Respir Crit Care Med. 2002;165:1119-24.

33. Hajeer $\mathrm{AH}$, Hutchinson IV. Influence of TNFalpha gene polymorphisms on TNFalpha production and disease. Hum Immunol. 2001;62:1191-9.

34. Morohashi K, Takada T, Omori K, Suzuki E, Gejyo F. Vascular endothelial growth factor gene polymorphisms in Japanese patients with sarcoidosis. Chest. 2003;123: 1520-6.

35. Sato H, Williams HR, Spagnolo P, Abdallah A, Ahmad T, Orchard TR, Copley SJ, Desai SR, Wells AU, du Bois RM, Welsh KI. CARD15/NOD2 polymorphisms are associated with severe pulmonary sarcoidosis. Eur Respir J. 2010;35:324-30.

36. Zorzetto M, Bombieri C, Ferrarotti I, Medaglia S, Agostini C, Tinelli C, Malerba G, Carrabino N, Beretta A, Casali L, Pozzi E, Pignatti PF, Semenzato G, Cuccia MC, Luisetti M. Complement receptor 1 gene polymorphisms in sarcoidosis. Am J Respir Cell Mol Biol. 2002;27:17-23. 


\section{Chapter 2}

Relationship between drug-induced interstitial lung diseases and CYP polymorphisms

P Wijnen, O Bekers, M Drent

Curr Opin Pul Med. 2010;16:496-502 


\section{Abstract}

\section{Background}

Interstitial lung disease and especially drug-induced interstitial lung disease can occur as a cause of drug(s) or drug-drug interactions. In this review we summarize the possible role of cytochrome P450 (CYP) enzymes in drug-induced interstitial lung disease.

\section{Recent findings}

The CYP enzyme family plays an important role in the metabolization of all sorts of ingested, injected or inhaled xenobiotic substances. Although the liver is considered to be the major metabolization site of CYP enzymes, in recent years more CYP isoforms have been detected in lung tissue. Polymorphisms in these CYP genes can influence the metabolic activity of the subsequent enzymes, which in turn may lead to localized (toxic) reactions and tissue damage.

\section{Summary}

Drug toxicity can be the consequence of no or very poor enzyme activity, especially if no other metabolic route is available. In case of reduced enzyme activity, dose reduction or prescribing an alternative drug metabolized by a different, unaffected CYP enzyme is recommended to prevent toxic side effects. Therefore, knowing a patient's CYP profile before drug prescription could be a way to prevent drug-induced interstitial lung disease. Moreover, it might be helpful in explaining serious adverse effects from inhaled, injected or ingested xenobiotic substances. 


\section{Introduction}

The lungs are a target for a variety of xenobiotic and possible toxic substances, because of their large contact surface with both the outside world and circulating blood. Air can deliver (mineral) particles or (toxic) fumes and blood is the main supplier of most drugs, independent of the way of administration. Moreover, they form not only an important first point of contact or barrier, but also can act as a metabolization site for certain substances. Drugs can induce specific respiratory reactions, or the lungs may be affected as part of a generalized response. The most common form of drug-induced respiratory disease is drug-induced interstitial lung disease (DI-ILD). The drugs involved not only include prescribed and over-the-counter-drugs, but also illicit drugs, herbs, alcohol, and dietary ingredients. ${ }^{1-4}$ An ever increasing number of drugs can produce or reproduce variegated patterns of naturally occurring infiltrative lung disease, including most forms of interstitial pneumonias, alveolar involvement, and, rarely, vasculitis. ${ }^{1,3,5}$ Although, only in a limited number of cases drugs unequivocally have been identified as cause, it is important to acknowledge the potential role of medication in the development of DI-ILD., 6 This is due to the severity of the potentially irreversible damage to the lungs and the improvement that is often easily achieved by stopping administration of drugs. Rational treatment of drug-toxicities in cases where the mechanism of toxicity is known is common clinical practice. However, often the connection with drug-use and the development of related inflammatory damage or idiosyncratic toxicities is hard to recognize and objectify, especially in those cases using multiple drugs. ${ }^{7}$

The aim of this review is to discuss drug-induced respiratory reactions and the possible mechanisms involved, focussing on the role of cytochrome P450 (CYP) polymorphisms.

\section{Drugs and lungs}

The diagnosis of DI-ILD primarily rests on the temporal association of exposure to $\operatorname{drug}(\mathrm{s})$, and the development of respiratory symptoms. It is also clinically challenging, especially when trying to find predictors for the possibility that an individual is at risk for developing such a reaction, and moreover, in avoiding re-challenge with the trigger. For an overview of drugs known to be able to damage the respiratory system see www.pneumotox.com. In some cases the evidence that reactions in the lungs are drug-induced is circumstantial. ${ }^{1} \mathrm{~A}$ straightforward interpretation is hampered when the damage is irreversible or when the symptoms aggravate after stopping drug administration. Thus, the 
diagnosis of DI-ILD is mainly one of exclusion and requires the meticulous ruling out of all other possible causes.

The variability in drug response among patients is multi-factorial, including extrinsic factors like environmental aspects and also genetic and intrinsic factors that affect the disposition (absorption, distribution, metabolism and excretion) of a certain drug (Table 2.1). The existence of large population differences with small intra-individual variability is consistent with inheritance as determinant of drug response; it is estimated that genetics can account for $20-95 \%$ of variability in drug disposition and effects, see also Figure $2.1 .^{8}$

Table 2.1 Factors influencing drug metabolism.

\begin{tabular}{|c|c|c|}
\hline \multirow[t]{2}{*}{ Extrinsic factors } & Environment & $\begin{array}{l}\text { Smoking } \\
\text { Diet } \\
\text { Alcohol } \\
\text { Inhalation of (toxic) fumes }\end{array}$ \\
\hline & Drug use & $\begin{array}{l}\text { Prescribed drugs } \\
\text { Illicit drugs } \\
\text { Over the counter drugs } \\
\text { Herbal supplements } \\
\text { Concomitant drugs }\end{array}$ \\
\hline \multirow[t]{2}{*}{ Intrinsic factors } & Demographic & $\begin{array}{l}\text { Gender } \\
\text { Age } \\
\text { Race }\end{array}$ \\
\hline & Disease & $\begin{array}{l}\text { Disturbed kidney excretion function } \\
\text { Diminished liver blood perfusion } \\
\text { Changed metabolic function }\end{array}$ \\
\hline Genetic factors & \multicolumn{2}{|c|}{ Polymorphisms in genes encoding for metabolic enzymes } \\
\hline
\end{tabular}

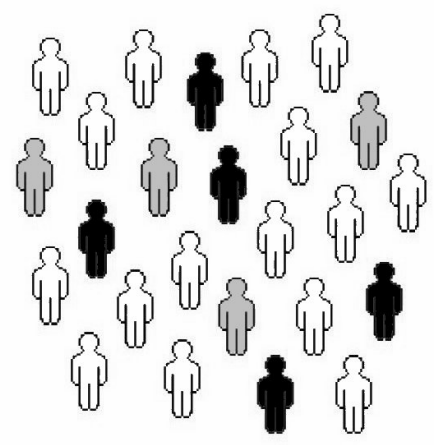

Figure 2.1 Drug response in a population.

Patients with the same diagnosis and treated with the same medication. Most patients react well (white), some of the patients do not respond to the therapy (grey) and some react with adverse reactions or toxicity (black). 
Two metabolization routes (phase I and phase II reactions) are responsible for the transformation of the majority of xenobiotic substances, with the purpose of facilitating elimination from the body. Phase I reactions, performed mainly by CYP enzymes, involve hydroxylation, reduction and oxidation while in phase II reactions glucuronidation, sulfation, acetylation or methylation take place. The risk of developing DI-ILD and clinical patterns vary, depending on a variety of host and drug factors. Several different xenobiotic-metabolizing CYP and phase II enzymes are present in the human lung, possibly contributing to in situ activation. Metabolism also affects the biological activity of the drug. Mostly, the biological activity of the parent drug is superior to that of the metabolite, but there are several exceptions. Sometimes CYP metabolism yields very toxic metabolites, e.g. acetaminophen, benzo[a]pyrene or carbamazepine. ${ }^{9}$ Occasionally, drugs may cause the formation of reactive oxygen species by uncoupling of the electron transport of the CYP system. These metabolites or reactive oxygen species may damage vital cellular components, such as proteins, lipids or DNA.

\section{CYP enzymes}

The most common DNA variations in the human genome are called single nucleotide polymorphisms (SNPs). The presence of certain SNPs can result in a less functional enzyme and a subsequently changed, i.e. slower, metabolization for certain drugs. SNPs in the CYP genes are one of the key factors known to cause variation in drug response between individuals. ${ }^{2,3,7-11}$ In recent years more CYP enzymes were detected within lung tissue. Local metabolization, or rather the lack of metabolization in some cases, might explain adverse reactions and subsequent tissue damage in the lungs. ${ }^{2,10,12-14}$

With the widespread possibility to determine the genetic profile of the CYP enzymes, their metabolic capacity can be determined. Patients can be divided into ultra-extensive (UM), extensive (EM), intermediate (IM) or poor metabolizers (PM). ${ }^{15}$

The most important CYP enzymes for drug metabolism are CYP1A2, CYP2C9, CYP2C19, CYP2D6, CYP3A4, and CYP3A5. This review will focus on clinical relevance and prevalence of CYP polymorphisms that are also important in relation to the lungs (Table 2.2 ).

The completion of the sequence of the human genome revealed the presence of 115 human CYP genes: 57 active and 58 pseudo-genes. ${ }^{16}$ The CYP enzymes are a superfamily of hemoproteins found in a wide range of different organs and tissues. ${ }^{9,17-21}$ 
Table 2.2 CYP distribution and metabolic activity in the liver and presence in lung tissue.

\begin{tabular}{lccc}
\hline CYP & \% Distribution & \% Metabolic activity & Presence in the lung \\
\hline $3 \mathrm{~A}$ & 30 & 55 & +++ \\
2C & 20 & 10 & ++ \\
IA2 & 13 & 2 & + \\
2E1 & 7 & 1.5 & +++ \\
2A6 & 4 & 1.5 & +++ \\
2D6 & 2 & 30 & ++ \\
\hline
\end{tabular}

CYP proteins are conveniently arranged into families and subfamilies on the basis of percentage amino acid sequence identity. ${ }^{22}$ Figure 2.2 illustrates an example of CYP enzyme nomenclature, see also www.cypalleles.ki.se for an overview of human CYP allele nomenclature. The CYP isoenzymes in families 1-3 are responsible for $70-80 \%$ of all phase I-dependent metabolism of clinically used drugs and also participate in the metabolism of a large number of xenobiotic substances. ${ }^{23-25}$

Substances (medicines or other compounds) that are metabolized by CYP enzymes are called substrates. Inhibitors can reduce the action of a cytochrome, while so-called inducers can enhance the metabolism of a specific CYP enzyme.

The metabolic capacity of the different CYP enzymes is also defined as low affinity/high capacity or high affinity/low capacity. The CYP2D6 enzyme is, like CYP2C9 and CYP2C19, defined as a high affinity/low capacity, which implies that these CYP enzymes prefer to metabolize specific substrates at a low concentration. As the concentration of a medicine increases, the metabolism can possibly spill over to CYP3A4 and CYP1A2, which are low affinity/high capacity enzymes.

Several CYP enzymes, important for metabolism in the liver, but also in the lungs, will be discussed in detail.

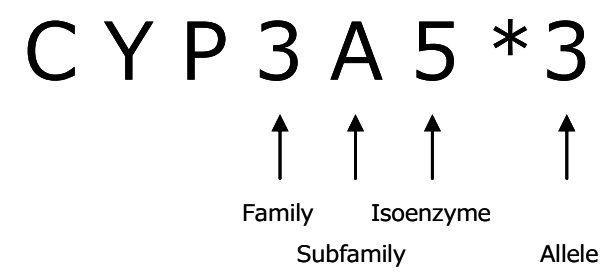

Figure 2.2 An example of the nomenclature of CYP enzymes.

The fully functional allele is indicated with $* 1$, whereas the variant alleles are indicated with higher allele numbers and result in an aberrant functioning enzyme. 


\section{CYP1A2}

Until recently, CYP1A2 was assumed to be present exclusively in the liver, but with more sensitive techniques available it has been detected in other tissues, including the lungs. ${ }^{9,12,13}$ Sixteen variant alleles, not counting the 20 isotypes of the $* 1$ allele, have been identified to date. The metabolic activity of CYP1A2 consists primarily of hydroxylating and demethylating compounds through oxidative metabolism. Substrates for CYP1A2 metabolism are, e.g. caffeine ${ }^{26}$, theophylline, and naproxen. ${ }^{27}$ Used in combination with an inhibitor, grapefruit juice for example, serum levels of substrates may increase, with toxicity and adverse drug reactions (ADRs) as a possible result. ${ }^{28}$ Induction of the CYP1A2 metabolism can be achieved by cruciferous vegetables such as Brussels sprouts, broccoli or cabbage, and charbroiled foods (burned meats). Another important inducer of CYP1A2 is tobacco smoke. ${ }^{29}$

CYP1A2 is a low affinity/high capacity enzyme in contrast to CYP2D6, CYP2C9, and $\mathrm{CYP} 2 \mathrm{C} 19$ in the metabolism of many drugs. ${ }^{30}$ Gender differences have been found in the Chinese population, with men having more CYP1A2 activity compared with women. ${ }^{31}$

\section{CYP2C9}

Of the CYP2C family, CYP2C9 is considered to be the most important isoform, being the largest contributor and responsible for the metabolic clearance of up to $15 \%$ of all drugs (among which a host of clinically important drugs such as NSAIDs, oral anticoagulants, and angiotensin II blockers) undergoing phase I metabolism. ${ }^{32}$ Most of the CYP2C9 activity in terms of drug metabolism takes place in the liver, but it is found in various other tissues. ${ }^{33}$ To date, 34 variant alleles of the CYP2C9 enzymes have been identified and Lee et al. ${ }^{34}$ determined that two of these CYP2C9 variant alleles, $* 2$ (430T) and $* 3$ (1075C), were found in $35 \%$ of the Caucasians. These CYP2C9 variant alleles are present much less frequently in African-Americans and Asians (about 2\% and 5\%, respectively). ${ }^{35}$ Patients with CYP2C9*2 or CYP2C9*3 variant alleles require lower doses of drugs metabolized by CYP2C9, because of the reduced activity of these common variants. ${ }^{36}$

The only clearly recognized inducer of CYP2C9 is rifampicin. Moreover, in the case of concomitant rifampicin use, serum levels of drugs metabolized by CYP2C9 have been shown to reduce, by induction. In the case of e.g. warfarin use, this can lead to not enough anticoagulation and in turn could cause thrombotic events. ${ }^{37}$ 


\section{CYP2C19}

CYP2C19 is found in many tissues, but predominantly in the liver were it accounts together with CYP2C9, for approximately $20 \%$ of the total CYP activity. Until recently, 26 different variant alleles for CYP2C19 were identified. ${ }^{38}$ The prevalence of CYP2C19 enzyme polymorphisms differs significantly between ethnic groups. For example, the PM phenotype occurs in 2-6\% of Caucasians, $10-20 \%$ of Africans, and in $15-30 \%$ of Asians. ${ }^{39,40}$ Variant alleles of CYP2C19 lead to reduced or no enzyme function. Determining the metabolizer phenotype may also help in the case of treatment with drugs that rely on CYP2C19. Rifampicin has been identified as an inducer of both CYP2C19 and CYP2C9. ${ }^{41}$ Other drugs (anti-convulsants and steroids) that typically induce other CYP enzymes may also induce CYP2C19, but to a lesser extent than CYP2C9 and CYP3A4. ${ }^{42}$

\section{CYP2D6}

Although CYP2D6 represents only 1-2\% of the liver CYP isoenzymes by weight, it takes care of some $30 \%$ of its metabolic activity (Table 2.2). ${ }^{43,44}$ Next to its important role in the liver's drug metabolism, CYP2D6 is also found in many other tissues, including the lungs. ${ }^{45,46}$ For many drugs, especially psychotropic drugs, CYP2D6 is considered a high affinity/low capacity enzyme, which implies that CYP2D6 will preferentially metabolize drugs at lower concentrations. ${ }^{47}$ Until recently, 75 different variant alleles for CYP2D6 were identified. There are ethnic differences in the distribution of EMs, PMs, and UMs. PMs are present in approximately $5-14 \%$ of Caucasians. ${ }^{48,49}$ Bradford $^{50}$ indicated that Asians, Pacific Islanders, Africans and African Americans have a higher percentage of reduced-function or non-functional CYP2D6 (40-50\%) than do Caucasians (26\%). UMs carry a duplication of a fully functional CYP2D6 allele which results in higher CYP2D6 enzyme levels. Due to these higher CYP2D6 enzyme levels, UMs require a higher daily dose to obtain a therapeutic drug blood level. UMs are generally rare representing $1-3 \%$ of the Caucasian population. ${ }^{51}$ CYP2D6 is the main metabolic enzyme for a whole range of (psychotropic) drugs and the presence of a less functional enzyme can have serious treatment consequences or lead to severe ADRs. ${ }^{52,53}$ 
CASE: A 43-year-old female presented with a non-productive cough and dyspnoea. The chest X-ray (CXR) and high resolution CT-scan (Figure 2.3A) showed coarse reticular opacities indicative of ILD. She used metoprolol for her hypertension, flecainide as an antiarrhythmic, and fenfluramide for obesity. Bronchoalveolar lavage fluid (BALF) showed an increased number of cells, predominantly lymphocytes, and the presence of plasma cells and foamy alveolar macrophages (Figure 2.3B), indicative of hypersensitivity pneumonitis or DI-ILD. Lung biopsy specimens demonstrated non-specific interstitial pneumonia (NSIP) of the cellular type. The patient's clinical condition deteriorated and artificial respiration was required for 6 weeks. She was treated with prednisone and fenfluramine was stopped. Hereafter, the clinical condition improved spectacularly and the CXR abnormalities resolved completely. Four years later, the patient's initial complaints returned. Again, the CXR showed the earlier reported reticular opacities and BALF analysis revealed the aforementioned signs of DI-ILD. To date, dexfenfluramine was started six weeks prior to this admission. The first clinical deterioration was not recognized as DI-ILD related to fenfluramine. The second deterioration appeared after starting dexfenfluramine as adjuvant therapy for her obesity. At that time, a role for (dex)fenfluramine was assumed in the development of pneumonitis. In addition genotyping revealed a $C Y P 2 D 6^{*} 1 / * 3$ heterozygote variant. She used metoprolol and flecainide on a regular base. When another drug metabolized by the CYP2D6 system was added she deteriorated. Therefore, the use of various drugs metabolized by the same affected enzyme should be avoided, for this may result in significant accumulation of these drug(s), leading to toxic serum levels and severe side effects. Avoiding those drugs or dose reduction appeared to be beneficial in this patient and protected her from similar adverse effects until now.
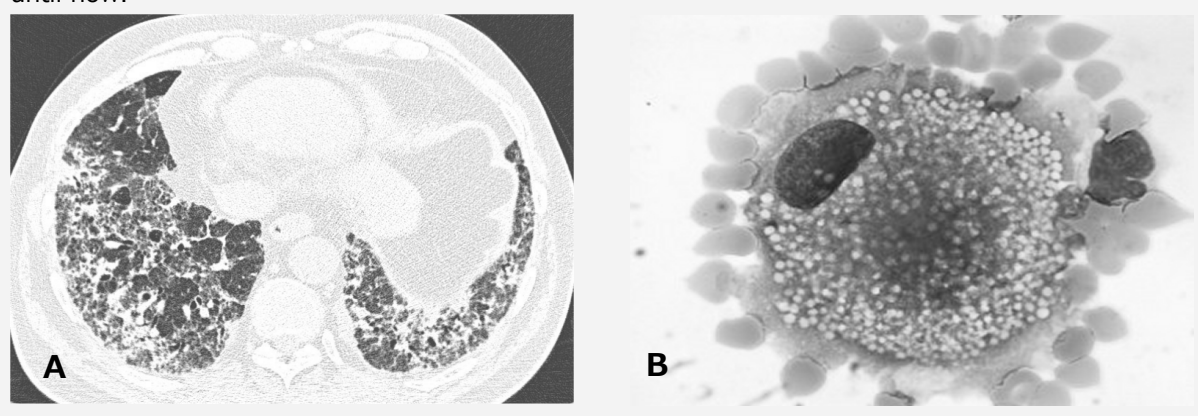

Figure 2.3 (A) High resolution CT-scan; (B) Foamy alveolar macrophage.

Table 2.2 CYP distribution and metabolic activity in the liver and presence in lung tissue.

\begin{tabular}{lccc}
\hline CYP & \% Distribution & \% Metabolic activity & Presence in the lung \\
\hline $3 \mathrm{~A}$ & 30 & 55 & +++ \\
2C & 20 & 10 & ++ \\
$1 \mathrm{~A} 2$ & 13 & 2 & + \\
$2 \mathrm{E} 1$ & 7 & 1.5 & +++ \\
$2 \mathrm{~A} 6$ & 4 & 1.5 & +++ \\
2D6 & 2 & 30 & ++ \\
\hline
\end{tabular}




\section{CYP3A4}

To date, 20 CYP3A4 allelic variants have been identified. CYP3A4 is considered to be one of the most contributing CYP enzymes in all phase I drug metabolizations. In the liver the CYP3A enzymes make up about $30 \%$ of all CYPs present, but take care of about $55 \%$ of the metabolism. CYP3A4, together with CYP3A5, are considered to be the major forms present. Whenever the concentration of a substrate increases beyond the capacity of the main metabolizing CYP enzyme, the metabolism can spill over to CYP3A4, which is a low affinity/high capacity enzyme.

The most common variant in the $5^{\prime}$-untranslated region is CYP3A4*1B, which is strongly associated with increased CYP3A5 expression in a study by Wojnowski et al. ${ }^{54}$ and also associated with enhanced CYP3A4 expression. ${ }^{55}$ Allelic frequencies range from $0 \%$ in Asians to $4-10 \%$ in Caucasians and $48-80 \%$ in African-Americans. ${ }^{56}$ Inducers of CYP3A4 are e.g. rifampicine, carbamazepine, phenobarbital, and St. John's Wort. Grapefruit juice, amiodarone and verapramil are some of the possible inhibitors of CYP3A4. ${ }^{4}$

\section{CYP3A5}

CYP3A5, together with CYP3A4, is one of the most contributing CYP enzymes, but not so much in the Caucasian population. For the homozygous CYP $3 A 5^{*} 3 / * 3$ variant, which is a less functional enzyme, is the more prevalent genotype in the Caucasian population. Moreover, in Caucasians the frequency of the CYP3A5*3 allele is about $90-95 \%$ and of the functional CYP3A5*1 allele only about $10 \% .{ }^{57,58}$ In Asians the CYP3A5*3 allelic frequency is about $75 \%$ and about $35 \%$ in African-Americans. ${ }^{58}$ In all CYPs the term 'wild type' stands for the most prevalent and fully functional $(* 1 / * 1)$ enzyme, CYP3A5 being the exception to the rule. As a consequence, an individual who possesses one or two CYP3A5*1 alleles, needs a higher (two to threefold) maintenance dose of medicines metabolized by CYP3A5, such as i.e. the immune modulator tacrolimus. ${ }^{59}$

Until recently, 11 different CYP3A5 allelic variants have been found. Furthermore, contrary to the situation in the liver, in the lungs CYP3A5 is the main CYP3A form expressed. ${ }^{20}$

\section{Discussion}

Many prescribed drugs are effective in only $25-60 \%$ of the patients (Figure 2.1). ${ }^{60}$ Therefore, it is also important to determine co-factors in drug metabolism, as depicted in Table 2.1. A disadvantage of drug development is the fact that most drugs are tested in a standardized population, which rules 
out severe toxicity and will not always predict drug interaction(s). Also, in a lot of trials multiple drug prescription or intake is not taken into account. Moreover, in many cases genetic metabolic differences, like the presence of one or multiple polymorphisms in CYP enzymes, can make it difficult to predict therapeutic drug reactions.

Although in most cases the clinical consequences may be minor, the impact can be enormous for patients receiving medicines with a narrow therapeutic index, due to either, sub-therapeutic drug levels, or (severe) ADRs, or increased mortality rates. For the latter this was established in a recent study about tamoxifen use and CYP2D6 polymorphisms. ${ }^{52}$ An example of CYP polymorphisms and subsequent lung involvement is shown in another recent study, in which the link between CYP2C9 and VKORC1 SNPS, the prescription of oral anticoagulants and the occurrence of diffuse alveolar hemorrhage (DAH) was established. ${ }^{61}$ Patients with CYP2C9*2 and/or CYP2C9*3 variant alleles require up to $61 \%$ lower maintenance doses of warfarin because of the reduced enzyme activity of these common variants. ${ }^{36}$ A common serious ADR in these patients, therefore, can be over-anticoagulation, resulting in (life threatening) bleeding complications, such as DAH.

Furthermore, in a case-control study it was found that $91.5 \%$ of patients with DI-ILD had at least one of the studied CYP2D6, CYP2C9 or CYP2C19 variant alleles compared with $70.5 \% \quad(p<0.001)$ of healthy volunteers. DI-ILD appeared to be associated with the presence of at least one variant CYP allele. ${ }^{2}$ These and other studies support the potential usefulness of personalized medicine by genotyping aiming to improve efficacy, tolerability and drug safety. ${ }^{25,62}$

Different patient categories should be tested for CYP polymorphisms: elderly patients with many drugs for different diseases, patients using drugs with a small therapeutic range and patients with unexplained side effects. Although the genotypic profile does not always predict the phenotypic expression, the interaction profile between different drugs can be estimated by computer models. Starting with a lower dose or using a medicine that is metabolized by another enzyme or route is often a way to prevent ADRs and reduce interactions. In addition, the best way to check the effect is to measure serum levels of the drug and its metabolites, the so called therapeutic drug monitoring (TDM). However, therapeutic serum levels of many drugs are not available or expensive to ascertain. In organ transplantation medicine, TDM together with CYP genotyping is already daily practice and can be cost effective, because of the high costs and the small therapeutic range of the immunosuppressive medication used. ${ }^{59,63}$

Nevertheless, genotyping should be considered to identify patients that might be at risk of severe toxic responses to environmental, pharmacological, herbal remedies and/or nutritional stimuli, in order to guide appropriate individual 
dosage(s). ${ }^{25}$ Nowadays, DNA material for genotyping can be easily obtained and patients do not even have to go to hospital for sample drawing. ${ }^{64}$ Both clinical and genetic risk stratification (pharmacogenomics) may lead to more accurate prevention of drug-induced damage in the future. ${ }^{11,25}$ However, further research is needed to explore the clinical relevance.

\section{Conclusion}

An ideal situation would be the introduction of a genetic medical passport for each patient to achieve a system in which therapeutic drug monitoring will be standard clinical practice. In this manner the incidence of ADRs and related medical consumption will decrease, which in the end will lead to a better pharmacotherapy for patients and reduced healthcare costs. To achieve this, a multi-disciplinary approach will be necessary to individualize pharmacotherapy on the basis of the pharmcogenetic profile. 


\section{References}

1. Camus $\mathrm{P}$, Fanton A, Bonniaud P, Camus C, Foucher P. Interstitial lung disease induced by drugs and radiation. Respiration. 2004;71:301-26.

2. Wijnen PA, Drent M, Nelemans PJ, Kuijpers PM, Koek GH, Neef C, Haenen GR, Bekers O. Role of cytochrome $\mathrm{P} 450$ polymorphisms in the development of pulmonary drug toxicity: a case-control study in the Netherlands. Drug Saf. 2008;31:1125-34.

3. Foucher P, Biour M, Blayac JP, Godard P, Sgro C, Kuhn M, Vergnon JM, Vervloet $D$, Pfitzenmeyer $\mathrm{P}$, Ollagnier M, Mayaud $C$, Camus $P$. Drugs that may injure the respiratory system. Eur Respir J. 1997;10:265-79.

4. Bressler R. Grapefruit juice and drug interactions. Exploring mechanisms of this interaction and potential toxicity for certain drugs. Geriatrics. 2006;61:12-8.

5. Camus $P$, Kudoh $S$, Ebina M. Interstitial lung disease associated with drug therapy. Br J Cancer. 2004;91 Suppl 2:S18-23.

6. Drent M, Singh S, Gorgels AP, Hansell DM, Bekers O, Nicholson AG, van Suylen RJ, du Bois RM. Drug-induced pneumonitis and heart failure simultaneously associated with venlafaxine. Am J Respir Crit Care Med. 2003;167:958-61.

7. Nemery B, Bast A, Behr J, Borm PJ, Bourke SJ, Camus PH, De Vuyst P, Jansen HM, Kinnula VL, Lison $\mathrm{D}$, Pelkonen $\mathrm{O}$, Saltini $\mathrm{C}$. Interstitial lung disease induced by exogenous agents: factors governing susceptibility. Eur Respir J Suppl. 2001;32: 30s-42s.

8. Kalow W, Tang BK, Endrenyi L. Hypothesis: comparisons of inter- and intraindividual variations can substitute for twin studies in drug research. Pharmacogenetics. 1998;8:283-9.

9. Castell JV, Donato MT, Gomez-Lechon MJ. Metabolism and bioactivation of toxicants in the lung. The in vitro cellular approach. Exp Toxicol Pathol. 2005;57 Suppl 1: 189-204.

10. Ding $X$, Kaminsky LS. Human extrahepatic cytochromes P450: function in xenobiotic metabolism and tissue-selective chemical toxicity in the respiratory and gastrointestinal tracts. Annu Rev Pharmacol Toxicol. 2003;43:149-73.

11. Kirchheiner J, Seeringer A. Clinical implications of pharmacogenetics of cytochrome P450 drug metabolizing enzymes. Biochim Biophys Acta. 2007;1770:489-94.

12. Nishimura $M$, Yaguti $H$, Yoshitsugu $H$, Naito $S$, Satoh $T$. Tissue distribution of mRNA expression of human cytochrome $\mathrm{P} 450$ isoforms assessed by high-sensitivity realtime reverse transcription PCR. Yakugaku Zasshi. 2003;123:369-75.

13. Sarikaya D, Bilgen C, Kamataki T, Topcu Z. Comparative cytochrome P450 -1A1, $-2 \mathrm{~A} 6,-2 \mathrm{~B} 6,-2 \mathrm{C},-2 \mathrm{D} 6,-2 \mathrm{E} 1,-3 \mathrm{~A} 5$ and $-4 \mathrm{~B} 1$ expressions in human larynx tissue analysed at mRNA level. Biopharm Drug Dispos. 2006;27:353-9.

14. Carlson GP. Critical appraisal of the expression of cytochrome P450 enzymes in human lung and evaluation of the possibility that such expression provides evidence of potential styrene tumorigenicity in humans. Toxicology. 2008;254:1-10.

15. Ereshefsky L, Dugan D. Review of the pharmacokinetics, pharmacogenetics, and drug interaction potential of antidepressants: focus on venlafaxine. Depress Anxiety. 2000;12 Suppl 1:30-44.

16. Nelson DR. Introductory remarks on human CYPs. Drug Metab Rev. 2002;34:1-5.

17. Oinonen $\mathrm{T}$, Lindros KO. Zonation of hepatic cytochrome P-450 expression and regulation. Biochem J. 1998;329 ( Pt 1):17-35.

18. Krishna DR, Klotz U. Extrahepatic metabolism of drugs in humans. Clin Pharmacokinet. 1994;26:144-60.

19. Hukkanen J, Pelkonen O, Raunio H. Expression of xenobiotic-metabolizing enzymes in human pulmonary tissue: possible role in susceptibility for ILD. Eur Respir J Suppl. 2001;32:122s-6s. 
20. Hukkanen J, Pelkonen O, Hakkola J, Raunio H. Expression and regulation of xenobiotic-metabolizing cytochrome P450 (CYP) enzymes in human lung. Crit Rev Toxicol. 2002;32:391-411.

21. Zhang JY, Wang Y, Prakash C. Xenobiotic-metabolizing enzymes in human lung. Curr Drug Metab. 2006; 7:939-48.

22. Nelson DR. Cytochrome P450 nomenclature, 2004. Methods Mol Biol. 2006;320: 1-10.

23. Evans WE, Relling MV. Pharmacogenomics: translating functional genomics into rational therapeutics. Science. 1999;286:487-91.

24. Rendic S, Di Carlo FJ. Human cytochrome P450 enzymes: a status report summarizing their reactions, substrates, inducers, and inhibitors. Drug Metab Rev. 1997;29:413-580.

25. Jaquenoud Sirot E, van der Velden JW, Rentsch K, Eap CB, Baumann P. Therapeutic drug monitoring and pharmacogenetic tests as tools in pharmacovigilance. Drug Saf. 2006;29:735-68.

26. Miners JO, Birkett DJ. The use of caffeine as a metabolic probe for human drug metabolizing enzymes. Gen Pharmacol. 1996;27:245-9.

27. Miners JO, Coulter S, Tukey RH, Veronese ME, Birkett DJ. Cytochromes P450, 1A2, and 2C9 are responsible for the human hepatic O-demethylation of R- and S-naproxen. Biochem Pharmacol. 1996;51:1003-8.

28. Fuhr U. Drug interactions with grapefruit juice. Extent, probable mechanism and clinical relevance. Drug Saf. 1998;18:251-72.

29. Zevin S, Benowitz NL. Drug interactions with tobacco smoking. An update. Clin Pharmacokinet. 1999;36:425-38.

30. Zhang ZY, Kaminsky LS. Characterization of human cytochromes P450 involved in theophylline 8-hydroxylation. Biochem Pharmacol. 1995;50:205-11.

31. Ou-Yang DS, Huang SL, Wang W, Xie HG, Xu ZH, Shu Y, Zhou HH. Phenotypic polymorphism and gender-related differences of CYP1A2 activity in a Chinese population. Br J Clin Pharmacol. 2000;49:145-51.

32. Rettie $A E$, Jones JP. Clinical and toxicological relevance of CYP2C9: drug-drug interactions and pharmacogenetics. Annu Rev Pharmacol Toxicol. 2005;45:477-94.

33. Pavek $P$, Dvorak Z. Xenobiotic-induced transcriptional regulation of xenobiotic metabolizing enzymes of the cytochrome P450 superfamily in human extrahepatic tissues. Curr Drug Metab. 2008;9:129-43.

34. Lee CR, Goldstein JA, Pieper JA. Cytochrome P450 2C9 polymorphisms: a comprehensive review of the in-vitro and human data. Pharmacogenetics. 2002; 12:251-63.

35. Bravo-Villalta HV, Yamamoto K, Nakamura K, Baya A, Okada Y, Horiuchi R. Genetic polymorphism of CYP2C9 and CYP2C19 in a Bolivian population: an investigative and comparative study. Eur J Clin Pharmacol. 2005;61:179-84.

36. Higashi MK, Veenstra DL, Kondo LM, Wittkowsky AK, Srinouanprachanh SL, Farin FM, Rettie AE. Association between CYP2C9 genetic variants and anticoagulationrelated outcomes during warfarin therapy. JAMA. 2002;287:1690-8.

37. Heimark LD, Gibaldi M, Trager WF, O'Reilly RA, Goulart DA. The mechanism of the warfarin-rifampin drug interaction in humans. Clin Pharmacol Ther. 1987;42: 388-94.

38. Lee SJ, Kim WY, Kim H, Shon JH, Lee SS, Shin JG. Identification of new CYP2C19 variants exhibiting decreased enzyme activity in the metabolism of S-mephenytoin and omeprazole. Drug Metab Dispos. 2009;37:2262-9.

39. Poolsup N, Li Wan Po A, Knight TL. Pharmacogenetics and psychopharmacotherapy. J Clin Pharm Ther. 2000;25:197-220.

40. Flockhart DA. Drug interactions and the cytochrome P450 system. The role of cytochrome P450 2C19. Clin Pharmacokinet. 1995;29 Suppl 1:45-52. 
41. Zhou HH, Anthony LB, Wood AJ, Wilkinson GR. Induction of polymorphic 4'-hydroxylation of S-mephenytoin by rifampicin. Br J Clin Pharmacol. 1990;30: 471-5.

42. Gerbal-Chaloin S, Pascussi JM, Pichard-Garcia L, Daujat M, Waechter F, Fabre JM, Carrere N, Maurel P. Induction of CYP2C genes in human hepatocytes in primary culture. Drug Metab Dispos. 2001;29:242-51.

43. Gough AC, Smith CA, Howell SM, Wolf CR, Bryant SP, Spurr NK. Localization of the CYP2D gene locus to human chromosome 22q13.1 by polymerase chain reaction, in situ hybridization, and linkage analysis. Genomics. 1993;15:430-2.

44. Alam DA, Sharma, R.P. Cytochrome enzyme genotype and the prediction of therapeutic response to psychotropics. Psychiatric Annals. 2001;31:715-22.

45. Guidice JM, Marez D, Sabbagh N, Legrand-Andreoletti M, Spire C, Alcaide E, Lafitte JJ, Broly F. Evidence for CYP2D6 expression in human lung. Biochem Biophys Res Commun. 1997;241:79-85.

46. Huang Z, Fasco MJ, Spivack S, Kaminsky LS. Comparisons of CYP2D messenger RNA splice variant profiles in human lung tumors and normal tissues. Cancer Res. 1997; 57:2589-92.

47. DeVane CL, Nemeroff CB. 2002 guide to psychtropic drug interactions. Primary Psychiatry. 2002;9:28-57.

48. de Leon J, Barnhill J, Rogers T, Boyle J, Chou WH, Wedlund PJ. Pilot study of the cytochrome P450-2D6 genotype in a psychiatric state hospital. Am J Psychiatry. $1998 ; 155: 1278-80$.

49. Daly AK, Brockmoller J, Broly F, Eichelbaum M, Evans WE, Gonzalez FJ, Huang JD, Idle JR, Ingelman-Sundberg $M$, Ishizaki T, Jacqz-Aigrain E, Meyer UA, Nebert DW, Steen VM, Wolf CR, Zanger UM. Nomenclature for human CYP2D6 alleles. Pharmacogenetics. 1996;6:193-201.

50. Bradford LD. CYP2D6 allele frequency in European Caucasians, Asians, Africans and their descendants. Pharmacogenomics. 2002;3:229-43.

51. Eichelbaum M, Evert B. Influence of pharmacogenetics on drug disposition and response. Clin Exp Pharmacol Physiol. 1996;23:983-5.

52. Schroth W, Goetz MP, Hamann U, Fasching PA, Schmidt M, Winter S, Fritz P, Simon W, Suman VJ, Ames MM, Safgren SL, Kuffel MJ, Ulmer HU, Bolander J, Strick R, Beckmann MW, Koelbl $H$, Weinshilboum RM, Ingle JN, Eichelbaum M, Schwab M, Brauch $\mathrm{H}$. Association between CYP2D6 polymorphisms and outcomes among women with early stage breast cancer treated with tamoxifen. JAMA. 2009;302: 1429-36.

53. Wijnen PA, Limantoro I, Drent M, Bekers O, Kuijpers PM, Koek GH. Depressive effect of an antidepressant: therapeutic failure of venlafaxine in a case lacking CYP2D6 activity. Ann Clin Biochem. 2009;46:527-30.

54. Wojnowski L, Hustert E, Klein K, Goldammer M, Haberl M, Kirchheiner J, Koch I, Klattig J, Zanger $U$, Brockmoller J. Re: modification of clinical presentation of prostate tumors by a novel genetic variant in CYP3A4. J Natl Cancer Inst. 2002; 94:630-1; author reply $1-2$.

55. Amirimani B, Ning B, Deitz AC, Weber BL, Kadlubar FF, Rebbeck TR. Increased transcriptional activity of the CYP3A4*1B promoter variant. Environ Mol Mutagen. 2003;42:299-305.

56. Ball SE, Scatina J, Kao J, Ferron GM, Fruncillo R, Mayer P, Weinryb I, Guida M, Hopkins PJ, Warner N, Hall J. Population distribution and effects on drug metabolism of a genetic variant in the $5^{\prime}$ promoter region of CYP3A4. Clin Pharmacol Ther. 1999;66:288-94.

57. Roy JN, Lajoie J, Zijenah LS, Barama A, Poirier C, Ward BJ, Roger M. CYP3A5 genetic polymorphisms in different ethnic populations. Drug Metab Dispos. 2005; 33:884-7. 
58. Lee SJ, Usmani KA, Chanas B, Ghanayem B, Xi T, Hodgson E, Mohrenweiser HW, Goldstein JA. Genetic findings and functional studies of human CYP3A5 single nucleotide polymorphisms in different ethnic groups. Pharmacogenetics. 2003;13:461-72.

59. Op den Buijsch RA, Christiaans MH, Stolk LM, de Vries JE, Cheung CY, Undre NA, van Hooff JP, van Dieijen-Visser MP, Bekers O. Tacrolimus pharmacokinetics and pharmacogenetics: influence of adenosine triphosphate-binding cassette B1 (ABCB1) and cytochrome (CYP) 3A polymorphisms. Fundam Clin Pharmacol. 2007;21:427-35.

60. Spear BB, Heath-Chiozzi M, Huff J. Clinical application of pharmacogenetics. Trends Mol Med. 2001;7:201-4.

61. Wijnen PA, Linssen CF, Haenen GR, Bekers O, Drent M. Variant VKORC1 and CYP2C9 Alleles in Patients with Diffuse Alveolar Hemorrhage Caused by Oral Anticoagulants. Mol Diagn Ther. 2010;14:1-8.

62. Daly AK. Individualized drug therapy. Curr Opin Drug Discov Devel. 2007;10:29-36.

63. Ekbal NJ, Holt DW, Macphee IA. Pharmacogenetics of immunosuppressive drugs: prospect of individual therapy for transplant patients. Pharmacogenomics. 2008;9:585-96.

64. Wijnen PA, Drent M, van Dieijen-Visser MP, Bekers O. Pharmacogenetic testing after a simple DNA isolation method on buccal swab samples. Pharmacogenomics. 2009;10:983-7. 


\section{Chapter 3}

Pharmacogenetic testing after a simple DNA isolation method

P Wijnen, O Bekers, M van Dieijen-Visser, M Drent

Adaptation from:

P Wijnen, R Op den Buijsch, S Cheung, J van der Heijden, K Hoogtanders,

L Stolk, M van Dieijen-Visser, C Neef, M Drent, O Bekers

Genotyping with a dried blood spot method: a useful technique for application in Pharmacogenetics. Clin Chim Acta. 2008;388:189-191

and

P Wijnen, M Drent, M van Dieijen-Visser, O Bekers

Pharmacogenetic testing after a simple DNA isolation method on buccal swab samples. Pharmacogenomics. 2009;10:983-987 


\section{Abstract}

\section{Background}

Several commercial DNA isolation kits are available for extracting genomic DNA from whole blood samples, but these procedures require quite some hands-on time and are rather expensive. An alternative technique could be dried blood spot (DBS) sampling, with which DNA isolation is faster, cheaper and logistics are easier. We have developed a non-commercial DBS method and examined whether the quality and quantity of DNA, isolated from DBS and noninvasively obtained buccal swab (BS) samples, was satisfactory.

\section{Study design}

DNA isolation from EDTA blood samples and blood spots on filter paper were compared after DNA isolation with a column method and two different DBS methods. BS samples were obtained by rubbing a sterile, dry cotton swab against the inside of the subject's cheek. In addition, the quantity of the obtained DNA was measured and melting curve analyses of five cytochrome P450 and three ATP-binding cassette polymorphisms were performed with real-time PCR FRET assays to establish the quality of the obtained DNA from both the DBS and BS samples.

\section{Results}

In all cases the genotype results corresponded completely. Moreover, the derivative melting curves of the DNA samples obtained from the capillary blood and BS were comparable and highly reproducible. The mean DNA concentrations measured were $16.0 \mathrm{ng} / \mu \mathrm{l}(12.6-19.4 \mathrm{ng} / \mu \mathrm{l})$ and $70.2 \mathrm{ng} / \mu \mathrm{l}(57.3-83.1 \mathrm{ng} / \mu \mathrm{l})$, respectively, for DBS and BS samples $(p<0.001)$.

\section{Conclusion}

The DBS DNA isolation appears to be a useful alternative for the commercially available DNA isolation kits and an extremely useful method to discriminate between genotypes. This expands the possibilities of this quick and easy DNA isolation procedure. In particular, the noninvasive BS sampling method appeared to be a good alternative to invasive sampling methods. 


\section{Introduction}

Pharmacogenetics, the study of the role of inheritance in the individual variation in drug response, is still a growing field and it is gaining more importance in the treatment and investigation of the cause of certain diseases, symptoms and adverse drug reactions (ADR). The promise of pharmacogenetics lies in its potential to identify the right drug and dose for each patient. Even though individual differences in drug response can result from the effects of age, sex, disease or drug interactions, genetic factors also influence both the efficacy of a drug and the likelihood of an adverse reaction occurring. ${ }^{1-3}$ There is an increasing number of examples in which pharmacogenetic studies have indicated that a genetic test prior to treatment may be useful either for setting the individual dose or making a decision to use a particular drug. ${ }^{4-6}$ Therefore, genetic testing of individuals, specific patient groups and possibly their family members or genotyping prior to prescribing certain drugs is becoming more important. The materials used for genotyping are mostly ethylene diamine tetra-acetic acid (EDTA) whole blood obtained by venous sampling and tissue samples. However, both require an invasive sampling method and for a number of subjects, this can be a reason to refrain from signing up to an investigation or trial.

Several commercial DNA isolation kits are available for extracting genomic DNA from EDTA whole blood samples. To obtain DNA from whole blood, commercially available DNA isolation procedures, require approximately one hour hands-on time of a technician and are rather expensive (approximately $€ 4.00$ per isolation). Simplification of the standard DNA isolation procedures by the dried blood spot method (DBS) might be advantageous. DBS sampling has already become common practice for newborns. Over the past decade many applications have been reported for both qualitative and quantitative screening of metabolic disorders. ${ }^{7}$ Possible advantages of genotyping with DBS are: 1. The patient does not have to leave home and no phlebotomist is necessary.

2. Genotyping results are known when the patient visits the clinician and the clinician can take these results into account when he prescribes (other) drugs. 3. Transport is easy and there is a decrease in transport costs because only an envelope with the DBS of the patient is required. 4. Lower isolation costs and faster handling: DNA isolation with DBS is rapid, simple and no expensive DNA isolation kits are necessary.

Previously, the usefulness of DBS genotyping has been described. ${ }^{8,9}$ However, a non-commercial method for DNA isolation with DBS in association with pharmacogenetics has not yet been reported in literature. In the present study a new non-commercial DBS method was developed for isolating DNA from capillary blood and this method is validated versus a standard commercial 
available DNA isolation kit and also compared to an already existing extraction method for DBS described by Fischer et al. ${ }^{10}$

The aim of this study was also to test if the same DNA isolation protocol as applied to DBS could be used for isolating DNA from noninvasive buccal swab (BS) samples. Subsequently, the DNA quality and quantity of the BS samples were compared with the obtained DBS samples. Real-time PCR melting curve analyses were performed and DNA yields were measured using UV spectrometry. Additional storage tests were performed in order to ascertain whether delays in sending the sample to the laboratory or rather time from acquiring the BS sample to isolation, had an influence on the final result. Moreover, establishing the turnaround time and storage conditions required to avoid problems allows storage recommendations to be provided for the patient to follow.

\section{Materials and methods}

\section{Samples and materials}

EDTA whole blood samples and blood spots on filter paper made from the same samples were obtained from 106 Chinese renal transplant recipients and isolated by using $200 \mu \mathrm{l}$ EDTA whole blood with a column method QIAamp blood mini kit, (Qiagen, Leusden, The Netherlands) according to manufacturer's instructions and the DBS method developed by our lab. Additionally, DNA was isolated from 10 samples obtained from healthy volunteers using the column method for EDTA blood and simultaneously obtained finger prick blood was isolated using the DBS method described in this study and the one described by Fischer et al.

Furthermore, another 100 DBS samples were collected by finger prick from healthy volunteers to examine our DBS method in clinical practice. When using the DBS method capillary blood can be obtained by a finger prick by the patients themselves. The drop of blood is spotted on filter paper (Whatman ${ }^{\circledR}$ Schleicher and Schuell, code 903 (2992), Whatman ${ }^{\circledR}$, Dassel, Germany).

Buccal swabs were obtained by thoroughly rubbing a sterile, dry cotton stick (Copan plain swab sterile plastic applicator rayon tipped, ref 155C, Copan, Brescia, Italy) twice up and down against the inside of the individual's cheek on the one side of the mouth. One DBS and one BS sample were collected at the same time from 25 healthy volunteers, resulting in a total of 25 DBS and 25 BS samples to examine the two sampling methods that could be used in clinical practice. In addition, the samples were isolated according to our DBS protocol. After obtaining 12 BS samples per individual from a total of five healthy volunteers for a storage test, four swabs from each subject were kept at room temperature, four were put in a refrigerator, and four in a freezer. The BS 
samples kept at room temperature were isolated at day 1, 3, 5, and 7 after sampling. The samples kept at $4-8^{\circ} \mathrm{C}$ were isolated at $1,2,3$, and 4 weeks and the BS samples stored at $-20^{\circ} \mathrm{C}$ were isolated at $1,2,3$, and 4 months after sampling.

The DNA concentrations of the samples were measured on the NanoDrop ${ }^{\circledR}$ ND-1000 UV Spectrophotometer (Witec AG, Littau, Switzerland).

Written informed consent for participation in this study was obtained from all subjects.

\section{DNA isolation}

EDTA whole blood samples, capillary DBS and BS samples were collected. In the laboratory, after drying for $1 / 2 \mathrm{~h}$ a $3 \mathrm{~mm}$ paper disk was cut out from the blood spot sample with a puncher (Harris Uni-core ${ }^{\mathrm{TM}}$ ) or the tip was cut off the cotton stick. In addition, the $3 \mathrm{~mm}$ bloodstained paper disk or the cotton tip was placed into a cup, $500 \mu \mathrm{l}$ sterilized Milli-Q water (Millipore B.V., Amsterdam, The Netherlands) was added and vortexed three-times for $5 \mathrm{~s}$ each. The water was pipetted off. After adding $200 \mu \mathrm{ll} 10 \%$ Chelex $^{\circledR} 100$ solution (Bio-Rad Laboratories, CA, USA), the cup was placed in a water bath at $95^{\circ} \mathrm{C}$ for $30 \mathrm{~min}$. Finally, this DNA solution was pipetted into a new cup and the DNA was ready for use.

With the method described by Fischer et al. ${ }^{10}$ the $3 \mathrm{~mm}$ disk is placed in an Eppendorf ${ }^{\mathrm{TM}}$ cup and washed twice with $1 \mathrm{ml}$ of phosphated-buffered saline$0.1 \%$ Tween during $10 \mathrm{~min}$ with shaking. After transferring the disk to a $2 \mathrm{ml}$ screw-cap cup and adding $200 \mu \mathrm{l}$ 5\% Chelex-100 solution (Sigma-Aldrich Chemie B.V., Zwijndrecht, The Netherlands), the cup is placed in a water bath at $60^{\circ} \mathrm{C}$ for $30 \mathrm{~min}$, followed by $30 \mathrm{~min}$ in a water bath boiling at $100^{\circ} \mathrm{C}$.

\section{Genotyping}

A total of five previously described cytochrome P450 (CYP) and three ATPbinding cassette $(A B C B 1)$ polymorphisms were performed in this study, using real-time PCR fluorescence resonance energy transfer (FRET) assays (TIB MOLBIOL, Berlin, Germany), namely: CYP3A4-V A-392G, CYP3A5*3 A6986G, CYP2C9*2 C430T, CYP2C9*3 A1075C, CYP2C19*2 G681A, CYP2C19*3 G636A, CYP2D6*3 2549delA, CYP2D6*4 G1846A, ABCB1 C1236T, ABCB1 G2677T/A, and $A B C B 1$ C3435T. ${ }^{11-15}$ The single nucleotide polymorphisms (SNPs) were genotyped by examining the melting curves from the aforementioned FRET assays using the LightCycler ${ }^{\circledR}$ (Roche Diagnostics, Basel, Switzerland).

For comparison an EDTA sample, isolated on the MagNA Pure Compact (Roche Diagnostics), was genotyped within the same run as the DBS and BS samples. Furthermore, a heterozygote plasmid sample supplied with the primer/probes sets of each assay and a negative water control were analysed within each run. 


\section{Statistical analysis}

The paired t-test was used to compare the two sampling methods.

Melting curves were generated by the LightCycler ${ }^{\circledR}$ and its software/integration program calculates melting temperature(s) for each detected peak.

Statistical analyses were performed with SPSS 15.0 (SPSS. Inc., IL, USA) for Windows. A p-value of less than 0.05 (two sided) was considered to indicate statistical significance.

\section{Results}

After analysing the melting curves obtained by real-time PCR FRET assays for the different DNA isolation methods, the results obtained with the DNA extracted with the column method were in complete concordance with the results of the DNA isolated with our DBS method. Additionally, the DNA isolation with the QIAamp blood mini kit and the two DBS methods performed for 10 healthy volunteers were also completely in concordance. Genotyping with the DNA isolated with our DBS method for the 100 healthy volunteers gave also satisfactory melting curves.

Although analysis of the column and previously described DBS DNA isolation methods were performed for five different real-time PCR FRET assays, an overview of the results is only given for the CYP3A5 A6986G polymorphism. Melting of a sample homozygous for the CYP3A5 6986G allele produced a melting peak at approximately $57.1^{\circ} \mathrm{C} \pm 0.1$ (mean \pm 2 SD) and $57.3^{\circ} \mathrm{C} \pm 0.2$, and the CYP3A5 6986A allele gave a melting peak at approximately $62.3^{\circ} \mathrm{C} \pm 0.2$ and $62.5^{\circ} \mathrm{C} \pm 0.5$, for respectively the QIAamp blood mini kit and our DBS DNA isolation method. Heterozygous samples contained both type of targets and thus generated both peaks. In addition, for heterozygous samples $(n=40)$, the difference between the two melting temperatures $\left(5.2^{\circ} \mathrm{C} \pm 0.1\right)$ had a coefficient of variation (CV) of respectively $0.64 \%$ and $1.24 \%$.

Hence, the derivative melting curves of the commercial DNA isolation method and our DBS method were highly reproducible and can therefore be used perfectly for discrimination between the CYP3A5*1 and CYP3A5*3 allele, which is illustrated in Figure 3.1. The results of the other real-time PCR FRET assays were similar to the results presented for the CYP3A5 A6986G polymorphism.

An issue that may be of importance when the DBS method is used for DNA isolation is a possible contamination risk. Because it is likely that the filter paper used will be contaminated before and/or after the blood spot is actually on the filter paper. Therefore, we examined whether the DBS DNA isolation procedure is robust enough to discriminate the blood spot of the patient from the contamination caused by rubbing vigorously over respectively the dry filter paper, the dry filter paper before adding a blood spot and the dried blood spot 
on the filter paper. In the cases with the blood sample only the genotypes of the patients were seen and in the case of the no blood blank disk, no signal was found, which implies that there is no disturbing influence when the filter paper is contaminated by hands before or after adding the blood spot on the filter paper.
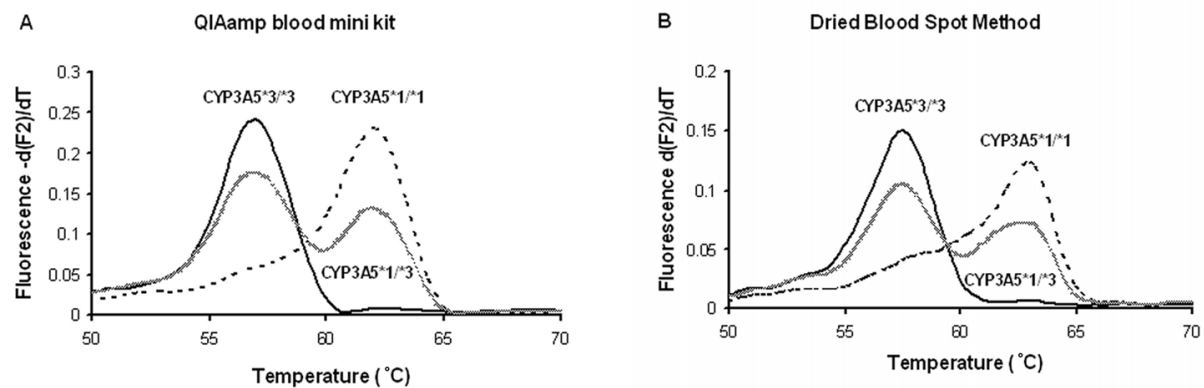

Figure 3.1 Examples of melting curves from DNA isolated with the QIAamp blood mini kit from EDTA whole blood, and the dried blood spot method from capillary blood.

Genotyping of the A6986G polymorphism of the CYP3A5 gene with allele specific fluorescent probes by derivative melting curve plots using DNA samples isolated with the QIAamp blood mini kit (A) and with our dried blood spot DNA isolation method (B).

The $-\mathrm{dF} 2 / \mathrm{dT}$ derivative melting curves are read in channel 2 for the detection of the CYP3A5 fragment. The derivative melting curves is plotted for a similar sample homozygous for the $6986 \mathrm{G}\left(\mathrm{CYP} 3 A 5^{*} 3 /{ }^{*} 3\right)$ allele $\left(\mathrm{Tm} 57^{\circ} \mathrm{C}\right)$; a similar heterozygous sample $\left(\mathrm{Tm} 57^{\circ} \mathrm{C}\left(\mathrm{CYP} 3 \mathrm{~A} 5^{*} 3\right)\right.$ and $\left.62^{\circ} \mathrm{C}\left(\mathrm{CYP} 3 \mathrm{~A} 5^{*} 1\right)\right)$ and a similar sample homozygous for the $6986 \mathrm{~A}\left(\right.$ CYP3A5*1/*1) allele $\left(\mathrm{Tm} 62^{\circ} \mathrm{C}\right)$.

The DNA concentrations of the DBS and BS samples resulted in mean concentrations of $16.0 \mathrm{ng} / \mu \mathrm{l}(12.6-19.4 \mathrm{ng} / \mu \mathrm{l})$ and $70.2 \mathrm{ng} / \mu \mathrm{l}(57.3-83.1 \mathrm{ng} / \mu \mathrm{l})$, respectively $(p<0.001)$ obtained using our isolation method. As a comparison, the samples isolated using the dried blood spot method previously described by Fischer et al. ${ }^{10}$ resulted in a mean concentration of $17.5 \mathrm{ng} / \mathrm{\mu l}$ $(12.8-22.2 \mathrm{ng} / \mu \mathrm{l})$ for these DBS samples (Figure 3.2).

The derivative melting curves of the DNA samples obtained from capillary blood and BS samples were comparable and highly reproducible for all SNPs studied. As a representative example, the melting results of the CYP2C9*2 C430T SNP are hereby presented below. Melting of a sample homozygous for the 430T allele produced a melting peak at approximately $50.6^{\circ} \mathrm{C} \pm 0.4$ and $50.7^{\circ} \mathrm{C} \pm 0.4$ for a BS and a DBS sample, respectively. In a sample homozygous for the $430 \mathrm{C}$ allele a melting peak was obtained at approximately $59.5^{\circ} \mathrm{C} \pm 1.2$ and $59.6^{\circ} \mathrm{C} \pm 1.3$, respectively, for a BS and a DBS sample. Heterozygous samples contained both type of targets and therefore generated both melting peaks, with a mean \pm 2 SD difference of $9.6^{\circ} \mathrm{C} \pm 0.4$ and $9.5^{\circ} \mathrm{C} \pm 0.7$ for the BS and DBS 
samples, respectively. An overview of all the melting temperature ranges for the SNPs investigated, stratified per sample type, are listed in Table 3.1.

Genotyping confirmed the results demonstrating the same amount of peaks at the same melting temperatures and concurrent results were obtained for the DBS and BS sample types per subject for the CYP3A4-V, CYP3A5, CYP2C9, CYP2C19 and CYP2D6 SNPs that were investigated (Table 3.1). An EDTA sample, isolated with the QIAamp blood mini kit, was also analyzed in the same run to illustrate and compare the height and position of the melting curves of the different sample types. A representative example of a FRET melting curve analyses is shown for the CYP2C9*2 assay in Figure 3.2.

Furthermore, we investigated the stability of the BS samples obtained using a plain cotton swab under different storage conditions. When kept at room temperature, the performed FRET assays gave only a weak signal that was difficult to interpret, or no signal at all, after isolating the swabs after a 7-day period. In contrast, when isolating the BS samples at day five all the samples still performed well. Storage at $4-8^{\circ} \mathrm{C}$ extended that period to one month, whereas storing the BS samples at $-20^{\circ} \mathrm{C}$ gave good results up until at least four months.

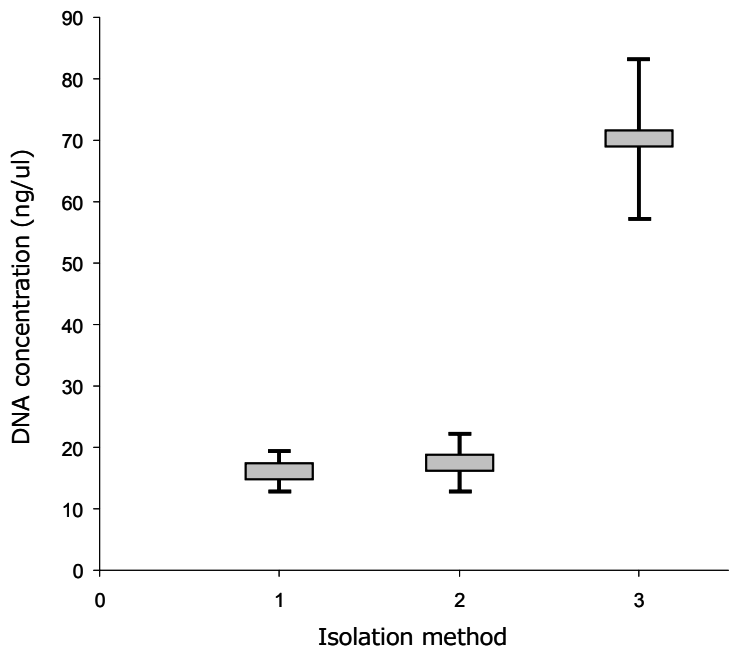

Figure 3.2 Mean DNA quantities, isolated with two different DBS DNA isolation protocols, using capillary blood DBS and BS samples.

1: DBS sample isolated using our method

2: DBS sample isolated using the method described by Fischer et al. ${ }^{10}$

3: BS sample isolated using our method

BS: Buccal Swab; DBS: Dried Blood Spot. 
Table 3.1 Overview of melting temperatures \pm 2 standard deviations per sample type for the CYP450 SNPs examined and isolated with our dried blood spot method.

\begin{tabular}{|c|c|c|c|c|c|}
\hline CYP450 & SNP & $\mathrm{Tm}$ & $\mathrm{BS}\left({ }^{\circ} \mathrm{C}\right)$ & DBS $\left({ }^{\circ} \mathrm{C}\right)$ & Expected $\operatorname{Tm}\left({ }^{\circ} \mathrm{C}\right)$ \\
\hline \multirow[t]{4}{*}{ CYP2D6 } & *3 2549delA & Tm1 & NA & NA & $52.1 \pm 0.4$ \\
\hline & & Tm2 & $58.8 \pm 0.6$ & $58.8 \pm 0.6$ & $59.4 \pm 0.2$ \\
\hline & *4 G1846A & Tm1 & $57.7 \pm 1.2$ & $58.0 \pm 1.9$ & $58.2 \pm 0.2$ \\
\hline & & Tm2 & $65.2 \pm 1.5$ & $66.9 \pm 1.8$ & $66.4 \pm 0.8$ \\
\hline \multirow[t]{4}{*}{ СYР2C9 } & *2 C430T & Tm1 & $50.6 \pm 0.4$ & $50.7 \pm 0.4$ & $50.5 \pm 0.2$ \\
\hline & & Tm2 & $59.5 \pm 1.2$ & $59.6 \pm 1.3$ & $60.4 \pm 1.0$ \\
\hline & *3 A1075C & Tm1 & $50.1 \pm 0.2$ & $50.2 \pm 0.2$ & $50.2 \pm 0.3$ \\
\hline & & Tm2 & NA & NA & $59.4 \pm 0.1$ \\
\hline \multirow[t]{4}{*}{ СYP2C19 } & *2 G681A & Tm1 & $49.3 \pm 1.0$ & $49.0 \pm 1.0$ & $49.3 \pm 0.1$ \\
\hline & & $\operatorname{Tm} 2$ & $55.4 \pm 1.2$ & $55.2 \pm 0.8$ & $56.1 \pm 0.1$ \\
\hline & *3 G636A & Tm1 & $54.0 \pm 0.6$ & $54.2 \pm 0.2$ & $54.1 \pm 0.2$ \\
\hline & & Tm2 & NA & NA & $61.4 \pm 0.2$ \\
\hline \multirow[t]{2}{*}{ СYР3A4-V } & A-392G & Tm1 & NA & NA & $50.1 \pm 0.4$ \\
\hline & & Tm2 & $58.5 \pm 0.8$ & $58.6 \pm 0.3$ & $58.8 \pm 0.4$ \\
\hline \multirow[t]{2}{*}{ СYРЗАБ } & *3 A6986G & Tm1 & $57.6 \pm 0.2$ & $57.5 \pm 0.2$ & $57.4 \pm 0.2$ \\
\hline & & Tm2 & NA & NA & $62.6 \pm 0.2$ \\
\hline
\end{tabular}

BS: Buccal Swab sample; CYP450: Cytochrome P450; DBS: Dried Blood Spot sample; Expected Tm: Positive control, a plasmid sample; NA: Not available; Tm: Melting temperature.

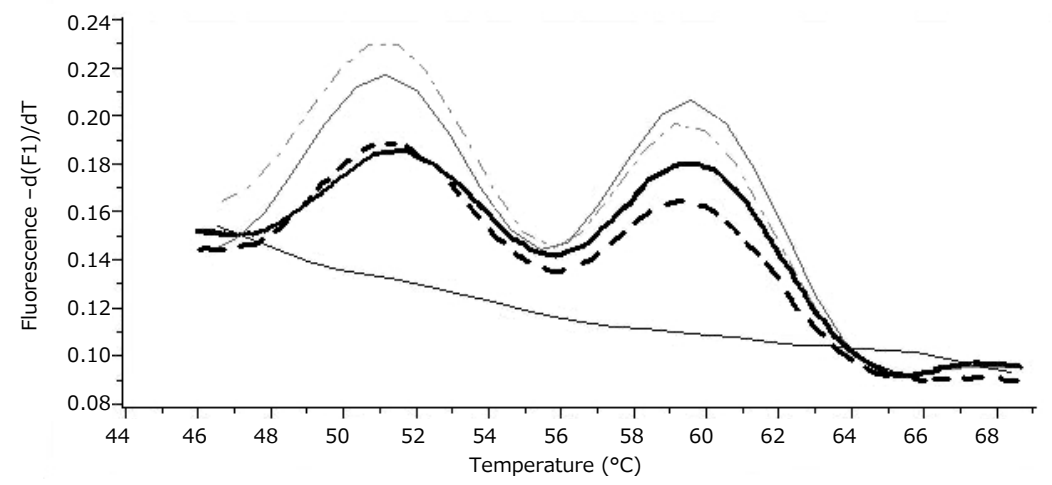

Figure 3.3 An example of completely concurrent CYP2C9*2 melting curves of an EDTA blood sample, a DBS sample and a BS sample.

Positive control

EDTA sample

DBS sample

BS sample

Negative control

The positive control is a heterozygote plasmid sample, supplied with the primer/probes of each assay. The negative control is sterile water (no peaks).

BS: Buccal Swab; DBS: Dried Blood Spot; EDTA: Ethylenediaminetetraacetic acid. 


\section{Discussion}

A large difference was found for labour time and costs between the QIAamp blood mini kit and our DBS method: it took approximately one hour and $€ 4.00$ per blood sample to isolate DNA from EDTA whole blood with the QIAmp mini blood kit while DNA isolation with the DBS method takes about 45 min handson time and less than $€ 2.00$ per capillary blood sample. Moreover, there was also a significant difference when comparing the two DBS methods, not so much in costs, but in hands-on and total time. The method described by Fischer et al. ${ }^{10}$ takes about one hour more before DNA is obtained. Furthermore a Tween/phosphate-buffered saline solution is necessary for washing the DBS. For DBS samples, there was virtually no difference in DNA yield between the isolation method previously described by Fischer et al. ${ }^{10}$ and the one described in this study. Moreover, an advantage of our method is that the use of chemicals is minimal, except for a $10 \%$ Chelex solution, and it has an incubation time of only $30 \mathrm{~min}$.

Although the amount of blood required for this DBS DNA isolation is less, an invasive finger prick is still required to obtain capillary blood. Another restriction of this DBS method can be the sometimes relatively low amount of DNA obtained from the blood spots.

Combined with the noninvasive BS as a sampling method, this provides a patient friendly and easy way of obtaining DNA samples that can be used for genotyping. Especially when conducting a large trial including family members, the BSs can be sent by post. Furthermore, attending the hospital in order to have a blood sample drawn would no longer be necessary. The sending by post and not having to travel to a hospital are advantages that also apply to DBS samples. However, when using that sampling method there is still the need to draw blood. The noninvasive nature of a BS sample combined with the other benefits implicate that there are even fewer drawbacks and people will be more motivated to participate.

We used plain sterile swabs that are readily available and cheap (approximately $€ 0.10$ each) to investigate if buccal-cell collection and subsequent isolation would work. Isolation with our method only takes $30 \mathrm{~min}$ in a water bath, and adding preparation and pipetting time, the procedure is completed well within an hour and with minimal chemical use and cost. On the other hand, commercially available saliva collection methods (up to approximately $€ 18.00$ per collection vial) currently being used in most community-based studies require an additional kit to isolate DNA, and all at considerably higher costs. The obtained BS samples, when using plain sterile cotton swabs, should be isolated within five days from the time of sampling to prevent loss of signal when performing melting curve analyses. The fact that we did not get a signal in the cases that were a week old was a strong indication that amplification of 
the desired fragment was no longer possible and DNA degradation was present. Whenever isolation within five days time is not possible, the BS samples can be stored for up to a month at $4-8^{\circ} \mathrm{C}$ or for up to at least four months at $-20^{\circ} \mathrm{C}$ prior to isolation. Therefore, amending the instructions to the patient to include: 'Store in the refrigerator when you are not able to send it off by mail the same day', is an important addition that will improve the final result.

After isolation, the ready to use DNA solution (approximately $150 \mu \mathrm{l}$ per isolation), when pipetted off the Chelex and transferred into a new vial, can be stored at $4-8^{\circ} \mathrm{C}$ or at $-20^{\circ} \mathrm{C}$ for more than one year.

\section{Conclusion}

The DNA isolation method described appeared to be extremely useful for the different sampling procedures (capillary blood and BS). Furthermore, it is able to isolate DNA with less hands-on time, is less invasive for the patient, and saves transport expenses and DNA isolation costs. Comparison of our DBS method to another non-commercially available DBS method resulted in similar DNA yields, less use of chemicals and it was less time consuming. All these advantages make our DSB method very useful in clinical practice.

Moreover, it appeared to be a useful alternative for commercially available DNA isolation kits. The DNA yields of BS samples were considerably higher compared with the yields of DBS samples. For DNA isolated from BS samples could be used perfectly to distinguish genotypes or polymorphisms. This expands the possibilities of this quick and easy DNA isolation procedure. Especially, the noninvasive BS sampling method appeared to be a good and patient friendly-alternative to invasive sampling methods. 


\section{References}

1. Meyer UA. Pharmacogenetics and adverse drug reactions. Lancet. 2000;356: 1667-71.

2. Weinshilboum R. Inheritance and drug response. N Engl J Med. 2003;348:529-37.

3. Bakker JA, Bierau J, Drent M. Therapeutic regimens in interstitial lung disease guided by genetic screening: fact or fiction? Eur Respir J. 2007;30:821-2.

4. Shurin SB, Nabel EG. Pharmacogenomics--ready for prime time? $N$ Engl $\mathrm{J}$ Med. 2008;358:1061-3.

5. Jaquenoud Sirot E, van der Velden JW, Rentsch K, Eap CB, Baumann P. Therapeutic drug monitoring and pharmacogenetic tests as tools in pharmacovigilance. Drug Saf. 2006;29:735-68.

6. Ensom MH, Chang TK, Patel P. Pharmacogenetics: the therapeutic drug monitoring of the future? Clin Pharmacokinet. 2001;40:783-802.

7. Chace DH, Kalas TA, Naylor EW. Use of tandem mass spectrometry for multianalyte screening of dried blood specimens from newborns. Clin Chem. 2003;49:1797-817.

8. Costa X, Jardi R, Rodriguez F, Miravitlles M, Cotrina M, Gonzalez C, Pascual C, Vidal R. Simple method for alpha1-antitrypsin deficiency screening by use of dried blood spot specimens. Eur Respir J. 2000;15:1111-5.

9. Poyser $\mathrm{KH}$, Wyatt HA, Chambers SM. Multiplex genotyping for cystic fibrosis from filter paper blood spots. Ann Clin Biochem. 1998;35:611-5.

10. Fischer A, Lejczak C, Lambert C, Servais J, Makombe N, Rusine J, Staub T, Hemmer R, Schneider F, Schmit JC, Arendt V. Simple DNA extraction method for dried blood spots and comparison of two PCR assays for diagnosis of vertical human immunodeficiency virus type 1 transmission in Rwanda. J Clin Microbiol. 2004;42: 16-20.

11. Cheung CY, Op den Buijsch RA, Wong KM, Chan HW, Chau KF, Li CS, Leung KT, Kwan TH, de Vrie JE, Wijnen PA, van Dieijen-Visser MP, Bekers O. Influence of different allelic variants of the CYP3A and $A B C B 1$ genes on the tacrolimus pharmacokinetic profile of Chinese renal transplant recipients. Pharmacogenomics. 2006;7:563-74.

12. Arjomand-Nahad F, Diefenbach K, Landt O, Gaikovitch E, Roots I. Genotyping of the triallelic variant G2677T/A in MDR1 using LightCycler with locked-nucleic-acidmodified hybridization probes. Anal Biochem. 2004;334:201-3.

13. Nauck M, Stein U, von Karger S, Marz W, Wieland H. Rapid detection of the C3435T polymorphism of multidrug resistance gene 1 using fluorogenic hybridization probes. Clin Chem. 2000;46:1995-7.

14. von Ahsen N, Richter M, Grupp C, Ringe B, Oellerich M, Armstrong VW. No influence of the MDR-1 C3435T polymorphism or a CYP3A4 promoter polymorphism (CYP3A4-V allele) on dose-adjusted cyclosporin A trough concentrations or rejection incidence in stable renal transplant recipients. Clin Chem. 2001;47:1048-52.

15. Wijnen PA, Drent M, Nelemans PJ, Kuijpers PM, Koek GH, Neef C, Haenen GR, Bekers O. Role of cytochrome p450 polymorphisms in the development of pulmonary drug toxicity: a case-control study in the Netherlands. Drug Saf. 2008; 31:1125-34. 


\section{Chapter 4}

Role of cytochrome P450

polymorphisms in the development

of pulmonary drug toxicity

A case-control study in the Netherlands

P Wijnen, M Drent, P Nelemans, P Kuijpers, G Koek, C Neef, G Haenen, O Bekers

Drug Saf. 2008;31:1125-1134 


\section{Abstract}

\section{Background}

Drug-induced pulmonary toxicity is a serious and expanding problem with often unknown aetiology. Many drugs are metabolized by cytochrome P450 (CYP) enzymes.

To establish whether allelic variation in CYP polymorphic genes contributes to variability in drug response and unexpected toxicity.

\section{Study design}

A case-control study was conducted. The cases consisted of patients with drug-induced interstitial lung disease (DI-ILD; $n=59$ ). Two control groups were used: one group of healthy volunteers $(n=173)$ and one group of patients with idiopathic pulmonary fibrosis (IPF; $n=110$ ).

\section{Results}

Of the patients with DI-ILD 91.5\% (54/59) had at least one of the studied variant genes compared with $70.5 \%(122 / 173, \mathrm{p}<0.001)$ of the healthy volunteers and $69.1 \%$ $(76 / 110, p<0.001)$ of the IPF patients. The percentage of individuals with one or more variant CYP genes was higher in DI-ILD group. Odds ratios were significantly increased and ranged from 3.25 to 40.8 , indicating a significant association between the development of DI-ILD and the presence of one or more variant CYP genes.

\section{Conclusion}

DI-ILD appeared to be associated with the presence of at least one variant CYP allele. This study supports the potential usefulness of personalized medicine by genotyping aiming to improve efficacy, tolerability and drug safety. 


\section{Background}

One may view the lung as bathed in two dissimilar environments: inhaled air and circulating blood. Both can carry noxious substances that may inflict damage to the lung. Air can deliver noxious particles and blood is the main supplier of most drugs, independent of the route of administration, and adverse respiratory reactions may follow by the most unlikely routes. Drugs can induce specific respiratory reactions, or the lungs may be affected as part of a generalized response. The most common form of drug-induced respiratory disease is diffuse interstitial lung disease (ILD). The drugs involved not only comprise prescribed and over-the-counter-drugs, but also illicit drugs, herbs, alcohol and ingredients of the diet. The list of compounds involved has grown rapidly over the last decades. ${ }^{1,2}$ Although drugs have been unequivocally identified as the cause in only a limited number of cases, it is important to acknowledge the potential role of medication in the development of ILD. This is due to the severity of the potentially irreversible damage to the lungs and the improvement that is often easily brought about by stopping administration of the drug involved.

The diagnosis of drug-induced ILD (DI-ILD) primarily rests on the link between drug intake and the subsequent development of respiratory symptoms. In some cases, the evidence that reactions in the lung are drug-induced is circumstantial. A straightforward interpretation is hampered when the damage is irreversible or when the symptoms are aggravated after stopping drug administration. Rechallenging the patient with the drug involved is frequently unethical and dangerous. Sensitive and specific tests are lacking. The key to diagnosis is a high clinical acuity. ${ }^{2}$ All medication needs to be recorded and reviewed meticulously.

The molecular mechanism involved in the development of DI-ILD is still enigmatic. Inflammation initiated by drugs, drug metabolites or drug-induced free radical generation processes has been implicated. ${ }^{3}$ There is also emerging evidence for a role of genetic factors in the development of ILD such as differences in gene expression profiles between pulmonary fibrosis (IPF) and hypersensitivity pneumonitis. ${ }^{4,5}$

Cytochrome P450 (CYP) single nucleotide polymorphisms (SNPs) are one of the key factors known to cause a variation in drug response between individuals. ${ }^{3,}$ 6-9 CYP is a super family of microsomal enzymes that metabolize various endogenous compounds and xenobiotics, including most drugs. Through CYP metabolism the chemical structure of drugs is changed, in general facilitating elimination of the drug from the body. ${ }^{3,7}$

The risk for development of DI-ILD and clinical patterns vary depending on a variety of host and drug factors. ${ }^{2}$ Several different phase I xenobioticmetabolizing CYP and phase II enzymes (i.e. conjugation enzymes including 
several transferases) are present in the human lung, possibly contributing to in situ activation. ${ }^{10-14}$ Metabolism also affects the biological activity of the drug. The biological activity of the parent drug is usually superior to that of the metabolite, but there are several exceptions. Sometimes CYP metabolism yields very toxic metabolites, for example, with paracetamol (acetaminophen), benzo[a]pyrene and carbamazepine. ${ }^{14}$ Occasionally, drugs may cause the formation of reactive oxygen species by uncoupling of the electron transport of the CYP system. ${ }^{15}$ These metabolites or reactive oxygen species may damage vital cellular components, such as proteins, lipids or DNA. ${ }^{16}$ This might be the cause of clinically relevant drug-induced pulmonary toxicity. ${ }^{12,17,18}$

Recently, we reported two cases of patients with interstitial pneumonia who developed cardiac failure following treatment with venlafaxine. ${ }^{19}$ In both cases, a strong relationship between the development of the patients' illness and the initiation of venlafaxine treatment was identified. Furthermore, members of the CYP family are involved in the metabolism of venlafaxine. Therefore, we hypothesized that genetically or environmentally induced inter-individual differences in the expression of pulmonary biotransformation enzymes such as CYP may form the basis for, or contribute to, the risk of DI-ILD. ${ }^{2,10,13,14}$

The aim of this study was to establish whether variation in CYP genes contributes to variability in individual drug response and toxicity. Therefore, the presence of the most clinically relevant variants of CYP genes (CYP2D6, CYP2C9 and CYP2C19 variants) was compared in a population of patients with DI-ILD with the presence of these variant genes in a population of patients with IPF and one of healthy volunteers.

\section{Materials and methods}

\section{Setting and study population}

The study was conducted as a case-control study. Between 2002 and 2006, 575 bronchoalveolar lavages (BAL) were performed on patients referred to the department of Respiratory Medicine of the Maastricht University Medical Centre (MUMC), Maastricht, The Netherlands, suspected of a non-infectious or infectious disorder. Out of these 575 cases, $51.1 \%$ appeared to have an infectious disorder, $17.8 \%$ had diffuse alveolar haemorrhage and $31.1 \%$ an ILD. Of this latter group, $59(10.2 \%)$ met the criteria of DI-ILD. All of the 59 patients were Caucasian, used multiple drugs for various indications and did not have a history of any pulmonary disorder. The clinical presentation of druginduced pulmonary toxicity varied. Besides pulmonary symptoms, some patients $(n=7 ; 12 \%)$ showed signs of other toxicity such as skin, cardiac and gastrointestinal involvement. The diagnosis DI-ILD was established by clinical presentation including dyspnoea and hypoxia, diffuse interstitial features on 
chest X-ray and a high-resolution CT scan as well as a BAL fluid (BALF) profile compatible with DI-ILD, excluding an infectious cause. ${ }^{2,20,21}$ A lung biopsy was performed in $20 \%(n=12)$ of the patients. Clinical records were reviewed carefully and present and past drug use was documented. After reviewing the drug use of all DI-ILD patients, the most important groups appeared to be antihypertensive medication, $\beta$-adrenergic receptor antagonists, anti-arrythmic agents, antidepressants and anticoagulants. Every DI-ILD patient used a combination of at least two or more of these drugs. Withdrawal of the suspected causative drug(s) led to a favorable outcome in $75 \%$ of the patients, including an improvement of the respiratory symptoms, lung function test results, especially the diffusing capacity, and the chest X-ray abnormalities. In $25 \%$ of cases the damage was irreversible. Subjects were genotyped retrospectively for CYP polymorphisms and the drug(s) which are metabolized by the CYP enzymes that show genetic polymorphisms were identified.

The first control group consisted of 173 healthy Caucasian volunteers, recruited for method validation, who did not use medication nor had any relevant medical history, especially no history of pulmonary complaints. ${ }^{22}$ All healthy volunteers were hospital employees. This healthy volunteer control group was also used to establish the distribution of allele variants in the general population.

The second control group consisted of 110 Caucasian patients with IPF, known at our out-patient clinic and collected during the timeframe of this study, who also used medication for various indications. This group was selected as a control group, for it was expected that drug use did not play a substantial role in the pathogenesis of this disease. The diagnosis IPF was based on consistent clinical features, radiographic findings and BALF analysis results. According to the international consensus a biopsy was obtained from $50 \%$ of the IPF group, which confirmed the diagnosis histologically as being usual interstitial pneumonia. ${ }^{23}$ Clinical records were reviewed carefully and present and past drug use was documented. All IPF patients used one or more drug(s). For the DI-ILD group as well as for the IPF group it was checked whether the drugs used were metabolized by polymorphic CYP enzymes.

The study was performed in accordance with the Declaration of Helsinki and its amendments. The protocol was approved by the local Medical Ethics Board of the MUMC. Written informed consent for participation in this study was obtained from all subjects. 


\section{Genotyping}

DNA was obtained from all subjects by using venous EDTA anti-coagulated blood and isolating with a High Pure PCR Template Preparation Kit (Roche Diagnostics, Mannheim, Germany) according to the manufacturer's instructions.

In this study, genotyping was carried out for the following CYP allelic variants: CYP2C9*2 C430T, CYP2C9*3 A1075C, CYP2C19*2 G681A, CYP2C19*3 G636A, CYP2D6*3 2549delA, and CYP2D6*4 G1846A. For genotyping the CYP2C9*1,*2,*3 and CYP2C19*1,*2,*3 SNPs, real-time PCR Fluorescence Resonance Energy Transfer (FRET) assays were performed using the CYP2C9 and CYP2C19 Mutation Detection Kits (Roche Diagnostics, Mannheim, Germany). The CYP2D6*1,*3 and *4 SNPs were genotyped using FRET assays (TIB MOLBIOL, Berlin, Germany) as described by Stamer et al. ${ }^{24}$ and Müller et al. $^{25}$ on the LightCycler ${ }^{\circledR}$ (Roche Diagnostics, Mannheim, Germany)

\section{Statistical analysis}

Statistical analyses were performed with SPSS 15.0 (SPSS. Inc., Chicago, IL, USA) for Windows. In order to evaluate the association between the presence of pulmonary disease and the presence of CYP polymorphisms, odds ratios (ORs) with corresponding 95\% confidence intervals (CI) were calculated. Actual allele distributions were compared against the expected frequencies calculated, using the Hardy-Weinberg equilibrium. Deviations from HardyWeinberg equilibrium were analysed using the chi-square test. A p-value of $<0.05$ (two sided) was considered to indicate statistical significance. A Bonferroni correction, to adjust for multiple comparisons, was applied were it was appropriate $(p<0.01$, indicating statistical significance).

\section{Results}

A summary of the characteristics of the DI-ILD, IPF and healthy volunteer population is shown in Table 4.1.

The subjects in the healthy volunteers group were younger than the subjects in the other two populations and used no medication. The age difference had no influence on the distribution of genetically variant genes, however, it does indicate that (multiple) drug use increases with age. The IPF control patients did use (multiple) drugs, but to a lesser extent than the DI-ILD patients. Table 4.1 also shows that of the patients in the ILD group, substantial larger percentages were receiving drugs that are metabolized by a polymorphic CYP enzyme system. For example, of the 43 patients who received a drug that 
should be metabolized by CYP2D6, 73\% had a genetic polymorphism that would be likely to influence their ability to metabolize drugs efficiently.

Table 4.1 Baseline characteristics of the drug-induced interstitial lung disease (DI-ILD), idiopathic pulmonary fibrosis (IPF) and healthy volunteers (HV) populations.

\begin{tabular}{l|l|l|l}
\hline Characteristic & DI-ILD & IPF & HV \\
\hline Subjects (no.) & 59 & 110 & 173 \\
Male/female (no.) & $28 / 31$ & $62 / 48$ & $78 / 95$ \\
Age (mean/range (y)) & $65.4 / 21-87$ & $63.3 / 27-89$ & $38.5 / 19-59$ \\
\hline
\end{tabular}

Percentages of above populations taking one or more drugs metabolized by CYP polymorphic enzymes:

\begin{tabular}{l|l|l|l}
\hline CYP2D6 & 73 & 18 & 0 \\
CYP2C9 & 52 & 19 & 0 \\
CYP2C19 & 88 & 17 & 0 \\
\hline
\end{tabular}

CYP=cytochrome P450.

The percentages of individuals having one of the studied individual polymorphisms (CYP2D6, CYP2C9 and CYP2C19) or combinations in DI-ILD, healthy volunteer and IPF control patient groups, respectively, are shown in Figure 4.1.

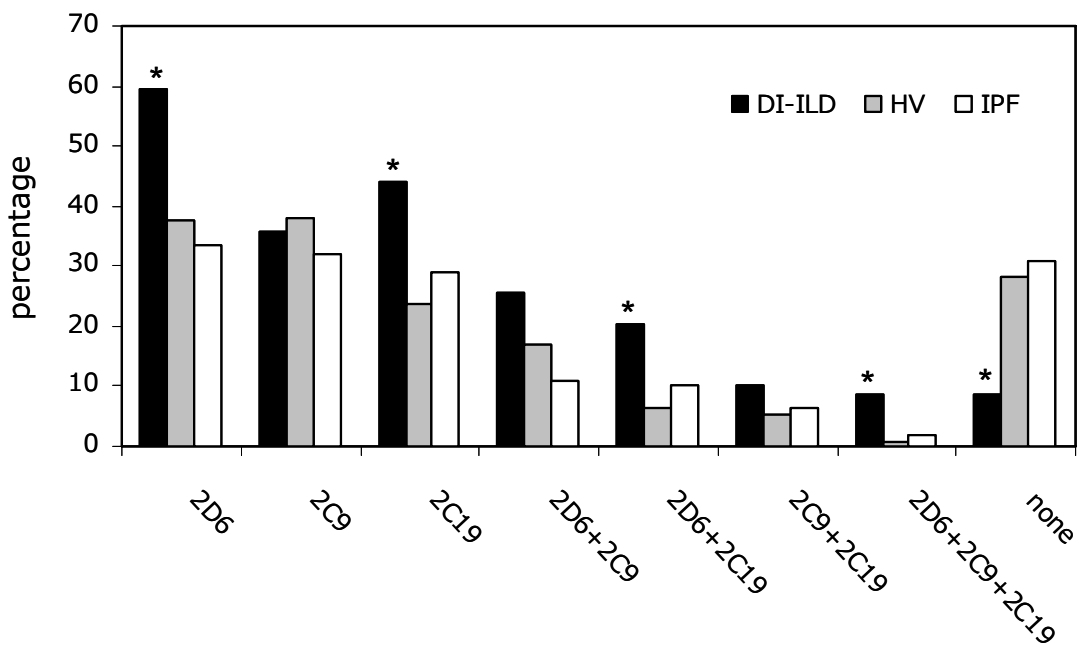

polymorphism

Figure 4.1 Percentage of individual and combinations of cytochrome P450 (CYP) polymorphic genes in individuals with drug-induced interstitial lung disease (DI-ILD, $n=59$ ), idiopathic pulmonary fibrosis (IPF, $\mathrm{n}=110)$ and healthy volunteer $(\mathrm{HV}, \mathrm{n}=173)$ groups. $* \mathrm{p}<0.05$. 
The genotype distribution for the three groups in this study showed that all results were generally consistent with the Hardy-Weinberg equilibrium (Table 4.2, upper panel, expected values not shown). ${ }^{26-29}$ One exception was the CYP2D6 polymorphism of the healthy volunteer group, in which a small but significant deviation from the Hardy-Weinberg equilibrium was observed $(p<0.01)$. Fewer heterozygotes (45 actually present in the healthy volunteer group versus 56 expected, calculated using the Hardy-Weinberg equilibrium) and more homozygotes (13 versus 7) were found. However, the allele frequencies in both control groups (healthy volunteers and IPF patients) were comparable with those in the reference populations from the literature (Table 4.2, lower panel). 26,27,29

Table 4.3 presents the results from the analyses that compared the proportions of persons with one ore more variant genes that express the polymorphic CYP enzymes between DI-ILD patients and both control groups. The proportion of persons without any allelic variants was only $8.5 \%$ among DI-ILD cases versus $30.9 \%$ and $29.5 \%$ in IPF patients and healthy volunteers. Furthermore, it appeared that there was a higher prevalence of combinations of variant genes within the DI-ILD patients compared with the IPF patients and healthy volunteers (Table 4.3, upper panel). Subjects without any CYP variant genes within the DI-ILD group and healthy volunteer group were used as reference group for the calculation of ORs associated with the presence of one or more of the studied genetic polymorphisms. Strong and significant associations were found comparing the prevalence of CYP2D6 and CYP2C19 genetic variants in DI-ILD patients with those of the healthy volunteers. The ORs calculated were 5.80 (95\% CI: 2.17-15.4, p<0.001) for CYP2D6, 3.25 (95\% CI: 1.18-8.86, $\mathrm{p}=0.026$ ) for CYP2C9 and 6.47 (95\% CI: 2.35-17.7, $\mathrm{p}<0.001$ ) for CYP2C19, respectively (Table 4.3). For the combined genotypes with variant CYP alleles, significant ORs were found of 4.91, 14.0, 6.80 and 40.8 (Table 4.3).

Similar results were found comparing the prevalence of variant CYP genes in DI-ILD patients with the IPF control patients. These analyses, as shown in Table 4.3, also resulted in significant associations between the development of DI-ILD and the presence of CYP genetic variants.

The percentage of DI-ILD patients having a CYP variant gene and receiving one or more drug(s) metabolized by a polymorphic CYP enzyme was $87 \%$ (47/54), compared with only $16 \%(12 / 76)$ of the IPF patients.

Table 4.4 lists the (suspected) causative drugs, the CYP enzymes involved in the metabolism of the mentioned drugs, the number of DI-ILD patients involved (with and without variant CYP genes) and also shows which of the variant forms of CYP genes were found. The last column lists the number of literature references mentioned on www.pneumotox.com, concerning the stated causative drug in relation to lung disease. 
CYP polymorphisms and pulmonary drug toxicity 63

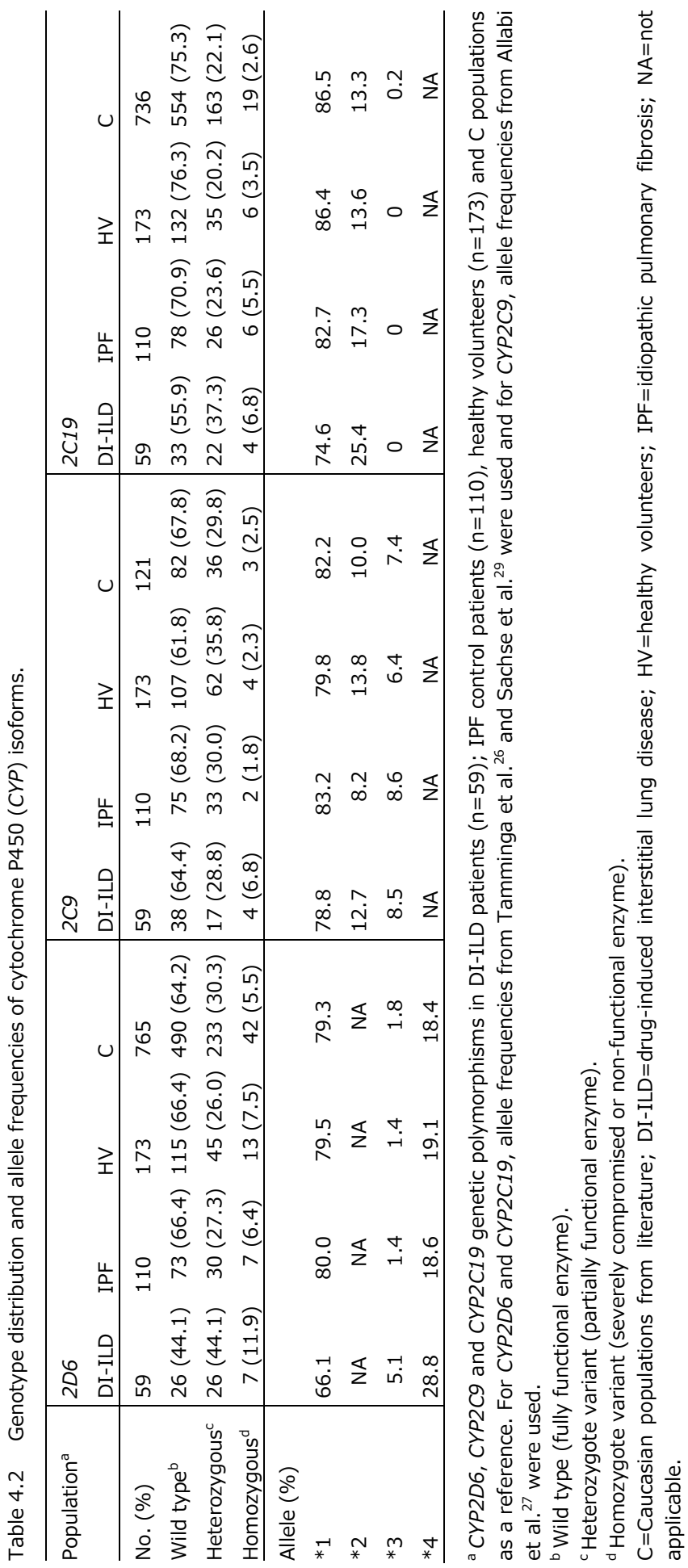


64 Chapter 4

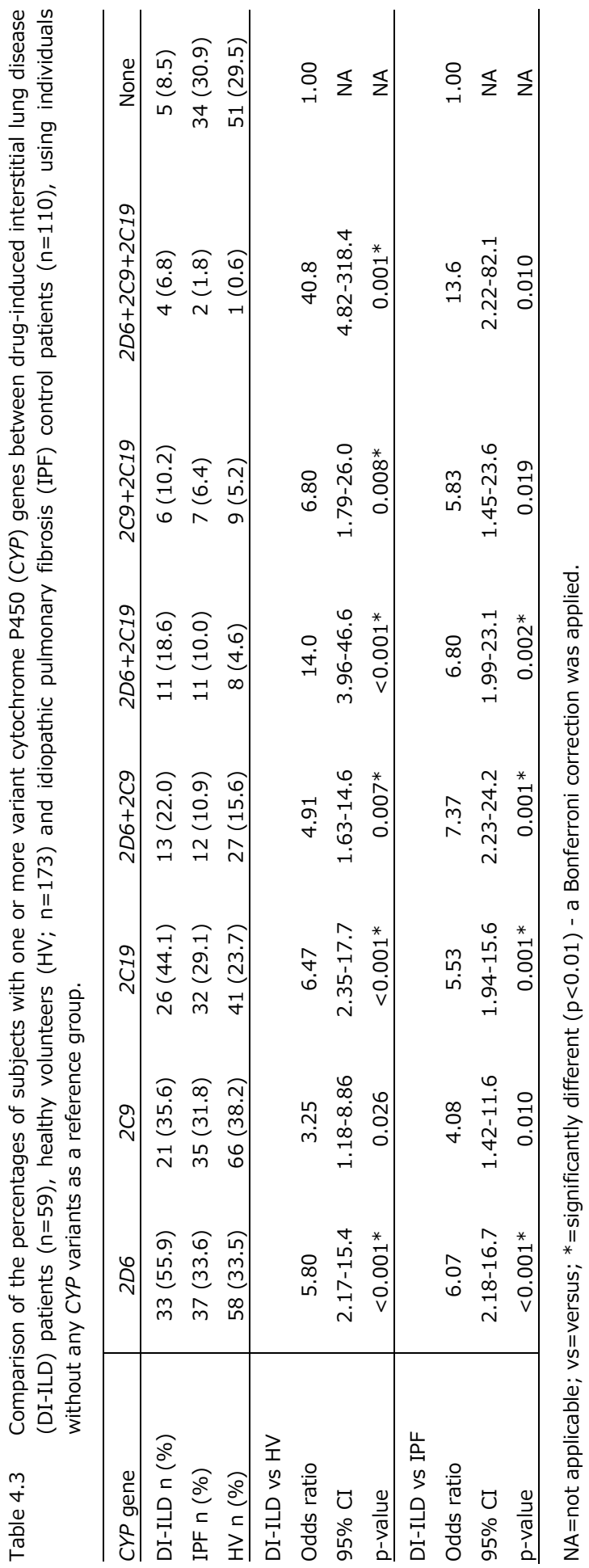


Table 4.4 List of potentially causative drugs and the cytochrome P450 (CYP) genes and variant genotypes expressing enzymes involved in their metabolism.

\begin{tabular}{|c|c|c|c|c|c|}
\hline Causative drug & CYP gene ${ }^{a}$ & Allelic variants present & $\begin{array}{c}\text { Drug+ } \\
\text { variant gene }\end{array}$ & $\begin{array}{c}\text { No variant gene+ } \\
\text { inhibitor }^{c}\end{array}$ & Literature $^{\mathrm{d}}$ \\
\hline \multirow[t]{2}{*}{ Acenocoumarol } & $2 \mathrm{C} 9$ & $* 1 / * 2 * 2 / * 3$ & 5 & 7 & 4 \\
\hline & 2C19 & $* 1 / * 2 * 2 / * 2$ & 8 & 2 & 4 \\
\hline \multirow{2}{*}{ Acetaminophen } & 2D6 & $* 1 / * 4$ & 2 & 2 & 11 \\
\hline & $2 \mathrm{C9}$ & $* 1 / * 2 * 2 / * 3$ & 2 & 1 & 11 \\
\hline \multirow{2}{*}{ Amiodarone } & 2D6 & $* 1 / * 4 * 1 / * 3 * 3 / * 4 * 4 / * 4$ & 8 & 7 & 276 \\
\hline & $2 \mathrm{C} 19$ & $* 1 / * 2$ & 6 & 9 & 276 \\
\hline \multirow[t]{2}{*}{ Amitriptyline } & 2D6 & $* 1 / * 4$ & 2 & & 4 \\
\hline & $2 \mathrm{C} 19$ & $* 1 / * 2$ & 1 & & 4 \\
\hline Captopril & 2D6 & $* 3 / * 4$ & 1 & 1 & 27 \\
\hline Carbamazepine & $2 \mathrm{C9}$ & & & 1 & 53 \\
\hline Carvedilol & 2D6 & $* 1 / * 3$ & 1 & 1 & 2 \\
\hline Cotrimoxazol & $2 \mathrm{C9}$ & & & 1 & 11 \\
\hline Cyclophosphamid & $2 \mathrm{C} 19$ & $* 1 / * 2$ & 1 & & 65 \\
\hline Diazepam & $2 \mathrm{C} 19$ & $* 1 / * 2$ & 1 & & \\
\hline \multirow[t]{2}{*}{ Diclofenac } & $2 \mathrm{C9}$ & $* 3 / * 3$ & 1 & 1 & 3 \\
\hline & 2C19 & $* 1 / * 2$ & 1 & & 3 \\
\hline Fenfluramine & 2D6 & $* 1 / * 3$ & 1 & & 39 \\
\hline Flecainide & 2D6 & $* 1 / * 3$ & 1 & & 10 \\
\hline \multirow{2}{*}{ Fluoxetine } & 2D6 & $* 1 / * 4 * 1 / * 3$ & 2 & 1 & 8 \\
\hline & $2 \mathrm{C} 19$ & $* 1 / * 2$ & 2 & & 8 \\
\hline Haloperidol & 2D6 & & & 1 & 2 \\
\hline \multirow[t]{2}{*}{ Ibuprofen } & $2 \mathrm{C9}$ & $* 1 / * 2$ & 1 & 1 & 6 \\
\hline & 2C19 & $* 1 / * 2$ & 1 & & 6 \\
\hline Methotrexate & & & & 2 & 117 \\
\hline Metoprolol & 2D6 & $* 1 / * 4 * 4 / * 4 * 1 / * 3$ & 10 & 1 & 2 \\
\hline Montelukast & 2C9 & $* 1 / * 2$ & 1 & & 6 \\
\hline Morphine & 2D6 & $* 1 / * 4$ & 1 & & 16 \\
\hline Naproxen & $2 \mathrm{C9}$ & $* 1 / * 2$ & 1 & 1 & 14 \\
\hline Omeprazol & $2 \mathrm{C} 19$ & $* 1 / * 2$ & 4 & 5 & 1 \\
\hline Pantoprazol & 2C19 & $* 1 / * 2 * 2 / * 2$ & 5 & 2 & \\
\hline Paroxetine & 2D6 & $* 1 / * 4$ & 2 & 2 & 2 \\
\hline Propranolol & 2D6 & $* 1 / * 4 * 3 / * 4$ & 1 & 1 & 11 \\
\hline \multirow[t]{2}{*}{ Ranitidine } & 2D6 & $* 1 / * 4$ & 2 & 1 & \\
\hline & 2C19 & $* 1 / * 2$ & 2 & 1 & \\
\hline Risperidone & 2D6 & $* 1 / * 4$ & 1 & & 1 \\
\hline Tamsulosin & 2D6 & $* 1 / * 3 * 3 / * 4$ & 3 & 1 & \\
\hline Temazepam & 2C19 & $* 1 / * 2 * 2 / * 2$ & 4 & & \\
\hline Tramadol & 2D6 & $* 1 / * 4$ & 1 & & 2 \\
\hline Valsartan & 2C9 & $* 1 / * 3 * 1 / * 2 * 2 / * 3$ & 3 & 1 & 3 \\
\hline \multirow[t]{2}{*}{ Venlafaxine } & 2D6 & $* 1 / * 4$ & 2 & & 5 \\
\hline & $2 \mathrm{C} 19$ & $* 1 / * 2$ & 1 & & 5 \\
\hline
\end{tabular}

${ }^{a}$ Gene expressing CYP enzyme involved in the metabolism of the drug.

${ }^{\mathrm{b}}$ Total number of patients with a variant CYP gene receiving the drug.

c Total number of patients receiving the drug, without a variant CYP gene, but with the drug being associated with an inhibition of the CYP enzyme involved in the metabolism of the drug.

${ }^{d}$ Total number of articles at www.pneumotox.com referring to the mentioned drug. 


\section{Discussion}

To the best of our knowledge, this is the first study indicating that DI-ILD may be attributable to a reduced metabolic capacity by CYP enzymes. According to our results, there seems to be an association between having one or more CYP genetic variants that may lead to reduced metabolism, receiving drugs that are metabolized inadequately by the affected system and the development of DI-ILD. Looking at the ORs, ranging from 3.25 to 40.8 , patients with variant CYP enzymes appear to be at a substantially greater risk of developing a DI-ILD when prescribed multiple drugs. These findings strengthened our presumption that inadequate drug metabolism predispose an individual for the development of DI-ILD. In $91.5 \%$ of the studied DI-ILD patients at least one CYP variant gene was present, whereas this percentage was about $70 \%$ in the control populations. In the DI-ILD group the prevalence of having more than one CYP variant gene was also substantially higher. The results support the potential usefulness of CYP genotyping in selecting appropriate drugs or dosages of drugs and avoiding subsequent serious adverse effects.

CYP isoenzymes have been detected in animal as well as in human lung tissues. ${ }^{30}$ It is generally agreed that the CYP super family of enzymes forms the first step in the inactivation and elimination of numerous drugs by oxidation and reduction. Considering the fact that bio-activation by CYP enzymes plays an important role in human drug toxicity, polymorphisms in the CYP450 enzyme system may result in large inter-individual variations in the metabolism and toxicity of xenobiotics.

Given the ever-increasing number of patients, especially seriously ill and/or elderly, who take more than one drug, also often metabolized by the same CYP enzyme, the inherent problems of drug-induced toxicity are alarming. ${ }^{31}$ Physicians should therefore be alert to the possibility that a drug-induced pulmonary reaction may originate from an inappropriate metabolism, especially in case of multiple drug use. The results in this study corroborate that genotyping a patient before drug initiation could lead to a more tailor-made dosing schedule that might protect the patient from the development of serious side effects at the start of the pharmacotherapy. Trial-and-error approaches could be reduced this way. ${ }^{32}$

In the present study we focused on CYP polymorphisms. The total 'genetic profile' of an individual patient should include genes expressing further polymorphic enzymes and other proteins involved in drug metabolism and response. For example, in the case of azathioprine indication, also used as treatment for IPF, testing for thiopurine methyltransferase (TPMT) variants 
involved in the azathioprine metabolism is advised before starting treatment. ${ }^{33-35}$ In the US, drug labels for azathioprine now include information on TPMT polymorphisms and recommend determining patients' phenotype or genotype prior to drug treatment. ${ }^{36}$

The finding that $87 \%$ of the studied DI-ILD patients received one or more drug(s) metabolized by an affected CYP metabolism route is consistent with the assumption that the interstitial lung reactions were drug-induced and that the case group in this study was well defined. In the other cases drug-drug interactions may have been responsible for the toxic drug effects or other pharmacogenetic factors might be involved, such as reduced TPMT activity involved in methotrexate metabolism. ${ }^{37,38}$

There are an increasing number of examples where pharmacogenetic studies have indicated that a genetic test prior to treatment may be useful either for setting the individual dose or making a decision to use a particular drug. ${ }^{39}$ The ability to identify individuals who are susceptible to ADRs has the potential to reduce the personal and population costs of drug-related morbidity. ${ }^{8}$

In this retrospective study, the healthy volunteers used no medication and among the IPF group patients used fewer drugs compared with the DI-ILD patients. However, this does not imply that the healthy control patients and IPF patients are not at risk of developing a drug-induced pulmonary reaction. Persons with more than one CYP polymorphism and/or other relevant polymorphisms may be susceptible to develop DI-ILD when (multiple) drugs are prescribed. ${ }^{9,35,37}$ To answer the question whether persons with one or more of these polymorphisms will develop a DI-ILD, whenever future drug prescription is mandatory, needs follow-up. However, since the CYP polymorphisms of these patients are already known, this can be taken into consideration when prescribing, thus avoiding (possible) adverse drug reactions. Moreover, a prospective case-control study deriving both treated patients and control patients from one population source of multi-drug users would be useful, in order to evaluate the cost effectiveness of the introduction of pharmacogenetic testing into routine healthcare. Such studies will help to identify factors that increase the risk of unwanted outcomes from drug therapy. They will also help to establish in which circumstances genotyping should be performed prior to commencing drug treatment and in tailoring drug treatment for individual patients. ${ }^{8,9}$ 


\section{Conclusion}

This study indicates that the presence of CYP variant genotypes appeared to be a substantial susceptibility risk factor in the development of drug-induced pulmonary adverse events. Therefore, genotyping prior to drug prescription may be clinical useful for the prediction and prevention of drug-induced pulmonary toxicity, especially in case of multiple drug use, where prior genotyping or phenotyping has the potential to contribute to the patients' safety. Both clinical and genetic risk stratification (pharmacogenomics) may lead to more accurate prevention of drug-induced damage in the future. 


\section{References}

1. McLeod HL, Evans WE. Pharmacogenomics: unlocking the human genome for better drug therapy. Annu Rev Pharmacol Toxicol. 2001; 41:101-21.

2. Camus $P$, Fanton $A$, Bonniaud $P$, Camus $C$, Foucher P. Interstitial lung disease induced by drugs and radiation. Respiration. 2004; 71:301-26.

3. Weinshilboum R. Inheritance and drug response. N Engl J Med. 2003; 348:529-37.

4. Yang IV, Burch LH, Steele MP, Savov JD, Hollingsworth JW, McElvania-Tekippe E, Berman KG, Speer MC, Sporn TA, Brown KK, Schwarz MI, Schwartz DA. Gene expression profiling of familial and sporadic interstitial pneumonia. Am J Respir Crit Care Med. 2007; 175:45-54.

5. Selman M, Pardo A, Barrera L, Estrada A, Watson SR, Wilson K, Aziz N, Kaminski N, Zlotnik A. Gene expression profiles distinguish idiopathic pulmonary fibrosis from hypersensitivity pneumonitis. Am J Respir Crit Care Med. 2006; 173:188-98.

6. Wilkinson GR. Drug metabolism and variability among patients in drug response. $N$ Engl J Med. 2005; 352:2211-21.

7. Nebert DW, Russell DW. Clinical importance of the cytochromes P450. Lancet. 2002; 360:1155-62.

8. Clark DW, Donnelly E, Coulter DM, Roberts RL, Kennedy MA. Linking pharmacovigilance with pharmacogenetics. Drug Saf. 2004; 27:1171-84.

9. Jaquenoud Sirot E, van der Velden JW, Rentsch K, Eap CB, Baumann P. Therapeutic drug monitoring and pharmacogenetic tests as tools in pharmacovigilance. Drug Saf. 2006; 29:735-68.

10. Nemery B, Bast A, Behr J, Borm PJ, Bourke SJ, Camus PH, De Vuyst P, Jansen HM, Kinnula VL, Lison $\mathrm{D}$, Pelkonen $\mathrm{O}$, Saltini $\mathrm{C}$. Interstitial lung disease induced by exogenous agents: factors governing susceptibility. Eur Respir J Suppl. 2001; 32:30s-42s.

11. Wormhoudt LW, Commandeur JN, Vermeulen NP. Genetic polymorphisms of human $\mathrm{N}$-acetyltransferase, cytochrome P450, glutathione-S-transferase, and epoxide hydrolase enzymes: relevance to xenobiotic metabolism and toxicity. Crit Rev Toxicol. 1999; 29:59-124.

12. Higenbottam T, Kuwano K, Nemery B, Fujita Y. Understanding the mechanisms of drug-associated interstitial lung disease. Br J Cancer. 2004; 91 Suppl 2:S31-7.

13. Hukkanen J, Pelkonen $\mathrm{O}$, Raunio $\mathrm{H}$. Expression of xenobiotic-metabolizing enzymes in human pulmonary tissue: possible role in susceptibility for ILD. Eur Respir J Suppl. 2001; 32:122s-6s.

14. Castell JV, Donato MT, Gomez-Lechon MJ. Metabolism and bioactivation of toxicants in the lung. The in vitro cellular approach. Exp Toxicol Pathol. 2005; 57 Suppl 1:189-204.

15. Bast A. Is formation of reactive oxygen by cytochrome $\mathrm{P}-450$ perilous and predictable? Trends Pharmacol Sci. 1986; 7:266-70.

16. Bast A, Haenen GR, Doelman CJ. Oxidants and antioxidants: state of the art. Am J Med. 1991; 91:2S-13S.

17. Guidice JM, Marez D, Sabbagh N, Legrand-Andreoletti M, Spire C, Alcaïde E, Lafitte JJ, Broly F. Evidence for CYP2D6 expression in human lung. Biochem Biophys Res Commun. 1997; 241:79-85.

18. Wilschut FA, Cobben NA, Thunnissen FB, Lamers RJ, Wouters EF, Drent M. Recurrent respiratory distress associated with carbamazepine overdose. Eur Respir J. 1997; 10:2163-5.

19. Drent M, Singh S, Gorgels AP, Hansell DM, Bekers O, Nicholson AG, van Suylen RJ, du Bois RM. Drug-induced pneumonitis and heart failure simultaneously associated with venlafaxine. Am J Respir Crit Care Med. 2003; 167:958-61. 
20. Drent M, Jacobs JA, Cobben NA, Costabel U, Wouters EF, Mulder PG. Computer program supporting the diagnostic accuracy of cellular BALF analysis: a new release. Respir Med. 2001; 95:781-6.

21. Lindell RM, Hartman TE. Chest imaging in iatrogenic respiratory disease. Clin Chest Med. 2004; 25:15-24.

22. Wijnen PA, Op den Buijsch RA, Cheung SC, van der Heijden J, Hoogtanders K, Stolk LM, van Dieijen-Visser MP, Neef C, Drent M, Bekers O. Genotyping with a dried blood spot method: A useful technique for application in pharmacogenetics. Clin Chim Acta. 2008;388:189-91.

23. American Thoracic Society. Idiopathic pulmonary fibrosis: diagnosis and treatment. International consensus statement. American Thoracic Society (ATS), and the European Respiratory Society (ERS). Am J Respir Crit Care Med. 2000; 161:646-64.

24. Stamer UM, Bayerer B, Wolf S, Hoeft A, Stüber F. Rapid and reliable method for cytochrome P450 2D6 genotyping. Clin Chem. 2002; 48:1412-7.

25. Muller B, Zopf K, Bachofer J, Steimer W. Optimized strategy for rapid cytochrome P450 2D6 genotyping by real-time long PCR. Clin Chem. 2003; 49:1624-31.

26. Tamminga WJ, Wemer J, Oosterhuis B, de Zeeuw RA, de Leij LF, Jonkman JH. The prevalence of CYP2D6 and CYP2C19 genotypes in a population of healthy Dutch volunteers. Eur J Clin Pharmacol. 2001; 57:717-22.

27. Allabi AC, Gala JL, Desager JP, Heusterspreute M, Horsmans Y. Genetic polymorphisms of CYP2C9 and CYP2C19 in the Beninese and Belgian populations. $\mathrm{Br} \mathrm{J}$ Clin Pharmacol. 2003; 56:653-7.

28. Bravo-Villalta HV, Yamamoto K, Nakamura K, Bayá A, Okada Y, Horiuchi R. Genetic polymorphism of CYP2C9 and CYP2C19 in a Bolivian population: an investigative and comparative study. Eur J Clin Pharmacol. 2005; 61:179-84.

29. Sachse C, Brockmoller J, Bauer S, Roots I. Cytochrome P450 2D6 variants in a Caucasian population: allele frequencies and phenotypic consequences. Am J Hum Genet. 1997; 60:284-95.

30. Zhang JY, Wang Y, Prakash C. Xenobiotic-metabolizing enzymes in human lung. Curr Drug Metab. 2006; 7:939-48.

31. Ensom MH, Chang TK, Patel P. Pharmacogenetics: the therapeutic drug monitoring of the future? Clin Pharmacokinet. 2001; 40:783-802.

32. Reitman ML, Schadt EE. Pharmacogenetics of metformin response: a step in the path toward personalized medicine. J Clin Invest. 2007; 117:1226-9.

33. Schutz E, von Ahsen N, Oellerich M. Genotyping of eight thiopurine methyltransferase mutations: three-color multiplexing, "two-color/shared" anchor, and fluorescence-quenching hybridization probe assays based on thermodynamic nearest-neighbor probe design. Clin Chem. 2000; 46:1728-37.

34. Baker DE. Pharmacogenomics of azathioprine and 6-mercaptopurine in gastroenterologic therapy. Rev Gastroenterol Disord. 2003; 3:150-7.

35. Bakker JA, Bierau J, Drent M. Therapeutic regimens in interstitial lung disease guided by genetic screening: fact or fiction? Eur Respir J. 2007; 30:821-2.

36. Daly AK. Individualized drug therapy. Curr Opin Drug Discov Devel. 2007; 10:29-36.

37. Campalani E, Arenas M, Marinaki AM, Lewis CM, Barker JN, Smith CH. Polymorphisms in folate, pyrimidine, and purine metabolism are associated with efficacy and toxicity of methotrexate in psoriasis. J Invest Dermatol. 2007; 127:1860-7.

38. Wessels JA, de Vries-Bouwstra JK, Heijmans BT, Slagboom PE, Goekoop-Ruiterman YP, Allaart CF, Kerstens PJ, van Zeben D, Breedveld FC, Dijkmans BA, Huizinga TW, Guchelaar HJ. Efficacy and toxicity of methotrexate in early rheumatoid arthritis are associated with single-nucleotide polymorphisms in genes coding for folate pathway enzymes. Arthritis Rheum. 2006; 54:1087-95.

39. Shurin SB, Nabel EG. Pharmacogenomics--ready for prime time? $N$ Engl J Med. 2008; 358:1061-3. 


\section{Chapter 5}

Depressive effect of an antidepressant: therapeutic failure of venlafaxine in a case lacking CYP2D6 activity

P Wijnen, I Limantoro, M Drent, O Bekers, P Kuijpers, G Koek

Ann Clin Biochem. 2009;46:527-530 


\section{Abstract}

\section{Background}

Understanding the mechanisms of drug metabolism and interactions can help to prevent side-effects.

\section{Study design}

Not only drug interactions, environmental factors, disease processes and aging are factors in the inter-individual metabolic capacity variance, but also genetic factors probably play an important role, as is illustrated in the case presented. Besides therapeutic drug monitoring, genotyping some important cytochrome P450 (CYP) enzymes was of additional value in explaining why the patient developed severe adverse effects and, moreover, did not experience any therapeutical effect of venlafaxine.

\section{Results}

Results indicated that the patient was a poor metabolizer for CYP2D6, the most important phase I enzyme to metabolize venlafaxine. This corroborates that polymorphisms in the CYP gene influence the metabolic activity of the corresponding enzymes, thus affecting the subsequent serum drug levels and their metabolites.

\section{Conclusion}

This case highlights the potential benefit of both clinical and genetic risk stratification (pharmacogenetics) prior to treatment, either for setting the individual dose or for making a decision about using a particular drug. 


\section{Introduction}

Adverse drug reactions (ADRs) pose a serious medical problem and are an important burden on health-care costs. ${ }^{1,2}$ In general, the recognition of ADRs has become an increasingly important area in clinical practice. Clinical presentation of ADRs varies and to relate certain reaction with a drug, there must be a temporal relationship, appropriate clinical presentation and, ideally, improvement with discontinuation of the drug. Drug-induced reactions can cause any known pathological pattern. At present, there are no specific tests; rechallenge is unlikely to be helpful and is generally regarded to be dangerous. Drugs metabolism is influenced by drug-drug interactions, environmental factors, disease processes, food and ageing. ${ }^{3}$ Furthermore, there is increasing evidence that interindividual difference in the genetic profile of phase I and II enzymes account for a substantial portion of the heterogeneity of the response to medication(s) and the development of ADRs. ${ }^{4,5}$

Antidepressants are widely used in clinical practice, although the effect is debated. Venlafaxine, for example, belongs to a new generation of antidepressants being a serotonin (5-HT)-norepinephrine (NE) reuptake inhibitor. Venlafaxine and its main active metabolite, $O$-desmethylvenlafaxine (ODV), inhibit the reuptake of both $5-\mathrm{HT}$ and NE with a potency greater for the 5 -HT than for the NE reuptake process. Venlafaxine is metabolized by CYP2D6 into its main active metabolite ODV and to a lesser extent by CYP3A4 into the inactive $N$-desmethylvenlafaxine, see also Figure $5.1 .^{6-8}$ The suggested therapeutic concentration range lies between 195 and $400 \mu \mathrm{g} / \mathrm{l}$ for the sum of venlafaxine and ODV, and depends mainly on the CYP2D6 activity. ${ }^{8,9}$ Decreased CYP2D6 activity increases the risk of side-effects. ${ }^{7}$

Side-effects, due to overdosing, cause only mild symptoms in the majority of patients. However, severe toxicity is reported with the most common symptoms being central nervous system depression, serotonin toxicity, seizure or cardiac conduction abnormalities. Although the exact mechanism of injury is unclear, total serum concentrations of venlafaxine and its major active metabolite ODV of $900 \mu \mathrm{g} / \mathrm{I}$ or more combined are likely to cause toxicity. ${ }^{6,10}$ Deaths have been reported following large doses and in combination with other medication and alcohol. ${ }^{9,11}$

Recently, we reported two cases of interstitial pneumonia with cardiac failure developing in patients treated with venlafaxine. ${ }^{12} \mathrm{~A}$ strong relationship between the development of patients' illness and the initiation of venlafaxine treatment was identified. It was hypothesized that alterations in metabolic drug clearance as a result of genetic factors or drug-drug interactions might, in part, be responsible for the drug-induced toxicity. Unfortunately, no DNA was available of these two cases and therefore CYP variants could not be confirmed. However, this observation prompted us to evaluate a possible role of this 
genetic variant in the presented case. We report a case with a severe refractory depression not responding to venlafaxine in which therapeutic drug monitoring (TDM) in combination with pharmacogenetics were performed in the diagnostic follow-up.

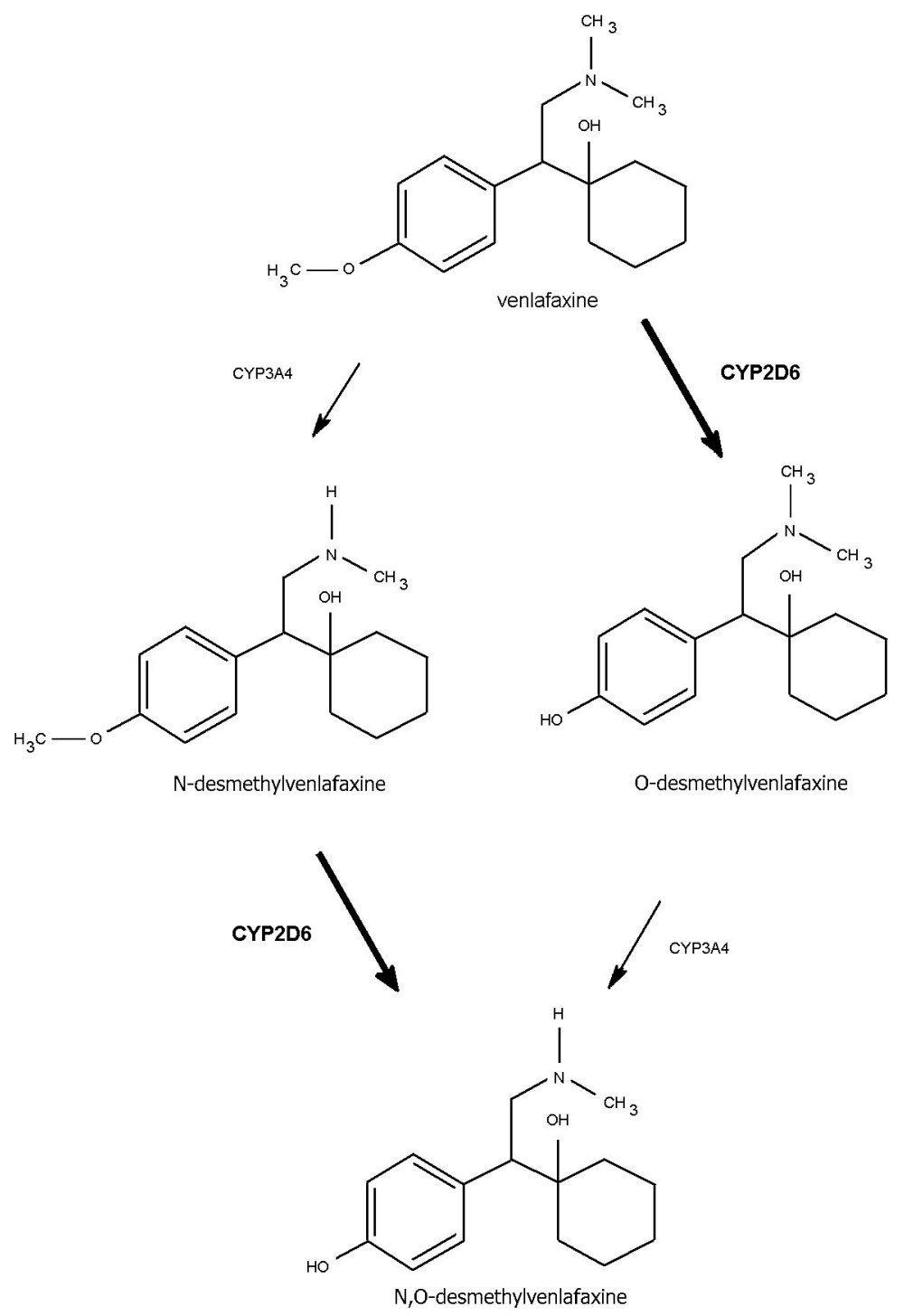

Figure 5.1 Main metabolic pathway of venlafaxine 


\section{Case report}

A 42-year-old woman was visiting the outpatient hepatology clinic because of, since six weeks existing, progressive fatigue, dyspnoea, paresthesias of the fingers, hands and legs. She felt agitated and had an elevated heart rate in rest of 110 beats per minute. She was known with morbid obesity (body mass index [BMI] $46 \mathrm{~kg} / \mathrm{m}^{2}$ ), arterial hypertension, left ventricle hypertrophy with a decreased left ventricle ejection fraction ( $40 \%$ of predicted), depression and non-alcoholic steatohepatitis. The medication she used is summarized in Table 5.1. At that time haematological and biochemical laboratory investigations revealed no abnormalities. After her last suicide attempt, two months before presentation at the outpatient clinic, the psychiatrist started venlafaxine $75 \mathrm{mg}$ to treat her depression. As no mental improvement occurred, the venlafaxine dose was increased gradually to $225 \mathrm{mg}$ daily, but still no improvement was established. Moreover, her mental situation worsened and so did the other complaints she presented with at the outpatient clinic. The fore-mentioned adverse effects (especially the tachycardia and agitation) coincided the most with the side-effects listed for venlafaxine, see also Table 5.1. This prompted us to measure the serum venlafaxine level and of its main active metabolite ODV which were $1300 \mu \mathrm{g} / \mathrm{l}$ and less than $100 \mu \mathrm{g} / \mathrm{l}$, respectively, well above the recommended combined concentration range of $195-400 \mu \mathrm{g} / \mathrm{I} .{ }^{8}$ At the same time, three common polymorphisms in the CYP genes (CYP2C9, CYP2D6 and CYP2C19) were analyzed, as described previously. ${ }^{13}$ These tests were performed to rule out or establish a genetic component. Moreover, the genotyping was used to investigate whether venlafaxine was the most likely cause for the ADR, or one or more of the prescribed co-medication not being metabolized properly by the investigated enzymes. For accumulation of other drugs might be causing additional drug-drug interaction problems. A homozygote variant of CYP2D6 (CYP2D6*4/*4) was found indicating that no functional CYP2D6 enzyme and, therefore, no metabolic activity, was present. Furthermore, a heterozygote variant of CYP2C9 (CYP2C9*1/*2) and a wildtype genotype of CYP2C19 (CYP2C19*1/*1) were found. Mainly the fact that the patient appeared to be a poor metabolizer of CYP2D6 substrates explained the high toxic serum levels of venlafaxine without the presence of its main active metabolite ODV. Venlafaxine was stopped immediately and so was metoprolol, also metabolized by CYP2D6, see also Table $5.1 .{ }^{14}$ Gradually, her complaints of agitation, dyspnoea and tachycardia disappeared. 
Table 5.1 Specifics of the medication and dosages administered at time of presentation.

\begin{tabular}{|c|c|c|c|}
\hline Drug and dose & Group & Main ADR & Metabolized by \\
\hline $\begin{array}{l}\text { Ursodeoxycholic acid } \\
3 \text { daily dose } 300 \mathrm{mg}\end{array}$ & Dissolves cholesterol stones & Nausea, constipation & Not applicable \\
\hline $\begin{array}{l}\text { Furosemide } \\
40 \mathrm{mg}\end{array}$ & Loop diuretic & Hypotension, nausea & Glucuronidation \\
\hline $\begin{array}{l}\text { Metoprolol } \\
100 \mathrm{mg}\end{array}$ & $\beta$-blocker & $\begin{array}{l}\text { Bradycardia, fatigue, } \\
\text { dizziness, hypotension }\end{array}$ & CYP2D6 \\
\hline $\begin{array}{l}\text { Simvastatin } \\
40 \mathrm{mg}\end{array}$ & Lipid-lowering agent & $\begin{array}{l}\text { Headache, asthenia, } \\
\text { nausea }\end{array}$ & CYP3A4 \\
\hline $\begin{array}{l}\text { Zopiclone } \\
7.5 \mathrm{mg}\end{array}$ & Hypnotic agent & $\begin{array}{l}\text { Confusion, clumsiness, } \\
\text { anxiety }\end{array}$ & $\begin{array}{l}\text { Major CYP3A4, } \\
\text { minor CYP2C8 }\end{array}$ \\
\hline $\begin{array}{l}\text { Valsartan } \\
80 \mathrm{mg}\end{array}$ & $\begin{array}{l}\text { Angiotensin II receptor } \\
\text { antagonist }\end{array}$ & $\begin{array}{l}\text { Headache, dizziness, } \\
\text { asthenia }\end{array}$ & CYP2C9 \\
\hline $\begin{array}{l}\text { Rosiglitazone } \\
4 \mathrm{mg}\end{array}$ & Thiazolidinedione & $\begin{array}{l}\text { Headache, fatigue, } \\
\text { diarrhea }\end{array}$ & $\begin{array}{l}\text { Major CYP2C8, } \\
\text { minor CYP2C9 }\end{array}$ \\
\hline $\begin{array}{l}\text { Pantoprazole } \\
20 \mathrm{mg}\end{array}$ & Proton pump inhibitor & $\begin{array}{l}\text { Headache, diarrhea, } \\
\text { anxiety }\end{array}$ & CYP2C19 \\
\hline $\begin{array}{l}\text { Venlafaxine } \\
75 \mathrm{mg} \text { to } 225 \mathrm{mg}\end{array}$ & $\begin{array}{l}\text { Serotonin-nor epinephrine } \\
\text { reuptake inhibitor }\end{array}$ & $\begin{array}{l}\text { Tachycardia, fatigue, } \\
\text { agitation, hypertension }\end{array}$ & $\begin{array}{l}\text { Major CYP2D6, } \\
\text { minor CYP3A4 }\end{array}$ \\
\hline
\end{tabular}

Type of medication (group), main adverse reactions (ADR) and CYP route metabolism is depicted.

\section{Discussion}

This case highlights the importance of CYP genotyping in combination with serum drug monitoring to establish a relationship between ADR and drug metabolism. High toxic serum levels of venlafaxine without a detectable concentration of its main active metabolite ODV strongly indicated that no CYP2D6 enzyme activity was present. This was confirmed by genotyping. The complaints with which patient presented herself at the outpatient clinic could be attributed to high levels of venlafaxine and were a direct consequence of the rate of CYP metabolism. ${ }^{7,15,16}$ Furthermore, this drug is known to cause serotonin-syndrome in some cases. ${ }^{17}$ The complaints were not related to metoprolol, which is also metabolized mainly by CYP2D6, see also Table 5.1. Metoprolol, a selective adrenergic beta-1-blocking agent, was prescribed to the patient because of hypertension. The drug competes with adrenergic neurotransmitters such as catecholamines; resulting in a decreased heart rate, cardiac output and blood pressure. Toxic effects include bradycardia, hypotension, bronchospasm, and cardiac failure, which were not observed in our patient. Another rare side-effect of metoprolol therapy can be depressive symptoms, but as the patient was prescribed metoprolol years before the onset of the depression, this was unlikely. ${ }^{18,19} \mathrm{~A}$ more plausible explanation is the fact that patients can also be non-responders to venlafaxine therapy, not linked to a certain CYP450 genotype, but in combination with a poor metabolizer the risk of a maintained depression and acquiring ADRs is increased substantially. ${ }^{8,20}$ 
Other more rare ADRs include pulmonary (e.g. interstitial pneumonia) and cardiovascular (e.g. agina pectoris, sinus arrythmia) problems and even sudden deaths have been reported, suggesting venlafaxine and/or its metabolites to be a possible proarrhythmic agent. ${ }^{21-23}$ Direct toxic effect or hypersensitivity is likely to be the mechanism.

Venlafaxine is mainly metabolized by CYP2D6 and only for a very small amount by CYP3A4, see also Figure 5.1. ${ }^{8,24}$ In particular, CYP2D6 variants may manifest phenotypically as poor, intermediate, extensive or rapid metabolizers. ${ }^{25,26}$ Administration of venlafaxine to poor metabolizers places them at risk of accumulation of the drug to toxic concentrations. ${ }^{7}$ Moreover, poor metabolizers are more likely to experience ADR. ${ }^{7}$ Also, co-administration of venlafaxine with drugs that inhibit the activity of CYP2D6, such as some antiarrhythmic agents, could provoke accumulation of the drug and predispose patients to drug-induced damage. ${ }^{27}$ However, the venlafaxine datasheet states that co-prescription of venlafaxine and metoprolol, although it should be exercised with caution, poses no problem in a normal situation when checking the patient's blood pressure regularly.

Genotyping prior to administration of the drug probably prevents unnecessary medication for at least six weeks (period needed for evaluating the effect of the medication). Furthermore, and possibly even more important, it warns the psychiatrist that increasing the dose is no option, since the active metabolite will not be formed due to the inappropriate metabolism of venlafaxine. Moreover, it exposes the patient to an increased ADR risk, because of decreased clearance. The risk for development of drug toxicity, including druginduced lung damage and cardiopulmonary effects, differ depending on a variety of host (including CYP polymorphisms) and drug factors. ${ }^{23,28}$ Increased serum levels of drugs can be observed, not only after overdose administration of the drug, but also because of decreased clearance in some subjects, due to, as in this case, an incapability to metabolize or drug-drug interactions. ${ }^{25}$

The promise of pharmacogenetics, the study of the relationship between variants in a large collection of genes and variable drug effects, lies in its potential to identify the right drug and dose for each individual patient. ${ }^{29}$ Thus, genotyping can provide therapeutic and pharmaco-economic benefits and should be considered in patients using (multiple) drugs. ${ }^{29,30}$ The affected CYP450 enzyme, causing an inappropriate effect of the antidepressant, can also influence other drugs metabolized by the same CYP system. Therefore, physicians should prescribe combinations of certain drugs with caution. 


\section{Conclusion}

Introduction of venlafaxine in our patient resulted in tachycardia and agitation without improvement of the depressive symptoms. It appeared that the patient was a poor metabolizer for CYP2D6, the most important phase I enzyme to metabolize venlafaxine. Discontinuation of this drug resulted in resolving of the symptoms. This case highlights the potential benefit of both clinical and genetic risk stratification (pharmacogenetics) prior to treatment, either for setting the individual dose or for making a decision about using a particular drug. To minimalize ADRs, genetic screening prior to prescription of certain 'risk drugs' and TDM during treatment would be an ideal situation. 


\section{References}

1. Beijer $\mathrm{HJ}$, de Blaey $\mathrm{CJ}$. Hospitalisations caused by adverse drug reactions (ADR): a meta-analysis of observational studies. Pharm World Sci. 2002;24:46-54.

2. Classen DC, Pestotnik SL, Evans RS, Lloyd JF, Burke JP. Adverse drug events in hospitalized patients. Excess length of stay, extra costs, and attributable mortality. JAMA. 1997;277:301-6.

3. Wilkinson GR. Drug metabolism and variability among patients in drug response. $N$ Engl J Med. 2005;352:2211-21.

4. Nebert DW, Russell DW. Clinical importance of the cytochromes P450. Lancet. 2002;360:1155-62.

5. Ereshefsky L, Dugan D. Review of the pharmacokinetics, pharmacogenetics, and drug interaction potential of antidepressants: focus on venlafaxine. Depress Anxiety. 2000;12 Suppl 1:30-44.

6. Feighner JP. The role of venlafaxine in rational antidepressant therapy. $J$ Clin Psychiatry. 1994;55 Suppl A:62-8; discussion 9-70, 98-100.

7. Shams ME, Arneth B, Hiemke C, Dragicevic A, Müller MJ, Kaiser R, Lackner K, Härtter S. CYP2D6 polymorphism and clinical effect of the antidepressant venlafaxine. J Clin Pharm Ther. 2006;31:493-502.

8. Veefkind AH, Haffmans PM, Hoencamp E. Venlafaxine serum levels and CYP2D6 genotype. Ther Drug Monit. 2000;22:202-8.

9. Levine B, Jenkins AJ, Queen M, Jufer R, Smialek JE. Distribution of venlafaxine in three postmortem cases. J Anal Toxicol. 1996;20:502-5.

10. Reeve HL, Nelson DP, Archer SL, Weir EK. Effects of fluoxetine, phentermine, and venlafaxine on pulmonary arterial pressure and electrophysiology. Am J Physiol. 1999;276:L213-9.

11. Mazur JE, Doty JD, Krygiel AS. Fatality related to a 30-g venlafaxine overdose. Pharmacotherapy. 2003;23:1668-72.

12. Drent M, Singh S, Gorgels AP, Hansell DM, Bekers O, Nicholson AG, van Suylen RJ, du Bois RM. Drug-induced pneumonitis and heart failure simultaneously associated with venlafaxine. Am J Respir Crit Care Med. 2003;167:958-61.

13. Wijnen PAHM, Drent M, Nelemans PJ, Kuijpers PMJC, Koek GH, Neef C, Haenen GRMM, Bekers O. Role of cytochrome P450 polymorphisms in the development of pulmonary drug toxicity. Drug Saf. 2008;31:1125-34.

14. Burnett FE, Dinan TG. Venlafaxine. Pharmacology and Therapeutic Potential in the Treatment of Depression. Hum Psychopharmacol. 1998;13:153-62.

15. Hermann M, Hendset M, Fosaas K, Hjerpset M, Refsum H. Serum concentrations of venlafaxine and its metabolites $\mathrm{O}$-desmethylvenlafaxine and $\mathrm{N}$-desmethylvenlafaxine in heterozygous carriers of the CYP2D6*3, *4 or *5 allele. Eur J Clin Pharmacol. 2008;64:483-7.

16. Grasmader $K$, Verwohlt $P L$, Rietschel $M$, Dragicevic A, Müller $M$, Hiemke $C$, Freymann N, Zobel A, Maier W, Rao ML. Impact of polymorphisms of cytochromeP450 isoenzymes 2C9, 2C19 and 2D6 on plasma concentrations and clinical effects of antidepressants in a naturalistic clinical setting. Eur J Clin Pharmacol. 2004;60: 329-36.

17. Blythe D, Hackett LP. Cardiovascular and neurological toxicity of venlafaxine. Hum Exp Toxicol. 1999;18:309-13.

18. Brogden RN, Heel RC, Speight TM, Avery GS. Metoprolol: a review of its pharmacological properties and therapeutic efficacy in hypertension and angina pectoris. Drugs. 1977; 14:321-48.

19. McAinsh J, Cruickshank JM. Beta-blockers and central nervous system side effects. Pharmacol Ther. 1990;46:163-97. 
20. Ciusani E, Zullino DF, Eap CB, Brawand-Amey M, Brocard M, Baumann $P$. Combination therapy with venlafaxine and carbamazepine in depressive patients not responding to venlafaxine: pharmacokinetic and clinical aspects. J Psychopharmacol. 2004; 18:559-66.

21. Liu X, Emery CJ, Laude E, Herget J, Gill G, Cope G, Barer GR. Adverse pulmonary vascular effects of high dose tricyclic antidepressants: acute and chronic animal studies. Eur Respir J. 2002;20:344-52.

22. Reznik I, Rosen Y, Rosen B. An acute ischaemic event associated with the use of venlafaxine: a case report and proposed pathophysiological mechanisms. J Psychopharmacol. 1999;13:193-5.

23. Colucci VJ, Berry BD. Heart failure worsening and exacerbation after venlafaxine and uloxetine therapy. Ann Pharmacother. 2008;42:882-7.

24. Khalifa M, Daleau $P$, Turgeon J. Mechanism of sodium channel block by venlafaxine in guinea pig ventricular myocytes. J Pharmacol Exp Ther. 1999;291:280-4.

25. Wijnen PA, Op den Buijsch RA, Drent M, Drent M, Kuijpers PM, Neef C, Bast A, Bekers $\mathrm{O}$, Koek GH. Review article: The prevalence and clinical relevance of cytochrome P450 polymorphisms. Aliment Pharmacol Ther. 2007;26 Suppl 2:211-9.

26. Michalets EL. Update: clinically significant cytochrome P-450 drug interactions. Pharmacotherapy. 1998;18:84-112.

27. Birgersdotter UM, Wong W, Turgeon J, Roden DM. Stereoselective geneticallydetermined interaction between chronic flecainide and quinidine in patients with arrhythmias. Br J Clin Pharmacol. 1992;33:275-80.

28. Camus $\mathrm{PH}$, Foucher $\mathrm{P}$, Bonniaud $\mathrm{PH}$, Ask K. Drug-induced infiltrative lung disease. Eur Respir J Suppl. 2001;32:93s-100s.

29. Jaquenoud Sirot E, van der Velden JW, Rentsch K, Eap CB, Baumann P. Therapeutic drug monitoring and pharmacogenetic tests as tools in pharmacovigilance. Drug Saf. 2006;29:735-68.

30. Clark DW, Donnelly E, Coulter DM, Roberts RL, Kennedy MA. Linking pharmacovigilance with pharmacogenetics. Drug Saf. 2004;27:1171-84. 


\section{Chapter 6}

Variant VKORC1 and CYP2C9 alleles in patients with diffuse alveolar haemorrhage caused by oral anticoagulants

P Wijnen, C Linssen, G Haenen, O Bekers, M Drent

Mol Diagn Ther. 2010;14:23-30 


\section{Abstract}

\section{Background}

Diffuse alveolar hemorrhage (DAH) is a life threatening bleeding complication that can occur as a result of oral anti-coagulation therapy.

We hypothesized that in patients treated with coumarins, alveolar hemorrhage is associated with vitamin $\mathrm{K}$ epoxide reductase (VKORC1) and cytochrome P450 (CYP) 2C9 (CYP2C9) variant alleles. In addition, in the case of acenocoumarol use, CYP2C19 allelic variants also play a role.

\section{Study design}

During a 7-year period patients using coumarins with confirmed DAH were gathered. Out of 173 confirmed DAH cases, 75 received oral anticoagulants, and 63 patients (84\%) of these 75 were included because their DNA was available. For genotyping the CYP2C $* 2$ (C430T), CYP2C9*3 (A1075C), CYP2C19*2 (G681A), CYP2C19*3 (G636A), VKORC1 (G-1639A) and VKORC1 (C1173T) single nucleotide polymorphisms (SNPs), real-time PCR's were performed.

\section{Results}

In $62(98.4 \%)$ out of $63 \mathrm{DAH}$ patients, variant genes were found. In 51 (81.0\%) of the 63 patients VKORC1 allelic variants (20 homozygote and 31 heterozygote) were present. In $31(49.2 \%)$ of the 63 DAH cases CYP2C9 variant alleles (three homozygote, 26 heterozygote, and two compound heterozygote) and in $20(32.0 \%)$ of the 63 patients both allelic variants were observed.

\section{Conclusion}

Genotyping of four SNPs for VKORC1 and CYP2C9 polymorphisms is useful in predicting a high probability of the occurrence of $\mathrm{DAH}$, in patients on oral anticoagulants. Early and timely use of genotyping is recommended to prevent a fatal outcome and to provide a safer and more individualized anticoagulant therapy. 


\section{Background}

Coumarin-based oral anticoagulants act as vitamin $\mathrm{K}$ antagonists. They are the most commonly prescribed drugs for therapy (such as in venous thrombosis or pulmonary embolism) or prophylaxis (as in chronic atrial fibrillation, prosthetic heart valves and other cardiovascular diseases) of thromboembolic conditions. The primary goal of coumarin administration is to prevent clot formation and its expansion while carefully avoiding unintended adverse drug reactions (ADR) from over-anticoagulation. ${ }^{1}$ The effect of the therapy is monitored by the prothrombin-time international normalized ratio (INR). An INR of less than 2.0 is associated with an increased risk of thromboembolism, and an INR of 4.0 or more denotes an increased risk of bleeding. ${ }^{2}$

One of the bleeding complications occurring in patients receiving coumarins, is diffuse alveolar hemorrhage (DAH). ${ }^{3}$ DAH may be fulminant and lead to death. Due to the severe effects of overdosing and the narrow therapeutic window, correct management of coumarins is challenging. A safe and effective dose has to be determined during the early phase of therapy, and maintenance doses need to be adjusted to compensate for changes in patients' weight, diet, disease state and concomitant use of other medication. ${ }^{4}$ The challenge is becoming even more demanding because of the increased use of coumarins that is a consequence of the aging of populations in industrialised countries.

Despite the ability to closely monitor the therapeutic effect of coumarins, by means of the INR, there is a relatively high incidence of complications. ${ }^{1}$ Since early treatment of these complications is life-saving and may result in complete recovery. Therefore, early diagnosis can be critical. At present the diagnosis of DAH is often made by an increased percentage of siderophages $(>20 \%)$ in bronchoalveolar lavage fluid (BALF), indicated with Perl's staining. ${ }^{5}$

Instead of early diagnosis, prevention would of course be much more preferable. The relatively high inter-individual drug requirement indicates that genetic factors may impact the therapeutic effect of coumarins. The strongest predictors of coumarin induced anticoagulant effects appear to be genes encoding for the enzyme vitamin $\mathrm{K}$ epoxide reductase complex 1 (VKORC1), the target of vitamin $\mathrm{K}$ antagonists. The enzyme VKORC1 recycles vitamin $\mathrm{K}$ epoxide to the reduced form of vitamin $\mathrm{K}$, an essential cofactor in the formation of active vitamin $\mathrm{K}$ dependent clotting factors II (prothrombin), VII, IX, and $\mathrm{X}$ through $\mathrm{y}$-glutamyl carboxylation, see also Figure $6.1 .^{6}$

Another predictor appears to be cytochrome P450 (CYP) 2C9, the enzyme mainly responsible for the metabolism of coumarins. ${ }^{4,7,8}$ For instance patients with the common, functionally defective, $* 2$ and $* 3$ allelic variants of the CYP2C9 gene require significantly lower maintenance doses, take longer to achieve dose stabilization, and are at higher risk for serious and life-threatening bleeding than are patients without these variants. ${ }^{8}$ 
When using acenocoumarol as an oral anticoagulant, one might even consider CYP2C19, although its contribution to the metabolism of acenocoumarol is small compared with CYP2C9. ${ }^{9}$

This study evaluates the association between the occurrence of DAH in patients after initiating coumarin anticoagulant therapy and the presence of $V K O R C 1$ and CYP2C9 allelic variants.

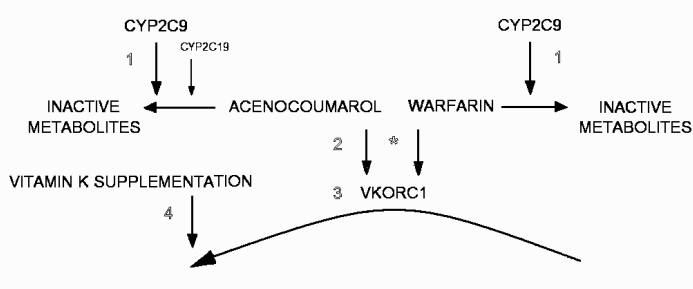<smiles>[R]c1c(C)c(O)c2ccccc2c1O</smiles><smiles>[R]C12OC1(C)C(=O)c1ccccc1C2=O</smiles>

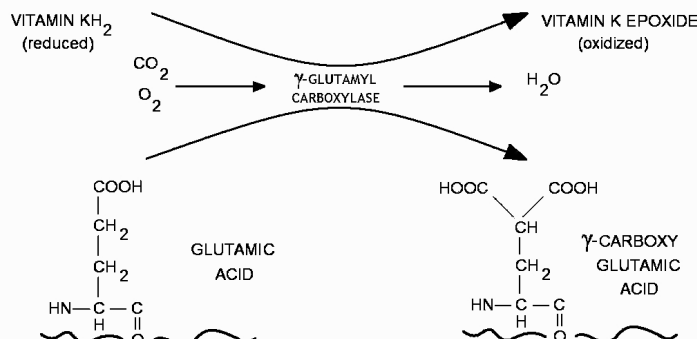

PROTHROMBIN PRECURSOR $(=\mathrm{FII}) /$

FVII / FIX / FX
PROTHROMBIN $(=\mathrm{FII}) /$

FVII / FIX / FX

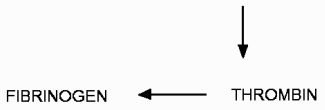

Figure 6.1 Interactions in the vitamin $\mathrm{K}$ cycle and coagulation. The vitamin $\mathrm{K}$ cycle plays an important role in the formation of functional vitamin K-dependent clotting factors (FII, FVII, FIX, and FX). Within the vitamin K cycle VKORC1 is responsible for the reduction of vitamin $\mathrm{K}$ epoxide (the inactive form) to vitamin $\mathrm{KH}_{2}$ (the active form) and the target for oral anticoagulants. Interactions can occur on several levels: (1) If variant CYP2C9 alleles are present, inadequate metabolism of coumarins by the affected CYP enzyme will result in more inhibition of VKORC1. (2) If variant VKORC1 alleles are present, the VKORC1 enzyme will be more sensitive to inhibition by anticoagulants, resulting in overanticoagulation. (3) Inhibition of VKORC1 by coumarins will prevent vitamin $\mathrm{K}$ epoxide to revert back to vitamin $\mathrm{KH}_{2}$, slowing down the vitamin $\mathrm{K}$ cycle. This inhibits the formation of vitamin $\mathrm{K}$-dependent clotting factors. High levels of coumarins cause overanticoagulation. (4) Vitamin $\mathrm{K}$ supplementation stimulates the vitamin $\mathrm{K}$ cycle, thus preventing over-anticoagulation. * indicates antagonism. 


\section{Materials and methods}

\section{Setting and study population}

Patients who were diagnosed with DAH at the Maastricht University Medical Centre (Maastricht, the Netherlands) from 2002 until 2009 were enrolled in the study. The inclusion criteria were bronchoalveolar lavage (BAL) performed in the diagnostic work-up and confirmed anticoagulant therapy initiated before the clinical episode of DAH. During this 7-year period, 1258 BAL analyses were carried out, and 252 cases with suspected DAH were identified. BAL was performed according to the hospital protocol, as reported previously. ${ }^{10}$ A total of 200 macrophages were counted, the total number of iron-stain (Perl's stain)-positive macrophages were expressed as a percentage of the 200 cells counted. A percentage of $>20 \%$ iron-positive macrophages was considered indicative for an alveolar hemorrhage. ${ }^{5}$ Of the obtained BALF samples, 173 samples had $>20 \%$ iron-stain-positive cells. In 75 of these 173 confirmed DAH cases, treatment with coumarins had been recently initiated. This study was a retrospective evaluation, and DNA was available only in $63(84 \%)$ out of 75 cases. In 40 of these 63 DAH cases, either genotyping for CYP2D6, CYP2C9, and $C Y P 2 C 19$ had been performed previously to evaluate whether there might be a drug-induced reaction involved in the observed clinical deterioration, or EDTA material was still available. In 23 cases, DNA was isolated from the cells in the BALF samples. All remaining samples were genotyped for CYP polymorphisms. In addition, for this study, VKORC1 genotyping was performed in these $63 \mathrm{DAH}$ cases.

A control population of 173 healthy, unrelated, Caucasian volunteers was also genotyped for the studied single nucleotide polymorphisms (SNPs).

The study was performed in accordance with the Declaration of Helsinki and its amendments. Written informed consent was obtained. The protocol was approved by the Medical Ethics Board of the Maastricht University Medical Centre.

\section{Collection of clinical data}

Inpatient and outpatient medical records of these 63 unrelated patients of Caucasian origin, presenting with DAH and using coumarins, were reviewed. Two patients received phenprocoumol, and the remaining 61 patients received acenocoumarol. Routine laboratory tests, chest X-rays, and high-resolution CT scans were reviewed in all patients. Appropriate and relevant biopsies were also evaluated when available (18 cases). 


\section{Genotyping}

In addition to the previously determined polymorphisms, VKORC1 genotyping was performed.

DNA was obtained from all subjects by using venous EDTA anticoagulated blood or BALF samples and isolated with a High Pure PCR Template Preparation Kit (Roche Diagnostics, Mannheim, Germany) according to the manufacturer's instructions.

For genotyping the CYP2C9*2 (C430T), CYP2C9*3 (A1075C), CYP2C19*2 (G681A), CYP2C19*3 (G636A), VKORC1 (G-1639A), and VKORC1 (C1173T) SNPs, three real-time PCR Fluorescence Resonance Energy Transfer (FRET) analyses were performed. FRET LightMix ${ }^{\circledR}$ assays (cat.-no. 40-0298-16, 40-0304-16, and 40-0302-16; TIB MOLBIOL, Berlin, Germany) on the LightCycler $^{\circledR}$ (Roche Diagnostics) were used, according to the manufacturer's protocols. These three FRET assays simultaneously determined the two SNPs of CYP2C9, CYP2C19 and VKORC1, respectively, in separate capillaries. Each assay consisted of a duplex reaction measuring the melting curves of the used specific fluorescent probes in two different channels, each with a distinct wavelength. Positive (heterozygote, provided with the kit) and negative controls were determined with each run.

\section{Statistical analysis}

Statistical analyses were performed with SPSS version 15.0 software for Windows (SPSS Inc., Chicago, IL, USA) for Windows. The chi-square test was used to test for statistically significant differences between groups. Odds ratios (ORs) with 95\% confidence intervals (CIs) were derived from these tables to evaluate the strength of associations between genotypes and the DAH event. Actual allele distributions were compared against the expected frequencies that were calculated, using the Hardy-Weinberg equilibrium. Deviations from Hardy-Weinberg equilibrium were analysed using the chi-square test. A $\mathrm{p}$-value of $<0.05$ (two-sided) was considered to indicate statistical significance. A Bonferroni correction was applied, if appropriate, to adjust for multiple comparisons ( $p<0.01$, indicating statistical significance).

\section{Results}

The characteristics and summary of relevant clinical data of the studied patients (15 females and 48 males) with DAH are listed in Table 6.1. Data subdivided on the basis of the presence of the studied polymorphisms did not show substantial differences (Table 6.1). 


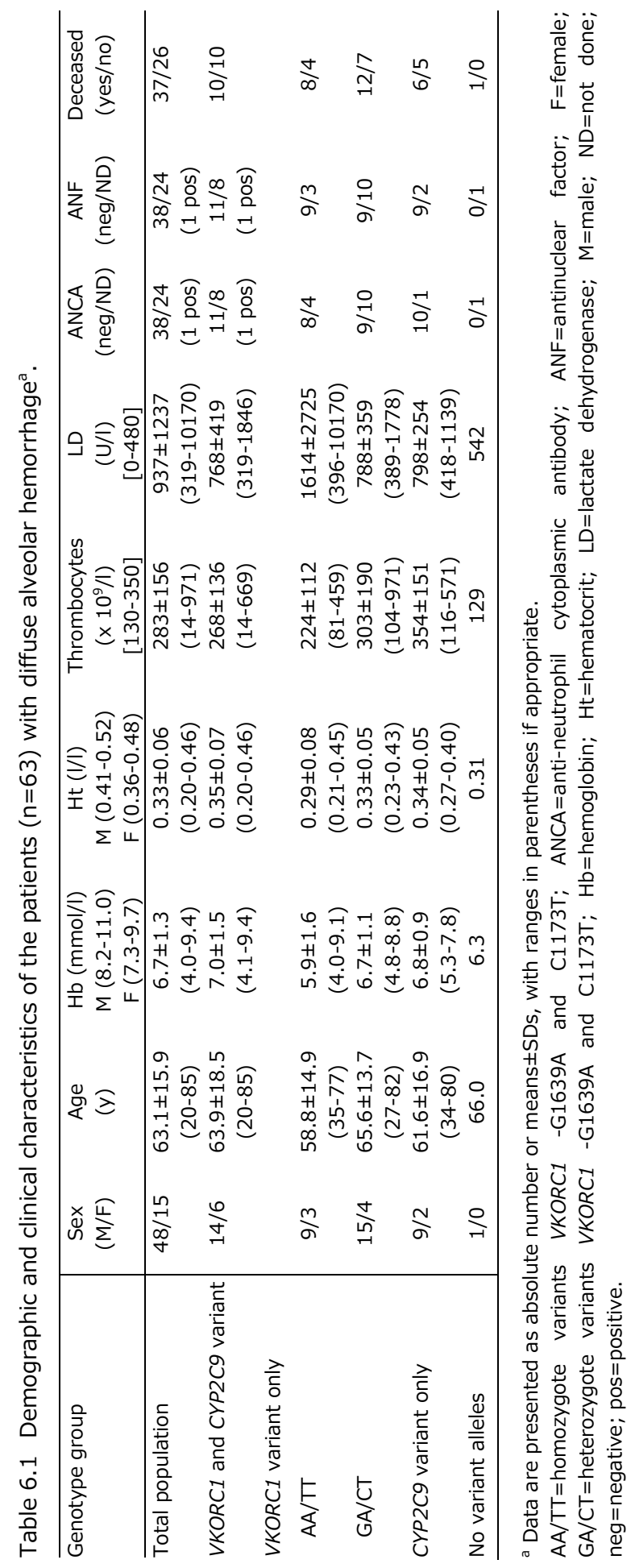


The reasons for the patients being on anticoagulants were as follows: atrial fibrillation or flutter $(n=34)$; previous myocardial infarction $(n=12)$; chronic heart failure $(n=7)$; lung embolisms $(n=4)$; valve replacement surgery $(n=4)$; deep-vein thrombosis $(n=2)$. The average dose of the coumarins was low (maximum $2 \mathrm{mg} /$ day, with an initial dosing scheme of $6 \mathrm{mg} /$ day for one day, then $4 \mathrm{mg} /$ day for one day, and then $2 \mathrm{mg} /$ day or $4 \mathrm{mg} /$ day for two days and then $2 \mathrm{mg} /$ day in elderly patients). The INR was above the therapeutic range within two weeks after initiation of anticoagulant treatment in all DAH cases (median 5.50, with $80 \%$ INR $>4.00$ and $40 \%$ INR >6.00). Most of the patients had several episodes of an increased INR during the follow-up, were difficult to normalize, and had to be kept on lower anticoagulant doses than is standard for the general population. Immunological analysis revealed no abnormalities, and no underlying systemic diseases were found. The high-resolution CT showed wide spread signs of DAH, with patchy bilateral or diffuse areas of ground-glass attenuation in all cases. A BAL was performed in all subjects, showing hemorrhagic BALF with a markedly positive iron staining ( $>22 \%$, mean $59.3 \pm 25.7$ ) and the presence of erythrocytes and pneumocytes type II, confirming the diagnosis DAH. ${ }^{10}$

The allele frequencies and genotype distribution in the DAH patients were determined and compared with the distribution of the same polymorphisms in a healthy, unrelated, Caucasian population from our hospital and from populations in the literature (Table 6.2). ${ }^{11,12}$ Allele frequencies and genotype distributions of both control populations were in Hardy-Weinberg equilibrium. A VKORC1 variant allele was found in 51 of the 63 patients with $\mathrm{DAH}(81.0 \%$, $\mathrm{p}<0.025)$. This included 20 homozygotes $(A A / T T)$, including the only two patients in our population receiving phenprocoumol, and 31 heterozygotes (GA/CT). A CYP2C9 allelic variant was found in 31 of the 63 patients $(49.2 \%$, $\mathrm{p}<0.025)$, including three homozygotes, 26 heterozygotes, and two compound heterozygotes. Twenty (32.0\%) out of the $63 \mathrm{DAH}$ cases had both VKORC1 and CYP2C9 allelic variants. In $31(49.2 \%)$ out of these 63 DAH cases, only a VKORC1 allelic variant was found. Of the $12 \mathrm{DAH}$ cases without a VKORC1 allelic variant $(\mathrm{GG} / \mathrm{CC})$, five were CYP2C9*1/*2 heterozygotes, four were CYP2C9*1/*3 heterozygotes, and two had a compound heterozygous variant CYP2C $* 2 / * 3$ genotype. The remaining subject had no variant of the studied alleles. When comparing patients with controls for the presence of a polymorphism (polymorphism present versus no polymorphism), a significant difference was found ( $O R=14.6,95 \% \mathrm{CI}: 1.96-109.3 ; \mathrm{p}<0.001)$. Furthermore, a CYP2C19 variant allele was found in one third of the DAH cases. In all of these patients, this coincided with the presence of a CYP2C9 and/or VKORC1 allelic variant (Table 6.3). 
Table 6.2 Allele frequencies and polymorphism distribution in diffuse alveolar hemorrhage (DAH) patients compared with healthy volunteers and historical controls.

\begin{tabular}{|c|c|c|c|c|c|c|c|c|c|}
\hline & \multicolumn{3}{|c|}{ Patients with $\mathrm{DAH}^{\mathrm{a}}$} & \multicolumn{3}{|c|}{ Healthy volunteers ${ }^{\mathrm{b}}$} & \multicolumn{3}{|c|}{ Controls from the literature $^{c}$} \\
\hline & $\begin{array}{c}\text { CYP2C9 } \\
(\%)\end{array}$ & $\begin{array}{c}\text { KORC1 } \\
(\%)\end{array}$ & $\begin{array}{c}Y P 2 C 19 \\
(\%)\end{array}$ & $\begin{array}{c}\text { CYP2C } \\
(\%)\end{array}$ & $\begin{array}{c}\text { KORC } \\
(\%)\end{array}$ & $\begin{array}{l}Y P 2 C 19 \\
(\%)\end{array}$ & $\begin{array}{c}\text { CYP2C9 } \\
(\%)\end{array}$ & $\begin{array}{c}\text { KORC1 } \\
(\%)\end{array}$ & $\begin{array}{c}\text { CYP2C1912 } \\
(\%)\end{array}$ \\
\hline No variant allele & 50.8 & 19.0 & 66.7 & 61.9 & 29.5 & 76.3 & 64.0 & 34.0 & 75.3 \\
\hline Variant allele & $49.2^{\mathrm{d}}$ & $81.0^{\mathrm{e}}$ & $33.3^{f}$ & 38.1 & 70.5 & 23.7 & 36.0 & 66.0 & 24.7 \\
\hline \multicolumn{10}{|l|}{ Allele $^{g}$} \\
\hline$*_{1}$ & 71.4 & & 81.7 & 79.7 & & 86.4 & 80.0 & & 86.5 \\
\hline *2 & 15.9 & & 18.3 & 13.9 & & 13.6 & 13.5 & & 13.3 \\
\hline$* 3$ & 12.7 & & 0.0 & 6.4 & & 0.0 & 6.5 & & 0.2 \\
\hline $\mathrm{G} / \mathrm{C}$ & \multicolumn{3}{|c|}{43.7} & \multicolumn{3}{|c|}{52.3} & \multicolumn{3}{|c|}{58.5} \\
\hline$A / T$ & \multicolumn{3}{|c|}{56.3} & \multicolumn{3}{|c|}{47.7} & \multicolumn{3}{|c|}{41.5} \\
\hline
\end{tabular}

${ }^{a} \mathrm{n}=63$; sex $76.2 \%$ male, $23.8 \%$ female; age range $=20-85$ y. ${ }^{\mathrm{b}} \mathrm{n}=173$; sex $56.6 \%$ male, $43.4 \%$ female; age range $=19-59$ y. ${ }^{\circ}$ For CYP2C9 and VKORC1: $\mathrm{n}=200$; sex $50 \%$ male, $50 \%$ female; age range $=18-24$ y; For CYP2C19: $n=736$; sex $82 \%$ male, $18 \%$ female; age range $=18-79$ y. ${ }^{d} p=0.022$ vs healthy volunteers; $p=0.006$ vs historical controls. ${ }^{e} p=0.021$ vs healthy volunteers; $p=0.0015$ vs historical controls. ${ }^{f} p=0.024$ vs healthy volunteers; $p=0.046$ vs historical controls. ${ }^{9}$ For CYP2C9: $* 1=$ wild type, $* 2=430 \mathrm{~T}$, and $* 3=1075 \mathrm{C}$; for CYP2C19: $* 1=$ wild type, $* 2=681 \mathrm{~A}$ and $* 3=636 \mathrm{~A}$. VKORC1 SNPs are G-1639A and C1173T; genotype $\mathrm{G} / \mathrm{C}$ is wild type and $\mathrm{A} / \mathrm{T}$ is variant.

Table 6.3 Influences on the coagulation: allelic variants and co-medication in patients $(n=63)$ with diffuse alveolar hemorrhage.

\begin{tabular}{lccccccc}
\hline $\begin{array}{l}\text { Patient } \\
\text { no. }\end{array}$ & \multicolumn{2}{c}{ CYP2C9 $^{\text {a }}$} & \multicolumn{2}{c}{ VKORC1 } & \multicolumn{2}{c}{ CYP2C19 } & $\begin{array}{c}\text { Influence of } \\
\text { co-medication } \\
\text { (yes/no) }\end{array}$ \\
\hline 3 & genotype & influence & genotype & influence & genotype & influence & Yes \\
1 & $* 1 / * 3$ & Yes & AA/TT & Yes & $* 1 / * 2$ & Yes & $2 / 1$ \\
1 & $* 1 / * 2$ & Yes & AA/TT & Yes & $* 1 / * 2$ & Yes & $1 / 0$ \\
1 & $* 2 / * 2$ & Yes & AA/TT & Yes & $* 1 / * 1$ & No & $0 / 1$ \\
2 & $* 1 / * 3$ & Yes & AA/TT & Yes & $* 1 / * 1$ & No & $1 / 0$ \\
2 & $* 1 / * 2$ & Yes & AA/TT & Yes & $* 1 / * 1$ & No & $2 / 0$ \\
3 & $* 1 / * 1$ & No & AA/TT & Yes & $* 2 / * 2$ & Yes & $1 / 1$ \\
7 & $* 1 / * 1$ & No & AA/TT & Yes & $* 1 / * 2$ & Yes & $2 / 1$ \\
2 & $* 1 / * 1$ & No & AA/TT & Yes & $* 1 / * 1$ & No & $3 / 4$ \\
6 & $* 2 / * 2$ & Yes & GA/CT & Yes & $* 1 / * 1$ & No & $1 / 1$ \\
4 & $* 1 / * 3$ & Yes & GA/CT & Yes & $* 1 / * 1$ & No & $5 / 1$ \\
11 & $* 1 / * 2$ & Yes & GA/CT & Yes & $* 1 / * 1$ & No & $3 / 1$ \\
8 & $* 1 / * 1$ & No & GA/CT & Yes & $* 1 / * 2$ & Yes & $8 / 3$ \\
2 & $* 1 / * 1$ & No & GA/CT & Yes & $* 1 / * 1$ & No & $4 / 4$ \\
1 & $* 2 / * 3$ & Yes & GG/CC & No & $* 1 / * 1$ & No & $1 / 1$ \\
3 & $* 1 / * 3$ & Yes & GG/CC & No & $* 1 / * 2$ & Yes & $0 / 1$ \\
5 & $* 1 / * 3$ & Yes & GG/CC & No & $* 1 / * 1$ & No & $2 / 1$ \\
1 & $* 1 / * 2$ & Yes & GG/CC & No & $* 1 / * 1$ & No & $2 / 3$ \\
\hline & $* 1 / * 1$ & No & GG/CC & No & $* 1 / * 1$ & No & $1 / 0$ \\
\hline
\end{tabular}

${ }^{a}$ CYP2C9 SNPs are C430T and A1075C; allele designations: $* 1=$ wild type, $* 2=430 \mathrm{~T}$, and $* 3=1075 \mathrm{C}$. b VKORC1 SNPs are -G1639A and C1173T; genotype GG/CC is homozygous wild type and AA/TT is homozygous variant. ' CYP2C19 SNPs are G681A and G636A; allele designations: *1=wild type, $* 2=681 \mathrm{~A}$ and $* 3=636 \mathrm{~A}$. 
The influence of allelic variants and co-medication on the anticoagulation in each individual case is summarized in Table 6.3 . In about $60 \%$ of all the patients, co-medication was prescribed that might have influenced the coagulation. In only one patient - the one without any variant alleles in the VKORC1 or CYP2C9 - the co-medication might have caused the bleeding. In this patient, a drug-drug interaction was most likely, with no fewer than four drugs (amiodarone, paroxetine, pantoprazole, and clopidogrel), being used that could have interacted with the anticoagulant. The drugs prescribed to the patients that might have influenced the anticoagulation are listed in Table 6.4.

Since May 2007, genotyping for the VKORC1 polymorphism, together with the earlier described CYP polymorphisms, has been available on request for clinicians in our hospital. Subsequently, in the period between May 2007 and December 2008, 11 patients with DAH were identified and included in this study. In all of these patients, vitamin $\mathrm{K}$ supplementation ( $1 \mathrm{mg} / \mathrm{day}$, orally) was started. Out of the 11 patients, 10 responded quite well, recovered, and are still alive. Of the 63 studied DAH cases, 37 patients died, primarily because of complications related to heart failure in combination with $\mathrm{DAH}$.

Table 6.4 Medication influencing the coagulation in the patients in which this was relevant $(n=39)$.

\begin{tabular}{lc}
\hline Administered co-medication & No. of patients \\
\hline amiodarone & 15 \\
amitriptyline & 1 \\
aspirin & 5 \\
atorvastatine & 7 \\
carvedilol & 5 \\
clopidogrel & 2 \\
colchicine & 1 \\
esomeprazol & 1 \\
felodipine & 1 \\
fluoxetine & 1 \\
insulin & 2 \\
isoniazid & 1 \\
levothyroxine & 1 \\
nifedipine & 1 \\
omeprazole & 5 \\
pantoprazole & 15 \\
paroxetine & 4 \\
prednisone & 8 \\
ranitidine & 1 \\
rifampin & 1 \\
simvastatin & 2 \\
trimethoprim/sulfamethoxazole & 2 \\
valproic acid & 2 \\
verapamil & 2 \\
\hline
\end{tabular}




\section{Discussion}

Anticoagulants can cause fatal pulmonary hemorrhage. Barnett et al. ${ }^{13}$ reported a case of DAH due to superwarfarin ingestion. More recently, Erdogan et al. $^{3}$ reported a case of DAH associated with coumarin therapy. We described a case of DAH in a patient who had malnutrition and was taking antibacterials and anticoagulants; at that time, genotyping was not yet available. ${ }^{14} \mathrm{DAH}$ results in accumulation of iron in the lungs and, in turn, iron causes oxidative stress and inflammation. It has been suggested that oxidative damage plays a role in the pathophysiology of various diseases. ${ }^{15}$ It is important to prevent or recognize DAH at an early stage to avoid irreversible damage. Particularly, in critically ill patients with unexplained infiltrates, DAH should be considered. DAH events can occur as a result of over-anticoagulation due to coumarin sensitivity, caused by VKORC1 or CYP2C9 polymorphisms, resulting in a relative vitamin $\mathrm{K}$ deficiency. Prophylactic administration of vitamin $\mathrm{K}$ to patients at risk can prevent severe damage. ${ }^{16-18}$ Just recently, the information gathered from genotyping in this study has become available to clinicians. Subsequently, vitamin $\mathrm{K}$ supplementation ( $1 \mathrm{mg} /$ day) was initiated in $11 \mathrm{DAH}$ cases, resulting in a stabilization of the INR and a positive outcome in 10 of these $11 \mathrm{DAH}$ cases. This supports the concept that the use of new pharmacogenetic-based dosing schemes and the concomitant application of low-dose vitamin $\mathrm{K}$ with coumarins will greatly improve coumarin drug safety. ${ }^{18,19}$

Pharmacogenomics uses the tools of human genetics to tailor medical treatment to an individual's genetic make-up. To this end, phenotypic manifestations, a therapeutic outcome, or ADRs are considered in relation to the underlying genetic background of a patient. 7,20 The identification of the molecular target of coumarins, VKORC1, has greatly improved the understanding of coumarin treatment and illuminated new perspectives for a safer and more individualized oral anticoagulation therapy. Rieder et al. ${ }^{4}$ previously demonstrated that the VKORC1 genotype appeared to be the most important genetic factor determining variability in coumarin dose; its effect was approximately three times higher than that of the CYP2C9 genotype. More recently, in line with this, Schwarz et al. ${ }^{16}$ concluded that the initial variability was more strongly associated with genetic variability in the pharmacogenetic target of coumarins, VKORC1, than with CYP2C9.

Variations and SNPs within the translated and non-translated regions of the VKORC1 gene have been shown to cause coumarin resistance and sensitivity, respectively. ${ }^{21}$ A frequent SNP within the VKORC1 promoter (G-1639A) has been identified as a major determinant of coumarin sensitivity, reducing vitamin $\mathrm{K}$ epoxide reductase enzyme activity to $50 \%$ of wild type (GG=fully functional). Homozygous carriers of the VKORC1-1639A allele (AA) are 
strongly predisposed to coumarin sensitivity and require lower coumarin dosages. However, the link between DAH and the presence of VKORC1 and CYP2C9 variant alleles has never been made before.

To the best of our knowledge, our study is the first one evaluating the association between the occurrence of a serious adverse reaction of anticoagulant therapy, DAH, and the presence of relevant polymorphisms. We found that in $62(98.4 \%)$ of the patients in our study population, a variant allele was present. In $81.0 \%(51 / 63)$ of the studied patients, the bleeding complication could be explained by the VKORC1 haplotype (61.0\% without and $39.0 \%$ with a CYP2C9 allelic variant) alone. As also shown in Table 6.2, only $19.0 \%$ of the patients had no VKORC1 1173T/-1639A variant alleles, compared with $29.5 \%$ in a healthy volunteer population $(n=173)$ and $34.0 \%$ in a historical control population $(n=200)$ from the literature. ${ }^{11}$ In 11 of the 12 DAH cases without a VKORC1 variant the CYP2C9 variant allele could explain the problems in reaching an appropriate INR. The present CYP2C9 functionally defective allelic variant required a $34 \%$ lower maintenance dose for the $* 1 / * 3$ genotype and a $61 \%$ reduction for the $* 2 / * 3$ genotype, compared with $13 \%$ for the CYP2C9*1/*2. In the one remaining patient without any variant of the alleles studied, the high INR and subsequent DAH event seemed attributable to drug-drug interactions. One third of the patients had an extremely high risk as they appeared to have both genetic risk factors that are known to stratify patients into low dose/high-risk cases. ${ }^{16}$ Furthermore, the patients with VKORC1 and/or CYP2C9 allelic variants present need longer times before dose stabilization and are at a higher risk for serious and life-threatening bleeding, including DAH, than patients without these variants. ${ }^{8,22}$

Our observation confirms that genotyping four SNPS, namely of the VKORC1 and the CYP2C9 genes, predicts a high risk of overdosing with coumarins (warfarin, acenocoumarol, phenprocoumon). ${ }^{23}$ Although other studies have reported a strong linkage disequilibrium between the SNPS in the VKORC1 gene, our own experience shows that sometimes only one of the examined SNPs can display a variant allele. ${ }^{24,25}$ Accordingly, this implies a potential risk factor could be missed if only one SNP is examined. Moreover, in this study, the $V K O R C 1$ results were obtained in one run, using a reagent combining primers and probes for both SNPs, without any extra time or costs. In the case of oral anticoagulation with acenocoumarol, genotyping for the *2 (G681A) and *3 (G636A) allelic variants in the CYP2C19 gene could be performed. Although acenocoumarol is mainly metabolized by CYP2C9 it is also partly metabolized by CYP2C19 (Figure 6.1). ${ }^{9}$ Polymorphisms in this enzyme system could therefore present additional anticoagulation problems. In our population, however, this polymorphism was of minor importance. All of the subjects with a CYP2C19 variant allele (33.3\% of all of the patients) also displayed one or both of the other two studied polymorphisms. 
One of the limitations of this study was the fact that DNA was available in only 63 of the 75 subjects who used oral anticoagulants and were diagnosed with $\mathrm{DAH}$. Therefore, conclusions from this case series should be interpreted with care, and prospective studies should be conducted to evaluate the cost effectiveness of genotyping. Moreover, confirmation of our findings in other populations is mandatory. However, the fact that all but one of the included patients with DAH demonstrated at least one of the studied genetic defects makes the association highly likely. The merits of genotyping before starting treatment involving drugs such as coumarins, the effectiveness of which depends on genetic variants of CYP2C9 and VKORC1, is still an area of debate between regulatory authorities and clinicians. Even though genotyping four SNPs is relatively cheap (about \$US 200-250 in 2009) and needs to be performed only once in a lifetime, until its cost effectiveness is established, one could choose to only genotype patients who experience unstable INRs, in order to avoid serious complications. Nevertheless, as of August 2007, the US FDA issued a recommendation to genotype CYP2C9 and VKORC1 in warfarin product labeling, to optimize dosing schedules when prescribing warfarin. ${ }^{24,26}$ Furthermore, it is tempting to speculate that by using individualized dose adaptation, a significant reduction of bleeding complications, including DAH, can be expected, especially in the initial drug-saturation phase. ${ }^{4}$

\section{Conclusion}

In all but one of the studied patients with DAH treated with coumarins, an association with either a VKORC1 or a CYP2C9 variant allele, or both, was found. Early and timely use of appropriate genotyping is important in case of coumarin treatment, because of the potential fatal outcome of overanticoagulation and the fact that simple vitamin $\mathrm{K}$ supplementation can be lifesaving. Therefore, in concordance with the FDA, genotyping of only four SNPs for VKORC1 and CYP2C9 allelic variants is recommended in order to provide a safer and more individualized anticoagulant therapy. 


\section{References}

1. Sharma P, Bentley P. Of rats and men: superwarfarin toxicity. Lancet. 2005; 365:552-3.

2. Kearon C, Ginsberg JS, Kovacs MJ, Anderson DR, Wells P, Julian JA, MacKinnon B, Weitz JI, Crowther MA, Dolan S, Turpie AG, Geerts W, Solymoss S, van Nguyen P, Demers C, Kahn SR, Kassis J, Rodger M, Hambleton J, Gent M; Extended LowIntensity Anticoagulation for Thrombo-Embolism Investigators. Comparison of lowintensity warfarin therapy with conventional-intensity warfarin therapy for long-term prevention of recurrent venous thromboembolism. N Engl J Med. 2003;349:631-9.

3. Erdogan D, Kocaman O, Oflaz H, Goren T. Alveolar hemorrhage associated with warfarin therapy: a case report and literature review. Int J Cardiovasc Imaging. 2004;20:155-9.

4. Rieder MJ, Reiner AP, Gage BF, Nickerson DA, Eby CS, McLeod HL, Blough DK, Thummel KE, Veenstra DL, Rettie AE.. Effect of VKORC1 haplotypes on transcriptional regulation and warfarin dose. N Engl J Med. 2005; 352:2285-93.

5. De Lassence A, Fleury-Feith J, Escudier E, Beaune J, Bernaudin JF, Cordonnier C. Alveolar hemorrhage. Diagnostic criteria and results in 194 immunocompromised hosts. Am J Respir Crit Care Med. 1995; 151:157-63.

6. Laposata M, Van Cott EM, Lev MH. Case records of the Massachusetts General Hospital. Case 1-2007. A 40-year-old woman with epistaxis, hematemesis, and altered mental status. N Engl J Med. 2007; 356:174-82.

7. Krynetskiy $E$, McDonnell P. Building individualized medicine: prevention of adverse reactions to warfarin therapy. J Pharmacol Exp Ther. 2007; 322:427-34.

8. Higashi MK, Veenstra DL, Kondo LM, Wittkowsky AK, Srinouanprachanh SL, Farin FM, Rettie AE. Association between CYP2C9 genetic variants and anticoagulationrelated outcomes during warfarin therapy. JAMA. 2002; 287:1690-8.

9. Thijssen $\mathrm{HH}$, Flinois JP, Beaune PH. Cytochrome P4502C9 is the principal catalyst of racemic acenocoumarol hydroxylation reactions in human liver microsomes. Drug Metab Dispos. 2000; 28:1284-90.

10. Linssen KC, Jacobs JA, Poletti VE, van Mook W, Cornelissen EI, Drent M. Reactive type II pneumocytes in bronchoalveolar lavage fluid. Acta Cytol. 2004; 48:497-504.

11. Geisen C, Watzka M, Sittinger K, Steffens M, Daugela L, Seifried E, Müller CR, Wienker TF, Oldenburg J. VKORC1 haplotypes and their impact on the interindividual and inter-ethnical variability of oral anticoagulation. Thromb Haemost. 2005; 94:773-9.

12. Tamminga WJ, Wemer J, Oosterhuis B, de Zeeuw RA, de Leij LF, Jonkman JH. The prevalence of CYP2D6 and CYP2C19 genotypes in a population of healthy Dutch volunteers. Eur J Clin Pharmacol. 2001; 57:717-22.

13. Barnett VT, Bergmann $F$, Humphrey $H$, Chediak J. Diffuse alveolar hemorrhage secondary to superwarfarin ingestion. Chest. 1992; 102:1301-2.

14. Drent M, Wessels S, Jacobs JA, Thijssen H. Association of diffuse alveolar haemorrhage with acquired vitamin K deficiency. Respiration. 2000; 67:697.

15. Rahman I, Skwarska E, Henry M, Davis M, O'Connor CM, FitzGerald MX, Greening A, MacNee W. Systemic and pulmonary oxidative stress in idiopathic pulmonary fibrosis. Free Radic Biol Med. 1999; 27:60-8.

16. Schwarz UI, Ritchie MD, Bradford Y, Li C, Dudek SM, Frye-Anderson A, Kim RB, Roden DM, Stein CM. Genetic determinants of response to warfarin during initial anticoagulation. N Engl J Med. 2008;358:999-1008.

17. Ansell J, Hirsh J, Hylek E, Jacobson A, Crowther M, Palareti G; American College of Chest Physicians. Pharmacology and management of the vitamin $\mathrm{K}$ antagonists: American College of Chest Physicians Evidence-Based Clinical Practice Guidelines (8th Edition). Chest. 2008;133:160S-98S. 
18. Sconce E, Avery P, Wynne H, Kamali F. Vitamin K supplementation can improve stability of anticoagulation for patients with unexplained variability in response to warfarin. Blood. 2007; 109:2419-23.

19. Oldenburg J, Bevans CG, Fregin A, Geisen C, Müller-Reible C, Watzka M. Current pharmacogenetic developments in oral anticoagulation therapy: the influence of variant VKORC1 and CYP2C9 alleles. Thromb Haemost. 2007;98:570-8.

20. Wijnen PA, Drent M, Nelemans PJ, Kuijpers PM, Koek GH, Neef C, Haenen GR, Bekers O. Role of cytochrome p450 polymorphisms in the development of pulmonary drug toxicity: a case-control study in the Netherlands. Drug Saf. 2008; 31:1125-34.

21. Voora D, Eby C, Linder MW, Milligan PE, Bukaveckas BL, McLeod HL, Maloney W, Clohisy J, Burnett RS, Grosso L, Gatchel SK, Gage BF. Prospective dosing of warfarin based on cytochrome P-450 2C9 genotype. Thromb Haemost. 2005;93:700-5.

22. Sconce EA, Khan TI, Wynne HA, Avery P, Monkhouse L, King BP, Wood P, Kesteven $P$, Daly AK, Kamali F. The impact of CYP2C9 and VKORC1 genetic polymorphism and patient characteristics upon warfarin dose requirements: proposal for a new dosing regimen. Blood. 2005;106:2329-33.

23. Cooper GM, Johnson JA, Langaee TY, Feng H, Stanaway IB, Schwarz UI, Ritchie MD, Stein CM, Roden DM, Smith JD, Veenstra DL, Rettie AE, Rieder MJ. A genome-wide scan for common genetic variants with a large influence on warfarin maintenance dose. Blood. 2008;112:1022-7.

24. Wang D, Chen H, Momary KM, Cavallari LH, Johnson JA, Sadée W. Regulatory polymorphism in vitamin $\mathrm{K}$ epoxide reductase complex subunit 1 (VKORC1) affects gene expression and warfarin dose requirement. Blood. 2008;112:1013-21.

25. Bodin L, Verstuyft C, Tregouet DA, Robert A, Dubert L, Funck-Brentano C, Jaillon P, Beaune $P$, Laurent-Puig $P$, Becquemont L, Loriot MA. Cytochrome P450 2C9 (CYP2C9) and vitamin K epoxide reductase (VKORC1) genotypes as determinants of acenocoumarol sensitivity. Blood. 2005; 106:135-40.

26. Gage BF, Lesko LJ. Pharmacogenetics of warfarin: regulatory, scientific, and clinical issues. J Thromb Thrombolysis. 2008;25:45-51. 



\section{Chapter 7} polymorphisms in the course of pulmonary sarcoidosis

P Wijnen, P Nelemans, J Verschakelen, O Bekers, C Voorter, M Drent 


\section{Abstract}

\section{Background}

This study was designed to evaluate the relationship between the presence of tumor necrosis factor (TNF) polymorphisms, human leukocyte antigen (HLA)-DRB1*03 linkage and the prognosis of sarcoidosis.

\section{Study design}

In a retrospective case-control study, TNF- $a$ G-308A, TNF- $a$ G-238A, lymphotoxin- $a$ (LTA) and HLA-DRB1*03 were genotyped in 625 sarcoidosis patients. These patients were classified into 298 patients with persistent disease and 327 patients with nonpersistent disease using chest X-ray (CXR) appearances and lung function parameters after at least two years of follow-up.

\section{Results}

The TNF- $a-308 \mathrm{~A}$ variant allele was observed in $25.5 \%$ of patients with persistent disease compared with $44.0 \%$ of patients with non-persistent disease. The corresponding odds ratio (OR) was 0.43 with a $95 \%$ confidence interval (CI) of 0.30-0.61. A strong linkage was found between TNF- $a$ G-308A and HLA-DRB1*03 (OR=0.03, 95\% CI: 0.02-0.05). For TNF- $a$ G-238A and LTA NcoI A252G, there were no statistically significant differences in the distribution of genotypes between the groups with and without persistent disease.

\section{Conclusion}

The data indicate that presence of a TNF- $a-308 \mathrm{~A}$ variant allele and HLA-DRB1*03 were associated with a favorable prognosis. Because of the strong linkage between TNF- $a$ G-308A and HLA-DRB1*03, genotyping of one simple and less expensive TNF-a single nucleotide polymorphism can be used to predict the prognosis of pulmonary sarcoidosis in clinical practice. 


\section{Introduction}

Sarcoidosis is a multisystem granulomatous disorder with distinct immunopathologic features. The disease is most likely the product of genetic susceptibility and an appropriate environmental antigen. ${ }^{1-3}$ The clinical presentation and outcome of sarcoidosis varies considerably. Therapeutic options range from no treatment to a variety of therapeutic agents.

It is well known that the outcome of sarcoidosis varies considerably. ${ }^{4}$ The presence of hilar adenopathy alone ${ }^{5,6}$ or patients presenting with Löfgren's syndrome more often have a favorable outcome as compared with those with parenchymal lung disease. ${ }^{7-9}$ By contrast, the presence of pulmonary fibrosis is associated with chronic disease. ${ }^{5}$ Pulmonary disease is the most common manifestation of sarcoidosis, and pulmonary symptoms are the most common reason for treatment. ${ }^{1,3}$ It is important to identify the patients who are likely to have a poor prognosis, to ensure the appropriate individual treatment regimen without delay. ${ }^{10}$ Genetic polymorphisms contribute to clinical phenotypes. ${ }^{6,9,11}$ Association of sarcoidosis and class I and II human leukocyte antigens (HLA) antigens is well known. 3,6,12 Grunewald et al. reported an influence of both HLA class I and class II alleles on the disease course in patients with sarcoidosis. They found that $76.8 \%$ of patients with resolving disease, appeared to be HLADRB $1 * 03$ positive, in contrast to only $9.2 \%$ of patients with persistent disease. ${ }^{6}$ Tumor necrosis factor alpha (TNF-a), a potent pro-inflammatory cytokine that plays a pivotal role in inflammatory and immune responses, regulates and sustains granuloma formation in sarcoidosis. ${ }^{3}$ TNF-a production is an innate host characteristic that varies between individuals and is associated with certain HLA-D receptor (HLA-DR) alleles. ${ }^{13}$ The TNF gene locus, comprising of the TNF-a, lymphotoxin-a (LTA, formerly also referred to as TNF- $\beta$ ) and lymphotoxin- $\beta$ genes, is located in the class III region of the major histocompatibility complex (MHC). Genetic analysis has showed a number of polymorphisms in these genes and new polymorphisms with potential functional consequences. ${ }^{7,14-16}$ Of genes in the MHC III region, the TNF- $a$ polymorphisms have been extensively studied. Several single nucleotide polymorphisms (SNPs) are identified in the TNF- $a$ gene. Among these, a common polymorphism in the promoter region, a $G$ to $A$ substitution at position -308, has been associated with variation of TNF-a production. Especially the A-allele of the TNF- $a$ G-308A gene is associated with higher TNF-a serum levels and an acute course of sarcoidosis. ${ }^{17}$ The existence of a strong linkage disequilibrium between HLA-DRB1*03 and the TNF- $a-308 \mathrm{~A}$ variant allele has been shown. ${ }^{6,9,18}$ In addition to the TNF- $a$ G-308A polymorphism, others found that the TNF-a G-238A and LTA NCOI A252G SNPs were associated with variations in TNF-a production and suggested a possible role in the course of sarcoidosis. $7,8,11,17$ 
The aim of the present study was to assess the association among TNF- $a$ G-308A, TNF- $a$ G-238A and LTA NcoI A252G variant alleles and clinical outcome in sarcoidosis. In addition, the linkage between TNF- $a$ G-308A and HLA-DRB $1 * 03$ and its influence on disease course in our population was studied.

\section{Materials and methods}

\section{Patients}

From January 2000 to July 2008, 625 consecutive Dutch Caucasian sarcoidosis patients, attending the outpatient referral clinic of the Sarcoidosis Management Center of the Department of Respiratory Medicine of the Maastricht University Medical Centre (MUMC) were included in this study. The time since diagnosis to inclusion and/or follow-up for all patients was at least two years. The diagnosis was based on a positive biopsy in $71 \%$ of cases. In patients with typical features of Löfgren's syndrome and characteristic features of bronchoalveolar lavage (BAL) fluid analysis results, no biopsy was obtained. This policy is consistent with the World Association of Sarcoidosis and Other Granulomatous diseases (WASOG) guidelines. ${ }^{1}$

The study was performed in accordance with the Declaration of Helsinki and its amendments. The protocol was approved by the Medical Ethics Board of the MUMC. Written informed consent for participation in this study was obtained from all subjects.

\section{Collection of clinical data}

Clinical course of patients with sarcoidosis was defined using changes in CXR stage and lung function parameters during follow-up. All CXR films were graded by a single observer, who was not aware of the clinical data. Five stages of the radiographical abnormality were recognized: stage 0 (normal CXR), stage I (bilateral hilar lymphadenopathy $[\mathrm{BHL}]$ ), stage II (BHL and parenchymal abnormalities), stage III (parenchymal abnormalities without $\mathrm{BHL}$ ) and stage IV (end stage lung fibrosis).

For the main analysis, patients were categorized into groups with and without persistent sarcoidosis. Persistent disease was defined as worsening of the CXR stage to stage II or higher, or remaining at CXR stage II or III, at least two years after diagnosis. Non-persistent disease cases were those who remained at or regressed to stage 0 or $\mathrm{I}$.

At inclusion, the forced vital capacity (FVC) and forced expiratory volume in $1 \mathrm{~s}$ $\left(F_{E V}\right)$ were measured with a pneumotachograph (Masterlab, Jaeger, Würzburg, Germany). The diffusing capacity for carbon monoxide (DLCO) was 
measured by the single-breath method (Masterlab). Values were expressed as a percentage of predicted values. The cut-off value for the DLCO, FEV 1 and FVC was $<80 \%$ of predicted ( $\geq 80 \%$ is normal). ${ }^{19}$

\section{TNF and HLA typing}

\section{TNF}

DNA was obtained using venous EDTA anti-coagulated blood and isolated with a High Pure PCR Template Preparation Kit (Roche Diagnostics, Mannheim, Germany) according to the manufacturer's instructions.

All patients were genotyped for two TNF-a promoter polymorphisms (G-308A and G-238A) and one LTA polymorphism (LTA NCOI A252G, also known as lymphotoxin-a, LTA_NCOI, LTA+252, or TNF- $\beta$ NCOI A329G). ${ }^{20,21}$ For genotyping TNF- $a$ G-308A, TNF- $a$ G-238A and LTA NCOI A252G SNPS, real-time PCR Fluorescence Resonance Energy Transfer (FRET) assays (TIB MOLBIOL, Berlin, Germany) were performed as described by Bestmann et al. ${ }^{20}$ on the LightCycler ${ }^{\circledR}$ (Roche Diagnostics). The person who performed the analyses was blinded to the clinical data that were used for the classification of subjects according to disease course.

\section{HLA}

Genomic DNA was isolated with QIA-AMP kits following the supplier's protocol (Qiagen, Westburg, Leusden, The Netherlands). Concentration and purity of DNA samples were measured at $260 \mathrm{~nm}$ and $260 / 280 \mathrm{~nm}$.

Low-resolution typing of HLA-DRB1 was obtained by Luminex reverse SSO, using bead kits from One Lambda (One Lambda, Bethesda, MD) or by PCR-SSP using 45 in-house primer mixes as described previously. ${ }^{22}$

\section{Statistical analysis}

Statistical analyses were performed with SPSS 15.0 (SPSS Inc., Chicago, IL) for Windows.

Cross tables were used to compare the observed percentages with each genotype between groups of patients differing in prognosis. The chi-square test was used to test for statistical significant differences between groups. Odds ratios (ORs) with 95\% confidence intervals (CIs) were also derived from these tables to evaluate the strength of associations between genotypes and the course of sarcoidosis. Multivariate logistic regression models were used to adjust for differences in baseline characteristics between compared groups. A $\mathrm{p}$-value of $<0.05$ (two sided) was considered to indicate statistical significance. Deviations from the Hardy-Weinberg equilibrium were analysed using the chi-square test. 


\section{Results}

Patient characteristics of the studied total population and within groups of patients with and without persistent sarcoidosis are summarized in Table 7.1. Patients with persistent disease more often were male, smoked less often and were more frequently treated with corticosteroids. At diagnosis, the percentage with CXR stage 0 or I was much lower in patients with persistent disease than in the patients with non-persistent disease. Persistent disease was also associated with lower mean values of DCLO, $\mathrm{FEV}_{1}$ and FVC at diagnosis.

Table 7.1 Patient characteristics for the total population and sorted by disease persistence.

\begin{tabular}{|c|c|c|c|c|c|}
\hline & & $\begin{array}{c}\text { Total population } \\
\quad(n=625)\end{array}$ & $\begin{array}{c}\text { Non-persistent } \\
\quad(n=327)\end{array}$ & $\begin{array}{l}\text { Persistent } \\
(n=298)\end{array}$ & $\begin{array}{c}\mathrm{p}^{\mathrm{a}} \\
\text { value }\end{array}$ \\
\hline \multirow[t]{2}{*}{ Gender } & Female & $280(44.8)$ & $178(54.4)$ & $102(34.2)$ & \\
\hline & Male & $345(55.2)$ & $149(45.6)$ & $196(65.8)$ & $<0.001$ \\
\hline \multirow[t]{4}{*}{ Age at diagnosis } & Year \pm SD & $40.2 \pm 11.7$ & $40.5 \pm 12.6$ & $39.8 \pm 10.6$ & \\
\hline & (range) & $(12-84)$ & $(17-84)$ & $(12-76)$ & \\
\hline & $<40$ year & $353(56.5)$ & $185(56.6)$ & $168(56.4)$ & \\
\hline & $\geq 40$ year & $272(43.5)$ & $142(43.4)$ & $130(43.6)$ & 1.00 \\
\hline \multirow[t]{2}{*}{ Smoking } & No & $556(89.1)$ & $282(86.2)$ & 275 (92.3) & \\
\hline & Yes & 68 (10.9) & 45 (13.8) & $23(7.7)$ & 0.020 \\
\hline \multirow[t]{2}{*}{ Time since diagnosis } & $<5$ year & $154(24.6)$ & $82(25.1)$ & $72(24.2)$ & \\
\hline & $\geq 5$ year & $471(75.4)$ & 245 (74.9) & $226(75.8)$ & 0.78 \\
\hline \multirow[t]{2}{*}{ Corticosteroid use } & No & $281(45.0)$ & $185(56.6)$ & $96(32.2)$ & \\
\hline & Yes & $344(55.0)$ & $142(43.4)$ & $202(67.8)$ & $<0.001$ \\
\hline \multirow[t]{4}{*}{ CXR at diagnosis } & 0 & $59(9.4)$ & $59(18.1)$ & 0 & \\
\hline & I & $188(30.1)$ & $178(54.4)$ & $10(3.4)$ & \\
\hline & II & $244(39.1)$ & 65 (19.9) & $179(60.1)$ & \\
\hline & III & $134(21.4)$ & $25(7.6)$ & 109 (36.5) & $<0.001^{c}$ \\
\hline \multirow[t]{5}{*}{ CXR at follow-up } & 0 & $270(43.2)$ & $270(82.6)$ & 0 & \\
\hline & I & $57(9.1)$ & $57(17.4)$ & 0 & \\
\hline & II & $142(22.7)$ & 0 & $142(47.7)$ & \\
\hline & III & 74 (11.9) & 0 & $74(24.8)$ & \\
\hline & IV & $82(13.1)$ & 0 & $82(27.5)$ & $<0.001^{d}$ \\
\hline \multirow[t]{4}{*}{$\mathrm{DLCO}^{\mathrm{b}}$} & Mean \pm SD & $81.2 \pm 17.3$ & $86.9 \pm 15.1$ & $75.0 \pm 17.5$ & \\
\hline & (range) & (23-129) & $(37-129)$ & $(23-121)$ & \\
\hline & $\geq 80 \%$ & $341(56.0)$ & 228 (71.9) & $113(38.7)$ & \\
\hline & $<80 \%$ & $268(44.0)$ & $89(28.1)$ & 179 (61.3) & $<0.001$ \\
\hline \multirow[t]{4}{*}{$\mathrm{FEV}_{1}^{\mathrm{b}}$} & Mean \pm SD & $89.8 \pm 21.5$ & $99.8 \pm 15.6$ & $78.7 \pm 21.7$ & \\
\hline & (range) & $(23-140)$ & $(54-140)$ & $(23-128)$ & \\
\hline & $\geq 80 \%$ & $439(72.4)$ & $289(91.2)$ & 150 (51.9) & \\
\hline & $<80 \%$ & 167 (27.6) & $28(8.8)$ & $139(48.1)$ & $<0.001$ \\
\hline \multirow[t]{4}{*}{$\mathrm{FVC}^{\mathrm{b}}$} & Mean \pm SD & $98.7 \pm 19.1$ & $106.0 \pm 15.5$ & $90.5 \pm 19.4$ & \\
\hline & (range) & $(25-152)$ & $(66-152)$ & $(25-148)$ & \\
\hline & $\geq 80 \%$ & $509(84.8)$ & $301(95.3)$ & $208(73.2)$ & \\
\hline & $<80 \%$ & $91(15.2)$ & $15(4.7)$ & $76(26.8)$ & $<0.001$ \\
\hline
\end{tabular}

\footnotetext{
${ }^{a}$ Non-persistent versus persistent. ${ }^{\mathrm{b}} \%$ of predicted $\left(<80 \%\right.$ is abnormal). ${ }^{\mathrm{c}} \mathrm{CXR} 0+\mathrm{I}$ versus II+III. ${ }^{d}$ CXR IV versus $0+I+I I+I I I . ~ n=$ number, $S D=$ standard deviation, $C X R=$ chest $X$-ray, DLCO $=$ diffusing capacity of carbon monoxide, $\mathrm{FEV}_{1}=$ forced expiratory volume in $1 \mathrm{~s}, \mathrm{FVC}=$ forced vital capacity. Missing: 16/19/25 for DLCO/FEV $1 / F V C$, respectively. All values presented are absolute numbers with percentages in parentheses unless otherwise specified.
} 
Table 7.2 shows the distribution of polymorphisms for TNF- $a$ G-308A, TNF- $a$ G-238A, LTA and HLA-DRB1*03 in patients with and without persistent disease. The TNF- $a-308 \mathrm{~A}$ variant allele was more often present in the patients with non-persistent disease $(44.0 \%)$ when compared with patients having persistent disease (25.5\%). This difference was statistically significant $(p<0.001)$. HLA-DRB1*03 was comparable with the TNF- $a$ G-308A with $34.9 \%$ of patients with non-persistent disease being DRB1*03 positive and of the patients with persistent sarcoidosis $13.4 \%$ having DRB1*03, see Table 7.2.

Table 7.2 Genotype distributions for the total population and sorted by disease persistence.

\begin{tabular}{llcccl}
\hline & Genotype & $\begin{array}{c}\text { Total population } \\
(\mathrm{n}=625)\end{array}$ & $\begin{array}{c}\text { Non-persistent } \\
(\mathrm{n}=327)\end{array}$ & $\begin{array}{c}\text { Persistent } \\
(\mathrm{n}=298)\end{array}$ & $\begin{array}{l}\mathrm{p}^{\mathrm{a}} \\
\text { value }\end{array}$ \\
\hline TNF-308 & GG & $405(64.8)$ & $183(56.0)$ & $222(74.5)$ & \\
& GA & $200(32.0)$ & $129(39.4)$ & $71(23.8)$ & $<0.001^{\mathrm{b}}$ \\
& AA & $20(3.2)$ & $15(4.6)$ & $5(1.7)$ & \\
TNF-238 & GG & $562(89.9)$ & $290(88.7)$ & $272(91.3)$ & \\
& GA & $63(10.1)$ & $37(11.3)$ & $26(8.7)$ & $0.29^{\mathrm{b}}$ \\
& AA & 0 & 0 & 0 & \\
LTA & AA & $281(45.0)$ & $130(39.8)$ & $151(50.7)$ & \\
& GG & $279(44.7)$ & $158(48.3)$ & $121(40.6)$ & $0.09^{\mathrm{b}}$ \\
& GG & $65(10.3)$ & $39(11.9)$ & $26(8.7)$ & \\
DRB1 $*$ 03 & Neg & $471(75.4)$ & $213(65.1)$ & $258(86.6)$ & \\
& PoS & $154(24.6)$ & $114(34.9)$ & $40(13.4)$ & $<0.001$ \\
\hline
\end{tabular}

${ }^{a}$ Non-persistent versus persistent. ${ }^{b}$ No variant allele versus variant allele. TNF-308 $=T N F-a$ G-308A, TNF-238=TNF- $a$ G-238A, LTA=LTA NCOI A252G, DRB1*03=HLA-DRB1*03, GG=wild type for TNF-308 and TNF-238, for LTA wild type=AA. All values presented are absolute numbers with percentages in parentheses unless otherwise specified.

For TNF- $a$ G-238A and LTA there were no statistically significant differences in the distribution of genotypes between the groups with and without persistent disease; therefore, these polymorphisms were not used for further analysis. However, for the LTA there was a trend towards a higher G-allele percentage in the group with non-persistent disease (60.2\%) compared with the group with a persistent course (49.3\%).

In Table 7.3, patients were classified according to genotype distribution and next to persistent versus non-persistent disease outcome or HLA-DRB1*03 presence, alternative clinical parameters for clinical course, such as CXR stage and lung function test results are shown. Patients with poor prognosis were compared with patients with good prognosis with respect to the distribution of the TNF- $a-308 \mathrm{~A}$ variant allele. Those with CXR stage 0 and lung function parameters $\geq 80 \%$ represented the group with good prognosis and were used as reference. The ORs with $95 \%$ CIs were consistently and in most comparisons significantly lower than 1 , indicating a protective effect of the presence of a TNF- $a-308 \mathrm{~A}$ variant allele. Presence of the TNF- $a-308 \mathrm{~A}$ variant 
allele is associated with good prognosis: in the groups with favorable clinical outcome this allele was observed significantly more often than in the groups with a less favorable clinical outcome. The OR was 0.43 with $95 \% \mathrm{CI}$ : 0.31 0.61 . After adjustment for age, gender, corticosteroid use and smoking, the odds ratio remained the same: $\mathrm{OR}=0.43$ (95\% CI: 0.30-0.61).

Table 7.3 Prognosis by genotype distribution of the TNF- $a$ G-308A variant.

\begin{tabular}{|c|c|c|c|c|c|c|}
\hline & & $\begin{array}{c}\text { GG } \\
(n=405)\end{array}$ & $\begin{array}{c}\mathrm{GA} \\
(\mathrm{n}=200) \\
\end{array}$ & $\begin{array}{c}\text { AA } \\
(n=20)\end{array}$ & $\begin{array}{c}\mathrm{OR}^{\mathrm{a}}(95 \% \mathrm{CI}) \\
\text { carriage }-308 \mathrm{~A}\end{array}$ & $\begin{array}{c}\mathrm{p}^{\mathrm{a}} \\
\text { value }\end{array}$ \\
\hline \multirow[t]{2}{*}{ Persistence } & No & $183(56.0)$ & $129(39.4)$ & $15(4.6)$ & 1 & \\
\hline & Yes & $222(74.5)$ & $71(23.8)$ & $5(1.7)$ & $0.43(0.30-0.61)$ & $<0.001$ \\
\hline \multirow[t]{2}{*}{ DRB1*03 } & Pos & $18(11.7)$ & $118(76.6)$ & $18(11.7)$ & 1 & \\
\hline & $\mathrm{Neg}$ & $387(82.2)$ & $82(17.4)$ & $2(0.4)$ & $0.03(0.02-0.05)$ & $<0.001$ \\
\hline \multirow[t]{5}{*}{ CXR stage } & 0 & $150(55.6)$ & $109(40.4)$ & $11(4.0)$ & 1 & \\
\hline & I & 33 (57.9) & $20(35.1)$ & $4(7.0)$ & $0.91(0.51-1.63)$ & 0.75 \\
\hline & II & $105(74.0)$ & $34(23.9)$ & $3(2.1)$ & $0.45(0.28-0.68)$ & $<0.001$ \\
\hline & III & $47(63.5)$ & $25(33.8)$ & $2(2.7)$ & $0.72(0.41-1.23)$ & 0.23 \\
\hline & IV & $70(85.4)$ & $12(14.6)$ & 0 & $0.19(0.09-0.38)$ & $<0.001$ \\
\hline \multirow[t]{2}{*}{ CXR improving } & No & $286(70.1)$ & $111(27.2)$ & $11(2.7)$ & 1 & \\
\hline & Yes & $11954.8)$ & $89(41.0)$ & $9(4.2)$ & $1.93(1.37-2.72)$ & $<0.001$ \\
\hline \multirow[t]{2}{*}{ CXR stable } & No & $197(63.8)$ & 103 (33.3) & $9(2.9)$ & 1 & \\
\hline & Yes & $208(65.8)$ & $97(30.7)$ & $11(3.5)$ & $0.91(0.66-1.27)$ & 0.62 \\
\hline \multirow[t]{2}{*}{ CXR worsening } & No & 327 (61.3) & $186(34.9)$ & $20(3.8)$ & 1 & \\
\hline & Yes & $78(84.8)$ & $14(15.2)$ & 0 & $0.28(0.16-0.52)$ & $<0.001$ \\
\hline \multirow[t]{4}{*}{$\mathrm{DLCO}^{\mathrm{b}}$} & Mean \pm SD & $80.3 \pm 17.0$ & $82.2 \pm 18.1$ & $89.2 \pm 14.9$ & & \\
\hline & (range) & $(37-128)$ & $(23-129)$ & $(57-121)$ & & \\
\hline & $\geq 80 \%$ & $208(61.0)$ & $116(34.0)$ & $17(5.0)$ & 1 & \\
\hline & $<80 \%$ & $188(70.2)$ & 77 (28.7) & $3(1.1)$ & $0.68(0.48-0.97)$ & 0.031 \\
\hline \multirow[t]{3}{*}{$\mathrm{FEV}_{1}{ }^{\mathrm{b}}$} & $\begin{array}{l}\text { Mean } \pm S D \\
\text { (range) }\end{array}$ & $\begin{array}{c}87.6 \pm 21.7 \\
(26-140)\end{array}$ & $\begin{array}{c}93.0 \pm 20.9 \\
(23-136)\end{array}$ & $\begin{array}{c}100.4 \pm 16.1 \\
(71-128)\end{array}$ & & \\
\hline & $\geq 80 \%$ & $272(62.0)$ & 149 (33.9) & $18(4.1)$ & 1 & \\
\hline & $<80 \%$ & $122(73.1)$ & $43(25.7)$ & $2(1.2)$ & $0.61(0.40-0.93)$ & 0.020 \\
\hline \multirow[t]{4}{*}{$\mathrm{FVC}^{\mathrm{b}}$} & Mean $\pm S D$ & $97.2 \pm 18.9$ & $100.6 \pm 19.3$ & $109.1 \pm 15.6$ & & \\
\hline & (range) & $(33-152)$ & $(25-147)$ & $(83-148)$ & & \\
\hline & $\geq 80 \%$ & $320(62.9)$ & $170(33.4)$ & 19 (3.7) & 1 & \\
\hline & $<80 \%$ & $69(75.8)$ & $22(24.2)$ & 0 & $0.56(0.33-0.95)$ & 0.031 \\
\hline
\end{tabular}

\footnotetext{
${ }^{a}$ No variant allele versus variant allele. ${ }^{b} \%$ of predicted ( $<80 \%$ is abnormal). $n=$ number, OR=Odds ratio corrected for age, gender, corticosteroid use and smoking, SD=standard deviation, $\mathrm{DRB} 1 * 03=\mathrm{HLA}-\mathrm{DRB} 1 * 03, \mathrm{CXR}=$ chest $\mathrm{X}$-ray, $\mathrm{DLCO}=$ carbon monoxide diffusing capacity, $\mathrm{FEV}_{1}=$ forced expiratory volume in $1 \mathrm{~s}, \mathrm{FVC}=$ forced vital capacity, $-308 \mathrm{~A}=T N F-a-308 \mathrm{~A}$ variant allele, $\mathrm{GG}=$ wild type, $\mathrm{GA}=$ heterozygote, $\mathrm{AA}=$ homozygote variant. Missing: 16/19/25 for DLCO/FEV $1 / F V C$, respectively. All values are absolute numbers with percentages in parentheses unless otherwise specified.
}

The OR for the HLA-DRB $1 * 03$ positive versus negative cases compared with the presence of a TNF- $a-308 \mathrm{~A}$ variant allele was 0.03 (95\% CI: $0.02-0.05$ ) indicating a strong association. 
Table 7.3 also shows an increase in mean values of lung function test result parameters as the number of A-alleles in the TNF- $a$ G-308A genotype increases (e.g. mean \% DCLO GG=80.3 < GA=82.2 < AA=89.2).

In the total population the proportions of patients without or with a TNF-a G-308A variant allele were 64.8\% (GG) and 35.2\% (32.0\% GA and 3.2\% AA), respectively (chi2 $=0.61, p=0.74$ ). These findings were in accordance with the Hardy-Weinberg equilibrium. The observed allele frequencies for all 625 patients were $80.8 \%$ for the TNF- $a$ G-308 and $19.2 \%$ for the TNF- $a-308 \mathrm{~A}$ allele $(p=0.18)$. The frequency distribution is similar to the distribution reported in healthy Dutch controls (75.0\% for the G-allele and $25.0 \%$ for the A-allele) from the literature. ${ }^{23}$

\section{Discussion}

In this study, we observed that the presence of a TNF- $a-308 \mathrm{~A}$ variant allele had a favorable impact on radiologic evolution and prognosis in sarcoidosis. Patients without a TNF- $a-308 \mathrm{~A}$ variant allele had a significantly higher risk of developing persistent sarcoidosis with progression to a higher CXR stage and worsening of lung function, particularly the DLCO and FVC. Furthermore, the existence of a strong linkage disequilibrium between the TNF- $a-308 \mathrm{~A}$ variant allele and the presence of HLA-DRB $1 * 03$ was confirmed.

In our current study, the presence of a TNF- $a-308 \mathrm{~A}$ variant allele was associated with a lower risk of worsening of the disease. No association between the TNF- $a$ G-308A polymorphism and sarcoidosis in general was found as all genotype and allele frequencies of the 625 studied sarcoidosis patients were in Hardy-Weinberg equilibrium, similar to control populations in literature and in concurrence with findings from earlier studies. ${ }^{8,11,23,24}$ In a meta-analysis by Medica et al., it was concluded that the presence of the TNF- $a-308 \mathrm{~A}$ variant allele increased the susceptibility to and risk of sarcoidosis by as much as $47 \%$, and it was suggested that the polymorphism could be involved in the clinical presentation of sarcoidosis. ${ }^{17}$

When sorting the sarcoidosis patients into persistent and non-persistent categories a clear association did emerge between the absence of the TNF- $a$ $-308 \mathrm{~A}$ variant allele and sarcoidosis persistence $(\mathrm{OR}=0.43, \mathrm{p}<0.001)$. In earlier studies, it was found that carriers of the TNF- $a-308 \mathrm{~A}$ variant allele were more prone to go through the more acute form (i.e. Löfgren's syndrome) of sarcoidosis with frequent spontaneous remission. ${ }^{8,9,11}$ This is accordance with our finding that presence of the TNF- $a-308 \mathrm{~A}$ variant allele is more prevalent in the non-persistent group.

Categorizing the patients according alternative parameters for clinical course, instead of grouping them into patients with persistent and non-persistent 
disease, also showed strong associations with the distribution of the TNF- $a$ G-308A genotype. Looking at the results from this perspective revealed that the TNF- $a-308 \mathrm{~A}$ variant allele was absent in the large majority of patients who had evolved to CXR stage IV at the end of follow-up $(O R=0.19, p<0.001)$. Previous studies are hard to compare with our data as not only sample size and characteristics of the participants (ethnicity) displayed significant heterogeneity, but sarcoidosis patients were almost always only categorized into Löfgren and non-Löfgren patients, and not according to the different CXR stages. Therefore, previously no conclusions could be drawn about associations or differences in genotype distribution between the various CXR stages. ${ }^{6,8,11}$ The categorization according to alternative parameters of clinical outcome also showed that the mean lung function test results were worse in the wild type (TNF-308 GG) category (Table 7.3). The finding that presence of the variant A-allele is strongly and consistently associated with a more favorable prognosis, irrespective of the definition of good prognosis, lends support to the validity of this association. Moreover, the large sample size in this study also makes it very unlikely that the findings are due to chance.

When examining the selected TNF polymorphisms, only the TNF- $a$ G-308A SNP showed significant association with disease progression. The TNF- $a$ G-238A polymorphism did not show a different distribution for the non-persistent and persistent disease groups. In accordance to others, we observed that presence of the LTA NCOI 252G variant allele only tended to be higher in patients who did not progress, ruling it out as a prognostic factor. ${ }^{25}$ In a Japanese population, however, as studied by Yamaguchi et al., the A-allele of the LTA NcoI A252G polymorphism was found to be a marker for prolonged clinical course. ${ }^{26}$ This is an important reminder of the fact that populations of different ethnicity, as in this case Japanese versus Caucasian, can display different associations to the same polymorphisms. However, in line with Mrazek et al., we also found a slight increased but not statistically significant LTA NCOI 252G variant allele presence (34.6\%; chi2 $=1.52, p=0.22$ ) in CXR stage I at diagnosis compared with CXR stages 0 , II and III. ${ }^{7}$

In the current study, it was also found that smoking appeared to protect against progressing to persistent sarcoidosis, for fewer smokers were present in the persistent disease group. This was in accordance with findings from earlier studies. ${ }^{27-30}$

Interestingly, in our population, men more often showed progression to persistent sarcoidosis. It is tempting to speculate that this might be explained by the fact that males were more frequently exposed to occupational and/or environmental antigenic triggers than females $(67.4 \%$ versus $31.2 \%$, respectively). It is known that these triggers, beside genetic factors, are involved in the pathogenic concept of sarcoidosis. ${ }^{3,31,32}$ 
The frequency of use of systemic corticosteroids was higher in patients with persistent disease and may be a confounder for clinical course. However, after adjustment for differences in baseline characteristics between the groups with persistent and non-persistent disease using multivariate logistic regression, the OR associated with the presence of the TNF- $a-308 \mathrm{~A}$ variant allele did not change and was still indicative of a halving of the risk of persistent disease.

In the clinical management of sarcoidosis patients, it is important to identify those cases that might have a chance to develop a more severe manifestation of sarcoidosis. In those particular cases, treatment aimed at avoiding irreversible damage should be started early. ${ }^{33}$ Corticosteroids are still the first drug of choice to treat sarcoidosis in most cases, but it is well known that longterm use is associated with significant toxicity. ${ }^{33}$ Since a few years anti-TNF-a agents are being used more frequently, especially in chronic cases. ${ }^{10,34}$ Failure of patient response to conventional therapy or the presence of unacceptable side effects from other available drugs, especially prednisone, constitute the most common reasons for prescribing an anti-TNF-a agent for sarcoidosis. ${ }^{34}$ When considering anti-TNF-a treatment it can be very important to have information that might be helpful in predicting whether a patient will be a responder or non-responder. Studies into responders and non-responders to anti-TNF-a therapy have been carried out, e.g. in rheumatoid arthritis (RA) patients by Mugnier et al. ${ }^{35}$ They found that patients without a TNF- $a$ G-308A allelic variant were the overall better responders. As shown in the present study, patients without a TNF- $a-308 \mathrm{~A}$ variant allele were also more prone to develop the persistent form of sarcoidosis. Interestingly, in the infliximab trial by Baughman et al., it was found that the patients with a more severe or longer duration of (i.e. persistent) pulmonary disease including reduced FVC, severe dyspnoea as well as a more impaired quality of life were more likely to respond to anti-TNF-a treatment. ${ }^{36}$ This might suggest that they were most likely cases without a variant allele. In accordance to experiences with RA patients, it seems to be practical and helpful to monitor sarcoidosis patients without a TNF- $a$ G-308A allelic variant early and initiate treatment accordingly. So it appears that one simple and less expensive SNP test prior to treatment could not only render very useful information about progression. Given that this was beyond the scope of this study, future study should evaluate whether a single SNP test (TNF- $a$ G-308A) might also be helpful in deciding to start antiTNF-a treatment or not. Moreover, when anti-TNF-a treatment is considered genotyping TNF- $a$ G-308A may be a useful tool to differentiate between responders and non-responders of anti-TNF-a treatment in sarcoidosis. 


\section{Conclusion}

Our results clearly show that genotyping for the TNF- $a$ G-308A polymorphism is helpful in predicting prognosis in sarcoidosis patients. The risk of progressing to a more severe pulmonary involvement is higher in the absence of a TNF-a G-308A allelic variant and HLA-DRB1*03. Because of the strong linkage between TNF- $a$ G-308A and HLA-DRB1*03 genotyping of one simple TNF- $a$ SNP is useful in predicting the prognosis of pulmonary sarcoidosis. The findings in this study can be used as a base for further clinical validation of the use of TNF- $a$ G-308A genotyping to predict the clinical course of sarcoidosis in individual patients. Research must continue to depict the role of TNF genes in the immunogenetics and clinical management of sarcoidosis. 


\section{References}

1. Statement on sarcoidosis. Joint Statement of the American Thoracic Society (ATS), the European Respiratory Society (ERS) and the World Association of Sarcoidosis and Other Granulomatous Disorders (WASOG) adopted by the ATS Board of Directors and by the ERS Executive Committee, February 1999. Am J Respir Crit Care Med. 1999;160:736-55.

2. Moller DR, Chen ES. Genetic basis of remitting sarcoidosis: triumph of the trimolecular complex? Am J Respir Cell Mol Biol. 2002;27:391-5.

3. Iannuzzi MC, Rybicki BA, Teirstein AS. Sarcoidosis. N Engl J Med. 2007;357: 2153-65.

4. Thomas KW, Hunninghake GW. Sarcoidosis. JAMA. 2003;289:3300-3.

5. Neville E, Walker AN, James DG. Prognostic factors predicting the outcome of sarcoidosis: an analysis of 818 patients. Q J Med. 1983;52:525-33.

6. Grunewald J, Eklund A, Olerup O. Human leukocyte antigen class I alleles and the disease course in sarcoidosis patients. Am J Respir Crit Care Med. 2004;169: 696-702.

7. Mrazek F, Holla LI, Hutyrova B, Znojil V, Vasku A, Kolek V, Welsh KI, Vacha J, du Bois RM, Petrek M. Association of tumour necrosis factor-alpha, lymphotoxin-alpha and HLA-DRB1 gene polymorphisms with Lofgren's syndrome in Czech patients with sarcoidosis. Tissue Antigens. 2005;65:163-71.

8. Grutters JC, Sato H, Pantelidis P, Lagan AL, McGrath DS, Lammers JW, van den Bosch JM, Wells AU, du Bois RM, Welsh KI. Increased frequency of the uncommon tumor necrosis factor $-857 \mathrm{~T}$ allele in British and Dutch patients with sarcoidosis. Am J Respir Crit Care Med. 2002;165:1119-24.

9. Swider C, Schnittger L, Bogunia-Kubik K, Gerdes J, Flad H, Lange A, Seitzer U. TNFalpha and HLA-DR genotyping as potential prognostic markers in pulmonary sarcoidosis. Eur Cytokine Netw. 1999;10:143-6.

10. Baughman RP, Costabel U, du Bois RM. Treatment of sarcoidosis. Clin Chest Med. 2008;29:533-48.

11. Seitzer U, Swider C, Stuber F, Suchnicki K, Lange A, Richter E, Zabel P, MullerQuernheim J, Flad HD, Gerdes J. Tumour necrosis factor alpha promoter gene polymorphism in sarcoidosis. Cytokine. 1997;9:787-90.

12. Voorter CE, Drent M, van den Berg-Loonen EM. Severe pulmonary sarcoidosis is strongly associated with the haplotype HLA-DQB1*0602-DRB1*150101. Hum Immunol. 2005;66:826-35.

13. Bendtzen K, Morling N, Fomsgaard A, Svenson M, Jakobsen B, Odum N, Svejgaard A. Association between HLA-DR2 and production of tumour necrosis factor alpha and interleukin 1 by mononuclear cells activated by lipopolysaccharide. Scand $J$ Immunol. 1988;28:599-606.

14. Seitzer U, Gerdes J, Muller-Quernheim J. Genotyping in the MHC locus: potential for defining predictive markers in sarcoidosis. Respir Res. 2002;3:6.

15. Iannuzzi MC. Advances in the genetics of sarcoidosis. Proc Am Thorac Soc. 2007;4:457-60.

16. Sharma OP. Tumor necrosis factor polymorphism in sarcoidosis. Chest. 2001;119:678-9.

17. Medica I, Kastrin A, Maver A, Peterlin B. Role of genetic polymorphisms in ACE and TNF-alpha gene in sarcoidosis: a meta-analysis. J Hum Genet. 2007;52:836-47.

18. Chinoy H, Salway F, John S, Fertig N, Tait BD, Oddis CV, Ollier WE, Cooper RG. Tumour necrosis factor-alpha single nucleotide polymorphisms are not independent of HLA class I in UK Caucasians with adult onset idiopathic inflammatory myopathies. Rheumatology (Oxford). 2007;46:1411-6. 
19. Quanjer PH, Tammeling GJ, Cotes JE, Pedersen OF, Peslin R, Yernault JC. Lung volumes and forced ventilatory flows. Report Working Party Standardization of Lung Function Tests, European Community for Steel and Coal. Official Statement of the European Respiratory Society. Eur Respir J Suppl. 1993;16:5-40.

20. Bestmann L, Helmy N, Garofalo F, Demirtas A, Vonderschmitt D, Maly FE. LightCycler PCR for the Polymorphisms -308 and -238 in the TNF Alpha Gene and for the TNFB1/B2 Polymorphisms in the LT Alpha Gene. In: Dietmaier W, Wittwer C, Sivasubramanian N, editors. Rapid Cycle Real-Time PCR - Methods and Applications Genetics and Oncology. Berlin: Springer-Verlag; 2002. p. 95-105.

21. Castro-Giner $F$, Kogevinas $M$, Machler $M$, de Cid $R$, Van Steen $K$, Imboden $M$, Schindler C, Berger W, Gonzalez JR, Franklin KA, Janson C, Jarvis D, Omenaas E, Burney P, Rochat T, Estivill X, Anto JM, Wjst M, Probst-Hensch NM. TNFA -308G>A in two international population-based cohorts and risk of asthma. Eur Respir $\mathrm{J}$. 2008;32:350-61.

22. Voorter CE, Rozemuller EH, de Bruyn-Geraets D, van der Zwan AW, Tilanus MG, van den Berg-Loonen EM. Comparison of DRB sequence-based typing using different strategies. Tissue Antigens. 1997;49:471-6.

23. Bouma G, Xia B, Crusius JB, Bioque G, Koutroubakis I, Von Blomberg BM, Meuwissen SG, Pena AS. Distribution of four polymorphisms in the tumour necrosis factor (TNF) genes in patients with inflammatory bowel disease (IBD). Clin Exp Immunol. 1996;103:391-6.

24. Schaaf BM, Seitzer U, Pravica V, Aries SP, Zabel P. Tumor necrosis factor-alpha -308 promoter gene polymorphism and increased tumor necrosis factor serum bioactivity in farmer's lung patients. Am J Respir Crit Care Med. 2001;163:379-82.

25. Sharma S, Ghosh B, Sharma SK. Association of TNF polymorphisms with sarcoidosis, its prognosis and tumour necrosis factor (TNF)-alpha levels in Asian Indians. Clin Exp Immunol. 2008;151:251-9.

26. Yamaguchi $E$, Itoh A, Hizawa N, Kawakami $Y$. The gene polymorphism of tumor necrosis factor-beta, but not that of tumor necrosis factor-alpha, is associated with the prognosis of sarcoidosis. Chest. 2001;119:753-61.

27. Hance AJ, Basset F, Saumon G, Danel C, Valeyre D, Battesti JP, Chretien J, Georges R. Smoking and interstitial lung disease. The effect of cigarette smoking on the incidence of pulmonary histiocytosis $\mathrm{X}$ and sarcoidosis. Ann $N$ Y Acad Sci. 1986;465:643-56.

28. Maier LA. Is smoking beneficial for granulomatous lung diseases? Am J Respir Crit Care Med. 2004;169:893-5.

29. Blanchet MR, Israel-Assayag E, Cormier Y. Inhibitory effect of nicotine on experimental hypersensitivity pneumonitis in vivo and in vitro. Am J Respir Crit Care Med. 2004;169:903-9.

30. Valeyre D, Soler P, Clerici C, Pre J, Battesti JP, Georges R, Hance AJ. Smoking and pulmonary sarcoidosis: effect of cigarette smoking on prevalence, clinical manifestations, alveolitis, and evolution of the disease. Thorax. 1988;43:516-24.

31. Drent M, Bomans PH, Van Suylen RJ, Lamers RJ, Bast A, Wouters EF. Association of man-made mineral fibre exposure and sarcoidlike granulomas. Respir Med. 2000;94:815-20.

32. Barnard J, Rose C, Newman L, Canner M, Martyny J, McCammon C, Bresnitz E, Rossman M, Thompson B, Rybicki B, Weinberger SE, Moller DR, McLennan G, Hunninghake G, DePalo L, Baughman RP, Iannuzzi MC, Judson MA, Knatterud GL, Teirstein AS, Yeager $H$, Jr., Johns $C$ J, Rabin DL, Cherniack R. Job and industry classifications associated with sarcoidosis in A Case-Control Etiologic Study of Sarcoidosis (ACCESS). J Occup Environ Med. 2005;47:226-34.

33. Baughman RP. Pulmonary sarcoidosis. Clin Chest Med. 2004;25:521-30, vi.

34. Baughman RP, Lower EE, Drent M. Inhibitors of tumor necrosis factor (TNF) in sarcoidosis: who, what, and how to use them. Sarcoidosis Vasc Diffuse Lung Dis. 2008;25:76-89. 
35. Mugnier B, Balandraud N, Darque A, Roudier C, Roudier J, Reviron D. Polymorphism at position -308 of the tumor necrosis factor alpha gene influences outcome of infliximab therapy in rheumatoid arthritis. Arthritis Rheum. 2003;48:1849-52.

36. Baughman RP, Drent M, Kavuru M, Judson MA, Costabel $U$, du Bois R, Albera C, Brutsche M, Davis G, Donohue JF, Muller-Quernheim J, Schlenker-Herceg R, Flavin $\mathrm{S}$, Lo $\mathrm{KH}$, Oemar B, Barnathan ES. Infliximab therapy in patients with chronic sarcoidosis and pulmonary involvement. Am J Respir Crit Care Med. 2006;174: 795-802. 



\section{Chapter 8}

\section{Butyrophilin-like 2 in pulmonary}

sarcoidosis: a factor for susceptibility

and progression?

P Wijnen, C Voorter, P Nelemans, J Verschakelen, O Bekers, M Drent

Hum Immunol. 2011; accepted. 


\section{Abstract}

\section{Background}

The aims of this study were to assess the association of BTNL2 G16071A with the course of pulmonary sarcoidosis and verify association with disease predisposition. In addition, the linkage between BTNL2 G16071A and certain HLA-DRB1/DQB1 types was investigated.

\section{Methods}

In a retrospective case-control study BTNL2 G16071A, HLA-DQB1 and DRB1 were typed in 632 sarcoidosis patients. These patients were classified into 304 patients with persistent and 328 patients with non-persistent sarcoidosis.

\section{Results}

The BTNL2 16071A variant allele was significantly more often present in patients with persistent disease $(92.4 \% ; 281 / 304)$ compared with patients demonstrating a nonpersistent course $(86.6 \% ; 284 / 328)$; odds ratio $(O R)=1.89$ with $95 \%$ confidence interval (CI 95\%): 1.11-3.22.

Furthermore, BTNL2 16071A variant allele carriers have an increased risk (OR=1.85, CI 95\%: 1.19-2.88) to develop sarcoidosis. Moreover, the strong linkage between variant allele and HLA-DRB1*15 presence (OR=8.43, CI 95\%: 3.02-23.5) was confirmed.

\section{Conclusion}

The presence of a BTNL2 G16071A variant allele almost doubles the risk of progressing to persistent pulmonary sarcoidosis, besides increasing the risk to develop sarcoidosis. Presumably, these increased risks are due to the strong linkage between BTNL2 G16071A and DRB1*15. The choice between determining BTNL2 G16071A SNP or the HLA-DRB1 type depends on the ability and/or availability to perform either test. 


\section{Introduction}

Sarcoidosis is a multisystem granulomatous disorder of which clinical presentation and outcome vary considerably. ${ }^{1-3}$ The assumption that genes contribute to the etiology of sarcoidosis comes from the observation that prevalence and incidence rates of sarcoidosis are different between ethnic groups and that the disease tends to cluster in families. Next to family clustering, disease clustering in time and place, often with co-workers, was also noted. ${ }^{4}$ Therefore, shared common environmental exposures must be considered as well. However, the etiology may not prove to be a single, known exposure, and the confirmation of interactions of exposure with genetic predispositions would have important implications for the understanding of immune responses as well as the pathogenesis of sarcoidosis. ${ }^{4}$

In previous studies the association between single nucleotide polymorphisms (SNPs) in the butyrophilin-like 2 (BTNL2) gene and the risk to develop sarcoidosis has been shown. ${ }^{5-8}$ The BTNL2 G16071A (rs2076530) polymorphism showed the strongest association with sarcoidosis. ${ }^{6}$ Arnett et al. found that the functional BTNL2 reduces proliferation and cytokine production from activated T-cells, suggesting a role for BTNL2 as a negative costimulatory molecule with implications for inflammatory disease. ${ }^{9}$ The A-allele of the BTNL2 G16071A polymorphism causes a premature truncation of the protein, disrupting insertion in the cell membrane, a necessary process for downregulating activated T-cells (Th1). ${ }^{5,10}$ The truncated protein increases the risk of developing sarcoidosis independent of HLA-DRB1 risk alleles. ${ }^{5,6}$ However, a possible association with the prognosis of sarcoidosis was not investigated. Until now an association with chronic sarcoidosis only has been suggested, because of an established strong linkage of the BTNL2 16071A variant allele with HLA-DRB1*15 (DRB1*15). ${ }^{6}$ Association of sarcoidosis and class I and II HLA antigens is well known and several studies established the risk of progression of sarcoidosis and presence or absence of specific HLAtypes. ${ }^{11-15}$ In addition, DRB $1 * 15$ and the DQB $1 * 0602 / D R B 1 * 1501$ haplotype in particular, was associated with more severe sarcoidosis, whereas DRB1*03 has been associated with good prognosis. ${ }^{11,13,16,17}$

Pulmonary disease is the most common manifestation of sarcoidosis and pulmonary symptoms are the most common reason for treatment. ${ }^{1,18}$ Numerous studies have confirmed the utility of chest X-ray (CXR) stages as a prognostic guide. ${ }^{1}$ The presence of hilar adenopathy alone (CXR stage I) is usually associated with good prognosis. ${ }^{1,11,19}$ By contrast, presence of parenchymal infiltrates (CXR stages II-IV) is associated with chronic disease. ${ }^{1,19}$ Spontaneous remissions occur in $55-90 \%$ of patients with stage I, $40-70 \%$ of patients with stage II, $10-20 \%$ of patients with stage III, and in $0 \%$ of patients with stage IV disease. ${ }^{1}$ Because of recognized value, CXR staging 
was used in several studies to categorize sarcoidosis patients into subgroups with different pulmonary manifestations. ${ }^{1,20,21}$

The aims of this study were to assess the association of BTNL2 G16071A with the course of pulmonary sarcoidosis and to verify the association with disease predisposition. In addition, the linkage between BTNL2 G16071A and certain HLA-DRB1/DQB1 types was investigated.

\section{Materials and methods}

\section{Patients}

From January 2000 to July 2008, 632 consecutive Dutch Caucasian sarcoidosis patients, attending the outpatient referral clinic of the ild care center of the Department of Respiratory Medicine of the Maastricht University Medical Centre (MUMC) The Netherlands, were included in this study. Time between diagnosis or inclusion and end of follow-up for all patients was at least two years. Diagnosis was in $71 \%$ of cases based on a positive biopsy (lung, skin, lymph node or liver). In patients with typical features of Löfgren's syndrome and characteristic features of bronchoalveolar lavage (BAL) fluid analysis results (including lymphocytosis), no biopsy was obtained. ${ }^{22,23}$ This policy is consistent with the World Association of Sarcoidosis and Other Granulomatous diseases (WASOG) guidelines. ${ }^{1}$

A control group consisting of 1474 local, healthy, unrelated Dutch Caucasian volunteers, hospital workers, and blood or stem cell donors (age: 48.8 \pm 10.3 (21-86); 48.6\% female) was used for HLA typing. Out of this control group 200 samples were randomly selected and typed for the BTNL2 SNP.

The study was performed in accordance with the Declaration of Helsinki and its amendments. The protocol was approved by the Medical Ethics Board of the MUMC. Written informed consent for participation in this study was obtained from all subjects.

\section{Collection of clinical data}

At inclusion forced vital capacity (FVC) and forced expiratory volume in one second $\left(\mathrm{FEV}_{1}\right)$ were measured with a pneumotachograph (Masterlab, Jaeger, Würzburg, Germany). The diffusing capacity for carbon monoxide (DLCO) was measured by the single-breath method (Masterlab). Values were expressed as a percentage of predicted values. Missing values for DLCO/FEV $1 / F V C$ were $17 / 21 / 26$, respectively. The cut-off value for the DLCO, FEV 1 , and FVC was $<80 \%$ of predicted ( $\geq 80 \%$ is normal). ${ }^{24}$ Respiratory functional impairment (RFI) was defined as DLCO $<80 \%$, FVC $<80 \%$ or FEV $1<80 \%$ (percentage of 
predicted). Patients without RFI were those for whom all three indices were normal $(\geq 80 \%){ }^{25}$

Clinical course of patients with sarcoidosis was defined using changes in CXR stage during follow-up. All CXRs were graded by a single experienced observer, who was not aware of the clinical data. Five stages of radiographical abnormality were recognized: stage 0 (normal CXR), stage I (bilateral hilar lymphadenopathy $[\mathrm{BHL}]$ ), stage II (BHL and parenchymal abnormalities), stage III (parenchymal abnormalities without $\mathrm{BHL}$ ), and stage IV (end stage lung fibrosis).

For the analysis with respect to prognosis, patients were categorized into groups with persistent and non-persistent sarcoidosis. Persistent disease was defined as worsening of the CXR stage to stage II or higher, or remaining at CXR stage II or III, at least two years after diagnosis. Non-persistent disease cases were those who remained at or regressed to stage 0 or I.

In addition to the categorization into persistent/non-persistent sarcoidosis, CXR stages were used combined with lung function test results to classify the patients into groups with and without progressive disease. No progression was defined as remaining at stage 0 , I, II or III or regressing to stage 0 or I. Progression was defined as worsening of the CXR stage or remaining at stage I, II or III in combination with RFI.

\section{BTNL2 and HLA typing}

\section{DNA isolation}

DNA was obtained using venous EDTA or heparin anti-coagulated blood and isolated with a High Pure PCR Template Preparation Kit (Roche Diagnostics, Mannheim, Germany), or with QIA-AMP kits (Qiagen, Westburg, Leusden, The Netherlands) according to the manufacturer's instructions.

\section{BTNL2}

Patients and controls were genotyped for the BTNL2 G16071A (rs2076530) polymorphism using a real-time PCR Fluorescence Resonance Energy Transfer (FRET) assay (TIB MOLBIOL, Berlin, Germany) on the LightCycler ${ }^{\circledR}$ (Roche Diagnostics).

\section{HLA}

Low resolution typing of HLA-DRB1 and DQB1 was obtained by Luminex reverse SSO, using bead kits from One Lambda (One Lambda, Bethesda, USA) or by PCR-SSP, using 45 in-house primer mixes as described previously. ${ }^{26}$ High resolution typing of DRB1 and DQB1 was obtained by sequencing exon 2 and if needed exon 3, as previously described. ${ }^{26,27}$ Either solid phase 
sequencing was used as described, ${ }^{27,28}$ or cycle sequencing was performed using Big Dye Terminator Cycle Sequencing kit (Applied Biosystems, Foster City, USA). In cases of ambiguous typing, allele specific sequencing was performed, using suitable allele specific amplification primers in combination with adjusted sequencing primers as described. ${ }^{13}$

\section{Statistical analysis}

The chi-square test was used to test for statistical significant differences between groups. Odds ratios (OR) with 95\% confidence intervals (CI) were derived from cross tables to evaluate strength of associations. Multivariate logistic regression models were used to adjust for differences in baseline characteristics (sex, smoking, and corticosteroid use) between compared groups. A $p<0.05$ (two sided) was considered to indicate statistical significance. Deviations from the Hardy-Weinberg equilibrium were analysed using the chi-square test. Statistical analyses were performed with SPSS 15.0 (SPSS Inc., Chicago, USA) for Windows.

\section{Results}

Patient characteristics of the total sarcoidosis population and of the subgroups with persistent and non-persistent sarcoidosis are summarized in Table 8.1. Patients with persistent disease more often were male, smoked less often and were more frequently treated with corticosteroids. At the time of diagnosis, the percentage with CXR stage 0 or I was much lower in patients with persistent disease than in the patients with non-persistent disease. Persistent disease was also associated with lower mean values of DCLO, FEV 1 and FVC at diagnosis.

In Table 8.2 an overview of BTNL2 G16071A allele and HLA-DRB1*15 phenotype frequencies found in our entire sarcoidosis patient group $(n=632)$ and in sarcoidosis patients with persistent and non-persistent disease is shown. The local healthy Dutch Caucasian control population $(n=1474$ for HLA and $\mathrm{n}=200$ randomly selected out of the total 1474 for BTNL2 G16071A establishing that our 'local' healthy population did not differ from historic controls from literature with the same ethnicity regarding the BTNL2), and several patient and control populations taken from the literature, are also listed for comparison. 
Table 8.1 Patient characteristics for the total sarcoidosis population and sorted by disease persistence.

\begin{tabular}{|c|c|c|c|c|c|}
\hline & & $\begin{array}{c}\text { Total population } \\
\mathrm{n}=632 \\
\end{array}$ & $\begin{array}{c}\text { Non-persistent } \\
\mathrm{n}=328 \\
\end{array}$ & $\begin{array}{c}\text { Persistent } \\
\mathrm{n}=304\end{array}$ & $\begin{array}{c}\mathrm{p}^{\mathrm{a}} \\
\text { value }\end{array}$ \\
\hline \multirow[t]{2}{*}{ gender } & female & $283(44.8)$ & $177(54.0)$ & $106(34.9)$ & \\
\hline & male & $349(55.2)$ & $151(46.0)$ & $198(65.1)$ & $<0.001$ \\
\hline \multirow[t]{3}{*}{ age at diagnosis } & $\mathrm{yr} \pm \mathrm{SD}$ (range) & $40.2 \pm 11.7(12-84)$ & $40.5 \pm 12.6(17-84)$ & $39.9 \pm 10.7(12-76)$ & \\
\hline & $<40 \mathrm{yr}$ & $356(56.3)$ & $185(56.4)$ & $171(56.2)$ & \\
\hline & $\geq 40 \mathrm{yr}$ & $276(43.7)$ & $143(43.6)$ & $133(43.8)$ & NS \\
\hline \multirow[t]{2}{*}{ smoking } & no & $562(88.9)$ & $283(86.3)$ & $279(91.8)$ & \\
\hline & yes & $70(11.1)$ & $45(13.7)$ & $25(8.2)$ & 0.03 \\
\hline \multirow[t]{2}{*}{ corticosteroid use } & no & $285(45.1)$ & $187(57.0)$ & $98(32.2)$ & \\
\hline & yes & 347 (54.9) & $141(43.0)$ & $206(67.8)$ & $<0.001$ \\
\hline \multirow[t]{4}{*}{ CXR at diagnosis } & 0 & $66(10.4)$ & $66(20.1)$ & 0 & \\
\hline & I & $186(29.4)$ & $172(52.5)$ & $14(4.6)$ & \\
\hline & II & $245(38.8)$ & $66(20.1)$ & 179 (58.9) & \\
\hline & III & $135(21.4)$ & $24(7.3)$ & $111(36.5)$ & $<0.001^{\text {b }}$ \\
\hline \multirow[t]{5}{*}{ CXR at follow-up } & 0 & $282(44.6)$ & $282(86.0)$ & 0 & \\
\hline & I & $46(7.3)$ & $46(14.0)$ & 0 & \\
\hline & II & $141(22.3)$ & 0 & $141(46.4)$ & \\
\hline & III & $76(12.0)$ & 0 & $76(25.0)$ & \\
\hline & IV & $87(13.8)$ & 0 & $87(28.6)$ & $<0.001^{\mathrm{c}}$ \\
\hline \multirow[t]{3}{*}{$\mathrm{DLCO}^{\mathrm{d}}$} & mean $\pm \mathrm{SD}$ (range) & $81.4 \pm 17.3(23-129)$ & $87.0 \pm 15.0(37-129)$ & $75.4 \pm 17.5(23-121)$ & \\
\hline & $\geq 80 \%$ & $353(57.4)$ & $235(73.9)$ & $118(39.7)$ & \\
\hline & $<80 \%$ & $262(42.6)$ & $83(26.1)$ & $179(60.3)$ & $<0.001$ \\
\hline \multirow[t]{3}{*}{$\mathrm{FEV}_{1}{ }^{\mathrm{d}}$} & mean $\pm S D$ (range) & $90.2 \pm 21.5(23-140)$ & $100.5 \pm 15.3(54-140)$ & $79.0 \pm 21.8(23-128)$ & \\
\hline & $\geq 80 \%$ & $448(73.3)$ & $294(92.5)$ & $154(52.6)$ & \\
\hline & $<80 \%$ & $163(26.7)$ & $24(7.5)$ & $139(47.4)$ & $<0.001$ \\
\hline \multirow[t]{3}{*}{$\mathrm{FVC}^{\mathrm{d}}$} & mean $\pm \mathrm{SD}$ (range) & $99.0 \pm 19.1(25-152)$ & $106.6 \pm 15.3(66-152)$ & $90.7 \pm 19.4(25-148)$ & \\
\hline & $\geq 80 \%$ & $516(85.1)$ & $303(95.6)$ & $213(73.7)$ & \\
\hline & $<80 \%$ & $90(14.9)$ & $14(4.4)$ & $76(26.3)$ & $<0.001$ \\
\hline
\end{tabular}

a non-persistent versus persistent. ${ }^{\mathrm{b}}$ CXR $0+\mathrm{I}$ versus II+III. ${ }^{\mathrm{c}}$ CXR IV versus $0+\mathrm{I}+\mathrm{II}+\mathrm{III} .{ }^{\mathrm{d}} \%$ of predicted $(<80 \%$ is abnormal). $\mathrm{n}=$ number, $\mathrm{yr}=$ years, $\mathrm{NS}=$ not significant, $\mathrm{SD}=$ standard deviation, $\mathrm{CXR}=$ chest $\mathrm{X}$-ray, $\mathrm{DLCO}=$ diffusing capacity of carbon monoxide, $\mathrm{FEV}_{1}=$ forced expiratory volume in one second, $\mathrm{FVC}=$ forced vital capacity. Missing: $17 / 21 / 26$ for $\mathrm{DLCO} / \mathrm{FEV}_{1} / \mathrm{FVC}$, respectively. All values presented are absolute numbers with percentages in parentheses unless otherwise specified.

In the healthy controls the proportions of persons without or with a BTNL2 $16071 \mathrm{~A}$ variant allele were $18.0 \%$ (GG) and $82.0 \%(44.0 \% \mathrm{GA}$ and $38.0 \%$ $A A)$, respectively (chi2 $=1.39, p=0.24$ ). These findings were in accordance with the Hardy-Weinberg equilibrium. 
Table 8.2 Frequencies of BTNL2 G16071A and HLA-DRB1*15 sarcoidosis patients and controls.

\begin{tabular}{lccc}
\hline Population & number & $\begin{array}{c}\text { BTNL2 G-allele } \\
\%\end{array}$ & $\begin{array}{c}\text { BTNL2 A-allele } \\
\%\end{array}$ \\
\hline Sarcoidosis patients & 632 & 33.9 & 66.1 \\
Non-persistent sarcoidosis & 328 & 36.0 & 64.0 \\
Persistent sarcoidosis & 304 & 31.6 & 68.4 \\
UK+Dutch patients $^{45}$ & 288 & 33.2 & 66.8 \\
German patients $^{5}$ & 904 & 31.4 & 68.6 \\
German patients $^{7}$ & 210 & 30.7 & 69.3 \\
Local controls $^{\text {Dutch controls }}{ }^{41}$ & 200 & 40.0 & 60.0 \\
German controls $^{5}$ & 351 & 41.2 & 58.8 \\
German controls $^{7}$ & 427 & 42.7 & 57.3 \\
UK+Dutch controls $^{45}$ & 202 & 38.1 & 61.9 \\
& 446 & 42.6 & 57.4 \\
\hline & & HLA-DRB1*15 neg & HLA-DRB1*15 pos \\
\hline Sarcoidosis patients & & $\%$ & 31.8 \\
Non-persistent sarcoidosis & 632 & 68.2 & 25.9 \\
Persistent sarcoidosis & 328 & 74.1 & 38.2 \\
Local controls $^{40}$ & 304 & 61.8 & 22.9 \\
Dutch controls $^{46}$ & 1474 & 77.1 & 30.9 \\
Dutch controls & 207 & 69.1 & 26.0 \\
Dutch controls & & 74.0 & 23.8 \\
UK controls $^{49}$ & 2400 & 76.2 & 20.9 \\
\hline
\end{tabular}

Table 8.3 shows the distributions of the studied BTNL2 polymorphism and HLA types in healthy controls, the total sarcoidosis population, and subgroups with and without persistent disease or progression. The BTNL2 G16071A polymorphism occurs more frequently in the total sarcoidosis population than in the healthy local controls $(\mathrm{OR}=1.85 ; \mathrm{p}=0.007)$.

The BTNL2 16071A variant allele was more often present in patients with persistent disease when compared with patients having non-persistent disease $(\mathrm{OR}=1.89 ; \mathrm{p}=0.02)$. After multivariate correction for sex, smoking, and corticosteroid use the OR remained similar ( $O R=1.84$, CI 95\%: 1.06-3.21; $p=0.03)$. The ORs for the subgroups no progression and progression were similar to those with and without persistent disease (Table 8.3).

Significant differences with respect to the HLA types DRB1*03 and DRB1*15 (with or without $\mathrm{DQB1} 1 * 06$ ) were also observed. For the DRB1*15 a significantly larger proportion of patients with persistent sarcoidosis was positive, $38.2 \%$ versus $25.9 \%$ in the non-persistent group ( $O R=1.76$; $\mathrm{p}=0.001$ ). The presence of DRB1*15 in combination with DQB1*06 (15Q6 haplotype) was also associated with an increased risk of poor prognosis: OR of $1.63(p=0.006)$. From all but 60 patients high resolution typing of the DQB $1 * 06$ allele was available, and presence of the DQB1*0602 allele was 
associated with poor prognosis: $O R=2.36, C I$ 95\%: 1.59-3.49; $p<0.001$ (data not shown).

Table 8.3 Distributions for the controls, total sarcoidosis population, and sorted by disease persistence.

\begin{tabular}{|c|c|c|c|c|c|c|c|c|c|}
\hline & Type & Controls & $\begin{array}{l}\text { Total } \\
\text { population }\end{array}$ & Odds ratio & & $\begin{array}{l}\text { Non- } \\
\text { persistent }\end{array}$ & Persistent & Odds ratio & \\
\hline & & $n=200 / 1474^{c}$ & $n=632$ & (range) & value & $\mathrm{n}=328$ & $n=304$ & (range) & value \\
\hline \multirow[t]{3}{*}{ BTNL 71} & GG & $36(18.0)$ & $67(10.6)$ & & & $44(13.4)$ & $23(7.6)$ & & \\
\hline & GA & $88(44.0)$ & $294(46.5)$ & $1.85(1.19-2.88)$ & $0.007^{d}$ & $148(45.1)$ & $146(48.0)$ & $1.89(1.11-3.22)$ & $0.02^{d}$ \\
\hline & AA & $76(38.0)$ & $271(42.9)$ & & & $136(41.5)$ & $135(44.4)$ & & \\
\hline \multirow[t]{2}{*}{ DRB $1 * 03$} & neg & $1140(77.3)$ & $476(75.3)$ & & & $215(65.5)$ & $261(85.9)$ & & \\
\hline & pos & $334(22.7)$ & $156(24.7)$ & $0.89(0.72-1.11)$ & NS & $113(34.5)$ & $43(14.1)$ & $0.31(0.21-0.46)$ & $<0.001$ \\
\hline \multirow[t]{2}{*}{ DRB $1 * 15$} & neg & $1136(77.1)$ & $431(68.2)$ & & & $243(74.1)$ & $188(61.8)$ & & \\
\hline & pos & $338(22.9)$ & $201(31.8)$ & $1.57(1.27-1.93)$ & $<0.001$ & $85(25.9)$ & $116(38.2)$ & $1.76(1.26-2.47)$ & 0.001 \\
\hline \multirow[t]{2}{*}{ 15Q6 } & neg & $1145(77.7)$ & $441(69.8)$ & & & $245(74.7)$ & $196(64.5)$ & & \\
\hline & pos & $329(22.3)$ & $191(30.2)$ & $1.51(1.22-1.86)$ & $<0.001$ & $83(25.3)$ & $108(35.5)$ & $1.63(1.16-2.29)$ & 0.006 \\
\hline
\end{tabular}

a controls versus total population. b non-persistent versus persistent. c 200 healthy, unrelated, Dutch Caucasian volunteers for the BTNL2 and 1474 for the HLA typing. ${ }^{d}$ no variant allele versus variant allele. NS=not significant, BTNL 71=BTNL2 G16071A (rs2076530), DRB1*03=HLA-DRB1*03, DRB1*15=HLA-DRB1*15, 15Q6=HLA-DQB1*06/ DRB1*15 haplotype. All values presented are absolute numbers with percentages in parentheses unless otherwise specified.

Within the healthy Dutch Caucasian controls who were DRB $1 * 15$ positive, DQB $1 * 06$ was absent in $0.6 \%(9 / 1474)$. In the DRB1*15 positive sarcoidosis patients with non-persistent disease a comparable percentage without a DQB1*06 $(0.6 \% ; 2 / 328)$ was found, whereas in the subgroup with persistent disease $2.6 \%(8 / 304)$ of the patients possessed a DRB1*15 type without bearing a DQB1*06. Within the DRB1*15 bearing group, DQB1*06 showed a negative association with progressive disease, but due to the small numbers the confidence interval around the odds ratio is very wide. ( $O R=0.18, C I 95 \%$ : $0.02-1.54 ; p=0.14)$. These findings indicate a trend towards an effect of $\mathrm{DRB} 1 * 15$ on the course of sarcoidosis independent of $\mathrm{DQB} 1 * 06$. In contrast to the DRB $1 * 15$ results, the presence of a DRB $1 * 03$ allele was associated with a good prognosis $(\mathrm{OR}=0.31 ; \mathrm{p}<0.001)$.

The presence of DRB1*15 was strongly associated with the presence of a BTNL2 16071A variant allele: $O R=8.43$ (CI 95\%: 3.02-23.5; $p<0.001$ ). Within the subgroup of patients who were positive for the DRB1*15 $(n=201)$ only $2 \%$ $(n=4)$ did not possess a BTNL2 16071A variant allele, compared with $14.6 \%$ $(n=63)$ within the subgroup of DRB1*15 negative patients.

Possessing neither a DRB1*15 nor the BTNL2 G16071A variant allele compared with both the DRB1*15 and a BTNL2 16071A variant allele being present in patients displaying persistent disease, resulted in OR=2.61 (CI 95\%: 1.45$4.72 ; p=0.001$ ) for the DRB1*15/BTNL2 positive haplotype. The OR associated with presence of the BTNL2 G16071A in absence of DRB1*15 for persistence is 
1.53 (CI 95\%: 0.88-2.67; $p=0.17$ ) and this OR indicates that the effect of the BTNL2 is independent of DRB1*15.

The OR obtained for the combined presence of the $15 \mathrm{Q} 6$ haplotype and the BTNL2 16071A variant allele were comparable to the results of the DRB1*15 and BTNL2 16071A variant allele: OR=7.79 (CI 95\%: 2.79-21.7; $p<0.001$ ). The observed association between the presence of DRB1*03 and BTNL2 16071 A-allele presence was in the opposite direction: $\mathrm{OR}=0.08, \mathrm{CI} 95 \%$ : 0.02-0.32; $p<0.001$. Of the subgroup of patients who were positive for the DRB $1 * 03$ $(n=156)$ only $1.3 \%(n=2)$ did not possess a BTNL2 16071A variant allele, compared with $13.7 \%(n=65)$ within the subgroup of DRB1*03 negative patients.

\section{Discussion}

This study is the first that demonstrates that the presence of the BTNL2 $16071 \mathrm{~A}$ variant allele increases the risk of progressing to more severe and persistent pulmonary sarcoidosis. Previously, an association between the presence of the BTNL2 16071A variant allele and a susceptibility towards the chronic form of sarcoidosis was suggested and an increase in A-allele frequency in non-Löfgren patients was observed. ${ }^{7,29}$ However, the A-allele was not considered a risk factor in the progressing of pulmonary sarcoidosis. Furthermore, it is confirmed in accordance with others, that the BTNL2 16071A variant allele presence almost doubles the risk of developing sarcoidosis. In addition, the strong linkage of the BTNL2 G16071A with HLA-DRB1*15 is confirmed. This explains why DRB1*15 bearing also is found to be a risk factor for disease susceptibility as well as for disease course.

It is well known that the outcome of sarcoidosis varies considerably. ${ }^{30}$ Inconsistency exists on how to define severity. The course of sarcoidosis is mainly monitored by assessing clinical features and using auxiliary diagnostic tests. In the past decade, insight has been provided into the genetic risk for sarcoidosis and how the genetic make-up of a patient determines the clinical presentation and outcome. Two more provocative studies in sarcoidosis include the recognition of the $B T N L 2$ gene as a candidate sarcoidosis susceptibility gene $^{5,6}$ and the identification of mycobacterial catalase-peroxidase as a potential sarcoidosis antigen ${ }^{31}$ that drives granuloma formation. ${ }^{32}$ The BTNL2 gene is located close to and in linkage with HLA-DRB1, which in turn is implicated in the etiology of sarcoidosis. ${ }^{21,33-35}$ The BTNL2 G16071A polymorphism in particular has been linked with an increased susceptibility risk for developing sarcoidosis. ${ }^{5-7}$ However, other than the suggestion that susceptibility might be preferential towards the chronic form of sarcoidosis ${ }^{7}$, 
there were no studies done exploring the possibility that BTNL2 G16071A could also be associated with an increased risk of progression. In this study it was found that possessing the A-allele almost doubles (OR=1.89, CI 95\%: 1.113.22 ) the risk of a persistent course of sarcoidosis. When also using lung function test results to categorize the sarcoidosis patients into groups with and without progression the OR remains similar ( $O R=1.75, C I$ 95\%: 1.01-3.04). Next to other progression markers, such as DRB1*03 or DRB1*15 phenotypes $^{11,13,36}$ or the TNF- $a$ G-308A polymorphism ${ }^{14,37,38}$, one could argue that BTNL2 G16071A does not add much. However, especially in families with sarcoidosis patients, this SNP could provide information about the risk of developing sarcoidosis and when present, about the course of the disease. Moreover, as was found in a study by Coudurier et al. examining a family of sarcoidosis patients, the A/A genotype of BTNL2 G16071A can be defined as a putative prognosis and/or predictive factor of recurrent and severe sarcoidosis. ${ }^{8}$ Therefore, genotyping before developing sarcoidosis in persons with a relative with the disease, might give additional information about disease risk and course, and can facilitate disease management. Prospective family-based studies should be performed to confirm this.

In our study the A-allele of the BTNL2 G16071A also appeared to increase the risk of developing sarcoidosis almost twofold, in agreement with results found by Valentonyte et al. ${ }^{5}$ No significant association was established in a study performed on other diseases, despite the fact that these were also Th1 dominated granulomatous diseases similar to sarcoidosis, and a role for MHC class II (HLA-DR/DQ) genes was found in these conditions. ${ }^{35,39-44}$ A possible explanation for the lack of a significant association between BTNL2 and sarcoidosis in general might be the result of differences in the patient and healthy volunteer populations studied. This once again draws the attention to the importance of selection and description of the used populations in genetic association studies. ${ }^{45,46}$ In other studies the association between BTNL2 and HLA-DRB1/DQB1 was found, but because of the strong linkage disequilibrium attributed to HLA-DR/DQ haplotypes. ${ }^{35,47}$ Indeed, several previous studies in other diseases have convincingly and consistently shown association between HLA-DRB1 (more specifically the 15Q6 haplotype or DRB1*15) and disease susceptibility. ${ }^{48-50}$

In the present study, the strong linkage disequilibrium for the association between DRB1*15 and BTNL2 G16071A was confirmed (OR=8.43, CI 95\%: 3.02-23.5). Moreover, of the DRB1*15 bearing sarcoidosis patients only four did not possess a BTNL2 16071A variant allele. Comparing the healthy Dutch Caucasian controls $(n=1474)$ with the total sarcoidosis population $(n=632)$ for the $\mathrm{DRB} 1 * 15$ resulted in a significant difference indicating an increased risk for 
developing sarcoidosis when DRB1*15 positive. In addition, an association between presence of DRB1*15 and persistent sarcoidosis (OR=1.76, CI 95\%: 1.26-2.47) was established. This was in agreement with results from previous studies. $5,6,13$ This indicates that DRB1*15 positivity can be considered as an important factor in both the susceptibility to sarcoidosis and the severity of the disease, comparable with the presence of a BTNL2 16071A variant allele. In addition, the BTNL2 16071A/DRB1*15 positive haplotype increases the risk of a persistent course of pulmonary sarcoidosis almost threefold. However, the possibility remains that due to the strong linkage, other functional variations on this $B T N L 2 / D R B 1 * 15$ haplotype may be the true or additional causal determinants. ${ }^{35}$ Nevertheless, the strong linkage disequilibrium between BTNL2 and HLA-DR/DQ requires that BTNL2 G16071A should be considered relevant to any immune-related disease associated with HLA-DR/DQ. ${ }^{35}$

Previously, an association of the $15 \mathrm{Q} 6$ haplotype with the severity of sarcoidosis was found. ${ }^{13}$ However, because of the rather limited number of patients $(n=156)$ and controls $(n=418)$ and the strong linkage disequilibrium between $\mathrm{DRB} 1 * 15$ and $\mathrm{DQB} 1 * 06$, it could not be concluded whether the association was with either DRB $1 * 15$ or with $\mathrm{DQB} 1 * 06 .{ }^{13}$ In the present study, with an extended number of patients and controls, it was found that the number of DRB1*15 bearing individuals without DQB1*06 was nine out of 1474 for the healthy controls and 10 out of 632 for the patients. Furthermore, it was two out of 328 out of the non-persistent group and eight out of 304 out of the persistent group. Together with a higher OR observed for the DRB $1 * 15$, this implicates that typing for HLA-DRB1 and HLA-DQB1 to ascertain the $15 \mathrm{Q} 6$ haplotype does not give any extra information, and that typing for DRB1 is sufficient.

In conclusion, the presence of a BTNL2 $16071 \mathrm{~A}$ variant allele was found to be associated with an almost twofold increased risk of progressing to more severe and persistent pulmonary sarcoidosis in Caucasians. Furthermore, the predisposition to develop sarcoidosis was confirmed, as well as the strong linkage between the BTNL2 $16071 \mathrm{~A}$ variant allele and DRB1*15 positivity. It also became apparent that typing for DRB1 is sufficient because of the lack of additional information obtained by typing the DQB1*06, to establish the $15 \mathrm{Q} 6$ haplotype. Whether or not to determine the DRB1 type or test the BTNL2 G16071A SNP therefore, depends on the ability and/or availability to perform either test. Additional research will be necessary to explore the role of these findings in the clinical management of sarcoidosis patients. 


\section{References}

1. Statement on sarcoidosis. Joint Statement of the American Thoracic Society (ATS), the European Respiratory Society (ERS) and the World Association of Sarcoidosis and Other Granulomatous Disorders (WASOG) adopted by the ATS Board of Directors and by the ERS Executive Committee, February 1999. Am J Respir Crit Care Med. 1999;160:736-55.

2. Moller DR, Chen ES. Genetic basis of remitting sarcoidosis: triumph of the trimolecular complex? Am J Respir Cell Mol Biol. 2002;27:391-5.

3. Iannuzzi MC. Advances in the genetics of sarcoidosis. Proc Am Thorac Soc. 2007;4:457-60.

4. Design of a case control etiologic study of sarcoidosis (ACCESS). ACCESS Research Group. J Clin Epidemiol. 1999;52:1173-86.

5. Valentonyte R, Hampe J, Huse K, Rosenstiel P, Albrecht M, Stenzel A, Nagy M, Gaede KI, Franke A, Haesler R, Koch A, Lengauer T, Seegert D, Reiling N, Ehlers $S$, Schwinger E, Platzer M, Krawczak M, Muller-Quernheim J, Schurmann M, Schreiber S. Sarcoidosis is associated with a truncating splice site mutation in BTNL2. Nat Genet. 2005;37:357-64.

6. Rybicki BA, Walewski JL, Maliarik MJ, Kian H, Iannuzzi MC. The BTNL2 gene and sarcoidosis susceptibility in African Americans and Whites. Am J Hum Genet. 2005; 77:491-9.

7. Li Y, Wollnik B, Pabst S, Lennarz M, Rohmann E, Gillissen A, Vetter H, Grohe C. BTNL2 gene variant and sarcoidosis. Thorax. 2006;61:273-4.

8. Coudurier M, Freymond N, Aissaoui S, Calender A, Pacheco Y, Devouassoux G. Homozygous variant rs2076530 of BTNL2 and familial sarcoidosis. Sarcoidosis Vasc Diffuse Lung Dis. 2009;26:162-6.

9. Arnett HA, Escobar SS, Gonzalez-Suarez E, Budelsky AL, Steffen LA, Boiani N, Zhang M, Siu G, Brewer AW, Viney JL. BTNL2, a butyrophilin/B7-like molecule, is a negative costimulatory molecule modulated in intestinal inflammation. J Immunol. 2007; 178:1523-33.

10. Nguyen $T$, Liu $X K$, Zhang $Y$, Dong C. BTNL2, a butyrophilin-like molecule that functions to inhibit T cell activation. J Immunol. 2006;176:7354-60.

11. Grunewald J, Eklund A, Olerup O. Human leukocyte antigen class I alleles and the disease course in sarcoidosis patients. Am J Respir Crit Care Med. 2004;169: 696-702.

12. Iannuzzi MC. Genetics of sarcoidosis. Semin Respir Crit Care Med. 2007;28:15-21.

13. Voorter CE, Drent M, van den Berg-Loonen EM. Severe pulmonary sarcoidosis is strongly associated with the haplotype HLA-DQB1*0602-DRB1*150101. Hum Immunol. 2005;66:826-35.

14. Wijnen PA, Nelemans PJ, Verschakelen JA, Bekers O, Voorter CE, Drent M. The role of tumor necrosis factor alpha G-308A polymorphisms in the course of pulmonary sarcoidosis. Tissue Antigens. 2010;75:262-8.

15. Voorter CE, Amicosante M, Berretta F, Groeneveld L, Drent M, van den Berg-Loonen EM. HLA class II amino acid epitopes as susceptibility markers of sarcoidosis. Tissue Antigens. 2007;70:18-27.

16. Morais A, Alves H, Lima B, Delgado L, Goncalves R, Tafulo S. HLA class I and II and TNF-alpha gene polymorphisms in sarcoidosis patients. Rev Port Pneumol. 2008; 14:727-46.

17. Berlin M, Fogdell-Hahn A, Olerup O, Eklund A, Grunewald J. HLA-DR predicts the prognosis in Scandinavian patients with pulmonary sarcoidosis. Am J Respir Crit Care Med. 1997;156:1601-5.

18. Iannuzzi MC, Rybicki BA, Teirstein AS. Sarcoidosis. N Engl J Med. 2007;357: 2153-65. 
19. Neville E, Walker AN, James DG. Prognostic factors predicting the outcome of sarcoidosis: an analysis of 818 patients. Q J Med. 1983;52:525-33.

20. Iannuzzi MC, Maliarik MJ, Poisson LM, Rybicki BA. Sarcoidosis susceptibility and resistance HLA-DQB1 alleles in African Americans. Am J Respir Crit Care Med. 2003; 167:1225-31.

21. Sato H, Grutters JC, Pantelidis P, Mizzon AN, Ahmad T, Van Houte AJ, Lammers JW, Van Den Bosch JM, Welsh KI, Du Bois RM. HLA-DQB1*0201: a marker for good prognosis in British and Dutch patients with sarcoidosis. Am J Respir Cell Mol Biol. 2002;27:406-12.

22. Drent M, Jacobs JA, Cobben NA, Costabel U, Wouters EF, Mulder PG. Computer program supporting the diagnostic accuracy of cellular BALF analysis: a new release. Respir Med. 2001;95:781-6.

23. Drent M, Mansour K, Linssen C. Bronchoalveolar lavage in sarcoidosis. Semin Respir Crit Care Med. 2007;28:486-95.

24. Quanjer PH, Tammeling GJ, Cotes JE, Pedersen OF, Peslin R, Yernault JC. Lung volumes and forced ventilatory flows. Report Working Party Standardization of Lung Function Tests, European Community for Steel and Coal. Official Statement of the European Respiratory Society. Eur Respir J Suppl. 1993;16:5-40.

25. Rothkrantz-Kos S, van Dieijen-Visser MP, Mulder PG, Drent M. Potential usefulness of inflammatory markers to monitor respiratory functional impairment in sarcoidosis. Clin Chem. 2003;49:1510-7.

26. Voorter CE, Rozemuller EH, de Bruyn-Geraets D, van der Zwan AW, Tilanus MG, van den Berg-Loonen EM. Comparison of DRB sequence-based typing using different strategies. Tissue Antigens. 1997;49:471-6.

27. Voorter $C E$, Kik MC, van den Berg-Loonen EM. High-resolution HLA typing for the DQB1 gene by sequence-based typing. Tissue Antigens. 1998;51:80-7.

28. Voorter $\mathrm{CE}$, van den Berg-Loonen EM. Sequence-based typing of the complete coding sequence of DQA1 and phenotype frequencies in the Dutch Caucasian population. Hum Immunol. 2006;67:756-63.

29. Spagnolo P, Sato H, Grutters JC, Renzoni EA, Marshall SE, Ruven HJ, Wells AU, Tzouvelekis A, van Moorsel $\mathrm{CH}$, van den Bosch JM, du Bois RM, Welsh KI. Analysis of BTNL2 genetic polymorphisms in British and Dutch patients with sarcoidosis. Tissue Antigens. 2007;70:219-27.

30. Thomas KW, Hunninghake GW. Sarcoidosis. JAMA. 2003;289:3300-3.

31. Song Z, Marzilli L, Greenlee BM, Chen ES, Silver RF, Askin FB, Teirstein AS, Zhang $\mathrm{Y}$, Cotter RJ, Moller DR. Mycobacterial catalase-peroxidase is a tissue antigen and target of the adaptive immune response in systemic sarcoidosis. J Exp Med. 2005;201:755-67.

32. Noor A, Knox KS. Immunopathogenesis of sarcoidosis. Clin Dermatol. 2007;25: 250-8.

33. Foley PJ, McGrath DS, Puscinska E, Petrek M, Kolek V, Drabek J, Lympany PA, Pantelidis P, Welsh KI, Zielinski J, du Bois RM. Human leukocyte antigen-DRB1 position 11 residues are a common protective marker for sarcoidosis. Am J Respir Cell Mol Biol. 2001;25:272-7.

34. Rossman MD, Thompson $B$, Frederick $M$, Maliarik $M$, Iannuzzi MC, Rybicki BA, Pandey JP, Newman LS, Magira E, Beznik-Cizman B, Monos D. HLA-DRB1*1101: a significant risk factor for sarcoidosis in blacks and whites. Am J Hum Genet. 2003;73:720-35.

35. Traherne JA, Barcellos LF, Sawcer SJ, Compston A, Ramsay PP, Hauser SL, Oksenberg JR, Trowsdale J. Association of the truncating splice site mutation in BTNL2 with multiple sclerosis is secondary to HLA-DRB1*15. Hum Mol Genet. 2006;15:155-61.

36. Grunewald J. Genetics of sarcoidosis. Curr Opin Pulm Med. 2008;14:434-9. 
37. Seitzer U, Swider C, Stuber F, Suchnicki K, Lange A, Richter E, Zabel P, MullerQuernheim J, Flad HD, Gerdes J. Tumour necrosis factor alpha promoter gene polymorphism in sarcoidosis. Cytokine. 1997;9:787-90.

38. Swider C, Schnittger L, Bogunia-Kubik K, Gerdes J, Flad H, Lange A, Seitzer U. TNFalpha and HLA-DR genotyping as potential prognostic markers in pulmonary sarcoidosis. Eur Cytokine Netw. 1999;10:143-6.

39. Fernando SL, Britton WJ. Genetic susceptibility to mycobacterial disease in humans. Immunol Cell Biol. 2006;84:125-37.

40. Fitness J, Tosh K, Hill AV. Genetics of susceptibility to leprosy. Genes Immun. 2002;3:441-53.

41. Ahmad T, Marshall SE, Jewell D. Genetics of inflammatory bowel disease: the role of the HLA complex. World J Gastroenterol. 2006;12:3628-35.

42. Rybicki BA, Maliarik MJ, Poisson LM, Sheffer R, Chen KM, Major M, Chase GA, Iannuzzi MC. The major histocompatibility complex gene region and sarcoidosis susceptibility in African Americans. Am J Respir Crit Care Med. 2003;167:444-9.

43. Stammers M, Rowen L, Rhodes D, Trowsdale J, Beck S. BTL-II: a polymorphic locus with homology to the butyrophilin gene family, located at the border of the major histocompatibility complex class II and class III regions in human and mouse. Immunogenetics. 2000;51:373-82.

44. Johnson CM, Traherne JA, Jamieson SE, Tremelling M, Bingham S, Parkes $M$, Blackwell JM, Trowsdale J. Analysis of the BTNL2 truncating splice site mutation in tuberculosis, leprosy and Crohn's disease. Tissue Antigens. 2007;69:236-41.

45. Trikalinos TA, Salanti G, Khoury MJ, Ioannidis JP. Impact of violations and deviations in Hardy-Weinberg equilibrium on postulated gene-disease associations. $\mathrm{Am} \mathrm{J}$ Epidemiol. 2006;163:300-9.

46. Schaid DJ, Jacobsen SJ. Biased tests of association: comparisons of allele frequencies when departing from Hardy-Weinberg proportions. Am J Epidemiol. 1999;149:706-11.

47. Orozco G, Eerligh P, Sanchez E, Zhernakova S, Roep BO, Gonzalez-Gay MA, LopezNevot MA, Callejas JL, Hidalgo C, Pascual-Salcedo D, Balsa A, Gonzalez-Escribano MF, Koeleman BP, Martin J. Analysis of a functional BTNL2 polymorphism in type 1 diabetes, rheumatoid arthritis, and systemic lupus erythematosus. Hum Immunol. 2005;66:1235-41.

48. Barcellos LF, Oksenberg JR, Begovich AB, Martin ER, Schmidt S, Vittinghoff $E$, Goodin DS, Pelletier D, Lincoln RR, Bucher P, Swerdlin A, Pericak-Vance MA, Haines $\mathrm{JL}$, Hauser SL. HLA-DR2 dose effect on susceptibility to multiple sclerosis and influence on disease course. Am J Hum Genet. 2003;72:710-6.

49. Dyment DA, Herrera BM, Cader MZ, Willer CJ, Lincoln MR, Sadovnick AD, Risch N, Ebers GC. Complex interactions among MHC haplotypes in multiple sclerosis: susceptibility and resistance. Hum Mol Genet. 2005;14:2019-26.

50. Fogdell-Hahn A, Ligers A, Gronning M, Hillert J, Olerup O. Multiple sclerosis: a modifying influence of HLA class I genes in an HLA class II associated autoimmune disease. Tissue Antigens. 2000;55:140-8.

51. Geleijns K, Schreuder GM, Jacobs BC, Sintnicolaas K, van Koningsveld R, Meulstee J, Laman JD, van Doorn PA. HLA class II alleles are not a general susceptibility factor in Guillain-Barre syndrome. Neurology. 2005;64:44-9.

52. Bouma G, Oudkerk Pool M, Crusius JB, Schreuder GM, Hellemans HP, Meijer BU, Kostense PJ, Giphart MJ, Meuwissen SG, Pena AS. Evidence for genetic heterogeneity in inflammatory bowel disease (IBD); HLA genes in the predisposition to suffer from ulcerative colitis (UC) and Crohn's disease (CD). Clin Exp Immunol. 1997; 109:175-9.

53. Sutedja NA, Otten HG, Cats EA, Piepers S, Veldink JH, van der Pol WL, van den Berg $\mathrm{LH}$. Increased frequency of HLA-DRB1*15 in patients with multifocal motor neuropathy. Neurology. 2010;74:828-32. 
54. Brown JJ, Ollier WE, Thomson W, Bayat A. Positive association of HLA-DRB1*15 with keloid disease in Caucasians. Int J Immunogenet. 2008;35:303-7. 


\section{Chapter 9}

Summary, general discussion and directions for future research 


\section{Summary}

Many acute and chronic lung diseases can cause pulmonary fibrosis and are commonly referred to as interstitial lung disease (ILD) or diffuse lung disease. In most cases the origin of ILD is not known. Genetic predisposition and environmental antigens are indicated as risk factors in the majority of these ILDs. Several studies have explored the association of genetic polymorphisms or the presence of certain variant alleles, with the occurrence and/or progression of ILD of unknown etiology. ${ }^{1-7}$ Moreover, the search for more specific 'markers' still continues.

The aim of the studies presented in this thesis was to evaluate the clinical and prognostic importance of genetic testing in a group of patients with druginduced ILD (DI-ILD), a group of patients with oral anticoagulants induced diffuse alveolar hemorrhage (DAH), and a group of sarcoidosis patients. All these patients were referred to the ild care center of the Maastricht University Medical Centre, the Netherlands.

The analyses performed were executed on whole blood samples of druginduced ILD, idiopathic pulmonary fibrosis (IPF), and sarcoidosis patients. Of patients suffering from diffuse alveolar hemorrhage (DAH) analyses were done on whole blood samples and cells present in bronchoalveolar lavage fluid (BALF). For the analyses performed on healthy volunteer (HV) groups, whole blood and buccal swab (BS) samples were used. In afore mentioned populations the value of genotyping cytochrome P450 (CYP) enzymes (i.e. CYP2D6, CYP2C9 and CYP2C19) and/or vitamin K epoxide reductase (VKORC1) was examined. In sarcoidosis patients, next to tumor necrosis factor alpha (TNF- $a$ G-308A) and butyrophiline-like 2 (BTNL2 G16071A), human leukocyte antigen (HLA) DRB1 and DQB1 were typed.

Chapter 1, the general introduction, presents a summary of various ILDs, with an emphasis on drug-induced interstitial lung disease (DI-ILD), diffuse alveolar hemorrhage (DAH), and sarcoidosis. Furthermore, the term polymorphism and the possible ways in how to detect them are pointed out. In addition, the fluorescence resonance energy transfer (FRET) detection method used in this thesis is explained more in detail.

In chapter 2 the possible role of cytochrome P450 (CYP) enzymes in ILD, especially in drug-induced ILD (DI-ILD) was reviewed. The CYP enzyme family plays an important role in the metabolization of a variety of ingested, injected or inhaled xenobiotic substances. Polymorphisms in the CYP genes can 
influence the metabolic activity of the subsequent enzymes, which in turn may lead to localized (toxic) reactions and tissue damage. Drug toxicity can be due to either absence or to very poor enzyme activity. In case of reduced enzyme activity, dose reduction or prescribing an alternative drug metabolized by a different, unaffected CYP enzyme is recommended to prevent toxic side effects. This is particularly important in multi drug-use. Knowing a patient's CYP profile before drug prescription could prevent drug-induced ILD and other druginduced toxicity. Moreover, it might be helpful in explaining serious adverse effects from inhaled, injected or ingested xenobiotic substances.

Chapter 3 describes an easy DNA isolation method to be used prior to genetic testing. Several commercial DNA isolation kits are available for extracting genomic DNA from whole blood samples, but these procedures are time consuming and expensive. An alternative technique could be dried blood spot (DBS) sampling. With the subsequent simple isolation method DNA isolation is faster, cheaper, and logistics are easier. This DBS DNA isolation method, an alternative to the commercially available DNA isolation kits, is practical and it discriminates between genotypes. It can also be used for buccal swabs resulting in good DNA yields and giving completely concurrent results with samples isolated using commercial DNA isolation kits. This expands the possibilities of this quick and easy DNA isolation procedure, especially in combination with the noninvasive patient friendly buccal swab sampling method. In addition, buccal swab sampling appeared to be a good alternative to invasive sampling methods.

Chapter 4 describes drug-induced pulmonary toxicity, a serious and expanding problem. Many drugs are metabolized by cytochrome P450 (CYP) enzymes. To establish whether allelic variation in CYP polymorphic genes contributes to variability in drug response and unexpected toxicity, a case-control study was conducted. The cases consisted of patients with drug-induced interstitial lung disease. Furthermore, two control groups were used: one group of healthy volunteers and one group of patients with idiopathic pulmonary fibrosis (IPF). Of the patients with drug-induced ILD $91.5 \%$ had at least one of the studied variant genes compared with $70.5 \%$ of the healthy volunteers and $69.1 \%$ of the IPF patients (both p's<0.001). The percentage of individuals with one or more variant CYP genes was higher in the drug-induced ILD group. A significant association between the development of drug-induced ILD and the presence of one or more variant CYP genes was found. Drug-induced ILD was associated with the presence of at least one variant CYP allele. This study supports the potential usefulness of 'personalized' medicine by genotyping, aiming to improve efficacy, tolerability and drug safety. 
The case presented in chapter $\mathbf{5}$ illustrates that understanding the mechanisms of drug metabolism and interactions may help to prevent side effects. The patient was a poor metabolizer for CYP2D6 corroborating that polymorphisms in this CYP gene influenced the metabolic activity of the corresponding enzymes. In addition, this affected the subsequent serum drug levels of venlafaxine and to a much lesser degree metoprolol and their metabolites. This achieved that toxic serum levels of venlafaxine were present and no active metabolite ( $O$-desmethylvenlafaxine) could be detected. Besides therapeutic drug monitoring, genotyping some important cytochrome P450 (CYP) enzymes was of additional value in explaining why the patient developed severe adverse effects. It also helped us to understand why the patient did not experience any therapeutical effect of the prescribed venlafaxine. This case highlights the potential benefit of clinical and genetic risk stratification (pharmacogenetics) before starting treatment.

In chapter 6 diffuse alveolar hemorrhage (DAH) is highlighted. DAH is a serious bleeding complication that can occur as a result of, among others, oral anticoagulation therapy. This study explored the hypothesis that in patients treated with coumarins DAH may be associated with vitamin $\mathrm{K}$ epoxide reductase complex1 (VKORC1) and cytochrome P450 (CYP) variant alleles in CYP2C9, and in case of acenocoumarol use also with CYP2C19 variants. Clinical information of patients using coumarins with at least one episode of DAH was gathered retrospectively during a seven year period. Out of 173 confirmed DAH cases, 75 had received oral anticoagulants and 63 of these 75 (84\%) patients were included because DNA was available. Of these samples CYP and VKORC1 single nucleotide polymorphisms (SNPs) were genotyped. In 62 out of $63 \mathrm{DAH}$ cases VKORC1, CYP2C9 variant genes, or both were found. This indicates that genotyping appears to be useful in predicting a high risk of serious side effects related to oral anticoagulant use, including DAH. Consequently, in concurrence with the American Food and Drug Administration (FDA), we recommend this genotyping, in order to provide a safer and more individualized anticoagulant therapy.

Chapter 7 describes a study designed to evaluate the relationship between the presence of tumor necrosis factor alpha (TNF-a) polymorphisms and the prognosis of sarcoidosis. In a retrospective case-control study TNF-a G-308A, TNF- $a$ G-238A and lymphotoxin-a (LTA) were genotyped in 625 sarcoidosis patients. These patients were classified into 327 patients with non-persistent (regressing to or stable at chest X-ray stage 0 or I) disease and 298 patients with persistent disease using chest $X$-ray appearances and lung function test results after a period of at least two years of follow-up. The TNF- $a-308 \mathrm{~A}$ variant allele was observed in $25.5 \%$ of patients with persistent disease 
compared with $44.0 \%$ of patients with non-persistent disease. Consequently, the presence of a TNF- $a-308 \mathrm{~A}$ variant allele is associated with a favorable prognosis. Because of the strong linkage between TNF- $a$ G-308A and HLA-DRB $1 * 03$, genotyping of one relatively simple TNF-a SNP is useful in predicting the prognosis of pulmonary sarcoidosis.

In chapter 8 the association between butyrophiline-like 2 (BTNL2) G16071A with the course of pulmonary sarcoidosis was assessed and the association with disease predisposition was verified in 632 sarcoidosis patients. In addition, the linkage between BTNL2 G16071A and certain HLA-DRB1 and HLA-DQB1 types was investigated. It appeared that the BTNL2 16071A variant allele was significantly more often present in patients with persistent disease (92.4\%) compared with patients having non-persistent disease (86.6\%). The presence of a BTNL2 16071A variant allele was found to be associated with an almost twofold increased risk of progressing to more severe and persistent pulmonary sarcoidosis. Furthermore, the predisposition to develop sarcoidosis was confirmed, as well as the strong linkage between the BTNL2 16071A variant allele and DRB1*15 positivity. It also became apparent that typing for DRB1 is sufficient because of the lack of additional information obtained by typing the $\mathrm{DQB} 1 * 06$, to establish the $15 \mathrm{Q} 6$ haplotype. Whether or not to determine the DRB1 type or test the BTNL2 G16071A SNP therefore, depends on the ability and/or availability to perform either test. Additional research will be necessary to explore the role of these findings in the clinical management of sarcoidosis patients. 


\section{General discussion}

Both genetic and non-genetic information is important in the susceptibility, development, cause, and treatment response of diseases. The more we know about a patient's genes and context, the better disease management decisions can be made. ${ }^{8}$ Nevertheless, often the cause of a disease appears to be not only associated with a single nucleotide polymorphism (SNP), but is much more complicated. Some patients will continue to react unpredictably to therapy even though, according to obtained tests results, problems were not expected. Extending mapping of transcription factor binding SNPs and structural variants associated with transcription factor binding might gather useful information about the role of genetics in the phenotypic diversity in humans and provide insight into genetic causes of human disease. ${ }^{9,10}$

The success of modern medicine is partly the result of effective medical treatment. Although the overall advantage of many drugs outweighs the side effects, substantial costs are still made as a result of complications of drug therapy. The variability in drug response among patients is multi-factorial. These factors include extrinsic features like environmental aspects or comedication, but also genetic and intrinsic factors that affect the disposition (absorption, distribution, metabolism and excretion) of individual drugs. The existence of large population differences with small intra-patient variability is consistent with inheritance as determinant of drug response. It is estimated that genetics can account for $20-95 \%$ of the variability in drug disposition and effects. ${ }^{11}$ Together clinical and genetic risk stratification (pharmacogenetics) may lead to more accurate prevention of drug-induced damage in the future.

In a recent editorial the results of almost ten years after the revealing of a draft sequence of the human genome were assessed. Although detailed maps of genetic markers of human variation, have facilitated many remarkable genomewide efforts to associate known SNPs with disease predisposition, more than one decade of genomics will be required to understand the inborn risks of most common disorders. ${ }^{8}$ Nevertheless, reviews that highlight successful applications of gene-based medicine might hasten adoption of the beneficial changes in medicine that will eventually, if gradually, come from gene-based sciences. ${ }^{8}$ All the same, our increased understanding of the interactions between the entire genome and non-genomic factors that result in health and disease is paving the way for an era of 'genomic medicine'. ${ }^{12}$

There are an increasing number of examples where pharmacogenetic studies have indicated that a genetic test prior to treatment may be useful either for setting the individual dose or choosing a certain drug. ${ }^{13-18}$ The ability to identify 
individuals who are susceptible to adverse drug reactions has the potential to reduce the personal and population costs of drug-related morbidity and the potential to attribute to the patients' safety. Especially persons with more than one cytochrome P450 (CYP) polymorphism and/or other relevant polymorphisms may be susceptible to develop adverse effects, such as druginduced interstitial lung disease (ILD), when (multiple) drugs are prescribed. ${ }^{19}$ Moreover, other pharmacogenetic factors might be involved, such as those involved in methotrexate induced pneumonitis. ${ }^{20-22}$

One of the major conclusions of this thesis is that genetic screening prior to drug prescription may potentially prevent serious adverse effects such as diffuse alveolar hemorrhage (DAH) or drug-induced ILD. Another important finding is that the results obtained by genetic testing appeared to be useful in disease management, because of the prognostic value of the absence or presence of specific polymorphisms.

\section{Polymorphisms in drug-induced lung diseases}

Not only drug interactions, environmental factors, disease processes, and aging are factors in the inter-individual metabolic capacity variance, genetic factors also play an important role in developing adverse effects in general. Considering the fact that bio-(in)activation by CYP enzymes play an important role in human drug toxicity, polymorphisms in the CYP enzyme system may result in large inter-individual variations in the metabolism and toxicity of xenobiotics. The presence of CYP variant alleles adds a substantial susceptibility risk factor to the development of drug-induced pulmonary adverse events. ${ }^{19,23,24}$ In the study presented in chapter 6 , genetic allelic variants appeared to be one of the determinants of variability in sensitivity to coumarins. Furthermore, others found that even in patients with stable international normalized ratios (INRs) without adverse (bleeding) effects these polymorphisms had a profound influence on dose requirements and time to reach therapeutic INRs. ${ }^{15,25}$ Despite numerous attempts to standardize the management of oral anticoagulant therapy, a high proportion of patients are still inadequately anticoagulated and the optimal means to initiate the therapy is still a matter of debate. It has been suggested that dosing algorithms incorporating genetics might outperform usual care. However, a major obstacle to the widespread adoption of genetic based coumarin dose modelling is that access to timely genetic testing is currently not widely available. ${ }^{26}$ Nevertheless, even despite its limitations, prospective genotyping for CYP2C9 and VKORC1 of patients taking oral anticoagulants has the clear potential to significantly optimize the safety of drug therapy and set a promising example of 'personalized' medicine. ${ }^{10}$ 


\section{Drugs, oxidative stress and pulmonary damage}

Beside anticoagulants, D-penicillamine, nitrofurantoin, amiodarone, propylthiouracil, cocaine, or sirolimus, and/or exposure to toxic agents such as trimellitic anhydride, insecticides, and pesticides may also cause bleeding complications including DAH events. ${ }^{27}$ It has been suggested that oxidative damage plays a role in the pathophysiology of various diseases, including DAH and pulmonary fibrosis. ${ }^{28,29} \mathrm{DAH}$ is characterized by pulmonary alveolar cell death, inflammation, and hyaline membranes composed of fibrin and cellular debris. ${ }^{30}$ Idiopathic pulmonary fibrosis (IPF) is a chronic, progressive and frequently fatal form of ILD, characterized by impaired fibrinolysis and a complex pathogenesis. ${ }^{29,31,32}$ As a result of diffuse alveolar bleeding events iron is released in the lung. In turn this free toxic iron causes oxidative stress, inflammation, and finally irreversible damage or fibrosis. ${ }^{30,33}$ Moreover, people with VKORC1 and/or CYP2C9 variant alleles might have a predisposition for a greater risk of bleeding events in case they use oral anticoagulants, which might make them more susceptible to iron-catalysed toxicity caused by oxidants. This is important as anticoagulant therapy is considered to be an additional new strategy to treat IPF patients. ${ }^{34}$ In contrast, Thomassetti et al. did not find a beneficial effect of anticoagulants. ${ }^{35}$ It is tempting to speculate that an association with VKORC1 and/or CYP2C9 variant alleles might even be a risk factor for the development or exacerbation of IPF. Furthermore, it was accentuated that in DAH cases early recognition of the presence of one of the studied polymorphisms is important, because of a potential lethal outcome and the fact that simple vitamin $\mathrm{K}$ supplementation can be life-saving. ${ }^{36}$ Increased availability of vitamin $\mathrm{K}$ through daily supplementation, is expected to diminish the inhibitory activity and the relative day-to-day variability of coumarins and can significantly improve anticoagulation control in unstable patients. ${ }^{36,37}$

\section{Importance of various genetic variants}

It was emphasized that early recognition of the presence of certain polymorphisms is important. ${ }^{36,37}$ Not only in case of anticoagulant use, also in psychiatry, pharmacogenetic testing has become more common practice in the United States (US) with FDA approval of the AmpliChip CYP450 and CYP2D6 and CYP2C19 testing helping patients with a history of excessive difficulties with antidepressants. ${ }^{38-40}$ This was also illustrated by the case described in chapter 5. Besides CYP and VKORC1 polymorphisms other genetic variants are also important. Two main immunosuppressive drugs that are often used in the treatment of severe ILD are methotrexate (MTX) and azathioprine. MTX is frequently used in the treatment of autoimmune diseases such as rheumatoid arthritis, psoriasis, Crohn's disease, as well as in sarcoidosis. MTX toxicity and efficacy is associated with a number of polymorphic enzymes and testing for 
variants was found to be predictive of response to and safety of MTX treatment. ${ }^{17,21,22,41}$ Moreover, when a patient develops an adverse drug reaction after starting MTX treatment, testing the C677T and A1298C variants in the methylenetetrahydrofolate reductase (MTHFR) gene involved in the MTX metabolism, should be considered. ${ }^{42}$ In case of an azathioprine indication, also used as treatment for certain ILDs including IPF, testing thiopurine methyltransferase (TPMT) variants involved in the azathioprine metabolism is advised before starting treatment. ${ }^{43-45}$ In the US, drug labels for azathioprine now include information on TPMT polymorphisms and recommend determining patients' phenotype or genotype prior to drug treatment. ${ }^{46}$

\section{Sarcoidosis}

Sarcoidosis is a chronic granulomatous disorder of unknown cause with a highly variable course, characterized by activation of T-lymphocytes and macrophages. In an effort to determine the etiology of sarcoidosis the multicenter study A Case Control Etiologic Study of Sarcoidosis (ACCESS) was designed. ${ }^{47}$ One of the lessons learned from ACCESS was that genetic associations with sarcoidosis were observed and appeared to be stronger predictors of the course of sarcoidosis than environmental factors. ${ }^{48}$ The assumption that genes contribute to the etiology of sarcoidosis comes from the observation that prevalence and incidence rates of sarcoidosis are different between ethnic groups and that the disease tends to cluster in families. Interactions of exposures with genetic predispositions would have important implications for the understanding of immune responses as well as the pathogenesis of sarcoidosis. ${ }^{47}$ Prognostic factors of sarcoidosis are very important because certain obstacles confound the accurate prediction of the prognosis of sarcoidosis, such as the lack of reliable activity markers, the intensity level of granulomatous response, and the inability to differentiate the response from the dys-regulated repair process leading to fibrosis. ${ }^{47}$

\section{The role of genes in the etiology of sarcoidosis}

Association of sarcoidosis and class I and II HLA antigens is well known and in several studies the risk of progression of sarcoidosis, and the presence or absence of a polymorphism has been established. ${ }^{13,24,49,50}$ In addition to HLA types, co-stimulatory molecules of the immunoglobulin superfamily are also necessary to activate T-cells. The butyrophiline-like 2 (BTNL2) gene is located close to and in linkage with HLA-DRB1, which in turn is implicated in the etiology of sarcoidosis. ${ }^{51-54}$ Moreover, the presence of the BTNL2 16071A variant allele was recently associated with an increased risk of developing sarcoidosis. ${ }^{55-58}$ In T-helper cell 1 (Th1) dominated granulomatous diseases similar to sarcoidosis, an association between the presence of BTNL2 G16071A 
and disease predisposition was found. This association was attributed to the strong linkage with HLA-DRB1/DQB1 haplotypes. ${ }^{54,59}$ Nevertheless, because of this strong linkage between BTNL2 and HLA-DRB1/DQB1, BTNL2 G16071A should be considered relevant to any immune-related disease associated with HLA-DRB1/DQB1. ${ }^{54}$ In the study presented in this thesis, the strong linkage between the BTNL2 16071A variant allele and HLA-DRB1*15 was confirmed. Another conclusion was that the presence of the BTNL2 A-allele was also associated with an increased risk of progressing to a persistent form of pulmonary sarcoidosis. Another SNP that was confirmed to influence sarcoidosis susceptibility is cyclooxegenase-2 (COX2) T8473C, however, no association with progression was found. ${ }^{60}$ Therefore, determining the BTNL2 G16071A genotype even prior to the development of complaints, can be beneficial, for example when there is a family history of sarcoidosis. ${ }^{61}$ Not only to establish whether or not someone is more prone to develop sarcoidosis, but also whether there is an additional risk to progress to a more persistent form. Recently, strong evidence was found for the postulation that several SNPs in the vascular endothelial growth factor (VEGF) and its receptor genes VEGFR-1 and VEGFR-2 also possessed the ability to predict predisposition and progression of sarcoidosis, but further studies are needed to evaluate the clinical relevance. ${ }^{62}$

\section{The influence of genes on the course of sarcoidosis}

Recently, it was found that serum amyloid A plays an important role in granuloma formation in sarcoidosis as well as tumor necrosis factor (TNF), interleukin-10 (IL-10), interferon-gamma (INF-y), and Toll-like receptor 2 (TLR2). ${ }^{63}$ In turn, these cytokines and enzymes not only influence the serum amyloid A production, but their expression can also be influenced by possible polymorphisms in their coding or non-coding sequence, and thus influence the cause or course of sarcoidosis. ${ }^{7,50}$ The potent pro-inflammatory cytokine TNFalpha (TNF-a) for instance plays a pivotal role in inflammatory and immune responses, and regulates and sustains granuloma formation in sarcoidosis. ${ }^{64}$ Several SNPS are identified in the TNF- $a$ gene and especially the variant A-allele of the TNF- $a$ G-308A gene is associated with higher TNF-a serum levels and an acute course of sarcoidosis. ${ }^{65}$ The findings presented in chapter 7 of this thesis demonstrate that it is sometimes beneficial to possess a variant allele (i.e. TNF- $a-308 \mathrm{~A}$ ), opposed to not having a polymorphism, in the course of sarcoidosis. ${ }^{50}$ The risk of progressing to a more severe pulmonary involvement or persistent form of sarcoidosis was found to be higher in the absence of a TNF- $a$ G-308A allelic variant, corroborating findings of other studies conducted on smaller populations. ${ }^{66,67}$ In line with this, bearing the HLA-DRB $1 * 03$ type also predicted a more favorable outcome, as was previously established in sarcoidosis patients with Löfgren's syndrome, the 
acute form of sarcoidosis with predominantly spontaneous remission. ${ }^{1,2,66,68}$ What is more, both TNF- $a$ G-308A and HLA-DRB1*03 typing appear to be interchangeable as far as the outcome or prediction of the course of sarcoidosis is concerned, consequently confirming the strong linkage between both genes. ${ }^{68,69}$

\section{The role of genes in therapeutic management}

Because of the strong linkage disequilibrium found between several genes and HLA-types, the choice of whether or not to test for a simple SNP (for example BTNL2 or TNF- $a$ gene SNPs) or perform HLA typing appears to depend more on the availability of the technique or test. Conclusions drawn from studies presented in this thesis can be useful in furthering the clinical validation of applying genotyping in predicting the clinical course of sarcoidosis in individual patients and fine-tune disease management. Since available sarcoidosis therapies are not without risk and sometimes even toxic, patient care would benefit from the ability to predict the progression of the disease. ${ }^{70}$ Therefore, identifying those cases that might have a chance to develop a more severe manifestation of sarcoidosis is important and treatment aimed at avoiding irreversible damage can be started early. ${ }^{71}$ Furthermore, if the course of the disease has already progressed to severe or refractory sarcoidosis it would be of great clinical relevance to be able to select those cases who might benefit from a certain drug and who will not. For instance, when corticosteroids, most often the first drug of choice in sarcoidosis, are not effective, MTX might be considered. It has been beneficial in certain cases, however, it has a variety of clinical efficacies and toxicities, which are difficult to predict. ${ }^{22,72}$ Several reports have suggested that the use of pharmacogenetics might help to improve the understanding of drug efficacy and toxicity. However, studies in rheumatoid arthritis or psoriasis patients showed conflicting data whether or not these side effects were caused by the altered expression of genes by MTX. ${ }^{22,73,74}$

Recently, anti-TNF-a therapy has proven to be useful in the treatment of refractory sarcoidosis. However, response to this therapy is not always as promising as expected. ${ }^{70,75}$ Moreover, it takes some time before the effect of these so-called biologicals is apparent, substantial side-effects are reported and additionally, this therapy is expensive. In refractory sarcoidosis, bearing a TNF- $a$ G-308A variant allele appears to be a disadvantage. In previous studies conducted in rheumatoid arthritis patients not possessing a variant allele seem to respond to the therapy in contrast to variant allele carriers. ${ }^{76,77}$ Insight into the patient's probable response might provide important information, especially for those patients, who very likely will not benefit from this anti-TNF-a therapy, and therefore should be treated with alternative medication without delay. 


\section{Directions for future research}

There is still a need for well designed prospective clinical trials that measure patient-oriented outcomes of selected genomic applications, and studies that evaluate the role of genomic variation in disease susceptibility, predicting prognosis, treatment response and in tailoring drug treatment for individual patients. These investigations are aimed to help to bridge the gap between 'personalized' and 'evidence-based' medicine ${ }^{12}$

In order to ascertain anticoagulation levels quicker and safer, without the risk of serious side effects and identify coumarin sensitive cases, genotyping for VKORC1, CYP2C9, and CYP2C19 polymorphisms would be a preferable cause of action. This genotyping should be performed ideally prior to oral anticoagulant therapy, but certainly in case of high and unstable or even overshot target INRs. A cost-effectiveness study, evaluating whether or not screening for VKORC1 and CYP2C9 polymorphisms prior to administering oral anticoagulant therapy is of clinical relevance, is therefore highly recommended.

Furthermore, a prospective study to determine if, when variant alleles are present, simultaneous oral vitamin $\mathrm{K}$ supplementation can prevent diffuse alveolar hemorrhage (DAH) events is needed. Whether or not an association exists between CYP and VKORC1 polymorphisms and the development and/or progression of pulmonary fibrosis is another important issue for future studies. Hypothesizing that fibrosis could be associated with repeated episodes of diffuse alveolar damage to a certain extent is intriguing. Prospective clinical trials are needed to clarify the role of anticoagulant therapy and other alveolar bleeding initiating agents in the development of pulmonary fibrosis. Further investigations are also needed to assess if anticoagulant therapy is a friend or foe in the therapeutic strategies of pulmonary fibrosis. Therefore, it would be interesting to evaluate whether screening of patients before initiating anticoagulant therapy might be of clinical relevance.

MTX, frequently used in sarcoidosis in combination with or without anti-TNF-a therapy, is also influenced by the presence of variant alleles. For that reason, a study into the influence of these polymorphisms on the efficiency and efficacy of this drug in sarcoidosis therapy should certainly be considered. Moreover, these studies might even give an answer to the question about which patients would benefit from MTX and for whom no advantage can be achieved or for whom the result will even be detrimental. It might be fascinating to develop a screening system based on both clinical and genetic information. 
Next to the information about the progression of sarcoidosis, a patient's TNF-a status or genetic make-up can also play a significant role in therapeutic disease management. Assessing a possible association in individual cases between the absence of a TNF- $a$-308A variant allele and being a responder or nonresponder to anti-TNF-a therapy would be of great clinical relevance. The results could provide important information about whether or not a patient would possibly benefit from anti-TNF-a therapy. Therefore, research should continue to depict the role of $T N F$ genes in the immunogenetics and clinical management of sarcoidosis.

The ability to identify individuals who are susceptible to adverse drug reactions, with the inclusion of both clinical and genetic risk stratification, may lead to a more accurate prevention of drug-induced damage and has the potential to reduce the personal and population costs of drug-related morbidity. ${ }^{78,79}$ The introduction of a genetic medical passport for each patient aimed to achieve a more appropriate individual pharmacotherapy seems promising in therapeutic drug monitoring. However, whether this might reduce the risk of side effects and related medical consumption needs to be evaluated. Collaboration between medical specialists, clinical pharmacists, pharmacologists and laboratory specialists will be necessary to accomplish individualize pharmacotherapy based on the pharmacogenetic profile. ${ }^{80}$ 


\section{References}

1. Grunewald J, Eklund A, Olerup O. Human leukocyte antigen class I alleles and the disease course in sarcoidosis patients. Am J Respir Crit Care Med. 2004;169: 696-702.

2. Grutters JC, Sato $H$, Pantelidis $P$, Lagan AL, McGrath DS, Lammers JW, van den Bosch JM, Wells $A U$, du Bois RM, Welsh KI. Increased frequency of the uncommon tumor necrosis factor $-857 \mathrm{~T}$ allele in British and Dutch patients with sarcoidosis. Am J Respir Crit Care Med. 2002;165:1119-24.

3. Iannuzzi MC. Genetics of sarcoidosis. Semin Respir Crit Care Med. 2007;28:15-21.

4. Sato H, Williams HR, Spagnolo P, Abdallah A, Ahmad T, Orchard TR, Copley SJ, Desai SR, Wells AU, du Bois RM, Welsh KI. CARD15/NOD2 polymorphisms are associated with severe pulmonary sarcoidosis. Eur Respir J. 2010;35:324-30.

5. Yang IV, Burch LH, Steele MP, Savov JD, Hollingsworth JW, McElvania-Tekippe E, Berman KG, Speer MC, Sporn TA, Brown KK, Schwarz MI, Schwartz DA. Gene expression profiling of familial and sporadic interstitial pneumonia. Am J Respir Crit Care Med. 2007;175:45-54.

6. Nogee LM, Dunbar AE, 3rd, Wert SE, Askin F, Hamvas A, Whitsett JA. A mutation in the surfactant protein $C$ gene associated with familial interstitial lung disease. $N$ Engl J Med. 2001;344:573-9.

7. Veltkamp M, Wijnen PA, van Moorsel CH, Rijkers GT, Ruven HJ, Heron M, Bekers O, Claessen AM, Drent M, van den Bosch JM, Grutters JC. Linkage between Toll-like receptor (TLR) 2 promotor and intron polymorphisms: functional effects and relevance to sarcoidosis. Clin Exp Immunol. 2007;149:453-62.

8. Varmus $\mathrm{H}$. Ten years on--the human genome and medicine. $N$ Engl $\mathrm{J}$ Med. 2010;362:2028-9.

9. Kasowski M, Grubert F, Heffelfinger C, Hariharan M, Asabere A, Waszak SM, Habegger L, Rozowsky J, Shi M, Urban AE, Hong MY, Karczewski KJ, Huber W, Weissman SM, Gerstein MB, Korbel JO, Snyder M. Variation in transcription factor binding among humans. Science. 2010;328:232-5.

10. Stehle S, Kirchheiner J, Lazar A, Fuhr U. Pharmacogenetics of oral anticoagulants: a basis for dose individualization. Clin Pharmacokinet. 2008;47:565-94.

11. Evans WE, McLeod HL. Pharmacogenomics--drug disposition, drug targets, and side effects. N Engl J Med. 2003;348:538-49.

12. Feero WG, Guttmacher $A E$, Collins FS. Genomic medicine--an updated primer. $N$ Engl J Med. 2010;362:2001-11.

13. McLeod HL, Evans WE. Pharmacogenomics: unlocking the human genome for better drug therapy. Annu Rev Pharmacol Toxicol. 2001;41:101-21.

14. Meyer UA. Pharmacogenetics and adverse drug reactions. Lancet. 2000;356: 1667-71.

15. Moyer TP, O'Kane DJ, Baudhuin LM, Wiley CL, Fortini A, Fisher PK, Dupras DM, Chaudhry R, Thapa P, Zinsmeister AR, Heit JA. Warfarin sensitivity genotyping: a review of the literature and summary of patient experience. Mayo Clin Proc. 2009;84:1079-94.

16. Nebert DW, Russell DW. Clinical importance of the cytochromes P450. Lancet. 2002;360:1155-62.

17. Wessels JA, de Vries-Bouwstra JK, Heijmans BT, Slagboom PE, Goekoop-Ruiterman YP, Allaart CF, Kerstens PJ, van Zeben D, Breedveld FC, Dijkmans BA, Huizinga TW, Guchelaar HJ. Efficacy and toxicity of methotrexate in early rheumatoid arthritis are associated with single-nucleotide polymorphisms in genes coding for folate pathway enzymes. Arthritis Rheum. 2006;54:1087-95.

18. Rieder MJ, Reiner AP, Gage BF, Nickerson DA, Eby CS, McLeod HL, Blough DK, Thummel KE, Veenstra DL, Rettie AE. Effect of VKORC1 haplotypes on transcriptional regulation and warfarin dose. N Engl J Med. 2005;352:2285-93. 
19. Wijnen PA, Drent M, Nelemans PJ, Kuijpers PM, Koek GH, Neef C, Haenen GR, Bekers $\mathrm{O}$. Role of cytochrome $\mathrm{P} 450$ polymorphisms in the development of pulmonary drug toxicity: a case-control study in the Netherlands. Drug Saf. 2008;31:1125-34.

20. Zisman DA, McCune WJ, Tino G, Lynch JP, 3rd. Drug-induced pneumonitis: the role of methotrexate. Sarcoidosis Vasc Diffuse Lung Dis. 2001;18:243-52.

21. Wessels JA, Kooloos WM, De Jonge R, De Vries-Bouwstra JK, Allaart CF, Linssen A, Collee G, De Sonnaville P, Lindemans J, Huizinga TW, Guchelaar HJ. Relationship between genetic variants in the adenosine pathway and outcome of methotrexate treatment in patients with recent-onset rheumatoid arthritis. Arthritis Rheum. 2006;54:2830-9.

22. Kim YJ, Song M, Ryu JC. Mechanisms underlying methotrexate-induced pulmonary toxicity. Expert Opin Drug Saf. 2009;8:451-8.

23. Wijnen PA, Limantoro I, Drent M, Bekers O, Kuijpers PM, Koek GH. Depressive effect of an antidepressant: therapeutic failure of venlafaxine in a case lacking CYP2D6 activity. Ann Clin Biochem. 2009;46:527-30.

24. Wijnen PA, Linssen CF, Haenen GR, Bekers O, Drent M. Variant VKORC1 and CYP2C9 Alleles in Patients with Diffuse Alveolar Hemorrhage Caused by Oral Anticoagulants. Mol Diagn Ther. 2010;14:23-30.

25. Ozer N, Cam N, Tangurek B, Ozer S, Uyarel H, Oz D, Guney MR, Ciloglu F. The impact of CYP2C9 and VKORC1 genetic polymorphism and patient characteristics upon warfarin dose requirements in an adult Turkish population. Heart Vessels. 2010;25:155-62.

26. Lazo-Langner A, Kovacs MJ. Predicting warfarin dose. Curr Opin Pulm Med. 2010:6.

27. Ioachimescu OC, Stoller JK. Diffuse alveolar hemorrhage: diagnosing it and finding the cause. Cleve Clin J Med. 2008;75:258, 60, 64-5 passim.

28. Rahman I, Skwarska E, Henry M, Davis M, O'Connor CM, FitzGerald MX, Greening A, MacNee W. Systemic and pulmonary oxidative stress in idiopathic pulmonary fibrosis. Free Radic Biol Med. 1999;27:60-8.

29. Day BJ. Antioxidants as potential therapeutics for lung fibrosis. Antioxid Redox Signal. 2008;10:355-70.

30. Jin Y, Choi AM. Cytoprotection of heme oxygenase-1/carbon monoxide in lung injury. Proc Am Thorac Soc. 2005;2:232-5.

31. Selman M, Thannickal VJ, Pardo A, Zisman DA, Martinez FJ, Lynch JP, 3rd. Idiopathic pulmonary fibrosis: pathogenesis and therapeutic approaches. Drugs. 2004;64:405-30.

32. Demedts M, Behr J, Buhl R, Costabel U, Dekhuijzen R, Jansen HM, MacNee W, Thomeer M, Wallaert B, Laurent F, Nicholson AG, Verbeken EK, Verschakelen J, Flower CD, Capron F, Petruzzelli S, De Vuyst P, van den Bosch JM, RodriguezBecerra E, Corvasce G, Lankhorst I, Sardina M, Montanari M. High-dose acetylcysteine in idiopathic pulmonary fibrosis. N Engl J Med. 2005;353:2229-42.

33. Ghio AJ, Stonehuerner JG, Richards JH, Crissman KM, Roggli VL, Piantadosi CA, Carraway MS. Iron homeostasis and oxidative stress in idiopathic pulmonary alveolar proteinosis: a case-control study. Respir Res. 2008;9:10.

34. Kubo H, Nakayama K, Yanai M, Suzuki T, Yamaya M, Watanabe M, Sasaki H. Anticoagulant therapy for idiopathic pulmonary fibrosis. Chest. 2005;128:1475-82.

35. Tomassetti S, Ryu JH, Gurioli C, Ravaglia C, Buccioli M, Chilosi M, Carloni A, Piciucchi S, Gurioli C, Casoni G, Romagnoli M, Poletti V. The effect of anticoagulant therapy on survival of patients with idiopathic pulmonary fibrosis. Am J Respir Crit Care Med. 2010;181:A6028.

36. Sconce E, Avery P, Wynne H, Kamali F. Vitamin K supplementation can improve stability of anticoagulation for patients with unexplained variability in response to warfarin. Blood. 2007;109:2419-23. 
37. Sconce EA, Avery PJ, Wynne HA, Kamali F. Vitamin K epoxide reductase complex subunit 1 (VKORC1 ) polymorphism influences the anticoagulation response subsequent to vitamin K intake: a pilot study. J Thromb Haemost. 2008;6:1226-8.

38. de Leon J, Armstrong SC, Cozza KL. Clinical guidelines for psychiatrists for the use of pharmacogenetic testing for CYP450 2D6 and CYP450 2C19. Psychosomatics. 2006;47:75-85.

39. Gage BF, Lesko LJ. Pharmacogenetics of warfarin: regulatory, scientific, and clinical issues. J Thromb Thrombolysis. 2008;25:45-51.

40. Wang $D$, Chen $H$, Momary KM, Cavallari LH, Johnson JA, Sadee W. Regulatory polymorphism in vitamin $\mathrm{K}$ epoxide reductase complex subunit 1 (VKORC1) affects gene expression and warfarin dose requirement. Blood. 2008;112:1013-21.

41. Warren RB, Smith RL, Campalani E, Eyre S, Smith CH, Barker JN, Worthington J, Griffiths CE. Genetic variation in efflux transporters influences outcome to methotrexate therapy in patients with psoriasis. J Invest Dermatol. 2008;128: 1925-9.

42. Campalani E, Arenas M, Marinaki AM, Lewis CM, Barker JN, Smith CH. Polymorphisms in folate, pyrimidine, and purine metabolism are associated with efficacy and toxicity of methotrexate in psoriasis. $J$ Invest Dermatol. 2007; 127:1860-7.

43. Schutz E, von Ahsen N, Oellerich M. Genotyping of eight thiopurine methyltransferase mutations: three-color multiplexing, "two-color/shared" anchor, and fluorescence-quenching hybridization probe assays based on thermodynamic nearest-neighbor probe design. Clin Chem. 2000;46:1728-37.

44. Baker DE. Pharmacogenomics of azathioprine and 6-mercaptopurine in gastroenterologic therapy. Rev Gastroenterol Disord. 2003;3:150-7.

45. Bakker JA, Bierau J, Drent M. Therapeutic regimens in interstitial lung disease guided by genetic screening: fact or fiction? Eur Respir J. 2007;30:821-2.

46. Daly AK. Individualized drug therapy. Curr Opin Drug Discov Devel. 2007;10:29-36.

47. Design of a case control etiologic study of sarcoidosis (ACCESS). ACCESS Research Group. J Clin Epidemiol. 1999;52:1173-86.

48. Rossman MD, Kreider ME. Lesson learned from ACCESS (A Case Controlled Etiologic Study of Sarcoidosis). Proc Am Thorac Soc. 2007;4:453-6.

49. Voorter $C E$, Drent $M$, van den Berg-Loonen EM. Severe pulmonary sarcoidosis is strongly associated with the haplotype HLA-DQB1*0602-DRB1*150101. Hum Immunol. 2005;66:826-35.

50. Wijnen PA, Nelemans PJ, Verschakelen JA, Bekers O, Voorter CE, Drent M. The role of tumor necrosis factor alpha G-308A polymorphisms in the course of pulmonary sarcoidosis. Tissue Antigens. 2010;75:262-8.

51. Sato H, Grutters JC, Pantelidis P, Mizzon AN, Ahmad T, Van Houte AJ, Lammers JW, Van Den Bosch JM, Welsh KI, Du Bois RM. HLA-DQB1*0201: a marker for good prognosis in British and Dutch patients with sarcoidosis. Am J Respir Cell Mol Biol. 2002;27:406-12.

52. Foley PJ, McGrath DS, Puscinska E, Petrek M, Kolek V, Drabek J, Lympany PA, Pantelidis P, Welsh KI, Zielinski J, du Bois RM. Human leukocyte antigen-DRB1 position 11 residues are a common protective marker for sarcoidosis. Am J Respir Cell Mol Biol. 2001;25:272-7.

53. Rossman MD, Thompson $B$, Frederick $M$, Maliarik $M$, Iannuzzi MC, Rybicki BA, Pandey JP, Newman LS, Magira E, Beznik-Cizman B, Monos D. HLA-DRB1*1101: a significant risk factor for sarcoidosis in blacks and whites. Am J Hum Genet. 2003;73:720-35.

54. Traherne JA, Barcellos LF, Sawcer SJ, Compston A, Ramsay PP, Hauser SL, Oksenberg JR, Trowsdale J. Association of the truncating splice site mutation in BTNL2 with multiple sclerosis is secondary to HLA-DRB1*15. Hum Mol Genet. 2006;15:155-61. 
55. Spagnolo P, Sato $H$, Grutters JC, Renzoni EA, Marshall SE, Ruven HJ, Wells AU, Tzouvelekis A, van Moorsel $\mathrm{CH}$, van den Bosch JM, du Bois RM, Welsh KI. Analysis of BTNL2 genetic polymorphisms in British and Dutch patients with sarcoidosis. Tissue Antigens. 2007;70:219-27.

56. Valentonyte R, Hampe J, Huse K, Rosenstiel P, Albrecht M, Stenzel A, Nagy M, Gaede KI, Franke A, Haesler R, Koch A, Lengauer T, Seegert D, Reiling N, Ehlers S, Schwinger E, Platzer M, Krawczak M, Muller-Quernheim J, Schurmann M, Schreiber S. Sarcoidosis is associated with a truncating splice site mutation in BTNL2. Nat Genet. 2005;37:357-64.

57. Li Y, Wollnik B, Pabst S, Lennarz M, Rohmann E, Gillissen A, Vetter H, Grohe C. BTNL2 gene variant and sarcoidosis. Thorax. 2006;61:273-4.

58. Rybicki BA, Walewski JL, Maliarik MJ, Kian H, Iannuzzi MC. The BTNL2 gene and sarcoidosis susceptibility in African Americans and Whites. Am J Hum Genet. 2005; 77:491-9.

59. Orozco G, Eerligh P, Sanchez E, Zhernakova S, Roep BO, Gonzalez-Gay MA, LopezNevot MA, Callejas JL, Hidalgo C, Pascual-Salcedo D, Balsa A, Gonzalez-Escribano MF, Koeleman BP, Martin J. Analysis of a functional BTNL2 polymorphism in type 1 diabetes, rheumatoid arthritis, and systemic lupus erythematosus. Hum Immunol. 2005;66:1235-41.

60. Lopez-Campos JL, Rodriguez-Rodriguez D, Rodriguez-Becerra E, Alfageme Michavila I, Guerra JF, Hernandez FJ, Casanova A, Fernandez de Cordoba Gamero J, RomeroOrtiz A, Arellano-Orden E, Montes-Worboys A. Cyclooxygenase-2 polymorphisms confer susceptibility to sarcoidosis but are not related to prognosis. Respir Med. 2009;103:427-33.

61. Coudurier M, Freymond N, Aissaoui S, Calender A, Pacheco Y, Devouassoux G. Homozygous variant rs2076530 of BTNL2 and familial sarcoidosis. Sarcoidosis Vasc Diffuse Lung Dis. 2009;26:162-6.

62. Pabst S, Karpushova A, Diaz-Lacava A, Herms S, Walier M, Zimmer S, Cichon S, Nickenig G, Nothen MM, Wienker TF, Grohe C. VEGF gene haplotypes are associated with sarcoidosis. Chest. 2010;137:156-63.

63. Chen ES, Song Z, Willett MH, Heine S, Yung RC, Liu MC, Groshong SD, Zhang Y, Tuder RM, Moller DR. Serum amyloid A regulates granulomatous inflammation in sarcoidosis through Toll-like receptor-2. Am J Respir Crit Care Med. 2010;181: 360-73.

64. Iannuzzi MC, Rybicki BA, Teirstein AS. Sarcoidosis. N Engl J Med. 2007;357: 2153-65.

65. Medica I, Kastrin A, Maver A, Peterlin B. Role of genetic polymorphisms in ACE and TNF-alpha gene in sarcoidosis: a meta-analysis. J Hum Genet. 2007;52:836-47.

66. Seitzer U, Swider C, Stuber F, Suchnicki K, Lange A, Richter E, Zabel P, MullerQuernheim J, Flad HD, Gerdes J. Tumour necrosis factor alpha promoter gene polymorphism in sarcoidosis. Cytokine. 1997;9:787-90.

67. Mrazek F, Holla LI, Hutyrova B, Znojil V, Vasku A, Kolek V, Welsh KI, Vacha J, du Bois RM, Petrek M. Association of tumour necrosis factor-alpha, lymphotoxin-alpha and HLA-DRB1 gene polymorphisms with Lofgren's syndrome in Czech patients with sarcoidosis. Tissue Antigens. 2005;65:163-71.

68. Swider C, Schnittger L, Bogunia-Kubik K, Gerdes J, Flad H, Lange A, Seitzer U. TNFalpha and HLA-DR genotyping as potential prognostic markers in pulmonary sarcoidosis. Eur Cytokine Netw. 1999;10:143-6.

69. Seitzer U, Gerdes J, Muller-Quernheim J. Evidence for disease phenotype associated haplotypes (DR.TNF) in sarcoidosis. Sarcoidosis Vasc Diffuse Lung Dis. 2001;18:279-83. 
70. Baughman RP, Drent M, Kavuru M, Judson MA, Costabel U, du Bois R, Albera C, Brutsche M, Davis G, Donohue JF, Muller-Quernheim J, Schlenker-Herceg R, Flavin S, Lo KH, Oemar B, Barnathan ES. Infliximab therapy in patients with chronic sarcoidosis and pulmonary involvement. Am J Respir Crit Care Med. 2006;174: 795-802.

71. Baughman RP, du Bois RM, Lynch JP, Wells AU. Diffuse Lung Disease A Practical Approach: Hodder Arnold London;2004.

72. Baughman RP, Lower EE. A clinical approach to the use of methotrexate for sarcoidosis. Thorax. 1999;54:742-6.

73. Warren RB, Smith RL, Campalani E, Eyre S, Smith CH, Barker JN, Worthington J, Griffiths CE. Outcomes of methotrexate therapy for psoriasis and relationship to genetic polymorphisms. Br J Dermatol. 2009;160:438-41.

74. Hider SL, Bruce IN, Thomson W. The pharmacogenetics of methotrexate. Rheumatology (Oxford). 2007;46:1520-4.

75. Baughman RP, Lower EE, Drent M. Inhibitors of tumor necrosis factor (TNF) in sarcoidosis: who, what, and how to use them. Sarcoidosis Vasc Diffuse Lung Dis. 2008;25:76-89.

76. Mugnier B, Balandraud N, Darque A, Roudier C, Roudier J, Reviron D. Polymorphism at position -308 of the tumor necrosis factor alpha gene influences outcome of infliximab therapy in rheumatoid arthritis. Arthritis Rheum. 2003;48:1849-52.

77. Seitz M, Wirthmuller U, Moller B, Villiger PM. The -308 tumour necrosis factor-alpha gene polymorphism predicts therapeutic response to TNFalpha-blockers in rheumatoid arthritis and spondyloarthritis patients. Rheumatology (Oxford). 2007; 46:93-6.

78. Clark DW, Donnelly E, Coulter DM, Roberts RL, Kennedy MA. Linking pharmacovigilance with pharmacogenetics. Drug Saf. 2004;27:1171-84.

79. Jaquenoud Sirot E, van der Velden JW, Rentsch K, Eap CB, Baumann P. Therapeutic drug monitoring and pharmacogenetic tests as tools in pharmacovigilance. Drug Saf. 2006;29:735-68.

80. Wijnen PA, Op den Buijsch RA, Drent M, Kuijpers PM, Neef C, Bast A, Bekers O, Koek GH. Review article: The prevalence and clinical relevance of cytochrome P450 polymorphisms. Aliment Pharmacol Ther. 2007;26 Suppl 2:211-9. 


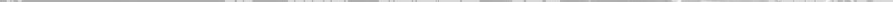

\section{Samenvatting}




\section{Samenvatting}

Verschillende acute en chronische longaandoeningen met variabele stadia van fibrose zijn beschreven en worden over het algemeen aangeduid als diffuse of interstitiële longaandoeningen (interstitial lung disease, ILD). De oorzaak van het ontstaan van ILD is veelal nog onbekend. Bij de meeste aandoeningen worden een genetische basis en omgevingsfactoren genoemd als mogelijke risicofactoren. Afgelopen jaren zijn er verschillende studies verricht die een associatie aantonen tussen genetische polymorfismen of de aanwezigheid van bepaalde variant allelen, en het voorkomen en/of de progressie van ILD van onbekende oorsprong. Daarnaast gaat de zoektocht naar met name meer specifieke 'markers' nog steeds door.

Het doel van de studies die in dit proefschrift worden beschreven, was om de klinische en prognostische waarde van genetische testen te evalueren. Als studiepopulatie werd een groep patiënten met door geneesmiddelen veroorzaakte ILD (drug-induced interstitial lung disease, DI-ILD), een groep patiënten met door orale antistolling veroorzaakte diffuse alveolaire bloedingen (diffuse alveolar hemorrhage, DAH) en een groep sarcoïdosepatiënten gebruikt, bekend bij het ild care team van het Maastrichts Universitair Medisch Centrum.

De analyses in de studies beschreven in dit proefschrift werden uitgevoerd op volbloedmonsters van patiënten met door geneesmiddelen veroorzaakte ILD, idiopathische longfibrose (idiopathic pulmonary fibrosis, IPF) en sarcoïdosepatiënten. Sarcoïdose is een chronische inflammatoire multisysteemziekte, waarvan de oorzaak nog niet bekend is. Het verloop en de prognose van deze grillige aandoening kan erg variëren. Van de groep patiënten die een episode van diffuse alveolaire bloedingen doorgemaakt hadden werden de analyses op volbloedmonsters en cellen die in bronchoalveolaire lavage (BAL) vloeistof aanwezig waren gedaan. Van gezonde vrijwilligers (healthy volunteers, HV) werden volbloedmonsters en wangslijmvliesuitstrijkjes (buccal swab, BS) gebruikt voor de analyses.

Het belang van het genotyperen van cytochroom P450 (CYP) enzymen (zoals CYP2D6, CYP2C9 en CYP2C19) en/of vitamine K epoxide reductase complex1 (VKORC1) werd in de bovengenoemde populaties onderzocht. Daarnaast werd in sarcoïdose patiënten tumor necrose factor alfa -308 (TNF-a G-308A), butyrophiline-like 2 (BTNL2 G16071A) en humaan leukocytenantigeen (human leukocyte antigen, HLA) DRB1 en DQB1 getypeerd.

In hoofstuk 1 wordt als inleiding een overzicht gegeven van de verschillende presentatievormen van interstitiële longaandoeningen. Speciale aandacht gaat uit naar door geneesmiddelen veroorzaakte ILD, diffuse alveolaire bloedingen 
en sarcoïdose. Verder wordt het begrip polymorfisme en de manieren waarop deze kunnen worden bepaald verklaard. De in dit proefschrift gebruikte detectiemethode, de fluorescentie resonantie energie overdracht (fluorescence resonance energy transfer, FRET) wordt wat meer in detail besproken.

In hoofdstuk 2 wordt de mogelijke rol van cytochroom P450 (CYP) enzymen in de pathogenese van interstitiële longaandoeningen, en in het bijzonder in door geneesmiddelen veroorzaakte ILD beschreven. De CYP enzymfamilie speelt een belangrijke rol in de metabolisatie van allerlei ingenomen of geïnhaleerde xenobiotische stoffen. Polymorfismen in deze CYP genen kunnen de metabole activiteit van de hieruit volgende enzymen beïnvloeden, en deze veranderde activiteit kan vervolgens leiden tot plaatselijke (toxische) reacties en weefselschade. Geneesmiddeltoxiciteit kan het gevolg zijn van geen of heel lage enzymactiviteit, in het bijzonder wanneer er geen andere metabole route beschikbaar is. Om toxische bijwerkingen te verhinderen wordt in het geval van een verlaagde enzymactiviteit een reductie van de voorgeschreven dosering of het gebruik van een alternatief geneesmiddel dat gemetaboliseerd wordt via een ander, niet aangetast (CYP) enzym, geadviseerd. Dit is vooral van belang wanneer er sprake is van meervoudig geneesmiddelengebruik. Daarom zou kennis over het CYP profiel van een patiënt voordat er een (bepaald) geneesmiddel wordt voorgeschreven van groot belang kunnen zijn en een manier om door geneesmiddelen veroorzaakte ILD en andere door geneesmiddelen geïnduceerde gevolgen te voorkomen. Verder kan het ook de ernstige bijwerkingen door ingeademde of ingenomen xenobiotische stoffen verklaren.

Hoofdstuk 3 beschrijft een eenvoudige DNA isolatiemethode die gebruikt kan worden om monsters te bewerken alvorens polymorfismen te bepalen. Hoewel er diverse commerciële DNA isolatie kits beschikbaar zijn om genomisch DNA uit volbloedmonsters te isoleren, vergen deze procedures behoorlijk wat tijd en zijn over het algemeen ook behoorlijk kostbaar. Een alternatieve techniek zou de op een filteerpapier gespotte bloeddruppel (dried blood spot, DBS) monsterafname (zie Figuur A1) en een daaropvolgende simpele isolatiemethode zijn. De DNA isolatie wordt daarmee ook sneller, goedkoper en logistiek eenvoudiger.

Deze gedroogde bloeddruppel DNA isolatiemethode bleek een goed alternatief voor commercieel verkrijgbare DNA isolatiekits en een zeer praktische methode om onderscheid te kunnen maken tussen verschillende genotypen. Dezelfde methode kan ook gebruikt worden om DNA uit wangslijmvliesuitstrijkjes (zie Figuur A2) te isoleren en geeft, naast goede DNA opbrengsten, totaal overeenkomende genotyperings resultaten vergeleken met monsters die met behulp van commerciële DNA isolatiekits geïsoleerd werden. Dit is een 
praktische uitbreiding van de toepasbaarheid van deze snelle en eenvoudige DNA isolatiemethode. Zeker in combinatie met de niet-invasieve en patiëntvriendelijke wangslijmvliesuitstrijkjes monsterafname, bleek dit een goed alternatief ten opzichte van invasieve monsterafname methoden.
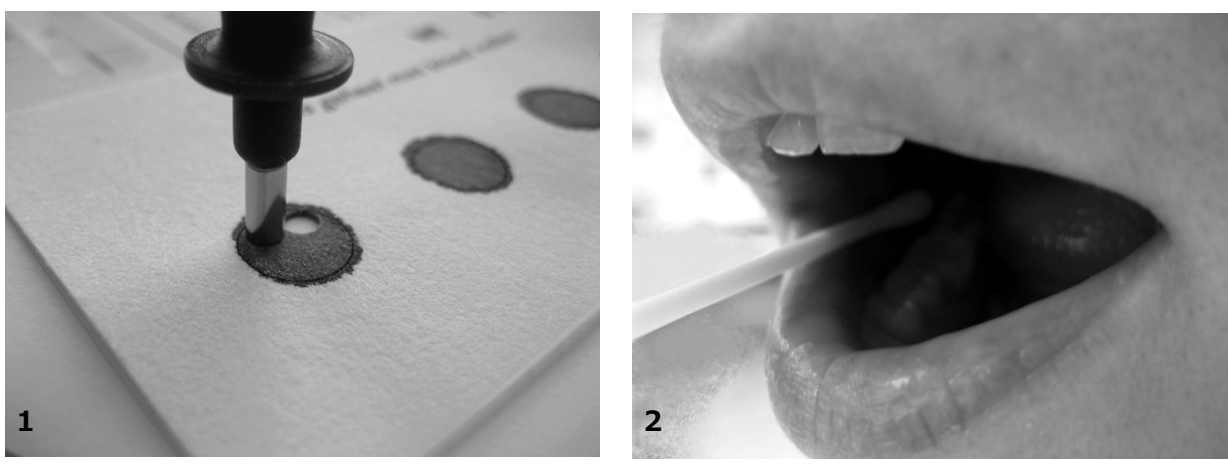

Figuur A (1) monstername van een gedroogde bloeddruppel, (2) monstername van wangslijmvlies met behulp van een wattenstokje.

Door geneesmiddelen geïnduceerde longtoxiciteit vormt een nog steeds groeiend probleem. Het precieze ontstaansmechanisme van deze toxiciteit is veelal nog onbekend. Allerlei verschillende geneesmiddelen worden gemetaboliseerd door cytochroom P450 (CYP) enzymen.

In hoofdstuk 4 wordt het onderzoek beschreven met de vraag of allel variatie in CYP polymorfe genen bijdraagt aan de tot nu toe onverklaarde toxiciteit en verschillen in het reageren op geneesmiddelen. Hiervoor werd een retrospectieve case-control studie uitgevoerd. De cases waren patiënten met door geneesmiddelen veroorzaakte interstitiële longaandoeningen. Daarnaast werden er twee controle groepen gebruikt: een groep gezonde vrijwilligers en een groep patiënten met idiopathische longfibrose. Het aantal mensen met één of meer variant CYP genen was duidelijk hoger in de door geneesmiddelen veroorzaakte ILD groep vergeleken met de gezonde vrijwilligers evenals van de bestudeerde longfibrosepatiënten. Bovendien werd er een significante associatie tussen het ontwikkelen van door geneesmiddelen veroorzaakte ILD en het bezitten van één of meer variant CYP genen gevonden. Door geneesmiddelen veroorzaakte ILD bleken geassocieerd met de aanwezigheid van tenminste één variant CYP allel. Deze studie ondersteunt het nut van het voorschrijven van geneesmiddelen na genotypering, de zogenaamde geïndividualiseerde geneeskunde, om zo efficiëntie, verdraagzaamheid en veiligheid van de voorgeschreven geneesmiddelen te verhogen. 
De klinische relevantie van genotypering voor het initiëren van medicamenteuze behandeling met name in geval van gebruik van meerdere geneesmiddelen tegelijkertijd wordt geïlustreerd aan de hand van het patiëntenvoorbeeld beschreven in hoofdstuk 5. Het beter begrijpen van het mechanisme van geneesmiddelmetabolisme en eventuele interacties kan bijdragen tot het voorkomen of verminderen van bijwerkingen. De patiënte werd behandeld met onder andere venlafaxine i.v.m. een depressie en metoprolol i.v.m. hartritmestoornissen. Ondanks deze behandeling ging ze klinisch gezien achteruit i.p.v. vooruit. Bij opname in het ziekenhuis rees de verdenking op een overgevoeligheidsreactie (ADR) die toegeschreven zou kunnen worden aan het gebruik van venlafaxine en/of metoprolol. Er werden toxische waarden van venlafaxine gemeten en de actieve metaboliet ( $O$ desmethylvenlafaxine) was niet aantoonbaar. Na genotypering werd duidelijk dat patiënte een slechte metaboliseerder voor CYP2D6 ten gevolge van een polymorfisme in dit cytochroom P450 (CYP) gen bleek te zijn. Dit betekent dat de metabole activiteit van het corresponderende enzym negatief beïnvloed werd, waardoor serumconcentraties van de door het aangedane enzym te metaboliseren geneesmiddelen (venlafaxine en metoprolol) veranderden. Venlafaxine kon hierdoor niet worden omgezet naar de bijbehorende actieve metaboliet ( $O$-desmethylvenlafaxine) en die was daarom niet aantoonbaar. Het gevolg was dat het doel waarvoor de venlafaxine werd voorgeschreven in het geheel niet werd bereikt en patiënte niet instaat was op de beoogde wijze te reageren op de voorgeschreven medicatie. De venlafaxine werd gestopt, een alternatieve therapie werd gestart en klinische toestand van de patiënte verbeterde aanzienlijk. Naast therapeutische geneesmiddelmonitoring, bleek het genotyperen van enkele belangrijke CYP enzymen van additionele waarde in het vinden van de verklaring waarom de patiënt ernstige bijwerkingen ontwikkelde. Daarnaast verschafte de genotypering inzicht in het waarom de patiënte geen therapeutisch effect bereikte van met name venlafaxine. Dit voorbeeld benadrukt het belang van zowel klinische als genetische risicostratificatie voor het starten van een behandeling. Dit kan uitermate behulpzaam zijn bij het nemen van het nemen van beslissingen betreffende welk geneesmiddel voorgeschreven kan worden, en tevens om een patiëntgerichte dosering vast te stellen.

In hoofdstuk 6 wordt een studie bij patiënten met diffuse alveolaire bloedingen $(\mathrm{DAH})$, een bloedingcomplicatie die kan optreden ten gevolge van onder andere orale antistollingstherapie, beschreven. De hypothese was dat bij patiënten die worden behandeld met coumarines deze complicatie geassocieerd zou kunnen worden met een polymorfisme in het vitamine $\mathrm{K}$ epoxide reductase complex1 (VKORC1) gen en de aanwezigheid van variant allelen in het cytochroom P450 gen CYP2C9, en in het geval van acenocoumarol gebruik ook 
met CYP2C19 varianten. Retrospectief werden patiënten die coumarines gebruikten en tenminste één episode met diffuse alveolaire bloedingen hadden doorgemaakt over een periode van zeven jaar verzameld. Van de 173 bevestigde gevallen van patiënten met diffuse alveolaire bloedingen gebruikten 75 patiënten orale antistolling waarvan uiteindelijk 63 (84\%) patiënten konden worden geïncludeerd aangezien er DNA monsters beschikbaar waren. Van deze monsters werden CYP2C9, CYP2C19 en VKORC1 single nucleotide polymorphismen (SNPs) gegenotypeerd. Bij 62 van de 63 bestudeerde patiënten was er of een VKORC1, of een CYP2C9 variant allel, of beiden aanwezig. Hieruit werd geconcludeerd dat het zinvol is om voorafgaand aan de behandeling met orale antistolling te genotyperen om met deze informatie zoveel mogelijk het risico op ernstige bijwerkingen, waaronder diffuse alveolaire bloedingen, te beperken. Om een veiligere en meer persoonlijke antistollingstherapie te garanderen wordt deze werkwijze reeds aanbevolen door de Amerikaanse federale Food and Drug Administration (FDA).

De studie beschreven in hoofdstuk 7 werd uitgevoerd om te evalueren of er een verband bestaat tussen de aanwezigheid van tumor necrose factor alfa ( TNF- $a$ ) polymorfismen en de prognose dan wel het verloop van sarcoïdose. In een retrospectieve case-control studie werd van 625 sarcoïdose patiënten TNF- $a$ G-308A, TNF- $a$ G-238A en lymphotoxin-a (LTA) gegenotypeerd. Deze patiënten werden onderverdeeld in een groep van 298 patiënten met persisterende sarcoïdose en 327 patiënten met niet-persisterende sarcoïdose. Niet-persisterende sarcoïdose werd gedefinieerd als patiënten die verbeterden naar of stabiel bleven met röntgenstadium 0 of I. Hierbij werd gebruik gemaakt van röntgenfoto's en longfunctietestuitslagen na een periode van tenminste twee jaar na diagnosestelling. Het TNF- $a-308 \mathrm{~A}$ variant allel werd in $25.5 \%$ van de patiënten met persisterende sarcoïdose aangetroffen, vergeleken met $44.0 \%$ voorkomen in patiënten met de niet-persisterende vorm. De gevonden data tonen dat, mede door de sterke associatie tussen TNF- $a$ G-308A en HLADRB1*03, de aanwezigheid van een TNF- $a$-308A variant allel geassocieerd kan worden met een gunstige prognose en dat een betrekkelijk eenvoudige bepaling van de TNF-a G-308A SNP bruikbaar is om het verloop van longsarcoïdose te voorspellen.

In hoofdstuk 8 wordt een studie beschreven die de associatie tussen butyrophiline-like 2 (BTNL2) G16071A en de progressie van longsarcoïdose onderzoekt en de associatie met de prevalentie van de ziekte in 632 sarcoïdose patiënten bevestigd. Verder werd de samenhang tussen BTNL2 G16071A en specifieke HLA-DRB1 en HLA-DQB1 types onderzocht. Bij patiënten met persisterende sarcoïdose werd het BTNL2 16071A variant allel significant meer aangetroffen (92.4\%) dan in patiënten met niet-persisterende sarcoïdose 
(86.6\%). Uit de resultaten van deze studie blijkt dat het bezitten van een BTNL2 16071A variant allel het risico op progressie van longsarcoïdose bijna verdubbeld. Dit verhoogde risico kan het gevolg zijn van de sterke link tussen BTNL2 G16071A en DRB1*15, waarvan de associatie tussen aanwezigheid en progressie naar een ernstigere en meer persistente vorm van longsarcoïdose bevestigd werd. Het werd verder duidelijk dat HLA-DRB1 typeren voldoende is, door het niet verkrijgen van extra informatie bij HLA-DQB1 typering. Of men uiteindelijk kiest voor een BTNL2 G16071A SNP bepaling of HLA-DRB1 typeren ligt meer aan de beschikbaarheid en/of uitvoerbaarheid van deze testen.

De belangrijkste bevindingen beschreven in dit proefschrift worden besproken in hoofdstuk 9, evenals de hieruit voortkomende mogelijkheden voor toekomstig onderzoek. Ondanks het continue voortschrijdende inzicht aangaande het metabolisme van geneesmiddelen blijven er nog veel vragen open. Door continuering van het onderzoek naar de relatie tussen kliniek en genetische eigenschappen kunnen mogelijk in de toekomst een aantal antwoorden ingevuld worden. De genetische basis van sarcoïdose en de invloed van het genotype op het fenotype, ofwel de klinische presentatie, en het beloop is nog steeds onvoldoende opgehelderd. Het vergaren van verder inzicht in deze aspecten van de pathogenese van sarcoïdose zal een interessant en uitdagend thema vormen voor verder onderzoek. Met name onderzoek naar mogelijke onderscheidende factoren tussen zogenaamde responders en nonresponders op therapeutische interventies zal heel klinisch relevant en uiteindelijk kostenbesparend kunnen zijn. Op die manier kan dan in de toekomst een duidelijke beperking worden aangebracht in het voorschrijven van (dure) geneesmiddelen. 



\section{Appendix}




\section{Appendix}

In the appendix drugs and other substances metabolized by and influencing (inhibit or induce) the most important CYP enzymes are listed. The drugs are subdivided into substrates, inhibitors, and inducers. The term substrate refers to a drug or other substance that is metabolized (activated or de-activated) by an enzyme. An inhibitor is a substance that inhibits the normal function of an enzyme and may result from non-competitive or competitive inhibition by a second drug or other substance, an effect that may occur rapidly. The result of non-competitive inhibition by the addition of a second agent is a slower metabolism of the first substance, higher plasma concentrations, and toxicity risk. In case of competitive inhibition, the metabolism of both substances can be reduced, resulting in higher than expected and possible toxic concentrations of both parent agents. An inducer is a substance that may result in increased CYP enzyme synthesis, faster drug metabolism, subtherapeutic drug concentrations and the risk for ineffective drug therapy. The promptness of the induction depends on the half-life of the inducing substance as well as the rate of synthesis of new enzymes.

The drugs and other substances are alphabetically ordered by CYP enzyme. The list of substrates metabolized by a specific (affected) enzyme and possible present inducers and/or inhibitors might be helpful to prevent possible problems.

This appendix is not comprehensive as new information is constantly being identified. ${ }^{1-11}$ 


\section{Drugs and other substances metabolized by and influencing CYP enzymes.}

\section{Substrates}

$1 A 2$

Acetaminophen

Aminophylline

Amitriptyline

Anagrelide

Bendamustine

Caffeine

Chlordiazepoxide

Chlorpromazine

Cimetidine

Cinacalcet

Citalopram

Clomipramine

Clopidogrel

Clozapine

Cyclobenzaprine

Dacarbazine

Desipramine

Diazepam

Duloxetine

Erlotinib

Estradiol

Ethinyl estradiol

Febuxostat

Fluoxetine

Fluphenazine

Flutamide

Fluvoxamine

Frovatriptan

Haloperidol

Imipramine

Isotretinoin

Levobupivacaine

Lidocaine

Melatonin

Mesoridazine

Methadone

Mexiletine

Mibrefradil

Mirtazapine

Naproxen

Nortriptyline

Olanzapine

Ondansetron

Oxtriphylline
$2 C 9$

2C19

\begin{tabular}{|c|c|c|c|c|}
\hline Paroxetine & Aceclofenac & Lornoxicam & Acenocoumarol & Primidone \\
\hline Pentazocine & Acenocoumarol & Losartan & Alprazolam & Progesterone \\
\hline Perphenazine & Acetaminophen & Mefenaminic acid & Amiodarone & Proguanil \\
\hline Phenacetin & Amitriptyline & Meloxicam & Amitriptyline & Propranolol \\
\hline Pimozide & Bosentan & Mephenytoin & Carisoprodol & Rabeprazole \\
\hline Pirfenidone & Candesartan & Mestranol & Chloramphenicol & Ranitidine \\
\hline Primaquine & Cannabinol & Mirtazapine & Cilostazol & Ritonavir \\
\hline Propafenone & Carmustine & Montelukast & Citalopram & R-Mephobarbital \\
\hline Propranolol & Carvedilol & Naproxen & Clobazam & R-Warfarin \\
\hline Ramelteon & Celecoxib & Nateglinide & Clomipramine & Sertraline \\
\hline Ranitidine & Chloramphenicol & Nicoumalone & Clopidogrel & S-Mephenytoin \\
\hline Rasagiline & Chlorpheniramine & Omeprazole & Cyclophosphamide & Temazepam \\
\hline Riluzole & Chlorporpamide & Paclitaxel & Desipramine & Teniposide \\
\hline Ritonavir & Clomipramine & Paroxetine & Diazepam & Thioridazine \\
\hline Ropinirole & Clopidogrel & Phenobarbital & Diclofenac & Tolbutamide \\
\hline Ropivacaine & Cotrimoxazol & Phenytoin & Divalproex & Trimipramine \\
\hline R-Warfarin & Dapsone & Pirfenidone & Efavirenz & Valproic acid \\
\hline Sertraline & Desogestrel & Piroxicam & Escitalopram & Venlafaxine \\
\hline Tacrine & Diazepam & Ritonavir & Esomeprazole & Voriconazole \\
\hline Tamoxifen & Diclofenac & Rosiglitazone & Flunitrazepam & \\
\hline Theophylline & Dicoumarol & R-Warfarin & Fluoxetine & \\
\hline Thioridazine & Divalproex sodium & Seratrodast & Fluvoxamine & \\
\hline Thiothixene & Dronabinol & Sertraline & Formoterol & \\
\hline Tizanidine & Efavirenz & Sildenafil & Hexobarbital & \\
\hline Toremifene & Febuxostat & Sulfamethoxazole & Ibuprofen & \\
\hline Trifluoperazine & Fluoxetine & Sulfaphenazole & Ifosfamide & \\
\hline Verapamil & Flurbiprofen & Sulfinpyrazone & Imipramine & \\
\hline Zileuton & Fluvastatin & Sulfonamides & Indomethacin & \\
\hline Ziprasidone & Fluvoxamine & Suprofen & Lansoprazole & \\
\hline Zolmitriptan & Formoterol & S-Warfarin & Loratidine & \\
\hline \multirow[t]{14}{*}{ Zolpidem } & Glibenclamide & Tamoxifen & Mephenytoin & \\
\hline & Gliclazide & Tenoxicam & Mephobarbital & \\
\hline & Glimepiride & Tertrahydrocannabinol & Methsuximide & \\
\hline & Glipizide & Testosterone & Moclobemide & \\
\hline & Glyburide & Tolbutamide & Nelfinavir & \\
\hline & Hexobarbital & Torsemide & Nevirapine & \\
\hline & Ibuprofen & Valdecoxib & Nilutamide & \\
\hline & Idarubicin & Valproic acid & Omeprazole & \\
\hline & Imipramine & Valsartan & Pantoprazole & \\
\hline & Indomethacin & Vardenafil & Paroxetine & \\
\hline & Irbesartan & Voriconazole & Pentamidine & \\
\hline & Irinotecan & Zafirlukast & Phenobarbital & \\
\hline & Ketoprofen & Zileuton & Phenytoin & \\
\hline & Leflunomide & Zolpidem & Pirfenidone & \\
\hline
\end{tabular}




\section{Substrates}

2D6

\begin{tabular}{|c|c|c|}
\hline Acetaminophen & Fentanyl & Penbutolol \\
\hline Alprenolol & Flecainide & Perhexiline \\
\hline Amiodarone & Flunarizine & Perphenazine \\
\hline Amitriptyline & Fluoxetine & Phenacetin \\
\hline Amphetamine & Fluphenazine & Phenformin \\
\hline Aripiprazole & Fluvoxamine & Pindolol \\
\hline Atomoxetine & Formoterol & Pirfenidone \\
\hline Benztropine & Galantamine & Procainamide \\
\hline Bisoprolol & Guanoxan & Promethazine \\
\hline Bufuralol & Haloperidol & Propafenone \\
\hline Captopril & Hydrocodone & Propoxyphene \\
\hline Carvedilol & Hydrocortisone & Propranolol \\
\hline Cevimeline & Hydroxyzine & Pyrantel \\
\hline Chlorpheniramine & Idarubicin & Quetiapine \\
\hline Chlorpromazine & Imipramine & Quinidine \\
\hline Chlorpropamide & Indinavir & Ranitidine \\
\hline Cinacalcet & Indoramin & Ranolazine \\
\hline Citalopram & Labetalol & Risperidone \\
\hline Clemastine & Lidocaine & Ritonavir \\
\hline Clomipramine & Loratadine & Ropivacaine \\
\hline Clozapine & Maprotiline & Selegiline \\
\hline Codeine & MDMA (ecstasy) & Sertindole \\
\hline Cyclobenzaprine & Meperidine & Sertraline \\
\hline Darifenacin & Mequitazine & Sparteine \\
\hline Debrisoquine & Methadone & Tacrine \\
\hline Delavirdine & Methamphetamine & Tamoxifen \\
\hline Desipramine & Methoxyamphetamine & Tamsulosine \\
\hline Dexfenfluramine & Metoclopramide & Thioridazine \\
\hline Dextroamphetamine & Metoprolol & Timolol \\
\hline Dextromethorphan & Mexiletine & Tolterodine \\
\hline Diltiazem & Minaprine & Tramadol \\
\hline Dimenhydrinate & Mirtazapine & Tranylcypromine \\
\hline Dimethoxyamphetamine & Moclobemide & Trazodone \\
\hline Diphenhydramine & Morphine & Trimipramine \\
\hline Dolasetron & Nebivolol & Tripelennamine \\
\hline Donepezil & Nefazodone & Tropisetron \\
\hline Doxepin & Nifedipine & Venlafaxine \\
\hline Doxorubicin & Nisoldipine & Yohimbine \\
\hline Duloxetine & Nortriptyline & Zuclopenthixol \\
\hline Encainide & Olanzapine & \\
\hline Escitalopram & Ondansetron & \\
\hline Ethylmorphine & Oxycodone & \\
\hline Fenfluramine & Paroxetine & \\
\hline
\end{tabular}




\section{Substrates}

3A4-5

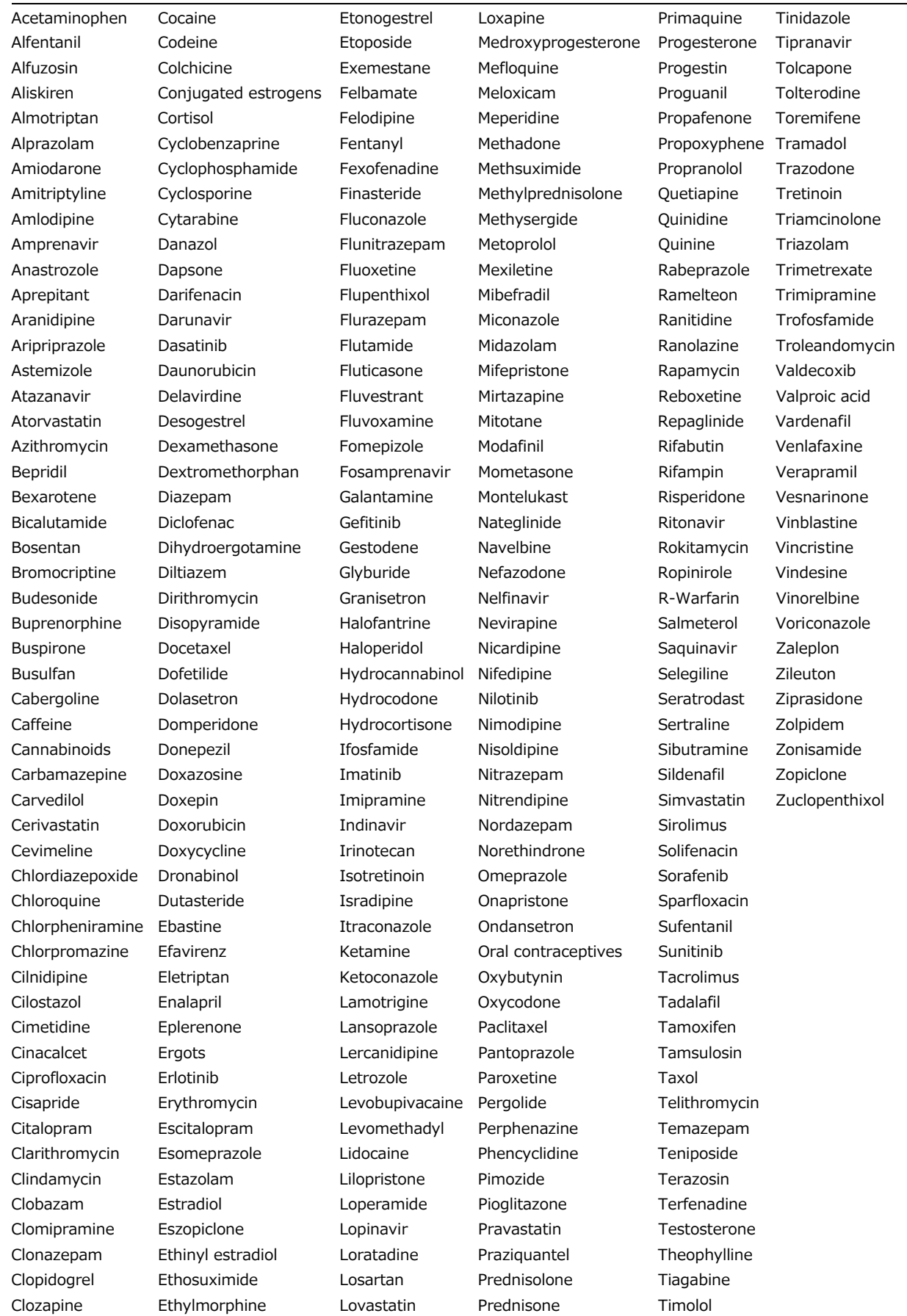


Inhibitors

$1 \mathrm{A2}$

Acyclovir

Amiodarone

Amitriptyline

Anastrozole

Atazanavir

Caffeine

Cimetidine

Ciprofloxacin

Citalopram

Clarithromycin

Diltiazem

Duloxetine

Echinacea

Enoxacin

Erythromycin

Estradiol

Ethinyl estradiol

Famotidine

Fluoxetine

Fluphenazine

Flutamide

Fluvoxamine

Furafylline

Gatifloxacin

Grapefruit (juice)

Imipramine

Interferon

Isoniazid

Ketoconazole

Levofloxacin

Levonorgestrel

Lidocaine

Lomefloxacin

Methoxsalen

Mexiletine

Mibefradil

Moclobemide

Moxifloxacin

Nalidixic acid

Nelfinavir

Norethindrone

Norfloxacin

Ofloxacin

Omeprazole

Oral contraceptives

Paroxetine

Perphenazine

Phenacetin

Pirfenidone

Propafenone

Ranitidine

Rifampin
2C9

2C19

Amiodarone

Anastrozole

Atazanavir

Benzbromarone

Capecitabine

Chloramphenicol

Cimetidine

Clopidogrel

Cocaine

Cotrimoxazole

Delavirdine

Devil's claw

Diclofenac

Disulfiram

Efavirenz

Fenofibrate

Fluconazole

Fluorouracil

Fluoxetine

Flurbifprofen

Fluvastatin

Fluvoxamine

Garlic

Gemfibrozil

Grapefruit (juice)

Imatinib

Isoniazid

Itraconazole

Ketoconazole

Ketoprofen

Leflunomide

Lovastatin

Methoxsalen

Metronidazole

Mexiletine

Modafinil

Nalidixic acid

Norethindrone

Norfloxacin

Omeprazole

Oral contraceptives

Paroxetine

Phenylbutazone

Pirfenidone

Probenicid

Ranitidine

Ritonavir

Rosuvastatin

Sertraline

St. John's Wort

Stiripentol

Sulfamethoxazole
Amitriptyline

Artemisinin

Chloramphenicol

Cimetidine

Citalopram

Cocaine

Delavirdine

Devil's Claw

Efavirenz

Esomeprazole

Felbamate

Fluconazole

Fluoxetine

Fluvastatin

Fluvoxamine

Garlic

Imipramine

Indomethacin

Interferon

Isoniazid

Ketoconazole

Lansoprazole

Letrozole

Modafinil

Norfluoxetine

Omeprazole

Oral contraceptives

Oxcarbazepine

Pantoprazole

Paroxetine

Pirfenidone

Probenicid

Rabeprazole

Ranitidine

Ritonavir

Sertraline

St. John's Wort

Sulfaphenazole

Telmisartan

Ticlopidine

Tolbutamide

Topiramate

Tranylcypromine

Troglitazone

Valdecobix

Voriconazole 


\section{Inhibitors}

2D6

\begin{tabular}{|c|c|c|c|}
\hline Amiodarone & Moclobemide & Acitretin & Mibefradil \\
\hline Amitriptyline & Nefazodone & Amiodarone & Miconazole \\
\hline Anti-histamine & Norfloxacin & Amprenavir & Mifepristone \\
\hline Aripiprazole & Norfluoxetine & Anastrozole & Nafimidone \\
\hline Black cohosh & Orphenadrine & Androstenedione & Nefazodone \\
\hline Black pepper & Paroxetine & Aprepitant & Nelfinavir \\
\hline Buproprion & Perphenazine & Atazanzvir & Nevirapine \\
\hline Cajuput & Pimozide & Black cohosh & Nicardipine \\
\hline Celecoxib & Pomegranate & Bromocriptine & Nifedipine \\
\hline Chloroquine & Propafenone & Cat's claw & Norethindrone \\
\hline Chlorpheniramine & Propoxyphene & Chloramphenicol & Norfloxacin \\
\hline Chlorpromazine & Propranolol & Chloroquine & Norfluoxetine \\
\hline Cimetidine & Quinacrine & Cimetidine & Omeprazole \\
\hline Cinacalcet & Quinidine & Ciprofloxacin & Oral contraceptives \\
\hline Cinnamon & Quinine & Cisapride & Oxiconazole \\
\hline Citalopram & Ranitidine & Clarithromycin & Paroxetine \\
\hline Clemastine & Ranolazine & Clomipramine & Phenobarbital \\
\hline Clomipramine & Risperidone & Clotrimazole & Pimozide \\
\hline Clove & Ritonavir & Cyclosporine & Pirfenidone \\
\hline Clozapine & Sandalwood & Dalfopristin & Posaconazole \\
\hline Cocaine & Sertindole & Danazol & Prednisone \\
\hline Darifenacin & Sertraline & Delavirdine & Primaquine \\
\hline Desipramine & St. John's Wort & Devil's claw & Propofol \\
\hline Diphenhydramine & Tegaserod & Diltiazem & Propoxyphene \\
\hline Doxepin & Terbinafine & Dithiocarbamate & Quinidine \\
\hline Doxorubicin & Thioridazine & Doxycycline & Quinine \\
\hline Duloxetine & Ticlopidine & Echinacea & Quinupristin \\
\hline Escitalopram & Tipranavir & Efavirenz & Ranitidine \\
\hline Febuxostat & Tripelennamine & Enoxacin & Ranolazine \\
\hline Fluoxetine & Valproic acid & Erythromycin & Ritonavir \\
\hline Fluphenazine & Venlafaxine & Ethinyl estradiol & Roxithromycin \\
\hline Fluvoxamine & Vinblastine & Ezetimibe & Saquinavir \\
\hline Ginger & Vinorelbine & Fluconazole & Sertindole \\
\hline Ginseng & Yohimbine & Fluoxetine & Sertraline \\
\hline Goldenseal & & Fluvoxamine & Sparfloxacin \\
\hline Halofantrine & & Garlic & St. John's Wort \\
\hline Haloperidol & & Gestodene & Star fruit \\
\hline Hydroxychloroquine & & Ginseng & Tacrolimus \\
\hline Hydroxyzine & & Goldenseal & Tamoxifen \\
\hline Imatinib & & Grapefruit (juice) & Telithromycin \\
\hline Imipramine & & Haloperidol & Troglitazone \\
\hline Indinavir & & Imatinib & Troleandomycin \\
\hline Lansoprazole & & Indinavir & Valproic acid \\
\hline Levomepromazine & & Isoniazid & Venlafaxine \\
\hline Lomustine & & Itraconazole & Verapamil \\
\hline Lopinavir & & Ketoconazole & Voriconazole \\
\hline Methadone & & Khella & Zafirlukast \\
\hline Methotrimeprazine & & Lopinavir & Zileuton \\
\hline Methylphenidate & & Methadone & \\
\hline Metoclopramide & & Methylprednisolone & \\
\hline Mibefradil & & Methylprednisone & \\
\hline Midodrine & & Metronidazole & \\
\hline
\end{tabular}

3A4-5

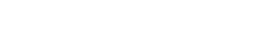




\section{Inducers}

$1 A 2$

2C9

2C19

2D6

3A4-5

beta-Naphthoflavone

Aprepitant

Artemisinin

Dexamethasone

Aminoglutethimide

Barbituates

Barbituates

Barbiturates

Rifampin

Amprenavir

Broccoli

Bosentan

Carbamazepine

Brussel sprouts

Carbamazepine

Ginko Biloba

Aprepitant

Cabbage

Cyclophosphamide

Lopinavir

Caffeine

Ethanol

Carbamazepine

Ginseng

Cauliflower

Glipizide

Charbroiled meats

Ifosfamide

Clotrimazole

Pentobarbital

Esomeprazole

Phenobarbital

Norethindrone

Barbiturates

Bosentan

Orphenadrine

Butalbital

Cannabinoids

Phenobarbital

Phenytoin

Prednisone

Carbamazepine

Cisplatin

Clotrimazole

Griseofulvin

Insulin

Phenytoin

Primidone

Cyclophosphamine

Rifabutin

Primidone

Rifampin

Lansoprazole

Marijuana

Rifabutin

Ritonavir

Rifampin

Mebendazole

Rifapentine

St John's Wort

Methylcholanthrene

Ritonavir

Valproic acid

Modafinil

Secobarbital

Dexamethasone

Efavirenz

Ethosuximide

Felbamate

Garlic supplements

Ginseng

Glucocorticoids

Glutethimide

Griseofulvin

Ifosfamide

Lopinavir

Methadone

Methylprednisolone

Modafinil

Nafcillin

Nevirapine

Oxcarbazepine

Pentobarbital

Phenobarbital

Phenylbutazone

Phenytoin

Pioglitazone

Prednisone

Primidone

Rifabutin

Rifampin

Rifapentine

Ritonavir

St. John's Wort

Sulfinpyrazone

Topiramate

Troglitazone

Troleandomycin 


\section{References}

1. Bibi Z. Role of cytochrome P450 in drug interactions. Nutr Metab. 2008;5:27.

2. Izzo $A A$, Ernst $E$. Interactions between herbal medicines and prescribed drugs: an updated systematic review. Drugs. 2009;69:1777-98.

3. Michalets EL. Update: clinically significant cytochrome P-450 drug interactions. Pharmacotherapy. 1998;18:84-112.

4. Thummel KE, Wilkinson GR. In vitro and in vivo drug interactions involving human CYP3A. Annu Rev Pharmacol Toxicol. 1998;38:389-430.

5. Ogu CC, Maxa JL. Drug interactions due to cytochrome P450. BUMC Proc. 2000;13:421-3.

6. Mann HJ. Drug-associated disease: cytochrome P450 interactions. Crit Care Clin. 2006;22:329-45, vii.

7. http://medicine.iupui.edu/clinpharm/ddis/table.asp

8. http://www.healthanddna.com/healthcare-professional/p450-drug-list.html

9. http://www.anaesthetist.com/physiol/basics/metabol/cyp/Findex.htm\#cyp.htm

10. http://www.edhayes.com/CYP450-4.html

11. http://www. proprofs.com/flashcards/story.php?title=cypp450-substrates-inhibitorsinducers 



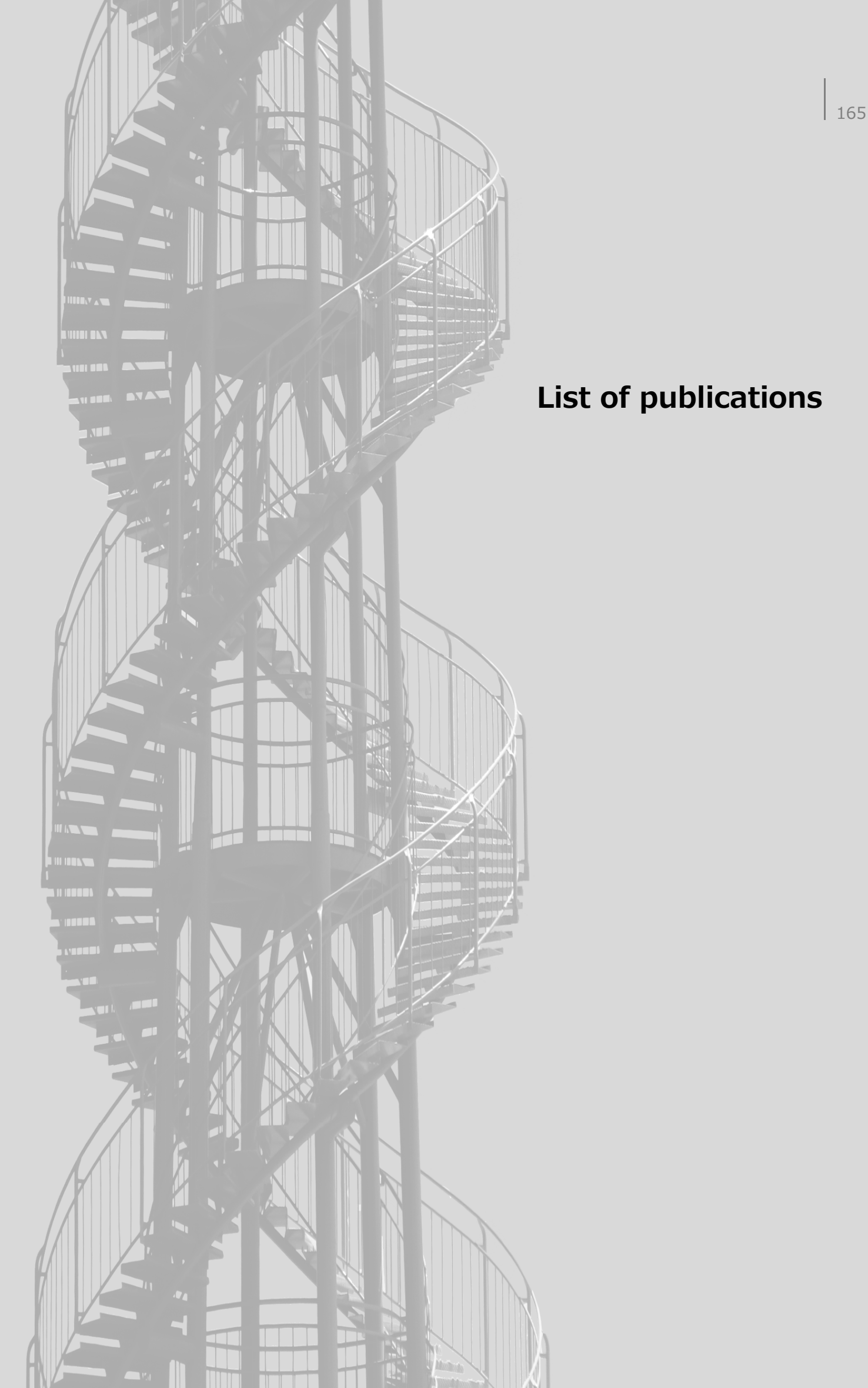




\section{List of publications}

1. Wijnen PA, van Dieijen-Visser MP. Capillary electrophoresis of serum proteins. Reproducibility, comparison with agarose gel electrophoresis and a review of the literature. Eur J Clin Chem Clin Biochem. 1996;34:535-45.

2. De Vries JE, Wijnen PA, Hamulyak K, van Dieijen-Visser MP, Bekers O. PCR on cell lysates obtainded from whole blood circumvents DNA isolation. Clin Chem. 2001;47:1701-2.

3. Bekers $\mathrm{O}$, Op den Buijsch RA, de Vries JE, Wijnen PA, van Dieijen-Visser MP. Capillary electrophoretic detection in apolipoprotein E genotyping. Electrophoresis. 2002;23:1878-81.

4. Op den Buijsch RA, de Vries JE, Loots WJ, Landt O, Wijnen PA, van Dieijen-Visser MP, Bekers O. Genotyping of the PXR A11156C polymorphism with locked nucleic acid containing fluorogenic probes. Pharmacogenomics J. 2005;5:72-4.

5. Op den Buijsch RA, Bekers O, Wijnen PA, van Dieijen-Visser MP, de Vries JE. Rapid genotyping of the OATP1B1 polymorphisms A388G and T521C with real-time PCR FRET assays. Pharmacogenomics. 2005;6:393-7.

6. Op den Buijsch RA, Cheung $C Y$, de Vries JE, Wijnen PA, van Dieijen-Visser MP, Bekers $\mathrm{O}$. Influence of cytochrome P450 $3 \mathrm{~A} 5$ and multidrug resistance-1 gene single nucleotide polymorphisms (SNPs) on the tacrolimus area under the curve (AUC) in renal transplant recipients. Ned Tijdschr Klin Chem Labgeneesk. 2006;31:204-6.

7. Op den Buijsch RA, de Vries JE, ten Kate J, Wijnen PA, Rothkrantz-Kos S, van Dieijen-Visser MP, Bekers O. Comparison of DNA Isolation Kits to extract DNA from Whole Blood Samples. Current Genomics. 2006;7:73-8.

8. Cheung $\mathrm{CY}$, Op den Buijsch RA, Wong KM, Chan HW, Chau KF, Li CS, Leung KT, Kwan $\mathrm{TH}$, de Vries JE, Wijnen PA, van Dieijen-Visser MP, Bekers O. Influence of different allelic variants of the CYP3A4 and $A B C B 1$ genes on the tacrolimus pharmacokinetic profile of Chinese renal transplant recipients. Pharmacogenomics. $2006 ; 7: 563-74$.

9. Veltkamp M, Wijnen PA, van Moorsel $\mathrm{CH}$, Rijkers GT, Ruven $\mathrm{HJ}$, Heron M, Bekers O, Claessen AM, Drent M, van den Bosch JM, Grutters JC. Linkage between Toll-like receptor (TLR) 2 promotor and intron polymorphisms: functional effects and relevance to sarcoidosis. Clin Exp Immunol. 2007;149:453-62.

10. Wijnen PA, Op den Buijsch RA, Drent M, Kuijpers PM, Neef C, Bast A, Bekers O, Koek GH. Review article: The prevalence and clinical relevance of P450 polymorphisms. Aliment Pharmacol Ther. 2007;26 Suppl 2:211-9.

11. Wijnen PA, Op den Buijsch RA, Cheung SC, van der Heijden J, Hoogtanders K, Stolk LM, van Dieijen-Visser MP, Neef C, Drent M, Bekers O. Genotyping with a dried blood spot method: A useful technique for application in pharmacogenetics. Clin Chim Acta. 2008;388:189-91. 
12. Wijnen PA, Drent M, Nelemans PJ, Kuijpers PM, Koek GH, Neef C, Haenen GR, Bekers O. Role of cytochrome P450 polymorphisms in the development of pulmonary drug toxicity: A case-control study in the Netherlands. Drug Saf. 2008;31:1125-34.

13. Wijnen PA, Drent $M$, van Dieijen-Visser MP, Bekers O. Pharmacogenetic testing after a simple DNA isolation method on buccal swab samples. Pharmacogenomics. 2009;10:983-7.

14. Wijnen PA, Limantoro I, Drent M, Bekers O, Kuijpers PM, Koek GH. Depressive effect of an antidepressant: therapeutic failure of venlafaxine in a case lacking CYP2D6 activity. Ann Clin Biochem. 2009 Nov;46:527-30.

15. Wijnen PA, Linssen CF, Haenen GR, Bekers O, Drent M. Variant VKORC1 and CYP2C9 Alleles in Patients with Diffuse Alveolar Hemorrhage Caused by Oral Anticoagulants. Mol Diagn Ther. 2010 Feb;14:23-30.

16. Wijnen PA, Nelemans PJ, Verschakelen JA, Bekers O, Voorter CE, Drent M. The role of tumor necrosis factor alpha G-308A polymorphisms in the course of pulmonary sarcoidosis. Tissue Antigens. 2010;75:262-8.

17. Wijnen PA, Bekers $O$, Drent $M$. Relationship between drug-induced interstitial lung diseases and CYP polymorphisms. Curr Opin Pul Med. 2010;16:496-502.

18. Elfferich MD, Nelemans PJ, Ponds RW, De Vries J, Wijnen PA, Drent M. Everyday congnitive failure in sarcoidosis: the prevalence and the effect of anti-TNF-atreatment. Respiration. 2010;80:212-9.

19. Wijnen $P A$, Bekers $O$, van Dieijen-Visser MP, Drent M. Pharmacogenetic testing after a simple DNA isolation method. B Contemp Clin Med. 2010;3;9-14.

20. Wijnen PA, Bekers O, Drent M. 'Drug'-induced pneumonitis associated with CYP and VKORC1 variants. B Contemp Clin Med. 2010;3:15-7.

21. Wijnen PA, Voorter CE, Nelemans PJ, Verschakelen JA, Bekers O, Drent M. Butyrophilin-like 2 in pulmonary sarcoidosis: a factor for susceptibility and progression? Hum Immunol. 2011; accepted. 



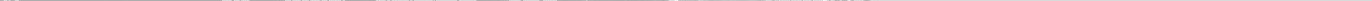




\section{Dankwoord}

Nou ben ik aan de leukste, meest gelezen, maar ook moeilijkste bladzijden aangekomen in dit proefschrift. Hoe ik ga voorkomen dat ik niemand vergeet is me nu nog een raadsel, maar ik ga een poging wagen.

Allereerst mijn promotoren Prof. dr. Marjolein Drent en Prof. dr. Marja van Dieijen-Visser en co-promotor Dr. Otto Bekers.

Beste Marjolein, ik heb door jou hoog leren springen en diep leren nadenken. Hoe jij je meer dan drukke bezigheden allemaal weet te combineren en te arrangeren, zodat je ook nog de tijd vond om mij te begeleiden, vind ik meer dan knap. Ik kon altijd bij je aankloppen en heb de afgelopen jaren ontzettend veel geleerd, waarin jij een heel groot aandeel had.

Beste Marja, ondanks je meer dan drukke werkzaamheden kon ik altijd bij je binnenlopen voor advies en hulp. Dank je voor het feit dat je me deze mogelijkheid hebt geboden. Ik was alleen een beetje langzaam met het benutten ervan, maar na ongeveer 11 jaar aan het idee wennen en wetende dat jij ervan overtuigd was dat ik het aankon, is het er nu dan toch van gekomen.

Otto, je zult het soms toch behoorlijk moeilijk gehad hebben met al die 'vrouwelijke hormonen', maar je hebt je er meer dan dapper doorheen geslagen. Dank je voor je kalme manier van 'procesbewaking' en voor de altijd open deur.

De leden van 'mijn' beoordelingscommissie, Prof. dr. Schrander-Stumpel, Prof. dr. Bast, Prof. dr. Bruggeman, Prof. dr. Camus en Dr. Ir. Ruven, dank u allen dat $u$ de tijd en moeite hebt genomen voor een grondige en kritische manuscriptbeoordeling.

Je tiens également à remercier Prof. dr. Camus pour le temps consacré au compte rendu approfondi et critique lors de la présentation de ma thèse. J'ai beaucoup apprécié votre présence, faisant partie du jury.

Collega's, ik ga een aantal met naam noemen en dat betekent niet dat de rest minder belangrijk is, maar ik moet voor sommigen het 'lastigvallen' een beetje meer goedmaken. Allereerst Petra: jij zat en zit nog steeds heel erg 'in de gevarenzone', dank je dat je me af en toe met humor weer 'op de rit' bracht. Voor het lezen en weer lezen van stukjes en zeker ook voor al het werk wat je me uit handen hebt genomen tijdens de afgelopen periode.

Dan de collega's in een straal van minder dan 10 meter, de mensen van 'Lab D \& co'. Beste Riet, Marlies, Gitte, Ludwine, Patricia, Rianne, Marie-Claire, Ellen, Kristel en Vincent: jullie hebben hopelijk niet al te veel geleden, dank jullie voor 
het 'meesleuren' naar de koffie, het luisterend oor, de gezelligheid en 'het komt goed' op het juiste moment.

Andere collega's zaten er dan wel wat verder vanaf, maar toch is dit een mooi moment om jullie allemaal te bedanken voor de vele jaren van heel prettige samenwerking. Dit geldt trouwens niet alleen voor mijn directe collega's van LCHE maar ook de mensen van LHLE \& BTD, MMB en de GLI, die aan mij blootgesteld worden. Het feit dat ik na al die jaren, zei het met veel moeite, 's morgens mijn bed uitkom om uiteindelijk toch met plezier naar mijn werk te gaan, zegt genoeg.

Mijn medepromovendi Alma, Bianca, Judith en Leo: dank jullie voor het feit dat ik er ondanks de op een aantal fronten aanwezige verschillen toch bij hoorde en dat er af en toe geklaagd (die vervelende tijdschriften met hun rare voorwaarden), gebrainstormd (zou je dat niet zus of zo kunnen doen) en vooral gelachen kon worden.

Alma, Bianca en Leo ik wens jullie heel veel succes bij het afronden van jullie promoties. Dat gaat zeker weten meer dan goed komen.

Beste Judith, jij bent ons al voorgegaan met een mooie promotie, nog even en Nederland is een Klinisch Chemicus rijker. Dank je, ook voor je tips en adviezen wat betreft de ' $\mathrm{P}$ '.

Ook de onderzoekers en klinisch-chemici in opleiding die ik in de loop van de jaren de revue heb zien passeren of er momenteel voor 'gaan': Snjezana, Jart, Etienne, Jaap, Lenneke en Steven, dank jullie voor de fijne samenwerking.

Dr. Patty Nelemans (J-R...), beste Patty, dank je voor al je hulp niet alleen bij het op een rijtje zetten en houden van de nullen en enen. Ook al zie ik ze soms nog steeds 'vliegen', door jouw deskundige adviezen gelukkig niet meer in de artikelen.

Prof. dr. Marcel Tilanus en Dr. Christien Voorter enorm bedankt voor de heel prettige samenwerking en ondersteuning tijdens mijn onderzoek.

Verder Eva, mijn aanspreekpunt op het lab weefseltypering, Fausto en alle anderen die ik extra werk heb bezorgd, enorm bedankt voor jullie hulp.

Prof. dr. Cees Neef, Dr. Petra Kuijpers, Dr. Ger Koek en Dr. Guido Haenen, medeleden van de 'CYP werkgroep'. Dank jullie voor de vele stimulerende en leerzame bijeenkomsten en hulp bij de totstandkoming van dit proefschrift.

Dr. Marinus Kroonenburgh en Dr. Stefan Vöö, van de 'Pettenclub', Rémy Mostard (Do-Re-Mi, Dr. to be) en Dr. Roel Erckens, 'het is maar een bolletje'. Dank jullie voor de ontzettend fijne en constructieve samenwerking, ik heb er al heel wat van opgestoken en ik verheug me op toekomstige 'projecten'. 
Dr. Kitty Linssen, kamergenote tijdens mijn eerste congres, dank je voor je steun en gezelligheid tijdens mijn 'eerste grote optreden'. En zeker ook voor je hulp bij een deel van het onderzoek in dit proefschrift.

Dr. Johan de Vries en Dr. Robert op den Buijsch, medeschuldig aan het feit dat dit boekje er nu is. Johan door me te begeleiden bij mijn eerste stappen op het pad van de DNA analyse en Robert, door me een flinke 'duw' te geven en me te laten beloven dat ik 'ermee door zou gaan'. Beste Robert, ook bedankt voor het feit dat ik een promotie al eens van heel dichtbij heb mogen meemaken doordat ik het genoegen had om bij jou paranimf te mogen zijn.

Mijn paranimfen Marianne Vrijsen en Mr. Ramona Batta: geweldig om te weten dat jullie dit samen met mij willen 'doorstaan'.

Leef Ramoon, als rechtgeaarde deurwaarder legde jij meteen beslag op deze positie en dat was al één zorg minder.

Lieve Marianne (Sch...), als langjarige vriendin en collega kan jij het in geval van nood zo van mij overnemen (geintje), dat is een pak van mijn hart.

Marjon Elfferich en Tiny Wouters, dank zij jullie kom ik goed beslagen ten ijs. Marjon, ik hoop dat al het 'koken en klaarstomen' je niet al te veel 'jaren van je leven' heeft gekost. Naast heel nuttig was het ook altijd heel gezellig, waarvoor dank.

Tiny, dank zij jou ziet het eindresultaat er perfect uit.

Alle vrienden/vriendinnen die er vooral het afgelopen jaar voor hebben gezorgd dat ik niet helemaal aan mijn computer vastgroeide. Dank jullie voor de uitnodigingen, gezelligheid, afleiding en vriendschap.

En tenslotte maar zeker niet in de laatste plaats mijn ouders (Ha T...). Zonder jullie onvoorwaardelijke steun en stimulering zonder enige vorm van dwang, was ik nooit zover gekomen. Dit hebben we toch maar mooi samen voor elkaar gekregen. 


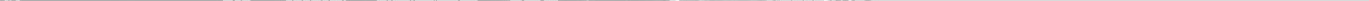





\section{Curriculum Vitae}

Petal (Petra Albertine Hildegard Maria) Wijnen was born on July $26^{\text {th }}, 1963$ in Heerlen, The Netherlands. From 1975 until 1981 she attended secondary school (Atheneum B) at the Albert Schweitzer Scholengemeenschap (ASA) in Geleen. After graduation, she started the higher laboratory education (HLO) at the Zuidlimburgse Laboratorium School (ZLS) in Sittard. She specialized in clinical chemistry and haematology and graduated in 1985. Thereafter, she started working as a general laboratory technician at the Department of Clinical Chemistry of the Maastricht University Medical Centre (MUMC). Her specialisation at that time was protein chemistry and high pressure liquid chromatography (HPLC). From 2003 she has been working as a research technician in the field of Molecular Diagnostics (PCR/DNA analyses). In that capacity, she cooperated in several research projects and assisted several researchers in completing their thesis. In 2007 she started the work presented in this thesis, supervised by Prof. dr. M. Drent, Prof. dr. M.P. van DieijenVisser, and Dr. O. Bekers. She is a member of the CYP task force and the ild care team of the MUMC. 
